UNIVERSIDADE DE SÃO PAULO

ESCOLA DE ENGENHARIA DE SÃO CARLOS

DEPARTAMENTO DE HIDRÁULICA E SANEAMENTO

MÉLIDA DEL PILAR ANZOLA ROJAS

ESTRATÉgIAS PARA A PRODUÇÃo CONTÍNUA DE HIDROGÊNIO EM REATOR ANAERÓBIO DE LEITO FIXO

VERSÃO CORRIGIDA

São Carlos

2014 


\title{
ESTRATÉGIAS PARA A PRODUÇÃO CONTÍNUA DE HIDROGÊNIO EM REATOR ANAERÓBIO DE LEITO FIXO
}

Tese apresentada à Escola de Escola de Engenharia de São Carlos, da Universidade de São Paulo, como parte dos requisitos para obtenção do título de Doutor em Ciências: Hidráulica e Saneamento.

Orientador: Prof. Dr. Marcelo Zaiat

\section{VERSÃO CORRIGIDA}

\author{
São Carlos
}


AUTORIZO A REPRODUÇÃO TOTAL OU PARCIAL DESTE TRABALHO, POR QUALQUER MEIO CONVENCIONAL OU ELETRÔNICO, PARA FINS DE ESTUDO E PESQUISA, DESDE QUE CITADA A FONTE.

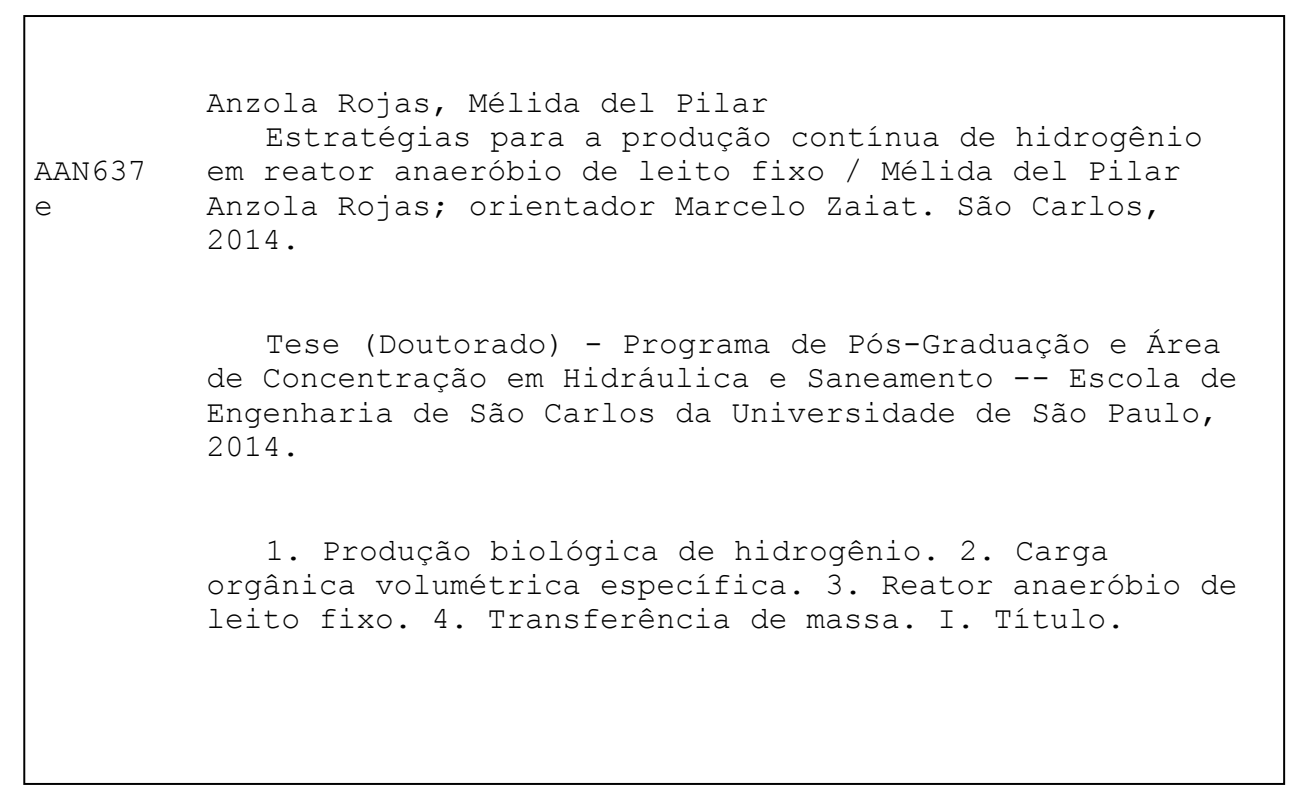




\section{FOLHA DE JULGAMENTO}

Candidata: Engenheira MELIDA DEL PILAR ANZOLA ROJAS.

Título da tese: "Estratégias para produção contínua de hidrogênio em reator anaeróbio de leito fixo".

Data da defesa: 05/08/2014

\section{Comissão Julgadora:}

Prof. Associado Marcelo Zaiat (Orientador)

(Escola de Engenharia de São Carlos/EESC)

Prof. Dr. Edson Luiz Silva

(Universidade Federal de São Carlos/UFSCar)

Prof. Associado José Alberto Domingues Rodrigues

(Instituto Mauá/IMT)

Prof. Dr. Luiz Olinto Monteggia

(Universidade Federal do Rio Grande do SUl/UFRGS)

Profa. Associada Magali Christe Cammarota

(Universidade Federal do Rio de Janeiro/UFRJ)

\section{Resultado:}
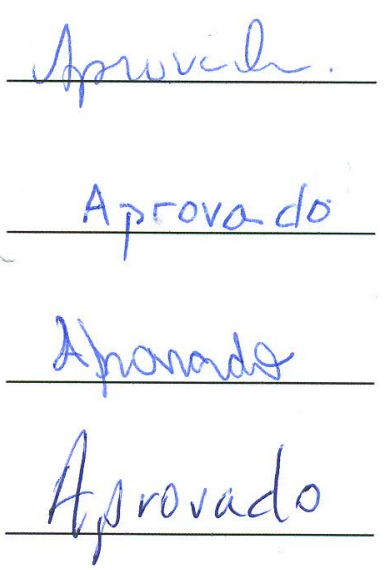

APROVADO

Coordenadora do Programa de Pós-Graduação em Engenharia Hidráulica e Saneamento:

Profa. Associada Maria Bernadete A. Varesche Silva

Presidente da Comissão de Pós-Graduação:

Prof. Associado Paulo César Lima Segantine 
DEDICATÓRIA

A minha esperada filhinha Valéria e ao meu namorado Jaime Alberto 


\section{AGRADECIMENTOS}

Obrigada ...

A Deus pela vida, a saúde e a oportunidade que colocou na minha frente, pelas pessoas que vieram junto com ela e por aquelas que sempre têm estado junto a mím.

Ao Professor Marcelo Zaiat por acreditar em mím, no meu trabalho, nas minhas capacidades, pela orientação e entalhamento dessa mínha vida acadêmica e o maís importante pelo tempinho para o café que nunca faltou.

Á Fundação de Amparo a Pesquisa e do Estado de São Paulo (FAPESP) pelo apoío financeiro a este projeto de pesquisa (Processo de doutorado número 2009/17491-1 e BEPE número 2012/06150-1).

Ao meu namorado Jaime Alberto pela sua inseparável companhia, incondicional carinho e inesqueciveis momentos de felicidade.

Aos meus país e o meu irmão pela força, motivação e por sempre torcer para que tudo desse certo.

Ao professor Eugenio Foresti pelas oportunas dicas de trabalho e o carinhoso abraço de sempre.

À Maria Angela Adorno (Janja) ... sempre tão disposta e carinhosa.

Aos meus colegas e amigos de laboratório pela colaboração quando preciseí, pelas conversas nos corredores do LPB, pelas boas dicas de trabalho Eduardo Penteado (Du), Djalma Ferraz (Dj), Dagoberto Okada (Dago), Priscila Camiloti (Pri), Tíago Palladino, Vivian Carminato.

Ass secretarias Pavi e Sá pela colaboração nos processos admínistrativos.

Aos meus queridos amigos de viagens e aventuras, do día a día ... pela sua incondicional amizade, companheiros de rísos e choros, Jesús García (Yisus), Marilia Horn e Adriana Maluf (Drikinha).

In Belgium, thanks to Heleen De Wever for the supervision and guidance of the research internship, friendly reception and cozy stay.

To Karolien Vanbroekhoven for the acceptance, administrative and locative support to the project development. 
To the Engineers, Technicians and Administratives Helmut Elsandar, Silvia Vangeel, Carine Gielen, Miranda Maesen and Jean-Pierre Luyckx for the collaboration in experimental assembly, analyses and monitoring.

To the colleagues Linsey Garcia-Gonzalez and Doga Arslan for the timely collaboration and guidance at laboratory and at city.

To the secretaries Sofie Sannen and Katrien Vanbroekhoven for the administrative guidance at VITO.

To the friends from far Boeretang Paolo, Salatul, Tanzina, Suman, Daniel, Tim,

Agurtzane, Urko, Emre, Vanessa, Xochitl, Bruno, Mohita, Chavi, Nabin, Giussepe and Ángela for the likeable companionship. 


\section{RESUMO}

Anzola-Rojas M. P. Estratégias para a produção contínua de hidrogênio em reator anaeróbio de leito fixo. 2014. Tese (Doutorado) - Escola de Engenharia de São Carlos Departamento de Hidráulica e Saneamento, Universidade de São Paulo.

O reator anaeróbio de leito fixo tem demonstrado viabilidade para produzir hidrogênio a partir de águas residuárias. No entanto, a liberação do biogás não tem sido contínua devido à diminuição constante da carga orgânica volumétrica específica $(\mathrm{COVe})$ causada pelo acúmulo de biomassa no leito ao longo do tempo. A redução da COVe junto com o envelhecimento da biomassa tem sugerido o estabelecimento de microorganismos consumidores dos constituintes do biogás $\left(\mathrm{H}_{2} / \mathrm{CO}_{2}\right)$ responsáveis por cessar a produção de hidrogênio. Neste trabalho, cinco estratégias foram propostas visando a produção de hidrogênio por longo prazo operacional e com estabilidade, mediante a fixação da COVe, as quais incluíram a alteração da estruturação do leito, inverter o escoamento, realizar descartes periódicos de biomassa e variar a carga orgânica volumétrica aplicada (COV) por meio da variação do tempo de detenção hidráulica (TDH) e da concentração do substrato. Os resultados demonstraram que a manutenção da COVe em um valor adequado permite a produção contínua de hidrogênio. A ordenação do leito, utilizando polietileno de baixa densidade e espuma, e o escoamento descendente favoreceram a diminuição do acúmulo de biomassa e junto com os descartes de biomassa foi possível manter a COVe em um valor estável próximo de $5 \mathrm{~g}$ sacarose $\mathrm{g}^{-1} \mathrm{SSV} \mathrm{d}^{-1}$. A produção volumétrica de hidrogênio $(P V H)$ foi contínua com valor médio de $0,6 \mathrm{~L} \mathrm{H}_{2} \mathrm{~L}^{-1} \mathrm{~d}^{-1} \mathrm{e}$ rendimento $\left(Y_{\mathrm{H}_{2}}\right)$ próximo a $0,5 \mathrm{~mol} \mathrm{H}_{2} \mathrm{~mol}^{-1}$ sc. Por outro lado, o escoamento ascendente e os descartes de biomassa em reator de leito empacotado e ordenado atingiram uma $P V H$ média de 2,2 $\pm 0,2$ e 3,13 $\pm 0,07 \mathrm{~L} \mathrm{H}_{2} \mathrm{~L}^{-1} \mathrm{~d}^{-1}$ quando a COVe foi mantida em 2,6 e 4,4 g sacarose $\mathrm{g}^{-1}$ $\mathrm{SSV} \mathrm{d}^{-1}$, respectivamente. Por ultimo a variação da COV permitiu manter a COVe entre $3,8 \mathrm{e}$ 6,2 g sacarose $\mathrm{g}^{-1} \mathrm{SSV} \mathrm{d}{ }^{-1}$, atingindo um $Y_{\mathrm{H}_{2}}$ médio de $2 \mathrm{~mol} \mathrm{H}_{2} \mathrm{~mol}^{-1}$ sc e um incremento da $P V H$ de 2,4 a $8,9 \mathrm{~L} \mathrm{H}_{2} \mathrm{~L}^{-1} \mathrm{~d}^{-1}$ durante 60 dias consecutivos. Ainda que com resultados satisfatórios referentes à manutenção por longo período operacional e estabilidade na produção de hidrogênio, a supersaturação deste gás no meio líquido, devido a limitações de transferência de massa, foi a principal causa de perdas de hidrogênio neste tipo de reator.

Palavras-chave: Produção biológica de hidrogênio. Carga orgânica volumétrica específica. Reator anaeróbio de leito fixo. Transferência de massa. 


\begin{abstract}
Anzola-Rojas, M. P. Strategies for continuous hydrogen production in fixed-bed, anaerobic reactors. 2014. Thesis (Ph.D Diploma) - São Carlos School of Engineering Graduate Program in Hydraulic and Sanitary Engineering, University of São Paulo.

Fixed-bed, anaerobic reactor has been shown to be feasible for hydrogen production from wastewater. However, biogas release has not been continuous due to the continuous specific organic load (SOL) decrease, which in turn is caused by biomass accumulation in the bed, through the time. SOL reduction and biomass ageing have indicated the establishment of the microorganisms that consumes the biogas constituents $\left(\mathrm{H}_{2} / \mathrm{CO}_{2}\right)$ as the main cause for ceasing hydrogen production. In this work, five strategies were proposed aiming at obtaining longterm, stable hydrogen production by using SOL maintenance, modifications of the bed structure, flow inversion, periodic biomass discards and diverse organic load rates (OLR), as a function of the hydraulic retention time (HRT) and of the substrate concentration. Results demonstrated that by maintaining the SOL at proper values, continuous hydrogen production can be accomplished. On one hand, structuring the bed by using low-density polyethylene and foam, together with a down-flow and biomass discards were shown to diminish biomass accumulation, which led to keep a stable SOL value close to $5 \mathrm{~g}$ sucrose $\mathrm{g}^{-1} \mathrm{VSS} \mathrm{d}^{-1}$. Volumetric hydrogen production (VHP) was continuous with an average value of $0.6 \mathrm{~L} \mathrm{H}_{2} \mathrm{~L}^{-1}$ $\mathrm{d}^{-1}$ and a yield $\left(\mathrm{Y}_{\mathrm{H} 2}\right)$ close to $0.5 \mathrm{~mol} \mathrm{H}_{2} \mathrm{~mol}^{-1}$ sc. On the other hand, up-flow with biomass discharges, when implemented structured-bed and packed-bed reactors reached average VHP values of $2.2 \pm 0.2$ and $3.13 \pm 0.07 \mathrm{~L} \mathrm{H}_{2} \mathrm{~L}^{-1} \mathrm{~d}^{-1}$ as SOL was maintained between 2.6 and $4.4 \mathrm{~g}$

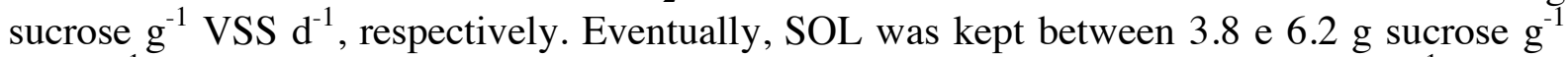
VSS d ${ }^{-1}$ by varying the OLR, thus reaching an average $\mathrm{Y}_{\mathrm{H} 2}$ value of $2 \mathrm{~mol} \mathrm{H}_{2} \mathrm{~mol}^{-1}{ }_{\text {sc }}$ and a VHP increase from 2.4 to $8.9 \mathrm{~L} \mathrm{H}_{2} \mathrm{~L}^{-1} \mathrm{~d}^{-1}$, along sixty consecutive days. As a consequence of mass-transfer limitations, oversaturation of hydrogen at the liquid medium was found as the main factor that causes hydrogen losses concerning fixed-bed reactors, even though the proposed strategies did indeed demonstrate long-term and stable hydrogen production.
\end{abstract}

Keywords: Biologic hydrogen production, specific organic load, fixed-bed anaerobic reactor, mass transfer 


\section{LISTA DE FIGURAS}

Figura 1 - Pontos de geração e consumo de hidrogênio no processo fermentativo (CHERNICHARO, 1997; SPEECE, 1996)

Figura 2 - Rotas metabólicas envolvidas na produção fermentativa de hidrogênio (HALLENBECK, ABO-HASHESH e GHOSH, 2012).

Figura 3 - Reator biológico do tipo anaeróbio de leito fixo para produção de hidrogênio usado no laboratório de processos biológicos da Escola de Engenharia de São Carlos da Universidade de São Paulo (LPB-EESC-USP).

Figura 4 - Produção de acetato a partir da glicólise. Dois terços de acetato são produzidos diretamente dos açúcares, enquanto um terço é produzido pela via Acetyl-CoA Wood-Lungdahl - homoacetogênese (DRAKE, KÜSEL e MATTHIES, 2002).

Figura 5 - Rota metabólica Acetil-CoA Wood-Lungdahl utilizada, quer para produção de ácido acético, quer para síntese celular (DRAKE, KÜSEL e MATTHIES, 2002).

Figura 6 - Esquema geral do desenvolvimento experimental. Estratégias 1, 2, 3 e 4 baseadas no controle da biomassa e estratégia 5 no controle da COV.

Figura 7 - Configuração do reator anaeróbio de leito fixo utilizado para produção de hidrogênio (a) com leito ordenado (b) com leito empacotado (c) escoamento descendente (d) escoamento ascendente.

Figura 8 - Materiais suporte para adesão da biomassa (a) e (b) polietileno de baixa densidade (c) carvão vegetal (d) argila expandida

Figura 9 - Materiais suporte para adesão da biomassa (a) polietileno de baixa densidade (b) espuma de poliuretano (c) cerâmica

Figura 10 - Montagem experimental dos reatores de leito empacotado

Figura 11- Concentração de dextrana em função do tempo em reatores com leito empacotado livres de biomassa. Leitos: $(\bullet)$ polietileno de baixa densidade ( $\square$ ) carvão vegetal ( $\mathbf{\Delta})$ argila expandia.

Figura 12 - Resposta ao estímulo degrau em reatores com leito ordenado livres de biomassa. Concentração $(\mathrm{C})$ em relação ao tempo (t); $(\triangle)$ Leito de polietileno; $(\bigcirc)$ Leito de espuma; $(\diamond)$ leito de cerâmica

Figura 13 - Curva E em reator anaeróbio de leito ordenado e escoamento descendente livre de biomassa (-) leito de polietileno; (-) leito de espuma; (-) leito de cerâmica.

Figura 14 - Produção temporal de biogás em reator anaeróbio de leito ordenado, escoamento descendente operado com e sem descarte de biomassa; (a) polietileno; (b) espuma; (c) cerâmica

Figura 15 - Eficiência de conversão de sacarose Es em reator anaeróbio de leito ordenado, escoamento descendente operado com e sem descartes de biomassa (a) polietileno (b) espuma (c) cerâmica

Figura 16 - Acúmulo de biomassa no fundo dos reatores de leito ordenado operado com escoamento descendente 
Figura 17 - Vazão mássica da biomassa de arraste wx em reator anaeróbio de leito ordenado, escoamento descendente operado com e sem descartes de biomassa (a) polietileno (b) espuma (c) cerâmica

Figura 18 - COVe ao longo do tempo em reator de leito ordenado, escoamento descendente operado com e sem descartes de biomassa

Figura 19 - Evidências fotográficas de biomassa flutuando no topo do reator anaeróbio de leito ordenado e escoamento descendente, operado com TDH de $2 \mathrm{~h}$ e concentração de substrato de $2 \mathrm{~g}$ DQO L ${ }^{-1}$

Figura 20 - Carga orgânica volumétrica específica (COVe) estimada a partir da concentração de sólidos suspensos voláteis (SSV) do primeiro descarte de biomassa em reator anaeróbio de leito empacotado e escoamento ascendente

Figura 21 - Crescimento e retenção de biomassa no leito empacotado ao longo do tempo

Figura 22 - Descartes frequentes de biomassa em reator anaeróbio de leito empacotado. Concentração de sólidos voláteis totais (SVT) e volume total descartado $(\mathrm{V})$......

Figura 23 - Comparativo da COVe real e estimada em reator anaeróbio de leito empacotado, escoamento ascendente com descartes de biomassa e COVe observada por Anzola-Rojas et al. (2014) em reator anaeróbio de leito empacotado, escoamento ascendente sem descartes de biomassa.

Figura 24 - Desempenho de reator anaeróbio de leito empacotado, escoamento ascendente e descartes periódicos de biomassa (- $\bullet$ ). Desempenho de reator anaeróbio de leito empacotado, escoamento ascendente sem descartes periódicos de biomassa (-) (Anzola-Rojas et al, 2014). Produção volumétrica de hidrogênio (PHV); rendimento de hidrogênio (YH2); eficiência de conversão de sacarose (Es).

Figura 25 - Carga orgânica volumétrica específica (COVe) estimada a partir da concentração de sólidos suspensos voláteis (SSV) do primeiro descarte de biomassa em reator anaeróbio de leito ordenado e escoamento ascendente

Figura 26 - Descartes frequentes de biomassa em reator anaeróbio de leito ordenado. Concentração de sólidos voláteis totais (SVT) e volume total descartado (V).

Figura 27 - Comparativo da COVe estimada com a COVe real em reator anaeróbio de leito ordenado, escoamento ascendente e descartes de biomassa e COVe real em reator anaeróbio de leito empacotado, escoamento ascendente e descartes de biomassa observada na estratégia 3

Figura 28 - Desempenho de reator anaeróbio de leito ordenado, escoamento ascendente e descartes periódicos de biomassa $(\boldsymbol{\Delta})$. Produção volumétrica de hidrogênio (PHV); rendimento de hidrogênio (YH2); eficiência de conversão de sacarose (Es).

Figura 29 - Perfil temporal da eficiência média de conversão de sacarose (Es) vazão (Q $Q_{\text {biogás }}$ e composição de biogás em reator anaeróbio de leito ordenado, escoamento descendente e variação da $\mathrm{COV}$

Figura 30 - Comportamento temporal da COVe (-) em relação à variação da COV (

-) em reator anaeróbio, leito ordenado e escoamento descendente. 
Figura 31 - Perfil temporal da produção de hidrogênio e COVe em reator anaeróbio de leito ordenado e escoamento descendente. Produção volumétrica de hidrogênio $(\mathrm{PVH})$; rendimento de hidrogênio (YH2)

Figura 32 - Tendência da produção de hidrogênio em relação à COVe em reator anaeróbio de leito ordenado e escoamento descendente e variação da COV (a) PVH (b) YH2

Figura 33 - Distribuição percentual dos PSF em relação à COVe em reator anaeróbio de leito ordenado, escoamento descendente e variação da COV (a) PSF principais; (b) PSF secundários

Figura 34 - Porcentagem de ácido acético formado pela via homoacetogênica em relação à $\mathrm{COVe}$ em reator anaeróbio de leito ordenado, escoamento descendente e variação da COV

Figura 35 - Distribuição percentual do hidrogênio teórico em relação à COVe em reator anaeróbio de leito ordenado, escoamento descendente e variação da $\mathrm{COV}$

Figura 36 - Vazão molar de hidrogênio teórico vH2 em relação à concentração de substrato afluente Cs0 em reator anaeróbio de leito ordenado e escoamento descendente

Figura 37 - Percentagem de vazão molar de hidrogênio liberado e homoacetogênese em relação à vazão molar de hidrogênio teórica

Figura 38 - Fotografia da superfície líquida do reator anaeróbio de leito ordenado, escoamento descendente e variação da $\operatorname{COV}$ (a) reator com 35 dias de operação, TDH de $2 \mathrm{~h}$, concentração de substrato de $2 \mathrm{~g} \mathrm{DQO} \mathrm{L}{ }^{-1}$ perfazendo

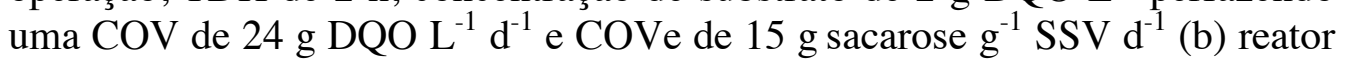
com 121 dias de operação, TDH de $4 \mathrm{~h}$, concentração de substrato de $4 \mathrm{~g}$ DQO $\mathrm{L}^{-1}$ perfazendo uma COV de $24 \mathrm{~g}$ DQO L $\mathrm{L}^{-1} \mathrm{~d}^{-1}$ e COVe de $4,1 \mathrm{~g}$ sacarose $\mathrm{g}^{-1}$ SSV d ${ }^{-1}$

Figura 39 - Ajuste do modelo teórico das concentrações aos dados experimentais da Fase 1

Figura 40 - Ajuste do modelo teórico das concentrações aos dados experimentais da Fase 2

Figura 41 - Ajuste do modelo teórico das concentrações aos dados experimentais da Fase 3

Figura 42 - Ajuste do modelo teórico das concentrações aos dados experimentais da Fase 4

Figura 43 - Ajuste do modelo teórico das concentrações aos dados experimentais da Fase 5

Figura 44 - Ajuste do modelo teórico das concentrações aos dados experimentais da Fase 6

Figura 45 - Velocidade da Reação 17 (Sacarose a ácido butírico) em reator anaeróbio de leito ordenado e escoamento descendente com variação da COV.

Figura 46 - Velocidade da Reação 18 (Sacarose a ácido acético) em reator anaeróbio de leito ordenado e escoamento descendente com variação da COV. 
xviii

Figura 47 - Velocidade da Reação 19 (Sacarose a ácido propiônico) em reator anaeróbio de leito ordenado e escoamento descendente com variação da $\mathrm{COV}$

Figura 48 - Velocidade da Reação 20 (Sacarose a ácido lático) em reator anaeróbio de leito ordenado e escoamento descendente com variação da COV

Figura 49 - Velocidade da Reação 21 (Ácido lático a ácido propiônico) em reator anaeróbio de leito ordenado e escoamento descendente com variação da COV 150

Figura 50 - Velocidade da Reação 22 (Ácido butírico a ácido acético) em reator anaeróbio de leito ordenado e escoamento descendente com variação da $\mathrm{COV}$

Figura 51 - Velocidade da Reação 23 (Ácido propiônico a ácido acético) em reator anaeróbio de leito ordenado e escoamento descendente com variação da COV

Figura 52 - Velocidade da Reação 24 (Ácido lático a ácido acético) em reator anaeróbio de leito ordenado e escoamento descendente com variação da COV

Figura 53 - Velocidade da Reação 25 (Sacarose a etanol) em reator anaeróbio de leito ordenado e escoamento descendente com variação da COV 


\section{LISTA DE TABELAS}

Tabela 1 - Características físicas dos materiais usados no leito empacotado (FERNANDES, 2008)

Tabela 2 - Características físicas dos materiais usados no leito ordenado (PEIXOTO, 2011)

Tabela 3 - Micronutrientes adicionados ao meio sintético por cada $1 \mathrm{~g}$ DQO L ${ }^{-1}$ (DEL NERY, 1987)

Tabela 4 - Análises realizadas durante o tempo experimental e a frequência

Tabela 5 - Resultados dos ensaios hidrodinâmicos e porosidade dos leitos empacotados

Tabela 6 - TDH médio e padrão de escoamento em reatores de leito ordenado e escoamento descendente.....

Tabela 7 - Vazão máxima e média de biogás em reator anaeróbio de leito ordenado, escoamento descendente, operado com e sem descartes de biomassa

Tabela 8 - Porcentagem média da composição do biogás em reator anaeróbio de leito ordenado, escoamento descendente operado com e sem descartes de biomassa.

Tabela 9 - Eficiência média de conversão de sacarose em reator anaeróbio de leito ordenado, escoamento descendente operado com e sem descartes de biomassa.

Tabela 10 - Vazão mássica média da biomassa de arraste em reator anaeróbio de leito ordenado, escoamento descendente operado com e sem descartes de biomassa.

Tabela 11 - Produção média dos PSF em reator anaeróbio de leito ordenado, escoamento descendente operado com e sem descartes de biomassa durante a fase de estabilidade

Tabela 12 - Balanço de carbono em reator anaeróbio de leito ordenado, escoamento descendente operado com e sem descartes de biomassa

Tabela 13 - Valores máximos de produção de hidrogênio em reator anaeróbio de leito ordenado, escoamento descendente operado com e sem descartes de biomassa (fase transiente)

Tabela 14 - Valores médios de produção de hidrogênio em reator anaeróbio de leito ordenado, escoamento descendente operado com e sem descartes de biomassa (fase de estabilidade)

Tabela 15 - Estimativa de biomassa total gerada e substrato total consumido em reator de leito ordenado, escoamento descendente operado com descartes de biomassa .......99

Tabela 16 - Estimativa de biomassa total gerada e substrato total consumido em reator de leito ordenado, escoamento descendente operado sem descarte de biomassa

Tabela 17 - Teste t para duas amostras supondo variâncias desiguais. Es em reator anaeróbio de leito ordenado, escoamento descendente, com e sem descartes de biomassa

Tabela 18 - Teste t para duas amostras supondo variâncias desiguais. PVH em reator anaeróbio de leito ordenado, escoamento descendente, com e sem descartes de biomassa . 
Tabela 19 - Teste t para duas amostras supondo variâncias desiguais. YH2 em reator anaeróbio de leito ordenado escoamento descendente, com e sem descartes de biomassa

Tabela 20 - Teste t para duas amostras supondo variâncias desiguais. Produção de ácido propiônico em reator anaeróbio de leito ordenado, escoamento descendente, com e sem descartes de biomassa

Tabela 21 - Faixa da COVe e COVe média na fase transiente em reator anaeróbio de leito ordenado, escoamento descendente operado com e sem descartes de biomassa

Tabela 22 - Faixa da COVe e COVe média na fase de estabilidade em reator anaeróbio de leito ordenado, escoamento descendente operado com e sem descartes de biomassa

Tabela 23 - Percentagem de ácido acético gerado via homoacetogênese em reator anaeróbio de leito ordenado, escoamento descendente operado com e sem descartes de biomassa.

Tabela 24 - Porcentagem da vazão molar de hidrogênio vH2 liberada em relação à teórica durante a fase de estabilidade em reator anaeróbio de leito ordenado, escoamento descendente operado com e sem descartes de biomassa

Tabela 25 - Estimativa da biomassa total gerada e substrato total consumido em reator anaeróbio de leito empacotado e escoamento ascendente

Tabela 26 - Desempenho de reator anaeróbio de leito empacotado e escoamento ascendente durante a fase de estabilidade.

Tabela 27 - Concentração média dos produtos solúveis da fermentação em reator anaeróbio de leito empacotado e escoamento ascendente durante a fase de estabilidade

Tabela 28 - Balanço da DQO em reator anaeróbio de leito empacotado e escoamento ascendente durante a fase de estabilidade.

Tabela 29 - Ácido acético gerado via homoacetogênese em reator anaeróbio de leito empacotado e escoamento ascendente durante a fase de estabilidade

Tabela 30 - Percentagem da vazão molar de hidrogênio vH2 liberada em relação à teórica em reator anaeróbio de leito fixo, usando polietileno como material suporte

Tabela 31 - Estimativa de biomassa total gerada e substrato total consumido em reator anaeróbio de leito ordenado, escoamento ascendente e descartes de biomassa

Tabela 32 - Desempenho de reator anaeróbio de leito ordenado, escoamento ascendente e descartes de biomassa.

Tabela 33 - Concentração média dos produtos solúveis da fermentação em reator anaeróbio de leito ordenado, escoamento ascendente e descartes de biomassa

Tabela 34 - Balanço da DQO em reator anaeróbio de leito ordenado, escoamento ascendente e descartes de biomassa.

Tabela 35 - Ácido acético gerado via homoacetogênese e percentagem da vazão molar de hidrogênio liberado em reator anaeróbio de leito ordenado, escoamento ascendente e descartes de biomassa. 
Tabela 36 - Desempenho médio de reator anaeróbio de leito ordenado e escoamento descendente com variação da COV

Tabela 37 - Produção média dos PSF principais em reator anaeróbio de leito ordenado, escoamento descendente e variação da COV

Tabela 38 - Produção média dos PSF secundários em reator anaeróbio de leito ordenado, escoamento descendente e variação da COV

Tabela 39 - Balanço de carbono em reator anaeróbio de leito ordenado, escoamento descendente e variação da COV

Tabela 40 - Estimativa de biomassa total gerada e substrato total consumido em reator anaeróbio de leito ordenado, escoamento descendente e variação da COV

Tabela 41 - COVe média estimada em cada fase operacional em reator anaeróbio de leito ordenado, escoamento descende e variação da COV

Tabela 42 - Produção de hidrogênio em reator anaeróbio de leito ordenado e escoamento descendente com variação da COV

Tabela 43 - Percentagem vazão molar de hidrogênio vH2 liberada em relação ao teórico em reator anaeróbio de leito ordenado, escoamento descendente e com variação da $\mathrm{COV}$

Tabela 44 - Concentração de sacarose ao longo do reator anaeróbio de leito ordenado, escoamento descendente e variação da COV em cada fase operacional

Tabela 45 - Concentração de etanol ao longo do reator anaeróbio de leito ordenado, escoamento descendente e variação da COV em cada fase operacional

Tabela 46 - Concentração de ácido butírico ao longo do reator anaeróbio de leito ordenado, escoamento descendente e variação da COV em cada fase operacional.

Tabela 47 - Concentração de ácido lático ao longo do reator anaeróbio de leito ordenado, escoamento descendente e variação da COV em cada fase operacional.

Tabela 48 - Concentração de ácido propiônico ao longo do reator anaeróbio de leito ordenado, escoamento descendente e variação da COV em cada fase operacional.

Tabela 49 - Concentração de ácido acético ao longo do reator anaeróbio de leito ordenado, escoamento descendente e variação da COV em cada fase operacional.

Tabela 50 - Constantes cinéticas 


\section{LISTAS DE SÍMBOLOS}

\section{Desempenho do reator}

\begin{tabular}{|c|c|c|}
\hline Símbolo & Parâmetro & Unidade \\
\hline $\mathrm{COV}$ & Carga orgânica volumétrica & $\begin{array}{l}\text { g DQO L } \mathrm{L}^{-1} \mathrm{~d}^{-1} \mathrm{ou} \\
\text { g sacarose } \mathrm{L}^{-1} \mathrm{~d}^{-1}\end{array}$ \\
\hline COVe & Carga orgânica volumétrica específica & 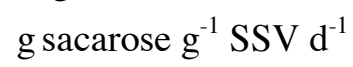 \\
\hline$D Q O$ & Demanda química de oxigênio & $\mathrm{mg} \mathrm{L}^{-1}$ \\
\hline$D Q O_{a f}$ & DQO afluente & $\mathrm{mg} \mathrm{L}^{-1}$ \\
\hline$D Q \mathrm{O}_{\mathrm{H}_{2}}$ & DQO envolvida na produção de hidrogênio & $\operatorname{mg~L}{ }^{-1}$ \\
\hline$D Q O_{S E}$ & DQO da sacarose efluente & $m g L^{-1}$ \\
\hline$D Q O_{t(P S F)}$ & DQO total teórica dos produtos solúveis da fermentação & $\operatorname{mg~L}{ }^{-1}$ \\
\hline$D Q O_{x}$ & DQO da biomassa & $\mathrm{mg} \mathrm{L}^{-1}$ \\
\hline$E_{s}$ & Eficiência de conversão de sacarose & $\%$ \\
\hline$F_{m}$ & Fator de calibração do medidor & \\
\hline$n$ & Número de mols & mols \\
\hline$P V H$ & Produção volumétrica de hidrogênio & $\mathrm{L} \mathrm{H}_{2} \mathrm{~L}^{-1} \mathrm{~d}^{-1}$ \\
\hline$R$ & Constante universal dos gases ideais & $\mathrm{L}$ atm K ${ }^{-1} \mathrm{~mol}^{-1}$ \\
\hline$Q$ & Vazão do líquido & $\mathrm{L} \mathrm{h}^{-1}$ \\
\hline$Q_{\text {biogás }}$ & Vazão de biogás & $\begin{array}{c}\mathrm{mL} \mathrm{h}^{-1} \mathrm{ou} \\
\mathrm{mol} \mathrm{h}^{-1}\end{array}$ \\
\hline$C s_{0}$ & Concentração de sacarose afluente & $\mathrm{mg} \mathrm{L}^{-1}$ \\
\hline Cs & Concentração de sacarose efluente & $\mathrm{mg} \mathrm{L}^{-1}$ \\
\hline$T$ & Temperatura absoluta & $\mathrm{K}$ \\
\hline$T D H$ & Tempo de detenção hidráulica & $\mathrm{h}$ \\
\hline$v_{H_{2}}$ & Vazão molar de hidrogênio & $\mathrm{mmol} \mathrm{h}^{-1}$ \\
\hline$v_{S}$ & Velocidade de conversão de sacarose & $\mathrm{mmol} \mathrm{h}^{-1}$ \\
\hline$V_{i}$ & Volume de gás injetado & $\mathrm{mL}$ ou $\mathrm{L}$ \\
\hline$V_{m}$ & Volume de gás marcado pelo medidor & $\mathrm{mL}$ ou L \\
\hline$Y_{H_{2}}$ & Rendimento de hidrogênio & $\mathrm{mol} \mathrm{H}_{2} \mathrm{~mol}_{\mathrm{sc}}^{-1}$ \\
\hline$Y x / s$ & Coeficiente de rendimento celular & $\mathrm{g} \mathrm{SSV} \mathrm{g}_{\mathrm{sc}}^{-1}$ \\
\hline
\end{tabular}

Carga orgânica volumétrica específica

\begin{tabular}{clc}
\hline Símbolo & \multicolumn{1}{c}{ Significado } & Unidade \\
\hline$d$ & Quantidade de SSV por descarte do fundo do reator & $\mathrm{g}$ \\
$S_{c}$ & Substrato total consumido & $\mathrm{g}$ \\
$S S V_{e}$ & Concentração de sólidos suspensos voláteis no efluente & $\mathrm{g} \mathrm{L}^{-1}$ \\
$Q_{S}$ & Vazão do substrato & $\mathrm{g} \mathrm{h}^{-1}$ \\
$Q_{\dot{w}}$ & Vazão mássica de biomassa produzida & $\mathrm{g} \mathrm{SSV} \mathrm{h}^{-1}$ \\
\hline
\end{tabular}


Carga orgânica volumétrica específica

\begin{tabular}{|c|c|c|}
\hline Símbolo & Significado & Unidade \\
\hline$x_{a}$ & $\begin{array}{l}\text { Sólidos suspensos voláteis aderidos e intersticiais no material } \\
\text { suporte }\end{array}$ & $\mathrm{g}$ \\
\hline$x_{d}$ & $\begin{array}{l}\text { Total de sólidos suspensos voláteis dos descartes realizados } \\
\text { durante todo o tempo operacional }\end{array}$ & $\mathrm{g}$ \\
\hline$x_{e}$ & $\begin{array}{l}\text { Total de sólidos suspensos voláteis no efluente líquido } \\
\text { durante todo o tempo operacional }\end{array}$ & $\mathrm{g}$ \\
\hline$x_{n}$ & Concentração de biomassa em um tempo determinado & $\mathrm{g} \mathrm{SSV} \mathrm{L}^{-1}$ \\
\hline$x_{n-1}$ & Concentração de biomassa no tempo menos um & $\mathrm{g} \mathrm{SSV} \mathrm{L}^{-1}$ \\
\hline$x_{s}$ & $\begin{array}{l}\text { Sólidos suspensos voláteis do líquido drenado do reator no } \\
\text { final da operação }\end{array}$ & $\mathrm{g}$ \\
\hline$x_{t}$ & Quantidade total de biomassa produzida ao final da operação & g SSV \\
\hline$V_{u}$ & Volume útil do reator & $\mathrm{L}$ \\
\hline$\dot{w}_{x}$ & Vazão mássica da biomassa de arraste & $\mathrm{g} \mathrm{SSV} \mathrm{h}^{-1}$ \\
\hline$Y x / s$ & Coeficiente de rendimento celular & $\mathrm{g} \mathrm{SSV} \mathrm{g}_{\mathrm{sc}}^{-1}$ \\
\hline
\end{tabular}

\section{Ensaios hidrodinâmicos}

\begin{tabular}{clc}
\hline Símbolo & \multicolumn{1}{c}{ Significado } & Unidade \\
\hline$C$ & Concentração & $\mathrm{mg} \mathrm{L}^{-1}$ \\
$C_{\max }$ & Concentração máxima & $\mathrm{mg} \mathrm{L}^{-1}$ \\
$E$ & Distribuição do tempo de residência & Adimensional \\
$N$ & Número de reatores de mistura completa em serie & Reatores \\
$\bar{\theta} h$ & TDH médio & $\mathrm{h}$ \\
$\sigma^{2}$ & Variância & \\
$\sigma_{\Theta}^{2}$ & Variância adimensional & \\
\hline
\end{tabular}




\section{SUMÁRIO}

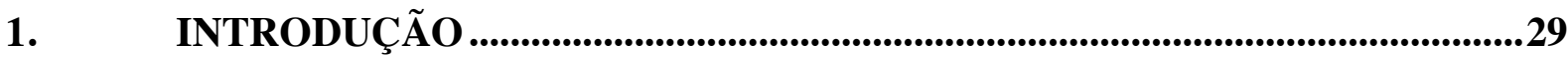

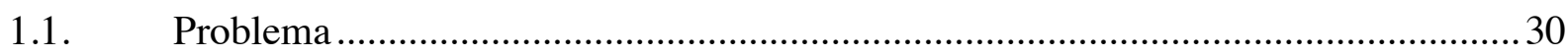

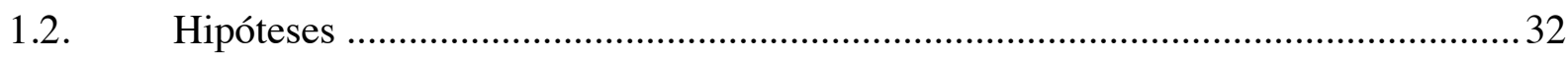

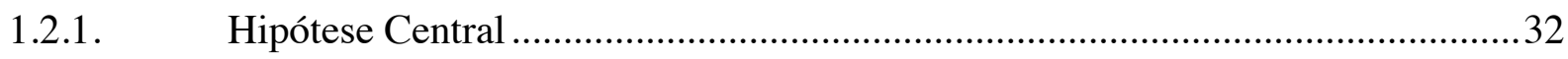

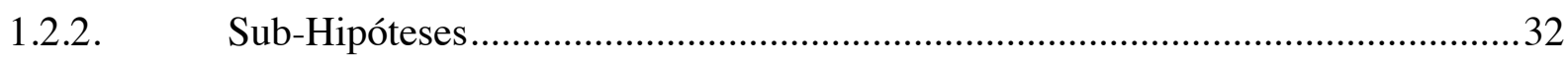

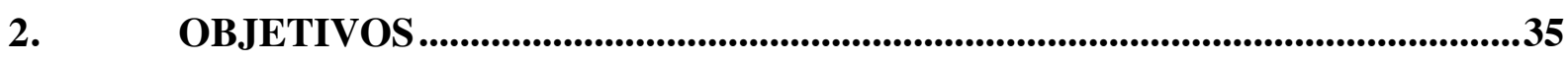

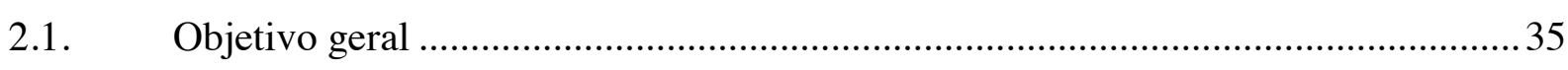

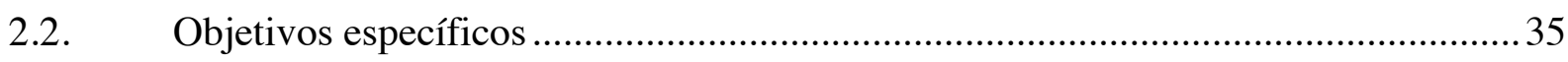

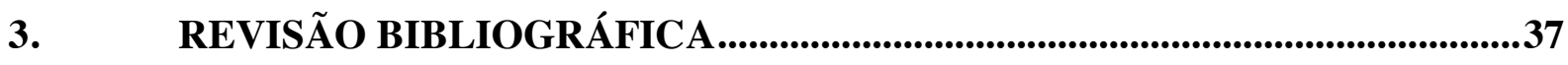

3.1. Processo fermentativo visando a produção de gás hidrogênio .................................37

3.2. Fatores que influenciam a produção biológica de hidrogênio .................................. 39

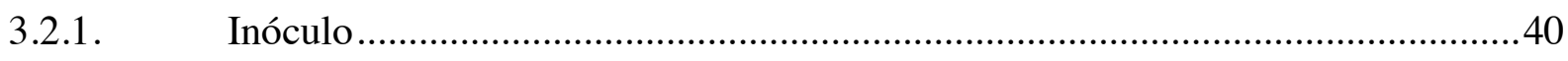

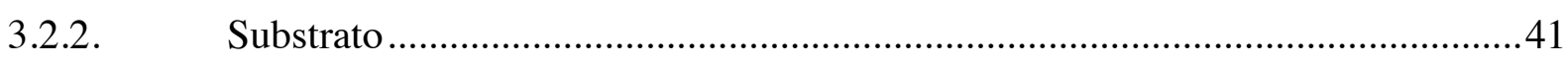

3.2.3. Carga orgânica volumétrica (COV) …........................................................... 41

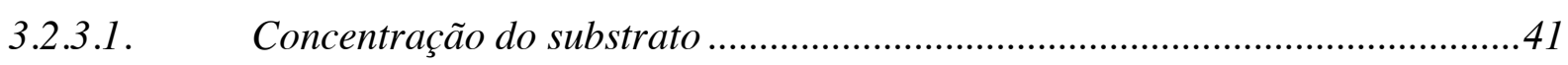

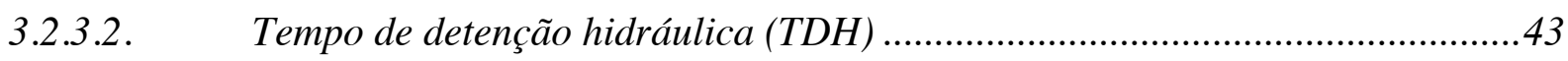

3.2.3.3. Carga orgânica volumétrica específica $(\mathrm{COVe})$...............................................4

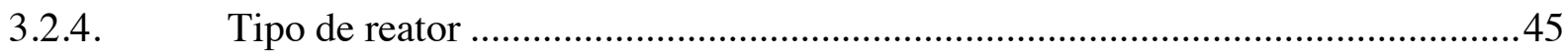

3.3. Reator anaeróbio de leito empacotado e escoamento ascendente: resultados obtidos e problemas enfrentados ..................................................................... 47

3.3.1. Material suporte, porosidade do leito e TDH ..................................................48

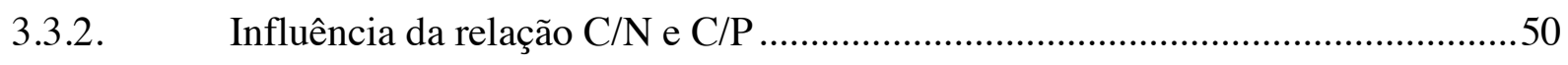

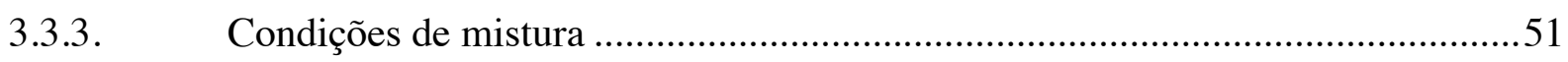

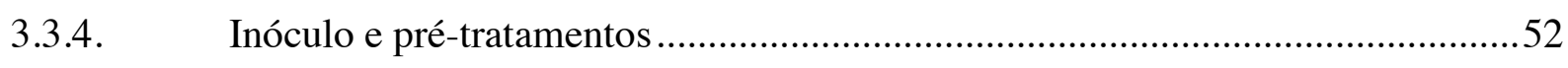

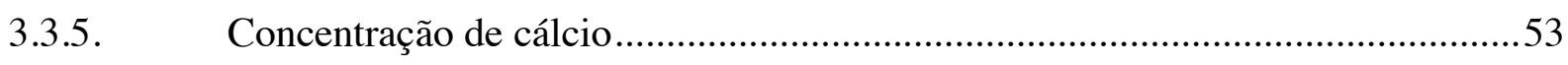

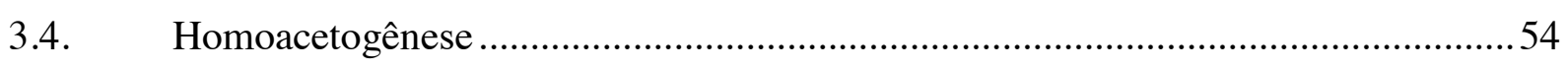

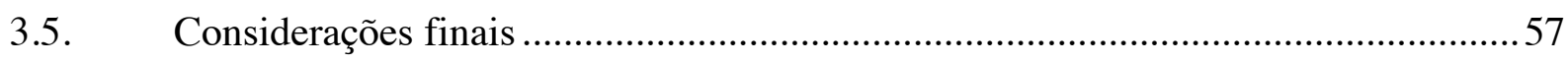

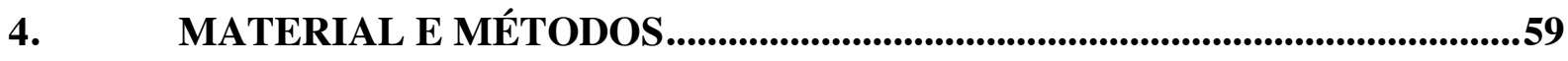

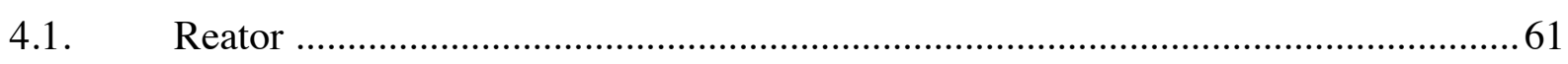

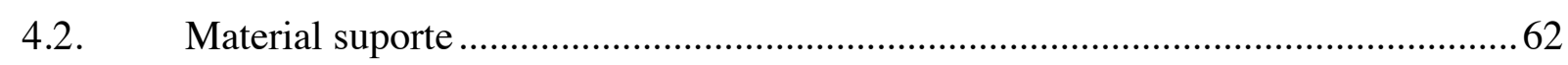

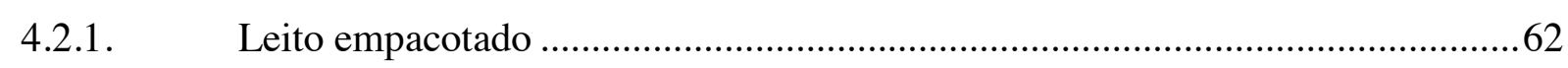

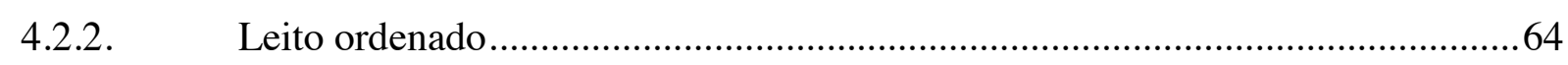

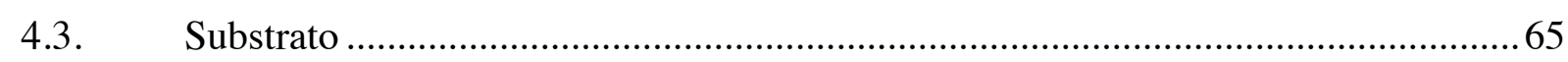




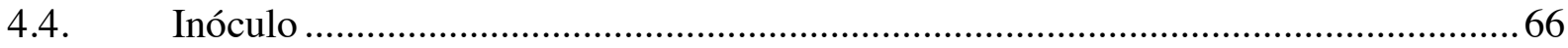

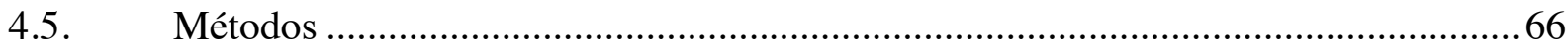

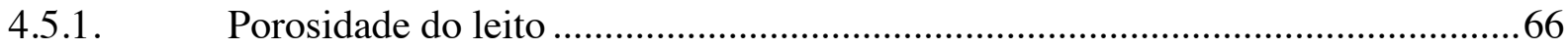

4.5.2. Ensaio hidrodinâmico no reator com leito empacotado ........................................66

4.5.3. Ensaio hidrodinâmico no reator com leito ordenado ...........................................68

4.5.4. Medida de vazão de biogás ...........................................................................69

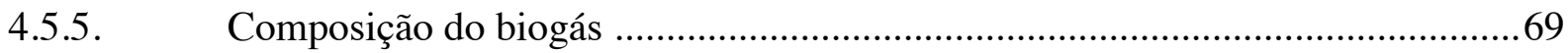

4.5.6. Determinação dos produtos solúveis da fermentação …………………………....70

4.5.7. Análises e frequência das análises ..................................................................73

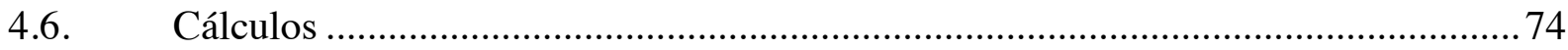

4.6.1. Desempenho do reator e produção de hidrogênio ..................................................74

4.6.2. Carga orgânica volumétrica específica (COVe) ………………………………....76

4.6.3. Reações químicas e balanço de carbono ……………………………………......78

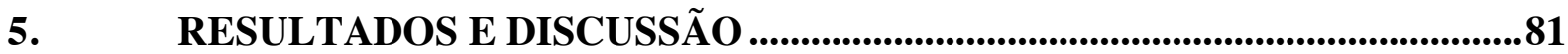

5.1. Estratégia 1 - Reator anaeróbio de leito empacotado e escoamento descendente ....81

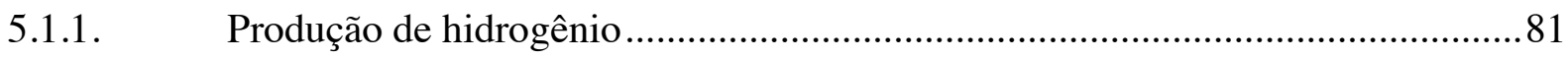

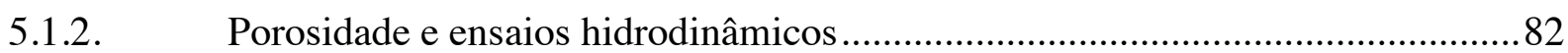

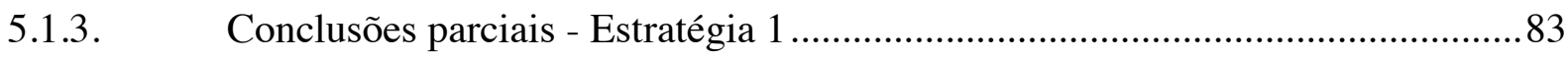

5.2. Estratégia 2 - Reator anaeróbio de leito ordenado e escoamento descendente .........84

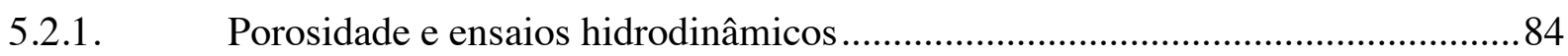

5.2.2. Desempenho dos reatores operados com e sem descarte de biomassa ................86

5.2.3. Produção de hidrogênio em reatores com leito ordenado ...................................93

5.2.4. Comparação entre as operações em reator anaeróbio de leito ordenado, escoamento descendente, com e sem descartes de biomassa e com diferentes

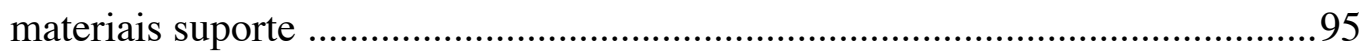

5.2.5. O comportamento da COVe em reator anaeróbio de leito ordenado, escoamento descendente, com e sem descartes de biomassa .................................................99

5.2.6. Homoacetogênese e hidrogênio não liberado em reator anaeróbio de leito ordenado, escoamento descendente, com e sem descartes de biomassa ............102

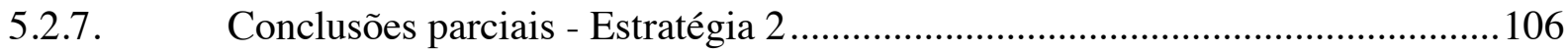

5.3. Estratégia 3 - Reator anaeróbio com leito empacotado operado com escoamento ascendente e descartes frequentes de biomassa. ………………………………...... 108

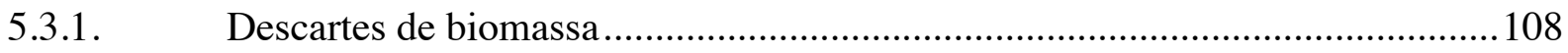

5.3.2. Desempenho de reator anaeróbio de leito empacotado, escoamento ascendente e descartes frequentes de biomassa ...................................................................... 111

5.3.3. Homoacetogênese e hidrogênio não liberado em reator anaeróbio de leito empacotado operado com escoamento ascendente e descartes de biomassa ....115 
5.3.4. Conclusões parciais - Estratégia 3.....

5.4. Estratégia 4 - Reator anaeróbio com leito ordenado operado com escoamento ascendente e descartes frequentes de biomassa

5.4.1. Descartes de biomassa.

5.4.2. Desempenho em reator de leito ordenado, escoamento ascendente e descartes frequentes de biomassa.

5.4.3. Conclusões parciais - Estratégia 4.

5.5. Estratégia 5: Variação da carga orgânica volumétrica $(\mathrm{COV})$ em reator anaeróbio de leito ordenado e escoamento descendente.

5.5.1. Desempenho geral de reator anaeróbio de leito ordenado, escoamento descendente e variação da COV

5.5.2. O comportamento da COVe mediante variação da COV em reator anaeróbio de leito ordenado e escoamento descendente.

5.5.3. Influência da COVe sobre a produção de hidrogênio em reator anaeróbio de leito ordenado, escoamento descendente e variação da COV

5.5.4. $\mathrm{O}$ TDH e a concentração do substrato em reator anaeróbio de leito ordenado e escoamento descendente

5.5.5. Modelagem matemática do desempenho espacial do reator anaeróbio de leito ordenado, escoamento descendente e variação da COV

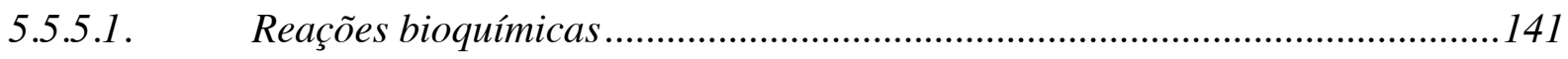

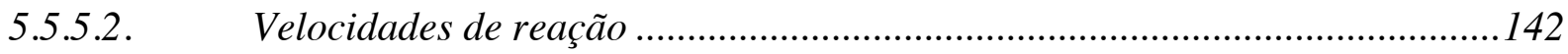

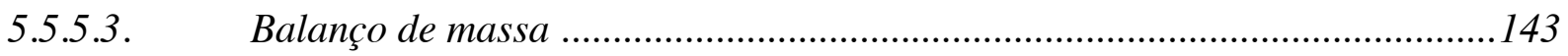

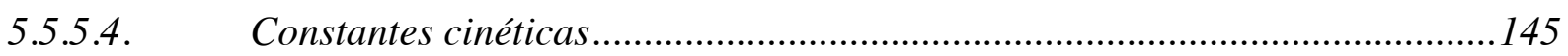

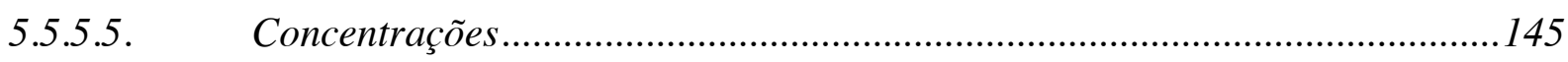

5.5.5.6. Velocidades de reação ao longo do reator anaeróbio de leito ordenado .......149

5.5.6. Conclusões parciais - Estratégia 5 ................................................................. 152

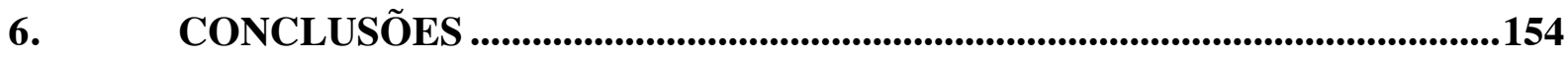

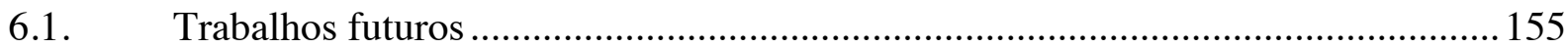

7. REFERÊNCIAS BIBLIOGRÁFICAS ...........................................................157 
xxviii 


\section{INTRODUÇÃO}

Devido ao rápido crescimento populacional, industrial e econômico, o consumo de energia está sendo incrementado continuamente. Estima-se um incremento de $50 \%$ no consumo de energia mundial de 2005 a 2030, de 462 quatrilhões de Btu para 695 quatrilhões de Btu em 2030 (KAHYAOğLU, ŞAHIN e SAKA, 2012). Por causa dessa crescente demanda e pela necessidade de combustíveis limpos, muitos estudos têm focado a produção de hidrogênio como carreador de energia devido a sua ampla possibilidade de aplicação além dos aspectos ecológicos (BICAKOVA e STRAKA, 2012). O uso do hidrogênio pode resultar em um sistema de energia sustentável, já que esse combustível pode ser produzido a partir de fontes renováveis e utilizado para geração de energia móvel ou estacionária (KRAEMER e BAGLEY, 2008), substituindo combustíveis fósseis em transporte, moradia, comércio e indústria (DAS e VEZIROGLU, 2001).

Dependendo do processo de obtenção, o hidrogênio pode ser considerado um combustível que causa baixo impacto ambiental, uma vez que sua combustão está livre de gases do efeito estufa além de poder ser facilmente convertido em eletricidade em células a combustível (SUZUKI, 1982; DAS e VEZIROGLU, 2001; BABU, MOHAN e SARMA, 2009).

Atualmente, a produção de hidrogênio a partir de fontes combustíveis não fósseis inclui a eletrólise de água, processos termoquímicos, radiolíticos e biológicos (KAHYAOğLU, ŞAHIN e SAKA, 2012). Dentre esses processos, a produção biológica a partir do uso de fontes mais baratas, como águas residuárias com quantidades consideráveis de fração orgânica biodegradável, torna-se cada vez mais interessante, visto que essas águas são abundantes e seu tratamento antes da disposição no ambiente é um requisito obrigatório (BABU, MOHAN e SARMA, 2009).

Nos processos biológicos para produção de hidrogênio utilizam-se microorganismos como as bactérias anaeróbias, facultativas, fotossintéticas, cianobactérias e algas verdes. As bactérias anaeróbias e facultativas envolvidas no processo fermentativo são capazes de gerar hidrogênio a partir de fontes ricas em carboidratos (CHEONG e HANSEN, 2007). Além disso, pelo processo fermentativo, o hidrogênio pode ser produzido durante o dia e a noite, com velocidade constante, já que não depende de uma fonte de energia externa como no caso do uso das bactérias fototróficas (ALZATE-GAVIRIA, SEBASTIAN, et al., 2007; DAS, 
2009). No entanto, as principais desvantagens da aplicação da tecnologia de hidrogênio pelo processo biológico fermentativo são os baixos rendimentos e as baixas velocidades de produção. A literatura tem reportado rendimentos entre 1 e $2 \mathrm{~mol} \mathrm{H}_{2} \mathrm{~mol}^{-1}$ glicose convertida, sendo o valor máximo teórico de $4 \mathrm{~mol} \mathrm{H}_{2} \mathrm{~mol}^{-1}$ glicose convertida se todo o substrato fosse convertido em ácido acético e os elétrons não fossem usados para crescimento (KRAEMER e BAGLEY, 2008). Diversas pesquisas estão em andamento, e nos últimos anos, têm sido propostas e estudadas novas abordagens para superar esses inconvenientes (HALLENBECK e GHOSH, 2009; HALLENBECK e GHOSH, 2012).

A literatura descreve vários fatores que afetam a produção biológica de hidrogênio (WANG e WAN, 2009), sendo a configuração do reator um dos mais importantes que influi no rendimento global do processo. Um tipo de reator em particular pode afetar fortemente o processo fermentativo, especialmente por meio da retenção de biomassa, do comportamento hidrodinâmico, da população microbiana que se desenvolve e da efetividade do contato do substrato com os microorganismos (BABU, MOHAN e SARMA, 2009; REN, GUO, et al., 2011).

\subsection{Problema}

Recentes estudos desenvolvidos no Laboratório de Processos Biológicos da Escola de Engenharia de São Carlos da Universidade de São Paulo (LPB-EESC-USP) visam a produção de hidrogênio por processo fermentativo em reator anaeróbio de leito fixo a partir de águas residuárias. Nesse tipo de reator, vários fatores que influenciam o processo têm sido analisados tais como: material suporte, porosidade do leito, tempo de detenção hidráulica (TDH) (FERNANDES, 2008), relação carbono/nitrogênio (relação C/N) (ANZOLA-ROJAS, 2010), condição de mistura (LIMA e ZAIAT, 2012), origem do inóculo e diferentes tipos de pré-tratamento (PENTEADO, LAZARO, et al., 2013) e concentração de micronutrientes, como cálcio (CARMINATO, 2013). Os rendimentos máximos observados superam os 3 mol $\mathrm{H}_{2} \mathrm{~mol}^{-1}{ }_{\text {sc }}$ (sacarose consumida). No entanto, o processo não é estável e a geração de hidrogênio não é mantida por longos tempos de operação, uma vez que a produção de biogás atinge um ponto de máximo com poucos dias de operação e vai decaindo ao longo do tempo até atingir baixos valores ou mesmo valores nulos de produção.

Os autores citados anteriormente (FERNANDES, 2008; CARMINATO, 2013) têm atribuído essa tendência ao acúmulo excessivo de biomassa no leito do reator, resultando em anomalias físicas tais como alteração no padrão de escoamento (caminhos preferenciais e 
zonas mortas) e em diminuição da carga orgânica volumétrica específica (COVe) aplicada ao sistema. Por um lado, zonas estagnadas, caminhos preferenciais e curtos-circuitos levam a graves implicações operacionais, com reflexos negativos na fase líquida e gasosa, já que o biogás produzido pode ficar retido nos interstícios do leito, dificultando sua liberação. Por outro lado, a constante diminuição da COVe pode causar mudanças negativas na estrutura microbiana e nas rotas metabólicas, tais como o desenvolvimento de microorganismos consumidores de $\mathrm{H}_{2}$ e $\mathrm{CO}_{2}$ ou a utilização da energia para crescimento e manutenção celular. Baixos valores de $\mathrm{COVe}$, obtidos principalmente pelo acúmulo excessivo de microorganismos no reator, implicam em baixa disponibilidade de compostos orgânicos para os organismos, sendo que alguns que possuem a capacidade de viver heterotroficamente e autotroficamente passam a potencializar a rota autotrófica, com consequente consumo de $\mathrm{H}_{2}$ e $\mathrm{CO}_{2}$ (MINTON e CLARKE, 1989; DRAKE, KÜSEL e MATTHIES, 2002; DRAKE, GÖBNER e DANIEL, 2008). Como um exemplo, está provado que C. ljungdahlii pode crescer heterotroficamente com consumo de hexoses e pentoses ou autotroficamente com uso de $\mathrm{H}_{2}$ e $\mathrm{CO}_{2}$ ou $\mathrm{CO}$, nesse caso com produção de acetato e metanol (KÖPKE, HELD, et al., 2010). Essa rota foi identificada por Lima e Zaiat (2012) em reator acidogênico de leito fixo alimentado com água residuária a base de glicose e foi responsabilizada pela instabilidade na produção de hidrogênio.

Portanto, o controle sobre a COVe pode ser fator chave para a produção de hidrogênio em reatores anaeróbios de leito fixo, com implicações tanto hidrodinâmicas quanto metabólicas (PAN, ZHANG, et al., 2008; HAFEZ, NAKHLA, et al., 2010; ANZOLAROJAS, GONÇALVES , et al., 2014). Aplicar e manter uma COVe adequada em um reator anaeróbio de leito fixo produtor de hidrogênio pode evitar o aumento da competição pelo substrato, quer para formação de produtos solúveis da fermentação relacionados ao consumo de biogás, quer para manutenção e crescimento celular. Sendo assim, o resultado pode ser a produção contínua e estável de hidrogênio ao longo do tempo nesse tipo de reator devido ao equilíbrio alcançado entre as populações microbianas. Assim, este trabalho apresenta cinco diferentes estratégias que visam o controle da COVe mediante a inversão do escoamento, alteração estrutural do leito e variação da carga orgânica volumétrica aplicada em um reator anaeróbio de leito fixo produtor de hidrogênio a partir de água residuária sintética a base de sacarose. 


\subsection{Hipóteses}

\subsubsection{Hipótese Central}

Com base no contexto apresentado e no estado da arte, levantou-se a hipótese de que é possível a produção contínua e estável de hidrogênio em reatores acidogênicos de leito fixo com controle da carga orgânica específica aplicada (COVe) e das características hidrodinâmicas no reator por meio da manipulação de variáveis operacionais ou da disposição adequada dos materiais suportes no leito.

\subsubsection{Sub-Hipóteses}

A hipótese central, mais ampla, foi dividida em sub-hipóteses levantadas com base nos aspectos construtivos e operacionais dos reatores acidogênicos, a saber:

Sub-hipótese 1: É possível a produção contínua e estável de hidrogênio em reatores acidogênicos de leito fixo empacotado desde que se controle a COVe por meio da operação com escoamento descendente ou pelo descarte periódico de lodo em reatores com escoamento ascendente. $\mathrm{O}$ escoamento descendente facilita a lavagem natural da biomassa excedente em um reator de leito fixo empacotado, permitindo maior controle da COVe. Adicionalmente, a saída do gás contracorrente com a fase líquida facilita a liberação do biogás produzido, principalmente no primeiro segmento do leito, minimizando o contato do hidrogênio com os possíveis microorganismos consumidores.

Sub-hipótese 2: O leito com material suporte ordenado longitudinalmente, em contraposição ao leito empacotado, diminui os interstícios, onde, provavelmente, são estabelecidos os organismos consumidores de biogás. A nova configuração do reator anaeróbio com leito ordenado e escoamento descendente ou ascendente evita o acúmulo de biomassa no leito permitindo um melhor controle da carga orgânica volumétrica específica (COVe). Adicionalmente, o leito ordenado com escoamento descendente permite a saída do gás em contracorrente com a fase líquida, facilitando a liberação do biogás produzido, principalmente no primeiro segmento do leito, minimizando o contato do hidrogênio com os possíveis microorganismos consumidores. 
Sub-hipótese 3: A variação da carga orgânica volumétrica aplicada (COV) permite controlar a COVe em um reator anaeróbio de leito ordenado e escoamento descendente, uma vez que estes parâmetros estão diretamente relacionados e as rotas metabólicas podem ser influenciadas pelo tempo de detenção hidráulica (TDH) ou pela concentração do substrato inicial. 


\section{OBJETIVOS}

\subsection{Objetivo geral}

O objetivo principal desse projeto foi a avaliação de estratégias operacionais que possibilitem a produção de hidrogênio em reator anaeróbio de leito fixo de forma contínua e estável ao longo do tempo.

\subsection{Objetivos específicos}

Os objetivos específicos foram:

- Avaliar a produção de hidrogênio em reator anaeróbio de leito fixo empacotado com escoamento descendente.

- Avaliar a produção de hidrogênio em reator anaeróbio de leito fixo ordenado e escoamento descendente com e sem descartes de biomassa.

- Realizar o controle da COVe em um reator anaeróbio de leito empacotado e escoamento ascendente mediante descartes periódicos de biomassa.

- Realizar o controle da COVe em um reator anaeróbio de leito ordenado e escoamento ascendente mediante descartes periódicos de biomassa.

- Variar a carga orgânica volumétrica (COV) em um reator anaeróbio de leito ordenado e escoamento descendente como método para controlar a COVe sem realizar descartes de biomassa. 


\section{REVISÃO BIBLIOGRÁFICA}

\subsection{Processo fermentativo visando a produção de gás hidrogênio}

A fermentação é um processo complexo que envolve diversas classes de microorganismos e várias fases intermediárias tais como hidrólise, acidogênese, acetogênese e metanogênese. Inicialmente, os componentes orgânicos complexos (polímeros) são hidrolisados em compostos mais simples (monômeros). A seguir, os produtos gerados são metabolizados no interior das bactérias fermentativas, sendo convertidos em ácidos orgânicos, álcoois, ácido lático, gás carbônico, hidrogênio, amoníaco e sulfeto de hidrogênio. Os ácidos orgânicos com mais de dois carbonos são convertidos em acetato e gás hidrogênio pelas bactérias acetogênicas e sintróficas, sendo essas últimas também chamadas de produtoras obrigatórias de hidrogênio (OHPA - obligate hydrogen producing acetogens). Finalmente o acetato e o gás hidrogênio são convertidos em metano pelas arqueias metanogênicas (SPEECE, 1996; CHERNICHARO, 1997). Um esquema desse processo é apresentado na Figura 1.

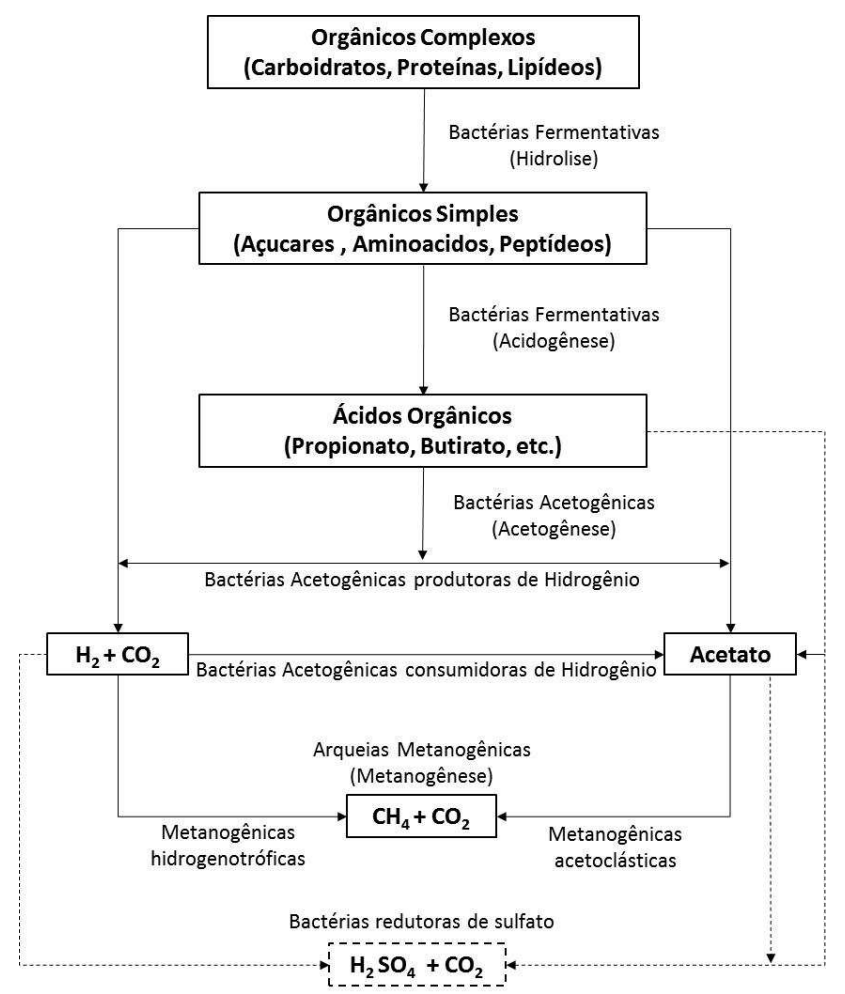

Figura 1 - Pontos de geração e consumo de hidrogênio no processo fermentativo (CHERNICHARO, 1997; SPEECE, 1996) 
Desta forma, quando o objetivo é a obtenção de hidrogênio e ácidos orgânicos, um desequilíbrio é necessário entre as bactérias produtoras (acetogênicas produtoras) e as consumidoras de hidrogênio (acetogênicas consumidoras, arqueias metanogênicas hidrogenotróficas e bactérias redutoras de sulfato) (LEITE, FERNANDES, et al., 2008). No entanto, embora a velocidade de produção de hidrogênio seja dez vezes maior do que a velocidade teórica de produção do metano (HILIGSMANN, MASSET, et al., 2011), o hidrogênio produzido em reatores anaeróbios é rapidamente utilizado pelas consumidoras de hidrogênio.

Contudo, se comparado com o resto de microorganismos, as arqueias metanogênicas contém pouco número de cepas, que adicionalmente são restringidas por condições muito específicas de crescimento, tais como $\mathrm{pH}$, tempo de detenção hidráulica (TDH), tipo de substrato, carga orgânica, entre outros (HILIGSMANN, MASSET, et al., 2011). Assim, a variação de algum desses parâmetros, como a operação do sistema com baixo $\mathrm{pH}(\approx 5.5)$ ou TDH $(\approx 2$ e $12 \mathrm{~h}$ ) pode inibir o desenvolvimento desses microorganismos (CHENG, LIN e CHANG, 2001; KRAEMER e BAGLEY, 2008; REN, GUO, et al., 2008). Por outro lado, a inibição das acetogênicas consumidoras de hidrogênio pode ocorrer mediante a diminuição da pressão parcial do hidrogênio por aspersão de nitrogênio (KIM, HAN, et al., 2006; HUSSY, HAWKES, et al., 2003) ou por remoção do dióxido de carbono (KRAEMER e BAGLEY, 2008).

Pela rota metabólica da glicólise, apenas 33\% do hidrogênio disponível no substrato (12 mol H $\mathrm{Hol}^{-1}$ hexose) pode ser atingido por processos fermentativos. Este resultado se deve principalmente às limitações do processo metabólico, pois ainda que existam várias rotas metabólicas para a produção de hidrogênio, somente um terço do substrato pode ser usado para este fim. Os dois terços restantes são utilizados para a formação de outros produtos da fermentação como o acetato, butirato, etanol, acetona, etc. Assim, em termos de crescimento e sobrevivência dos microorganismos, alguns desses produtos, como o acetato, permitem a formação de ATP (energia), enquanto outros permitem a oxidação do NADH necessário para manter o balanço redox da fermentação (HALLENBECK, ABO-HASHESH e GHOSH, 2012).

Como apresentado na Figura 2, basicamente, o açúcar é quebrado a piruvato gerando ATP e NADH. A seguir, o piruvato é convertido em acetil-CoA e dependendo do organismo, o acetil-CoA é convertido a formiato pela rota PFL (piruvate: formate lyase) ou a ferredoxina reduzida e $\mathrm{O}_{2}$ pela rota do PFOR (piruvate: ferredoxin oxidoreductase). Os organismos que desenvolvem somente a rota do PFL não podem usar o NADH para produção de 
hidrogênio, o que os limita a produzir unicamente 2 mols de hidrogênio por mol de glicose. $\mathrm{O}$ formiato pode ser convertido em hidrogênio e $\mathrm{CO}_{2}$ pela rota do formiato hidrogênio liase que contém a $[\mathrm{NiFe}]$ hidrogenase, ou possivelmente em alguns organismos por uma outra rota que contenha a $[\mathrm{FeFe}]$ hidrogenasse dependente do formiato (HALLENBECK, ABO-HASHESH e GHOSH, 2012).

Os microorganismos que fazem a rota do PFOR podem potencialmente derivar algum hidrogênio da oxidação do NADH usando uma ou várias [FeFe] hidrogenasses. Dependendo da hidrogenasse usada, podem ser produzidos de 2 a 4 mols de hidrogênio por mol de glicose (HALLENBECK, ABO-HASHESH e GHOSH, 2012).

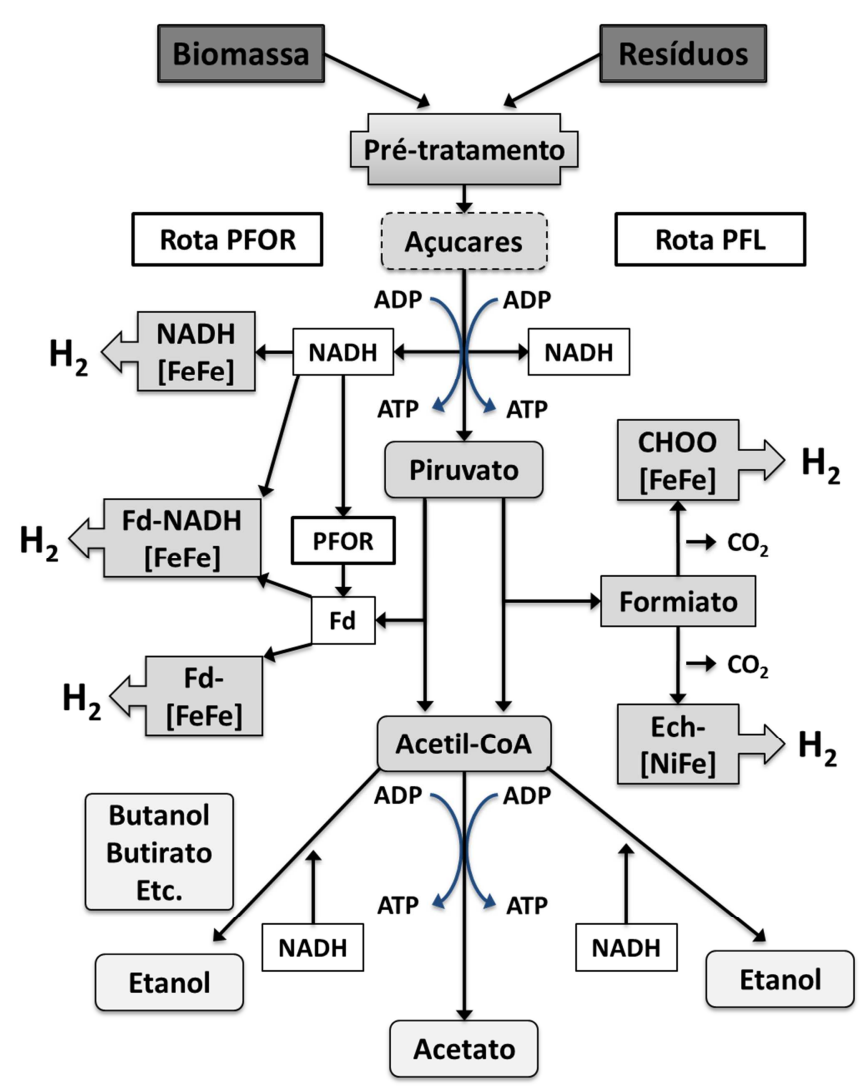

Figura 2 - Rotas metabólicas envolvidas na produção fermentativa de hidrogênio (HALLENBECK, ABO-HASHESH e GHOSH, 2012).

\subsection{Fatores que influenciam a produção biológica de hidrogênio}

Da mesma forma que no processo usado para produção de metano, existem muitas variáveis que afetam o processo quando o objetivo é levar a fermentação até a produção de hidrogênio e ácidos orgânicos. Os principais fatores reportados na literatura estão apresentados a seguir. 


\subsubsection{Inóculo}

A maioria das pesquisas sobre produção de hidrogênio por processo fermentativo envolve bactérias anaeróbias devido a sua elevada velocidade de produção e habilidade para usar uma ampla variedade de carboidratos (KAHYAOğLU, ŞAHIN e SAKA, 2012). Segundo Wang e Wan (2009) estes microorganismos encontram-se principalmente em ambientes naturais como o solo, lodo proveniente do esgoto doméstico e em processo de compostagem de resíduos sólidos. Alguns estudos reportam o uso do inóculo natural, que consiste no uso das bactérias próprias do substrato a utilizar (ANTONOPOULOU, GAVALA, et al., 2011).

Algumas espécies anaeróbias identificadas pertencem ao gênero Clostridium, tais como C. butyricum, C. thermolacticum, C. pasteurianum, $C$ acetoburyricum, C. beijerickki e C. saccharoperbutylacetonicum. Estas espécies são capazes de produzir hidrogênio a partir de carboidratos como glicose, sacarose, hexose e amido. Outras espécies pertencem ao gênero Enterobacter e algumas, termofílicas, ao gênero Thermoanaerobacterium (WANG e WAN, 2009; KAHYAOğLU, ŞAHIN e SAKA, 2012).

Muitas dessas bactérias têm sido isoladas visando produzir elevadas quantidades de hidrogênio. Os estudos têm sido levados a cabo em reatores operados em batelada e usando na maioria dos casos glicose como substrato (WANG e WAN, 2009). No entanto, o uso de culturas puras tem limitações práticas em grande escala devido à dificuldade de manter a pureza das culturas em sistemas que usam resíduos como substrato (PAN, ZHANG, et al., 2008).

Por outro lado, o uso de culturas mistas se apresenta mais interessante devido principalmente ao fato de ser mais simples de operar e fácil de controlar em comparação com as culturas puras. Porém, a principal barreira é que o hidrogênio produzido pelas bactérias produtoras de hidrogênio pode ser facilmente consumido pelas consumidoras de hidrogênio. Sendo assim, o inóculo deve sofrer um pré-tratamento que permita inibir as bactérias consumidoras de hidrogênio e ainda preservar a atividade das produtoras de hidrogênio. Dentre os pré-tratamentos encontram-se os métodos de choque térmico, exposição a meios ácidos ou básicos, aeração, congelamento e descongelamento, além de exposição a compostos químicos como clorofórmio, sódio 2-bromoetanosulfonato ou ácido 2-bromoetanosulfónico e iodo propano (WANG e WAN, 2009; REN, GUO, et al., 2008). No caso do inóculo natural a seleção das espécies desejadas depende das condições de operação do reator (ANTONOPOULOU, GAVALA, et al., 2011). 


\subsubsection{Substrato}

A sustentabilidade da produção de hidrogênio por processo fermentativo depende muito do meio de cultivo utilizado, uma vez que a eficiência geral do processo depende das propriedades físico-químicas desses meios. Adicionalmente, o meio deve reunir características tais como ter um elevado conteúdo de carboidratos e ser de baixo custo (KAHYAOğLU, ŞAHIN e SAKA, 2012).

Vários substratos têm sido usados nos estudos de produção fermentativa de hidrogênio, entre eles diferentes açúcares (como glicose, sacarose, frutose, xilose e lactose) e outros meios mais complexos como resíduos industriais ricos em matéria orgânica (WANG e WAN, 2009). Os estudos incluem materiais como resíduos orgânicos, esgoto doméstico, vinhaças de várias origens, resíduos alimentícios, resíduos de agricultura, efluentes da indústria de azeite de oliva, milho, arroz, mandioca, laticínios, papel, açúcar, amido, óleo de palma e outras fontes de matéria orgânica (KAHYAOğLU, ŞAHIN e SAKA, 2012).

Embora alguns destes substratos na forma pura não sejam ideais para a produção de hidrogênio devido a sua complexidade, se realizado algum tipo de pré-tratamento passam a ser facilmente utilizados pelas bactérias produtoras de hidrogênio. O ultrassom, acidificação, congelamento e descongelamento, esterilização e micro-ondas são métodos de pré-tratamento comumente usados para tal fim (WANG e WAN, 2009).

\subsubsection{Carga orgânica volumétrica (COV)}

Vários trabalhos apontam que um fator chave para a produção de hidrogênio é a carga orgânica volumétrica aplicada (COV) (KIM, HAN e SHIN, 2006; HAFEZ, NAKHLA, et al., 2010; SHEN, BAGLEY e LISS, 2009). Porém, a COV é um fator dependente da concentração do substrato e do tempo de detenção hidráulica (TDH). Assim, a variação destes parâmetros separadamente pode afetar os sistemas produtores de hidrogênio de forma diferente como apresentado a seguir:

\subsubsection{Concentração do substrato}

Tem sido demonstrado que o incremento da concentração do substrato, com consequente aumento da COV, pode melhorar a habilidade das bactérias produtoras de hidrogênio durante o processo fermentativo. No entanto, concentrações muito elevadas podem inibir o sistema por sobrecarga ou mudanças nas rotas microbianas. Na literatura têm-se 
muitos desacordos entre a faixa adequada, pois existem diferenças operacionais entre os estudos tais como o inóculo empregado, faixas de concentração do substrato abrangidas e tipo de reator (WANG e WAN, 2009).

Nos exemplos apresentados a seguir foi observado que o aumento da concentração do substrato resultou em aumento na velocidade de produção de hidrogênio. No entanto, em ambos os casos o limite superior da COV foi indicado pela inibição do sistema, causada pelo excesso do substrato. Hafez et al. (2010) avaliaram a influência da COV entre 6,5 e $206 \mathrm{~g}$ DQO L $\mathrm{L}^{-1} \mathrm{~d}^{-1}$ mediante a variação da concentração do substrato (glicose entre 2 e 64 g DQO L${ }^{1}$ ) e TDH de $8 \mathrm{~h}$ em um reator de agitação contínua acoplado a um clarificador. Os autores observaram um incremento na velocidade de produção de hidrogênio de 10 a $185 \mathrm{~L} \mathrm{H}_{2} \mathrm{~d}^{-1}$ com um rendimento estável de 2,8 $\mathrm{mol} \mathrm{H}_{2} \mathrm{~mol}^{-1}$ glicose consumida quando a $\mathrm{COV}$ foi entre 6,5 e $103 \mathrm{~g} \mathrm{DQO} \mathrm{L}^{-1} \mathrm{~d}^{-1}$. No entanto, quando a COV foi superior a $103 \mathrm{~g}$ DQO L $\mathrm{L}^{-1} \mathrm{~d}^{-1}$ notouse uma queda de aproximadamente $60 \%$ na velocidade $\left(60 \mathrm{~L} \mathrm{H}_{2} \mathrm{~d}^{-1}\right)$ e $50 \%$ no rendimento $\left(1,1 \mathrm{~mol} \mathrm{H}_{2} \mathrm{~mol}^{-1}\right.$ glicose consumida). Estas observações foram atribuídas a uma inibição causada por excesso de substrato quando a concentração foi de 48 e 64 g DQO L ${ }^{-1}$ (COV de 154 e $206 \mathrm{~g} \mathrm{DQO} \mathrm{L}^{-1} \mathrm{~d}^{-1}$, respectivamente), uma vez que a eficiência de conversão de glicose caiu de cerca de $100 \%$ para $44 \%$ e $60 \%$, respectivamente.

Similarmente, em um reator de membrana, Shen, Bagley e Liss (2009) variaram a concentração do substrato entre 1 e $10 \mathrm{~g} \mathrm{DQO} \mathrm{L}^{-1}\left(\mathrm{COV}\right.$ de 4, 6, 13, 22 e $\left.30 \mathrm{~g} \mathrm{DQO} \mathrm{L}^{-1} \mathrm{~d}^{-1}\right)$ mantendo o TDH em $8 \mathrm{~h}$. Um comportamento similar ao anterior foi observado neste trabalho, em que a produção volumétrica de hidrogênio aumentou de 0,02 a 0,20 mol $\mathrm{H}_{2} \mathrm{~L}^{-1} \mathrm{~d}^{-1}$ quando a COV passou de 4 a $22 \mathrm{~g} \mathrm{DQO} \mathrm{L}^{-1} \mathrm{~d}^{-1}$. No entanto, o rendimento manteve-se estável em $1 \mathrm{~mol} \mathrm{H}_{2}$ mol $^{-1}$ glicose consumida até uma COV de $13 \mathrm{~g} \mathrm{DQO} \mathrm{L}^{-1} \mathrm{~d}^{-1}$ e mostrou um notável incremento de até $1,7 \mathrm{~mol} \mathrm{H}_{2} \mathrm{~mol}^{-1}$ glicose consumida quando a COV foi de 22 e $30 \mathrm{~g}$ DQO L ${ }^{-1} \mathrm{~d}^{-1}$. Este aumento no rendimento sugeriu uma inibição por excesso de substrato a partir de $22 \mathrm{~g}$ DQO L L $\mathrm{d}^{-1}$, uma vez que o aumento da velocidade de conversão de glicose diminuiu e não se manteve de forma linear com a velocidade de produção de hidrogênio.

Por outro lado, dependendo dos microorganismos presentes no processo, o elevado aumento da concentração de substrato pode ocasionar mudanças nas rotas microbianas não favoráveis para a produção de hidrogênio. Um exemplo desta afirmação podem ser algumas espécies de Clostridium que contém a enzima responsável pela produção de ácido lático (lactato dehidrogenase). Este ácido não é um produto principal da fermentação pelo Clostridium, pois a enzima requer elevadas concentrações de fructose-1,6-bisfosfato para sua 
atividade. Neste caso, a disponibilidade de substrato em excesso pode incrementar a concentração intracelular de fructose-1,6-bisfosfato permitindo, assim, a produção de elevadas quantidades de ácido lático (MINTON e CLARKE, 1989).

Antonopoulou et al. (2011) analisaram a influência da concentração inicial de substrato usando extrato de sorgo doce entre 9,89 e 20,99 g carboidrato $\mathrm{L}^{-1}$ (COV entre 109,9 e 233,2 mmol carboidrato $\mathrm{L}^{-1} \mathrm{~d}^{-1}$, respectivamente) em um reator de mistura completa operado com TDH de 12 h. Observou-se um incremento na produção de hidrogênio de 0,7 a 2,8 $\mathrm{L} \mathrm{H}_{2} \mathrm{~L}^{-1} \mathrm{~d}^{-1}$ quando a concentração de carboidratos variou de 9,9 a 17,5 $\mathrm{g} \mathrm{L}^{-1}$. No entanto, acima de $17,5 \mathrm{~g} \mathrm{~L}^{-1}$ notou-se que existe um limite superior de concentração sob a qual as bactérias mudam seu metabolismo para produção de etanol, diminuindo a produção de hidrogênio.

\subsubsection{Tempo de detenção hidráulica $(T D H)$}

Em alguns sistemas produtores de hidrogênio, como nos reatores anaeróbios de agitação contínua (CSTR), os baixos valores do tempo de detenção hidráulica (TDH) podem ocasionar perdas graves de biomassa, o que é, muitas vezes, negativo para a produção de hidrogênio e para o desempenho dos sistemas em geral.

Arooj et al. (2008) operaram um reator de forma contínua e em bateladas sequenciais utilizando como substrato amido $\left(20 \mathrm{~g} \mathrm{COD} \mathrm{L}^{-1}\right)$ e variação do $\mathrm{TDH}^{1}$ entre $18 \mathrm{e} 4 \mathrm{~h}$ (COV entre 26,7 e $120 \mathrm{~g} \mathrm{COD} \mathrm{L}^{-1} \mathrm{~d}^{-1}$ ). Os autores encontraram que em modo contínuo a diminuição do TDH de $18 \mathrm{~h}$ para $12 \mathrm{~h}$ (COV de 26,7 e $40 \mathrm{~g} \mathrm{COD} \mathrm{L}^{-1} \mathrm{~d}^{-1}$, respectivamente) causou um decréscimo da concentração dos sólidos suspensos voláteis de $89 \%$, tornando o sistema inviável para produção de hidrogênio. Porém, em um segundo estágio experimental, operouse o reator de forma não contínua e a variação do TDH indicou mudanças nas rotas microbianas. $\mathrm{O}$ maior rendimento foi de $0,51 \mathrm{~mol} \mathrm{H}_{2} \mathrm{~mol}^{-1}$ glicose adicionada com TDH de $12 \mathrm{~h}$ (COV de $40 \mathrm{~g} \mathrm{COD} \mathrm{L}^{-1} \mathrm{~d}^{-1}$ ). Entre 18 e $12 \mathrm{~h}$ observou-se que o incremento do rendimento de hidrogênio foi acompanhado pelo incremento da produção do butirato e a diminuição do propionato, enquanto que para os TDH entre 9 e 4 h (COV 53,3 e 120 g COD $\mathrm{L}^{-1} \mathrm{~d}^{-1}$ ) observou-se principalmente incremento na produção de lactato junto com o decréscimo do rendimento de hidrogênio.

\footnotetext{
${ }^{1}$ Formalmente não é correto o uso de TDH para reatores operados em batelada, ainda que alimentada. No entanto, esse texto reproduz o que comumente se utiliza na literatura e é comum se encontrar valores de TDH calculados para esses reatores principalmente para comparação com operações contínuas. Nesses casos, é calculada uma "vazão média de alimentação", a qual é usada para estimativa desse TDH não convencional. O cálculo da COV para esses reatores está mais consolidada.
} 
Amorim et al. (2009) avaliaram a produção de hidrogênio a partir de glicose $\left(2 \mathrm{~g} \mathrm{~L}^{-1}\right)$ em um reator de leito fluidificado sob TDH de 8, 6, 4, 2 e 1 h (COV entre 17,7 e 116,6 g DQO $\mathrm{L}^{-1} \mathrm{~d}^{-1}$ ). O decréscimo do TDH com consequente aumento da COV levou a produção volumétrica de hidrogênio de 0,08 a $0,97 \mathrm{~L} \mathrm{H}_{2} \mathrm{~L}^{-1} \mathrm{~h}^{-1}$. Estes resultados foram associados a mudanças nas rotas microbianas quando a COV aumentou. Com a diminuição do TDH, a maioria da glicose foi usada para geração de mais produtos solúveis da fermentação favoráveis para a produção de hidrogênio em vez de crescimento e manutenção celular.

É importante ressaltar que os trabalhos que citam a COV como fator importante para a produção de hidrogênio em reatores acidogênicos raramente apresentam o cálculo da COVe que, pelas hipóteses levantadas nesse trabalho, seria o principal e mais importante fator a ser considerado. A escassez de dados de COVe na literatura deriva do fato da dificuldade em se calcular essa variável ou simplesmente pela pouca importância dada a ela pelos pesquisadores. Assim, nesse texto foram citados os trabalhos publicados que apresentaram a COV como fator importante sem o cálculo da correspondente COVe. Esse fator está abordado a seguir.

\subsubsection{Carga orgânica volumétrica específica (COVe)}

Os trabalhos anteriores demonstraram que a COV aplicada no processo fermentativo tem influência sobre a velocidade de produção e rendimento de hidrogênio. Contudo, a inibição causada por sobrecarga de substrato e algumas mudanças nas rotas microbianas observadas nas mesmas faixas de COV poderiam estar relacionadas com a quantidade de microorganismos presentes no sistema. Em outras palavras, essas alterações poderiam estar relacionadas com a carga orgânica volumétrica específica (COVe) dada em quantidade de substrato por microorganismos e por tempo (i.e. g substrato $\mathrm{g}^{-1} \mathrm{SSV}^{-1}$ ) em sistemas contínuos ou pela relação alimento/microorganismos (relação $\mathrm{A} / \mathrm{M}$ ) dada em quantidade de substrato por quantidade de microorganismo (i.e. $g$ substrato $\mathrm{g}^{-1} \mathrm{SV}$ ) em sistemas não contínuos.

Pan et al. (2008) estudaram a influência da relação A/M entre 1 e 10 g SV no substrato $\mathrm{g}^{-1} \mathrm{SV}$ no inóculo em sistemas não contínuos mesofílicos $\left(35 \pm 2{ }^{\circ} \mathrm{C}\right)$ e termófilicos $\left(50 \pm 2{ }^{\circ} \mathrm{C}\right)$. Cada relação F/M foi definida como a quantidade de sólidos voláteis do substrato, no caso resíduos alimentícios, em relação à quantidade de sólidos voláteis no inóculo. No sistema mesofílico, observou-se que a mudança da relação A/M de 1 a $6 \mathrm{~g} \mathrm{SV}$ no substrato $\mathrm{g}^{-1} \mathrm{SV}$ no inóculo aumentou lentamente o rendimento de hidrogênio até $39 \mathrm{~mL} \mathrm{H}_{2} \mathrm{~g}^{-1} \mathrm{SV}$. Logo após, 
com maiores relações $\mathrm{F} / \mathrm{M}$ o rendimento caiu bruscamente até zerar completamente a partir da relação F/M de 8 g SV no substrato $\mathrm{g}^{-1} \mathrm{SV}$ no inóculo.

Por outro lado, no sistema termofílico, entre a relação $\mathrm{A} / \mathrm{M}$ de 1 a $5 \mathrm{~g} \mathrm{~g}^{-1}$, houve aumento na produção de hidrogênio até $57 \mathrm{~mL} \mathrm{H}_{2} \mathrm{~g}^{-1} \mathrm{SV}$ e este se manteve quase constante nesse valor com relações $\mathrm{A} / \mathrm{M}$ maiores. Um comportamento similar foi observado na composição do biogás em ambos os casos. No sistema mesofílico o conteúdo de hidrogênio no biogás chegou próximo de $35 \%$ com relação $\mathrm{A} / \mathrm{M}$ de $6 \mathrm{~g} \mathrm{~g}^{-1}$, seguido de uma constante queda com maiores relações $\mathrm{A} / \mathrm{M}$, enquanto que no sistema termofílico o conteúdo chegou a $38 \%$ com relação A/M de $5 \mathrm{~g} \mathrm{~g}^{-1}$ e se manteve constante até a relação A/M de $10 \mathrm{~g} \mathrm{~g}^{-1}$ (PAN, ZHANG, et al., 2008).

Observou-se que a variação da relação A/M esteve relacionada com o pH do sistema, uma vez que este foi diminuindo conforme a relação A/M aumentou em ambos os sistemas. No sistema mesofílico, com relação $\mathrm{A} / \mathrm{M}$ de $6 \mathrm{~g} \mathrm{~g}^{-1}$, o pH chegou a 5,5 seguido de uma abrupta queda até 4,0 com relações maiores, enquanto que no sistema termofílico as melhores relações $\mathrm{A} / \mathrm{M}$ levaram o $\mathrm{pH}$ do sistema até 5,9. Desta forma, os autores concluíram que a variação da relação $\mathrm{A} / \mathrm{M}$ pode causar mudanças nas rotas microbianas derivadas da variação do pH (PAN, ZHANG, et al., 2008).

Em sistemas contínuos a COVe pode ter influência direta sobre a eficiência de conversão do substrato. Hafez et al. (2010) observaram uma inibição por excesso de substrato que levou a diminuição no rendimento de hidrogênio quando a COVe do sistema foi maior que 6,4 $\mathrm{g} \mathrm{DQO} \mathrm{g}^{-1} \mathrm{SSV} \mathrm{d}{ }^{-1}$. Em uma revisão realizada pelos autores observou-se que o rendimento de hidrogênio aumentou de 2,2 para 2,8 $\mathrm{mol} \mathrm{H}_{2} \mathrm{~mol}^{-1}$ glicose quando a COVe variou de 2 para $6,4 \mathrm{~g} \mathrm{DQO} \mathrm{g}^{-1} \mathrm{SSV} \mathrm{d}^{-1}$. E logo após, notou-se uma severa queda até $1 \mathrm{~mol} \mathrm{H}_{2}$ $\mathrm{mol}^{-1}$ glicose sob uma ampla faixa de COVe entre 8,5 e $20 \mathrm{~g} \mathrm{DQO} \mathrm{g}^{-1} \mathrm{SSV} \mathrm{d}^{-1}$, seguida de

rendimentos abaixo de $0,8 \mathrm{~mol} \mathrm{H}_{2} \mathrm{~mol}^{-1}$ glicose quando a COVe foi de $30 \mathrm{~g} \mathrm{DQO} \mathrm{g}^{-1} \mathrm{SSV} \mathrm{d}^{-1}$ ou maior. Desta forma, sugeriu-se que uma COVe adequada para melhorar a produção de hidrogênio em reatores contínuos CSTR está na faixa de 4,4 a 6,4 g DQO g ${ }^{-1} \mathrm{SSV} \mathrm{d}^{-1}$.

\subsubsection{Tipo de reator}

$\mathrm{Na}$ literatura têm-se estudado diferentes configurações de reatores viabilizando rendimentos mais altos, confiáveis, mais estáveis por longos períodos de tempo e resistentes a flutuações de curto prazo nos parâmetros operacionais, o que segundo Hallenbeck e Ghosh, (2009) tem permitido melhorar as taxas de produção volumétrica. Para otimizações e estudos 
iniciais, o reator mais frequentemente usado é o operado em batelada devido à fácil operação e controle. No entanto, para operações em grande escala são requeridos processos de produção contínua por razões práticas de Engenharia (WANG e WAN, 2009).

Os sistemas de reatores contínuos mais comumente usados são os tanques de agitação contínua (CSTR - Continuous [flow] stirred tank reactor) principalmente pela mistura homogênea mais eficaz, que além de levar a menores resistências a transferência de massa, permite obter parâmetros operacionais em várias circunstâncias (REN, GUO, et al., 2011). No entanto, nos CSTR a velocidade de crescimento microbiano é controlada pelo TDH que é igual ao tempo de retenção celular (TRC). Sendo assim, o TDH de operação deve ser maior do que a velocidade de crescimento máximo dos microorganismos, visto que valores menores causariam uma diluição e consequentemente a lavagem do sistema (HALLENBECK e GHOSH, 2009).

Uma segunda categoria conceitual de reatores de escoamento contínuo, caracterizado pela retenção física da biomassa microbiana, supera esse problema e oferece diversas vantagens. Nestes reatores o TRC e, consequentemente, a concentração da biomassa são independentes do TDH, o que permite obter melhores velocidades de produção volumétrica do gás, assim como melhor degradação do substrato (BABU, MOHAN e SARMA, 2009; HALLENBECK e GHOSH, 2009). Os reatores de crescimento aderido podem ser de leito fixo ou móvel, sendo que os de leito móvel podem ter vários níveis de expansão, denominados de reatores de leito expandido, até chegar à fluidificação, denominados, nesse caso, de reatores de leito fluidificado.

Em um estudo comparando um CSTR e um reator de leito fluidificado, em sistemas de células suspensas e imobilizadas, a formação de grânulos ou biolfilmes melhorou substancialmente a retenção de biomassa que é proporcional à velocidade de produção de hidrogênio. Por outro lado, enquanto no CSTR a lavagem de biomassa pode ocorrer com TDH menores de 2,5 dias, um reator anaeróbio de manta de lodo (UASB - Up-flow anaerobic sludge bed - UASB) e um reator de leito fixo podem oferecer melhor desempenho com TDH menores que 1 dia (REN, GUO, et al., 2011).

Existem diversas variações no tipo de reator de escoamento contínuo com retenção de biomassa, seja pela formação de flocos para autoimobilização dos microorganismos, imobilização em materiais inertes ou membranas de retenção celular. No entanto, neste tipo de reatores existe um potencial problema relacionado ao consumo do hidrogênio pelo possível crescimento lento de microorganismos consumidores de hidrogênio (HALLENBECK e GHOSH, 2009), como parece ser o caso do reator anaeróbio de leito fixo utilizado no 
Laboratório de Processos Biológicos da Escola de Engenharia de São Carlos da Universidade de São Paulo (LPB-EESC-USP), conforme relato a seguir.

\subsection{Reator anaeróbio de leito empacotado e escoamento ascendente: resultados obtidos e problemas enfrentados}

A produção de gás hidrogênio em reator anaeróbio de leito fixo e escoamento ascendente tem sido o foco principal dos pesquisadores do LPB-EESC-USP. Conforme a Figura 3, o reator padrão utilizado nos ensaios consiste em um tubo de acrílico com diâmetro interno de $80 \mathrm{~mm}$ e $750 \mathrm{~mm}$ de comprimento, perfazendo um volume total de 3,77 L. O leito apresenta comprimento de $50 \mathrm{~cm}$ e cinco pontos de amostragem igualmente espaçados para a obtenção de dados de concentração em função do comprimento.

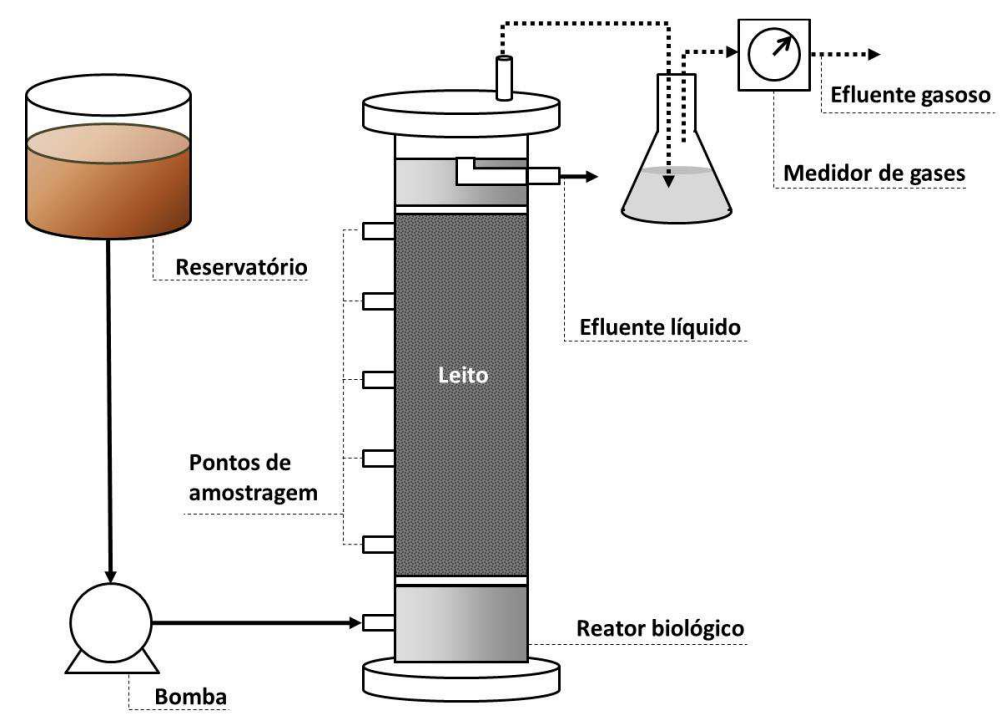

Figura 3 - Reator biológico do tipo anaeróbio de leito fixo para produção de hidrogênio usado no laboratório de processos biológicos da Escola de Engenharia de São Carlos da Universidade de São Paulo (LPB-EESC-USP).

Alguns parâmetros de operação foram fixados durante o desenvolvimento dos experimentos a fim de ter padrões de comparação: A principal água residuária utilizada tem sido a sintética a base de sacarose, com nutrientes adicionados segundo Del Nery (1987). O inóculo é geralmente obtido de forma natural, seguindo método descrito por Leite et al. (2008), segundo o qual o meio de alimentação é deixado em repouso por três dias e, a seguir, recirculado no reator durante uma semana. A temperatura é controlada a $25^{\circ} \mathrm{C}$ em câmara de climatização. O pH afluente é mantido em 6,5, pois foi comprovado que, logo após a entrada 
do meio no reator, este cai para 5,5, valor ótimo para produção de hidrogênio segundo a literatura revisada pelos pesquisadores (VAN GINKEL, SUNG e LAY, 2001).

A seguir são apresentados os trabalhos desenvolvidos no LPB-EESC-USP nas condições descritas no parágrafo anterior. A descrição de tais trabalhos é importante, pois as hipóteses levantadas nesse projeto foram estabelecidas com base nos resultados previamente observados. A instabilidade na produção de hidrogênio ao longo do tempo foi generalizada praticamente em todos os experimentos e a avaliação dos dados obtidos serve como base para a proposição de estratégias que viabilizem a produção contínua e estável de hidrogênio em reatores de leito fixo.

\subsubsection{Material suporte, porosidade do leito e TDH}

Fernandes (2008) realizou seus experimentos em duas fases; primeiro testou argila expandida, carvão vegetal e polietileno de baixa densidade como material suporte para adesão da biomassa e avaliou os TDH de 2 e $0,5 \mathrm{~h}$. Em uma segunda fase avaliou a produção de hidrogênio utilizando leito de polietileno de baixa densidade com diferentes porosidades. A DQO da água residuária sintética foi de $1 \mathrm{~g} \mathrm{~L}^{-1}$, relação $\mathrm{C} / \mathrm{N}$ de $63(\mathrm{gC} / \mathrm{gN})$ e relação carbono/fósforo (C/P) de $163(\mathrm{gC} / \mathrm{gP})$.

Na primeira fase, a porosidade do leito foi de $39 \%, 47 \%$ e $52 \%$ com argila expandida, carvão vegetal e polietileno de baixa densidade, respectivamente. O desempenho dos reatores foi avaliado com TDH de 2 horas por 89 dias. O sistema demonstrou capacidade de degradar sacarose com eficiência de conversão de $77 \%$ com argila expandida, $91 \%$ com carvão vegetal e $84 \%$ com polietileno de baixa densidade. $\mathrm{O}$ biogás gerado foi composto por $\mathrm{H}_{2}$ e $\mathrm{CO}_{2}$.

Durante o tempo de operação, o rendimento de hidrogênio não apresentou estabilidade, observando-se uma diminuição constante após sete dias de operação até zerar completamente perto do $40^{\circ}$ dia. Fernandes (2008) relacionou essa diminuição com as altas velocidades de crescimento microbiano que provocaram alterações no metabolismo e aumentaram a competição por diferentes substratos.

Os valores médios de rendimento foram $3,27 \mathrm{~mol} \mathrm{H}_{2} \mathrm{~mol}^{-1}$ sc na argila expandida, 3,45 mol H$~_{2}$ mol $^{-1}{ }_{\text {sc }}$ no carvão vegetal e $3,49 \mathrm{~mol} \mathrm{H}_{2} \mathrm{~mol}^{-1}$ sc no polietileno de baixa densidade. No entanto, no meio líquido houve estabilização na produção de ácido butírico e etanol. Logo após, os reatores foram operados com TDH de 0,5 h durante 43 dias. Nesta condição, o rendimento médio de hidrogênio foi de 4,44 $\mathrm{mol} \mathrm{H}_{2} \mathrm{~mol}^{-1}{ }_{\mathrm{sc}}$ com argila expandida, 4,52 mol $\mathrm{H}_{2} \mathrm{~mol}^{-1}{ }_{\text {sc }}$ com carvão vegetal e 4,38 mol H $\mathrm{mol}^{-1}$ sc com polietileno de baixa densidade. 
Embora estes valores fossem superiores aos alcançados com TDH de $2 \mathrm{~h}$, o sistema se caracterizou pela instabilidade e a baixa eficiência de conversão de sacarose.

Tal resultado foi relacionado com o aumento da carga orgânica aplicada, em torno de $96 \mathrm{~g} \mathrm{DQO} \mathrm{L}^{-1} \mathrm{~d}^{-1}$, sendo quatro vezes maior do que com o TDH de $2 \mathrm{~h}$. A instabilidade do processo também foi refletida na formação de ácidos e álcoois. A despeito desses resultados, Fernandes (2008) sugeriu que estas características de operação poderiam ser favoráveis se vários reatores fossem operados em série.

Os resultados de rendimento de hidrogênio entre os materiais suporte operados com TDH de 2 e 0,5 h apresentaram grande similaridade. Desta forma, a avaliação da influência do material suporte sobre a produção de hidrogênio foi baseada no caráter operacional dos reatores. A fragmentação da argila expandida e do carvão vegetal ao longo do processo, o que provocou entupimentos na saída dos reatores, não foi observada para o leito de polietileno de baixa densidade. Portanto, este último material se apresentou como o material mais adequado para adesão da biomassa no reator produtor de hidrogênio.

$\mathrm{Na}$ segunda fase de operação, Fernandes (2008) avaliou o polietileno de baixa densidade com porosidades do leito de 50\%, 71\% e 95\% durante 47, 37 e 65 dias, respectivamente. A variação desse tempo esteve relacionada com o rendimento, pois a ausência de produção de hidrogênio no reator com porosidade de $50 \%$ foi evidenciada após 30 dias de operação e, com porosidade de $71 \%$, aos 23 dias. O rendimento médio foi de 4,38 mol $\mathrm{H}_{2} \mathrm{~mol}^{-1}{ }_{\mathrm{sc}}, 3,76 \mathrm{~mol} \mathrm{H}_{2} \mathrm{~mol}^{-1}{ }_{\mathrm{sc}}$ e 4,20 $\mathrm{mol} \mathrm{H}_{2} \mathrm{~mol}^{-1}{ }_{\text {sc }}$ para porosidades do leito de $50 \%$ $71 \%$ e $95 \%$, respectivamente. O reator com porosidade de $91 \%$ apresentou oscilações na produção de hidrogênio, com ciclos de máximo e mínimo sendo obtidos ao longo da operação. Tais oscilações, segundo Fernandes (2008), poderiam estar associadas ao arraste periódico da biomassa excedente do sistema e, consequentemente, com as variações na carga orgânica específica aplicada (COVe). Os valores similares de rendimento dos leitos de menor porosidade $(50 \%$ e $71 \%)$ e geração por curto período de tempo foi atribuído à falta de equilíbrio entre o processo de geração e remoção do biofilme. Neste contexto, Fernandes (2008) sugere que o emprego de leitos com maior porosidade poderia evitar a retenção de biomassa nos interstícios o que seria favorável para a produção de hidrogênio.

Godoi (2010) avaliou a espuma de poliuretano como material suporte para adesão da biomassa e ordenou o leito de modo a aumentar a porosidade e evitar a formação de interstícios. Para estruturação do leito foram utilizados cilindros de espuma de poliuretano (aproximadamente de $2 \mathrm{~cm}$ de diâmetro e $2,5 \mathrm{~cm}$ de comprimento) que foram organizados em 
fileiras alternadas por meio de hastes de fixação. O afluente do reator teve DQO próxima de 2 $\mathrm{g} \mathrm{L}^{-1}$, relação C/P de 326 e relação C/N de 140 .

$\mathrm{O}$ reator foi operado continuamente com $\mathrm{TDH}$ de $2 \mathrm{~h}$ por 60 dias. Os resultados mostraram um comportamento de queda na produção de hidrogênio similar ao observado por Fernandes (2008) e por Anzola-Rojas (2010). Embora o processo de fermentação no meio líquido tenha sido estável, não foi possível determinar uma etapa de estabilização na produção de biogás com diminuição contínua até zerar completamente.

$\mathrm{O}$ valor médio de rendimento de hidrogênio foi de $1,2 \mathrm{~mol} \mathrm{H}_{2} \mathrm{~mol}^{-1}{ }_{\mathrm{sc}}$ e o biogás foi composto principalmente por $\mathrm{H}_{2}$ e $\mathrm{CO}_{2}$ com porcentagens próximas a $49 \%$ e $27 \%$, respectivamente. No entanto, a eficiência média de conversão de sacarose foi de $78 \%$. O ácido acético, o ácido butírico e o etanol foram os principais produtos intermediários. Observou-se arraste de sólidos do reator, atribuído ao desprendimento intermitente de biomassa e polímeros extracelulares do material suporte.

Embora a estratégia de estruturar o leito minimizasse o acúmulo de biomassa intersticial, não houve aumento no rendimento de hidrogênio, nem estabilização na produção de biogás, comparado com Fernandes (2008) e Anzola-Rojas (2010). Provavelmente, esses resultados foram devidos à baixa eficiência de conversão de sacarose, causada pelas perdas de biomassa.

\subsubsection{Influência da relação $\mathrm{C} / \mathrm{N}$ e $\mathrm{C} / \mathrm{P}$}

Diferentes relações C/N (40, 90, 140 e 190) foram avaliadas por Anzola-Rojas (2010). O material suporte utilizado nestes ensaios foi polietileno de baixa densidade e o leito teve uma porosidade próxima de $60 \%$. As relações $\mathrm{C} / \mathrm{N}$ se calcularam com base na porcentagem em massa de carbono e nitrogênio dos compostos sacarose $\left(1782 \mathrm{mg} \mathrm{L}^{-1}\right)$ e ureia $(8,5-40$ $\mathrm{mg} \mathrm{L}^{-1}$ ), respectivamente, que constituíram parte do meio.

Os sistemas foram operados continuamente com TDH de $2 \mathrm{~h}$ por 60 dias. Em relação à produção de biogás não foi possível diferenciar um período de estabilização nos sistemas, uma vez que houve uma tendência de queda a partir do $25^{\circ}$ dia de operação. No entanto, sob todas as relações $\mathrm{C} / \mathrm{N}$, a partir do dia 25 de operação, a eficiência de remoção de sacarose (acima de 88\%) junto com a geração de metabólitos intermediários (ácidos acético e butírico e etanol) foi estável. O biogás foi composto principalmente por $\mathrm{H}_{2}$ e $\mathrm{CO}_{2}$ com porcentagens próximas a $55 \%$ e $30 \%$, respectivamente. 
Observou-se a influência da relação $\mathrm{C} / \mathrm{N}$ na produção de biogás, indicando que, quanto maior a relação $\mathrm{C} / \mathrm{N}$ (menos nitrogênio), maior o rendimento de $\mathrm{H}_{2}$ com relações $\mathrm{C} / \mathrm{N}$ até 140. Com relação C/N de 190 observou-se, no entanto, diminuição na produção de biogás com consequente diminuição no rendimento de hidrogênio em comparação com a relação $\mathrm{C} / \mathrm{N}$ de 140. Os valores médios de rendimento de hidrogênio foram $0,6 \mathrm{~mol} \mathrm{H}_{2} \mathrm{~mol}^{-1}{ }_{\mathrm{sc}}, 1,3$ mol H mol $^{-1}{ }_{\text {sc }}, 2,7 \mathrm{~mol} \mathrm{H}_{2} \mathrm{~mol}^{-1}{ }_{\text {sc }}$ e $1,9 \mathrm{~mol} \mathrm{H}_{2} \mathrm{~mol}^{-1}{ }_{\text {sc }}$ com relação $\mathrm{C} / \mathrm{N}$ de 40, 90, 140 e 190, respectivamente.

Esta influência da relação $\mathrm{C} / \mathrm{N}$ no rendimento de hidrogênio foi atribuída ao direcionamento da energia. Com excesso de nitrogênio $(\mathrm{C} / \mathrm{N}<140)$, a energia pode ter sido utilizada principalmente para assimilação e crescimento celular, levando a menores produções de hidrogênio. No entanto, com relação C/N de 190, houve uma deficiência nutricional grave que provocou mudanças na estrutura microbiana e/ou nas rotas metabólicas desfavoráveis para a produção de hidrogênio. Anzola-Rojas (2010) concluiu que existe uma relação $\mathrm{C} / \mathrm{N}$ ótima próxima de 137 para a produção de hidrogênio.

Como já informado, da mesma forma que Fernandes (2008) e Godoi (2010), AnzolaRojas (2010) observou diminuição na produção de biogás $\left(\mathrm{H}_{2}\right.$ e $\left.\mathrm{CO}_{2}\right)$ ao longo do tempo após ser atingido o pico de produção por volta do $25^{\circ}$ dia operacional. Tal instabilidade foi associada à participação de microorganismos oxidadores de hidrogênio como as bactérias Knallgas capazes de usar o $\mathrm{CO}_{2}$ como fonte de carbono, o $\mathrm{H}_{2}$ como fonte de energia e o $\mathrm{O}_{2}$ (proveniente da possível microaeração do sistema) como aceptor final de elétrons.

As hipóteses do consumo de hidrogênio pelos organismos redutores de sulfato ou pelos metanogênicos foram descartadas, pois não explicariam o uso concomitante dos componentes do biogás $\left(\mathrm{H}_{2}\right.$ e $\left.\mathrm{CO}_{2}\right)$, pois não foi detectado metano em nenhuma das análises cromatográficas. A homoacetogênese, embora improvável de ocorrer no $\mathrm{pH}$ de operação (4,5), poderia explicar o consumo de $\mathrm{H}_{2}$ e $\mathrm{CO}_{2}$, mas levaria ao aumento na produção de ácido acético, o que não foi verificado pelo autor.

\subsubsection{Condições de mistura}

Lima e Zaiat (2012) variaram diferentes condições de mistura mudando a razão de recirculação $(R)$ entre 0,25 e 2,0. Os reatores foram operados sob as mesmas condições de Anzola-Rojas (2010) e relação C/N de 140 durante 60 dias. A eficiência de remoção de sacarose foi estável a partir do $23^{\circ}$ dia de operação com porcentagens próximas a $70 \%$. $\mathrm{O}$ biogás produzido foi composto principalmente por $\mathrm{H}_{2}$ e $\mathrm{CO}_{2}$, com porcentagem de $\mathrm{H}_{2}$ 
próxima a 50\% em todas as razões de recirculação. Os valores médios de rendimento de hidrogênio foram 1,14 mol $\mathrm{H}_{2} \mathrm{~mol}^{-1}{ }_{\mathrm{sc}}, 1,43 \mathrm{~mol} \mathrm{H}_{2} \mathrm{~mol}^{-1}{ }_{\mathrm{sc}}, 1,34 \mathrm{~mol} \mathrm{H}_{2} \mathrm{~mol}^{-1}{ }_{\mathrm{sc}} \mathrm{e}$ $0,86 \mathrm{~mol} \mathrm{H}_{2} \mathrm{~mol}^{-1}$ sc para $\mathrm{R}$ de $0,25,0,5,1,0$ e 2,0, respectivamente.

A variação no rendimento em função da razão de recirculação indicou que o $\mathrm{R}$ ótimo para produção de hidrogênio é próximo de 0,6. Lima e Zaiat (2012) afirmaram que o aumento da recirculação até $\mathrm{R}$ ótimo melhora a transferência de massa do estado líquido para o estado gasoso facilitando a liberação de hidrogênio. No entanto, o autor discute que condições de mistura mais próximas da mistura completa $(\mathrm{R}>0,6)$ podem inibir a formação de todos os intermediários das reações processadas incluindo hidrogênio, ácidos e solventes. Contudo, Lima e Zaiat (2012) também observaram em todos os reatores instabilidade na produção de biogás ao longo do tempo. O autor atribuiu este comportamento à participação de microorganismos consumidores de biogás $\left(\mathrm{H}_{2}\right.$ e $\left.\mathrm{CO}_{2}\right)$ ao longo do leito.

\subsubsection{Inóculo e pré-tratamentos}

Penteado et al. (2013) avaliaram três diferentes fontes de inóculo: lodo anaeróbio de reator de manta de lodo aplicado ao tratamento de águas residuárias de abatedouro de aves e de suinocultura e lodo proveniente da autofermentação (inóculo natural). Adicionalmente, analisaram o pré-tratamento ácido e de choque térmico no lodo anaeróbio proveniente dos reatores de manta de lodo. Como material suporte para adesão da biomassa usaram-se aparas de polietileno de baixa densidade empacotadas no leito de cada reator. Os reatores foram operados continuamente por 60 dias com TDH de $2 \mathrm{~h}$ e temperatura de $25^{\circ} \mathrm{C}$.

Segundo as observações de Penteado et al. (2013), a melhor produção volumétrica de hidrogênio de $62 \mathrm{~mL} \mathrm{H}_{2} \mathrm{~h}^{-1} \mathrm{~L}^{-1}$ observou-se no reator com lodo anaeróbio de abatedouro de aves com pré-tratamento ácido e o melhor rendimento de $2,1 \mathrm{~mol} \mathrm{H}_{2} \mathrm{~mol}^{-1}{ }_{\text {sc }}$ observou-se no reator com inóculo natural. O inóculo natural foi o único que não apresentou metano na composição do biogás produzido, demonstrando que a autofermentação pode selecionar as bactérias produtoras de hidrogênio de forma natural sob as condições experimentais impostas.

Contudo, apesar dos diferentes inóculos e pré-tratamentos, a tendência na produção de biogás foi similar aos demais experimentos descritos neste tópico. Após o tempo transiente definido pela eficiência da conversão de sacarose, o biogás tendeu a diminuir até cessar completamente. Penteado et al. (2013) atribuíram essa queda à elevada pressão parcial que desloca o equilíbrio das reações consumindo o hidrogênio. Por exemplo, uma reação poderia 
ser a homoacetogênese que usa o hidrogênio e o dióxido de carbono para sintetizar ácido acético ou a reação entre o hidrogênio e ácido acético que produz etanol.

\subsubsection{Concentração de cálcio}

A maioria dos trabalhos anteriores (FERNANDES, 2008; ANZOLA-ROJAS, 2010; PENTEADO, LAZARO, et al., 2013) associaram a queda do hidrogênio ao longo do tempo com microorganismos consumidores do biogás, que se estabeleceram no leito empacotado provavelmente devido ao excessivo acúmulo de biomassa ou ao aumento da pressão parcial do hidrogênio. Por outro lado, Godoi (2010) observou que ordenar o leito aumenta a porosidade, consequentemente diminui a colmatação do leito o que seria favorável para a liberação do hidrogênio. No entanto, as observações deste último autor foram desanimadoras ao notar que a saída intermitente de biomassa foi excessiva, prejudicando o desempenho geral do reator.

Dessa forma, uma vez que o cálcio tem sido relatado na literatura como uma exigência estrutural para manter uma elevada concentração de biomassa no reator, Carminato (2013) investigou a influência de diferentes dosagens de cálcio $(0,50 ; 1,06 ; 1,37 ; 1,87 ; 2,45$ e 3,61 $\mathrm{mg} \mathrm{L}^{-1}$ ) em um reator de leito fixo ordenado. O leito consistiu na estruturação longitudinal de pequenos cilindros de polietileno de baixa densidade fixados mediante hastes de inox. A porosidade do leito foi de aproximadamente $85 \%$. Os reatores foram operados continuamente por 60 dias, com TDH de $2 \mathrm{~h}$ e temperatura de $25^{\circ} \mathrm{C}$.

Os resultados mostraram aumento na concentração de biomassa no material suporte com maiores dosagens de cálcio. Tal fato mostrou que a adição de cálcio pôde ser usada como estratégia para melhorar a retenção de biomassa neste tipo de reator. Junto com o aumento da biomassa o maior rendimento médio de hidrogênio chegou a $1,4 \mathrm{~mol} \mathrm{H}_{2} \mathrm{~mol}^{-1}$ sc e a vazão molar média a 5,4 mmol h${ }^{-1}$ quando a concentração de cálcio foi de $1,37 \mathrm{mg} \mathrm{L}^{-1}$. Dosagens de cálcio acima desta concentração causaram crescimento excessivo de biomassa e consequente diminuição na produção de hidrogênio (CARMINATO, 2013).

Uma estimativa matemática sugeriu uma concentração ótima de cálcio de $1,54 \mathrm{mg} \mathrm{L}^{-1}$. Concentrações maiores de cálcio poderiam gerar o crescimento exagerado de biomassa, enquanto concentrações menores poderiam estar abaixo do requerimento nutricional mínimo dos microorganismos. Contudo, a tendência da queda de hidrogênio ao longo do tempo não

mudou em nenhuma das seis condições experimentais. Tal fato foi associado por Carminato 
(2013) à diminuição constante da carga orgânica volumétrica específica (COVe) ocasionada pelo crescimento e acúmulo constante de biomassa no leito.

\subsection{Homoacetogênese}

Os experimentos apresentados anteriormente demonstraram viabilidade na produção de hidrogênio em reator anaeróbio de leito fixo. Os fatores avaliados permitiram observar condições para melhorar os valores do rendimento de hidrogênio. No entanto, ainda não foi possível manter a estabilidade e a continuidade na liberação de biogás. As hipóteses levantadas sugerem que este comportamento está relacionado com o estabelecimento de microorganismos consumidores do biogás $\left(\mathrm{H}_{2}\right.$ e $\left.\mathrm{CO}_{2}\right)$ devido ao acúmulo de biomassa no leito.

Anzola-Rojas (2010) e Lima e Zaiat (2012) inferiram sobre o possível estabelecimento de bactérias Knallgas (i.e. Burkholderia sp.). Este tipo de microorganismos, segundo Gales (2004) pode crescer com $\mathrm{H}_{2}$ e $\mathrm{CO}_{2}$ como únicas fontes de energia e carbono, respectivamente, e com $\mathrm{O}_{2}$ como aceptor de elétrons. Nos experimentos de Anzola-Rojas (2010) e Lima e Zaiat (2012) o $\mathrm{O}_{2}$ podia estar presente no meio de alimentação ou decorrente da microaeração causada nas juntas de mangueiras. No entanto, esta hipótese foi descartada com as análises de biologia molecular feita por Anzola-Rojas et al. (2014).

Com base nos estudos realizados (ainda não publicados) não se encontrou algum microorganismo relativo às bactérias Knallgas e sim possíveis bactérias homoacetogênicas como o Clostridium carboxidivorans. As bactérias homoacetogênicas crescem heterotroficamente com diferentes substratos orgânicos ou autotroficamente em uma mistura de $\mathrm{H}_{2}$ e $\mathrm{CO}_{2}$, produzindo principalmente ácido acético (MINTON e CLARKE, 1989). Durante o crescimento das homoacetogênicas heterotróficas em hexoses, dois terços do acetato produzido é formado diretamente a partir dos açúcares (Reação 1), enquanto um terço é sintetizado pela via Acetyl-CoA Wood-Lungdahl (Reação 2) (Figura 4) (MINTON e CLARKE, 1989; DRAKE, KÜSEL e MATTHIES, 2002).

$$
\begin{array}{lr}
\mathrm{C}_{6} \mathrm{H}_{12} \mathrm{O}_{6}+2 \mathrm{H}_{2} \mathrm{O} \rightarrow 2 \mathrm{CH}_{3} \mathrm{COOH}+2 \mathrm{CO}_{2}+8 \mathrm{H}^{+}+8 \mathrm{e}^{-} & \text {Reação 1 } \\
2 \mathrm{CO}_{2}+8 \mathrm{H}^{+}+8 \mathrm{e}^{-} \rightarrow \mathrm{CH}_{3} \mathrm{COOH}+2 \mathrm{H}_{2} \mathrm{O} & \text { Reação 2 }
\end{array}
$$

$$
\mathrm{C}_{6} \mathrm{H}_{12} \mathrm{O}_{6} \rightarrow 3 \mathrm{CH}_{3} \mathrm{COOH} \text { (Reação global) Reação } 3
$$


A Reação 2 representa o total de síntese de acetato a partir de $\mathrm{CO}_{2}$ e demonstra que o $\mathrm{CO}_{2}$ é usado como um aceptor de elétrons gerados na fermentação da glicose (Reação 1) (MINTON e CLARKE, 1989). A redução global do $\mathrm{CO}_{2}$ para o acetato tem uma variação de energia livre de aproximadamente $-100 \mathrm{~kJ}$ por mol de acetato sintetizado (DRAKE, KÜSEL e MATTHIES, 2002)

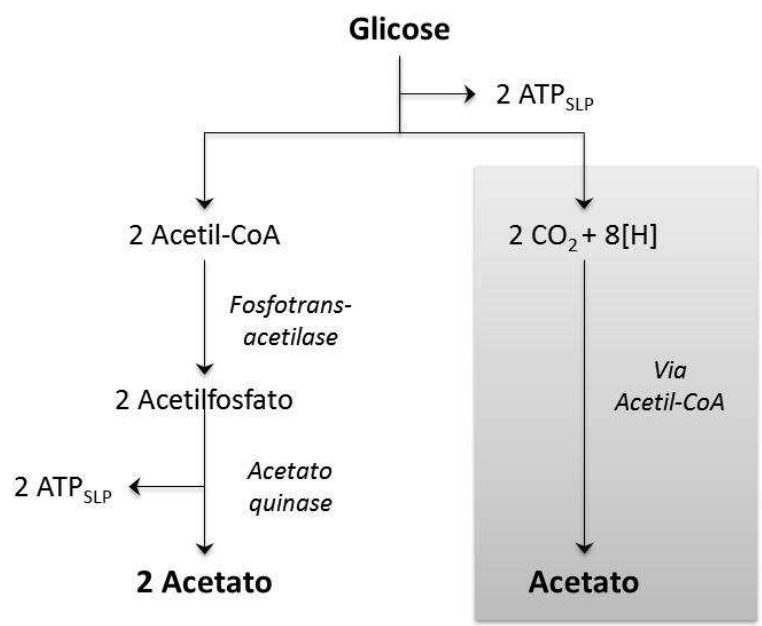

Figura 4 - Produção de acetato a partir da glicólise. Dois terços de acetato são produzidos diretamente dos açúcares, enquanto um terço é produzido pela via AcetylCoA Wood-Lungdahl - homoacetogênese (DRAKE, KÜSEL e MATTHIES, 2002)

A rota metabólica Acetyl-CoA Wood-Lungdahl (Figura 5) também pode ser utilizada pelas homoacetogênicas autotróficas para síntese de carbono celular (DRAKE, GÖBNER e DANIEL, 2008).

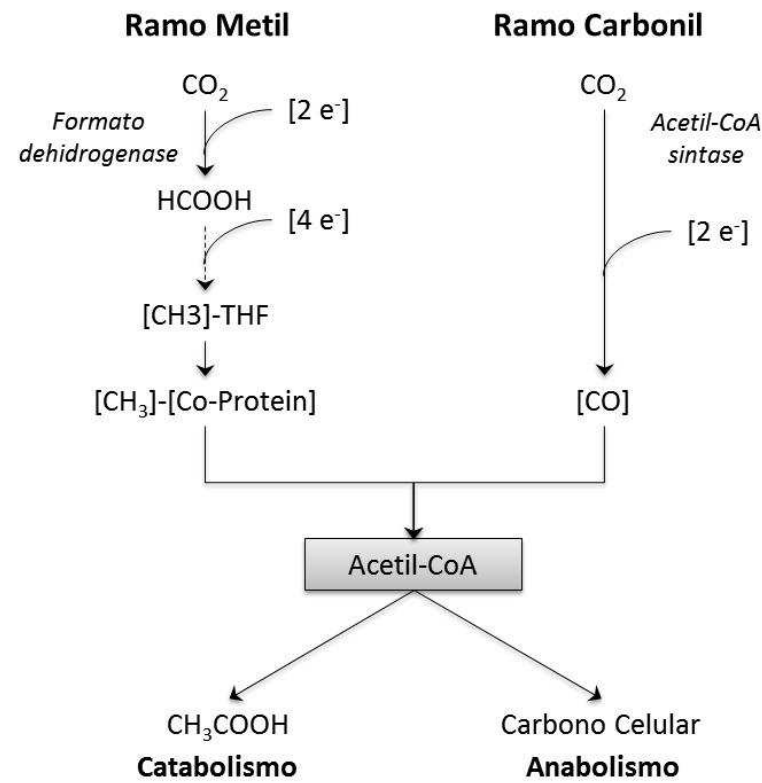

Figura 5 - Rota metabólica Acetil-CoA Wood-Lungdahl utilizada, quer para produção de ácido acético, quer para síntese celular (DRAKE, KÜSEL e MATTHIES, 2002). 
Inicialmente, a redução do $\mathrm{CO}_{2}$ é catalisada quer pela formatodehidrogenase (ramo metil), quer pela Acetil-CoA sintase (ramo carbonil). Depois, o Acetil-CoA formado pode ser utilizado pela síntese anabólica da biomassa ou convertido a acetato (Figura 5) (MINTON e CLARKE, 1989; DRAKE, KÜSEL e MATTHIES, 2002).

A literatura reporta a evidência da participação de bactérias homoacetogênicas que utilizam $\mathrm{H}_{2}$ e $\mathrm{CO}_{2}$ em reatores em batelada produzindo hidrogênio a partir de diferentes substratos. Por exemplo, Oh et al. (2003) observaram, após a fase lag de produção de hidrogênio, pressões negativas nas bateladas, remoção total do biogás $\left(\mathrm{H}_{2}\right.$ e $\left.\mathrm{CO}_{2}\right)$ no headspace após 130 h e elevadas quantidades de acetato após 230 h. Essa observação levou os autores a realizar experimentos com bicarbonato de sódio como fonte de carbono e hidrogênio como doador de elétrons para constatar a atividade homoacetogênica no inóculo utilizado (OH, VAN GINKEL e LOGAN, 2003). Embora a homoacetogênese tenha sido evidenciada, não foi possível definir se as bactérias mudam de produção de hidrogênio para acetato quando o substrato orgânico acaba, ou se as perdas de hidrogênio são constantes durante a fermentação (OH, VAN GINKEL e LOGAN, 2003; KOSKINEN, KAKSONEN e PUHAKKA, 2007).

A importância da homoacetogênese e o seu efeito sobre o rendimento de hidrogênio não é evidente em reatores contínuos (DINAMARCA e BAKKE, 2009). Vários autores sugerem que a homoacetogênese pode ser inibida pelas limitações termodinâmicas em reatores contínuos (RYAN, FORBES e COLLERAN). No entanto, as observações de Koskinen et al. (2007) em reator contínuo de leito fluidizado, demonstraram mudanças nas populações microbianas e desenvolvimento de prováveis microorganismos homoacetogênicos na formação do biofilme.

Arooj et al. (2008) observaram que, do total de acetato produzido em reatores operados em bateladas sequenciais, $40 \pm 5 \%$ foi gerado pela homoacetogênese, indicando que nem sempre a concentração de acetato implica um papel positivo na produção de hidrogênio. Ou seja, parte do hidrogênio que inicialmente é liberado na produção de acetato depois é consumida pelas homoacetogênicas.

Para Calli et al. (2008), os baixos valores de rendimento de hidrogênio a partir de xilose $\left(1,70 \mathrm{~mol} \mathrm{H}_{2} \mathrm{~mol}^{-1}\right.$ xilose $)$ e lactose $\left(3,45 \mathrm{~mol} \mathrm{H}_{2} \mathrm{~mol}^{-1}\right.$ lactose $)$ em reatores de mistura perfeita (CSTR) poderiam estar relacionados com a elevada pressão parcial do hidrogênio (>50 kPa), resultando em mudanças nas rotas metabólicas que favorecem o consumo de hidrogênio pelas bactérias homoacetogênicas. 
Siriwongrungson et al. (2007) afirmaram que bactérias homoacetogênicas podem estar presentes em ambientes anaeróbios, tais como o lodo dos reatores usados para o tratamento de esgoto sanitário, o qual é geralmente usado como inóculo de reatores acidogênicos produtores de hidrogênio. Como algumas bactérias homoacetogênicas são formadoras de esporos, o choque térmico, como pré-tratamento do inóculo, é uma técnica ineficiente para sua inibição (KIM, HAN e SHIN, 2006). Dinamarca e Bakke (2009) sugerem que o estabelecimento das bactérias homoacetogênicas está relacionado com o crescimento e a idade do lodo, pois foi observado que o desenvolvimento de biofilme nas paredes e acúmulo de biomassa no reator coincidiu com o decréscimo na produção de hidrogênio e aumento da geração de ácido acético.

\subsection{Considerações finais}

Os estudos apresentados nessa Revisão demonstram a viabilidade na produção de hidrogênio em reator anaeróbio de leito fixo a partir de águas residuárias. A variação dos diferentes parâmetros tais como TDH, porosidade do leito, relação $\mathrm{C} / \mathrm{N}$, condições de mistura, tipo de inóculo e pré-tratamento e concentração de cálcio permitiram melhorar a produção volumétrica e o rendimento de hidrogênio no sistema. No entanto, estas variações têm sido insuficientes para alcançar uma produção contínua e estável nesse tipo de reator.

Os autores sugerem que o comportamento de queda do hidrogênio durante a fase de estabilização do sistema, definido pela eficiência de conversão de sacarose, se deve à participação de microorganismos consumidores do biogás. Os resultados indicam que o uso do inóculo natural permite a inibição das arqueias metanogênicas mediante as condições experimentais impostas no reator, tais como baixo TDH $(2 \mathrm{~h})$ e $\mathrm{pH}(\mathrm{pH}<5,5)$. Apesar disso, as estratégias têm sido insuficientes para a inibição de outro tipo de consumidores, como as homoacetogênicas.

As observações dos pesquisadores do LPB-EESC-USP junto com as observações da literatura sugerem que as mudanças nas rotas microbianas podem ter sido causadas pelo acúmulo constante de biomassa no leito do reator. Varias inferências podem ser levantadas a partir dessas observações. Por um lado, o acúmulo de biomassa pode ter gerado uma constante diminuição da carga orgânica volumétrica específica (COVe), o que aumentou a competição pelo substrato inicial forçando ao uso dos produtos intermediários produzidos, como hidrogênio e dióxido de carbono, constituintes do biogás. Por outro lado, o acúmulo pode ter mudado o padrão de escoamento dos reatores, gerando anomalias, como zonas 
mortas, onde o biogás produzido ficaria retido. Adicionalmente, essas anomalias poderiam ter diminuído o grau de mistura do reator, diminuindo o efeito de transferência de massa líquidogás, elevando a pressão parcial de hidrogênio e consequentemente causando mudanças nas rotas microbianas.

Desta forma, no intuito de diminuir o acúmulo de biomassa no leito e manter uma adequada COVe que permita manter a produção de hidrogênio contínua, o seguinte trabalho apresenta cinco estratégias operacionais em um reator anaeróbio de leito fixo. Essas estratégias incluem variar o escoamento descendente e ascendente, ordenar o leito segundo Godoi (2010), Mockaitis (2011) e Carminato (2013), realizar descartes de biomassa e variar a carga orgânica volumétrica aplicada (COV) mediante a alteração do tempo de detenção hidráulica (TDH) e concentração do substrato. 


\section{MATERIAL E MÉTODOS}

A etapa experimental dividiu-se em cinco diferentes estratégias operacionais, tal como descrito na Figura 6. As estratégias 1 e 2 consistiram em inverter o escoamento de líquido e avaliar a produção de hidrogênio. Estas estratégias junto com a 3 e a 4 se caracterizaram pelo controle da COVe mediante a manipulação da quantidade de biomassa, enquanto a COV se manteve constante em $24 \mathrm{~g}$ DQO L $\mathrm{L}^{-1} \mathrm{~d}^{-1}$. Por último, a estratégia 5 se baseou no controle da COVe por meio da variação da COV mediante a alteração do TDH (2 e 4 h) e do aumento da concentração do substrato $\left(1,2,4,8\right.$ e $\left.16 \mathrm{~g} \mathrm{DQO} \mathrm{L}^{-1}\right)$.

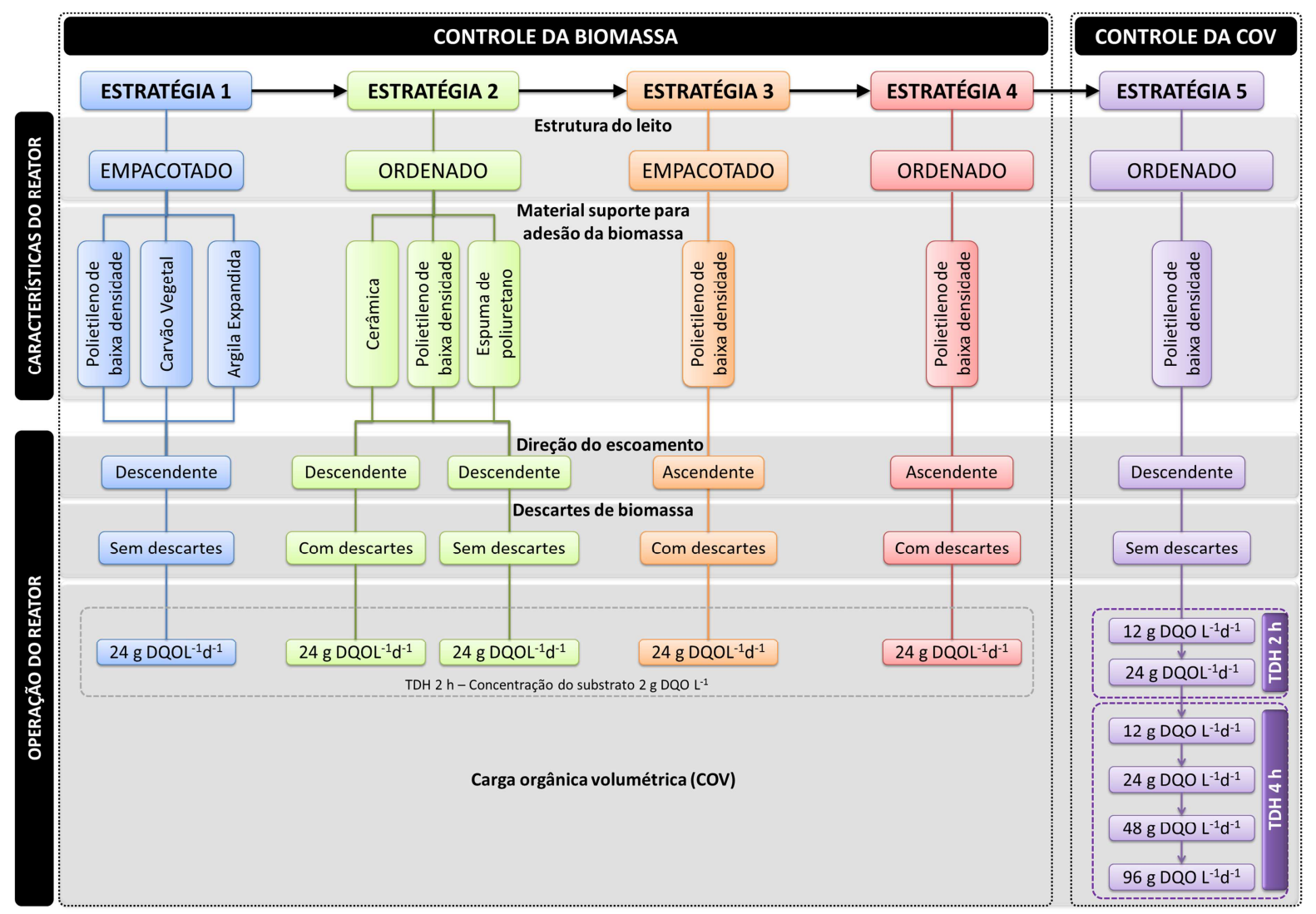

Figura 6 - Esquema geral do desenvolvimento experimental. Estratégias 1, 2, 3 e 4 baseadas no controle da biomassa e estratégia 5 no controle da COV.

As estratégias operacionais adotadas visaram testar a hipótese central desse trabalho e cada uma delas visou testar uma sub-hipótese específica como apresentado a seguir.

A estratégia 1 visou testar a sub-hipótese 1 referente à inversão do escoamento, de ascendente conforme comumente empregado nesse tipo de reator, para descendente. Utilizaram-se três reatores de leito fixo com aparas de polietileno de baixa densidade, 
partículas de carvão vegetal e argila expandida como material suporte para adesão da biomassa. Estes materiais foram dispostos no leito de forma empacotada. Os reatores foram operados com TDH de $2 \mathrm{~h}$, concentração do substrato de $2 \mathrm{~g}$ DQO L ${ }^{-1}$ e escoamento descendente. Embora Fernandes (2008) tenha testado e observado que diferentes materiais suporte não afetaram substancialmente o processo acidogênico, o escoamento descendente poderia trazer alguma informação adicional. A influência do material suporte no processo não está listada nos objetivos desse trabalho de pesquisa, mas pode ser considerado como teste adicional por reproduzir os experimentos de Fernandes (2008) apenas com variação do sentido do escoamento.

A estratégia 2 visou testar a sub-hipótese 2 referente à influência da estruturação do leito. Para esse fim, utilizaram-se três reatores com leito ordenado longitudinalmente e cada um com um material suporte diferente. A estruturação do leito consistiu em ordenar pequenos cilindros de polietileno de baixa densidade, espuma de poliuretano e cerâmica em fileiras alternadas verticalmente e fixadas mediante hastes de inox. Essa estratégia se dividiu em dois estágios diferentes; no entanto, em ambos, o TDH aplicado foi de $2 \mathrm{~h}$, a concentração de substrato de $2 \mathrm{~g} \mathrm{DQO} \mathrm{L}^{-1}$ e o escoamento descendente. O primeiro estágio consistiu em operar os reatores realizando descartes de biomassa a cada 20 dias. Cada descarte consistiu da retirada de $200 \mathrm{~mL}$ de líquido do fundo dos reatores, contendo biomassa sedimentada e acumulada durante o período. O segundo estágio consistiu na operação dos reatores sem descartes de biomassa.

A estratégia 3 visou avaliar a sub-hipótese 1 referente à manutenção da COVe em um valor adequado para a produção contínua de hidrogênio em um reator anaeróbio de leito fixo empacotado com aparas de polietileno de baixa densidade como material suporte para adesão da biomassa e operado com escoamento ascendente, TDH de $2 \mathrm{~h}$ e concentração do substrato de $2 \mathrm{~g}$ DQO L $\mathrm{L}^{-1}$. A manutenção da COVe se realizou mediante descartes programados de biomassa pelo fundo do reator conforme foi ocorrendo o acúmulo de biomassa.

A estratégia 4 visou testar e complementar a sub-hipótese 2. Para este fim, utilizou-se um reator de leito ordenado, com cilindros de polietileno de baixa densidade como material para adesão da biomassa. A operação do reator ocorreu de forma similar à estratégia 3, ou seja, escoamento ascendente, TDH de $2 \mathrm{~h}$, concentração do substrato de $2 \mathrm{~g} \mathrm{DQO} \mathrm{L}^{-1}$ e a manutenção da COVe por meio de descartes programados de biomassa pelo fundo do reator conforme foi ocorrendo o acúmulo de biomassa.

A estratégia 5 visou avaliar a sub-hipótese 3 referente ao controle da COVe mediante a variação da COV. Neste caso, utilizou-se um reator de leito ordenado, com cilindros de 
polietileno de baixa densidade como material suporte para adesão da biomassa. O experimento consistiu em operar o reator com escoamento descendente, sem descartes de biomassa e com variação da COV a cada 30 dias aproximadamente. Essa estratégia se dividiu em seis fases diferenciadas pela COV. Nas duas primeiras, avaliou-se o TDH de $2 \mathrm{~h}$ e as concentrações de substrato de 1 e 2 g DQO L ${ }^{-1}$, perfazendo uma COV de 12 e $24 \mathrm{~g} \mathrm{DQO} \mathrm{L}^{-1}$ $\mathrm{d}^{-1}$, respectivamente. Nas quatro seguintes fases, avaliou-se o TDH de $4 \mathrm{~h}$ e as concentrações de substrato de 2, 4, 8 e $16 \mathrm{~g}^{\mathrm{DQO}} \mathrm{L}^{-1}$ perfazendo uma COV de 12, 24, 48 e $96 \mathrm{~g}$ DQO L $\mathrm{L}^{-1}$ 1 , respectivamente.

Vale ressaltar que as estratégias 1, 2, 3 e 4 foram desenvolvidas no LPB-EESC-USP, enquanto a estratégia $5 \mathrm{fez}$ parte do estágio de doutorado desenvolvido no Flemish Institute for Technological Research (VITO), na Bélgica.

\subsection{Reator}

O estudo foi feito em reatores anaeróbios de leito fixo conforme Figura 7. Cada reator consistiu em um tubo de acrílico de diâmetro interno de $80 \mathrm{~mm}$, diâmetro externo de $88 \mathrm{~mm}$ e $810 \mathrm{~mm}$ de comprimento perfazendo um volume total de 4,1 L. O nível da água dentro do reator foi fixado mediante sifões adaptados na saída do efluente líquido. Para acumulação e posterior saída do biogás na parte superior do tubo acima do nível da água, deixou-se um compartimento de $50 \mathrm{~mm}$ de comprimento como headspace. O leito foi separado mediante grades de inox com abertura de aproximadamente $5 \times 5 \mathrm{~mm}$, evitando uma possível flutuação ou afundamento dos materiais suporte. $\mathrm{O}$ fundo dos reatores teve forma de cone para facilitar o acúmulo de biomassa e adicionalmente teve uma válvula acoplada para descartes.

A configuração do leito e a direção do escoamento variaram dependo da estratégia a desenvolver. Assim, na estratégia 1 usou-se o reator com leito empacotado (Figura 7b) e o escoamento descendente (Figura 7c). Na estratégia 2 usou-se o reator com leito ordenado (Figura 7a) e escoamento descendente. Na estratégia 3 se usou o reator com leito empacotado e escoamento ascendente (Figura 7d). Na estratégia 4 se usou o reator com leito ordenado e escoamento ascendente e, finalmente, na estratégia 5 usou-se o reator com leito ordenado e escoamento descendente. 


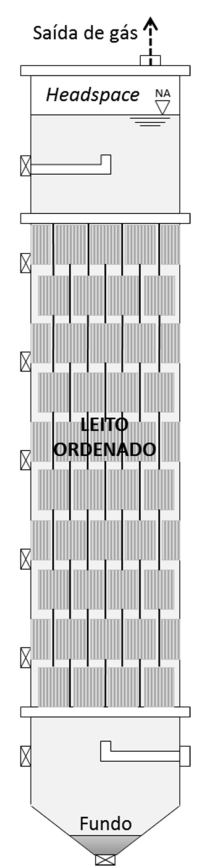

(a)

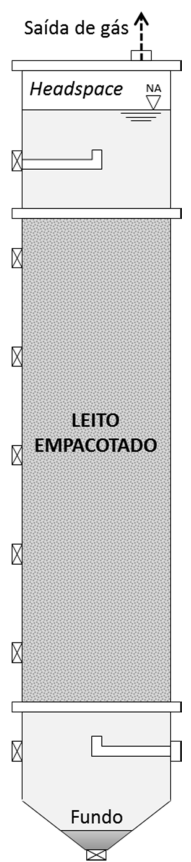

(b)

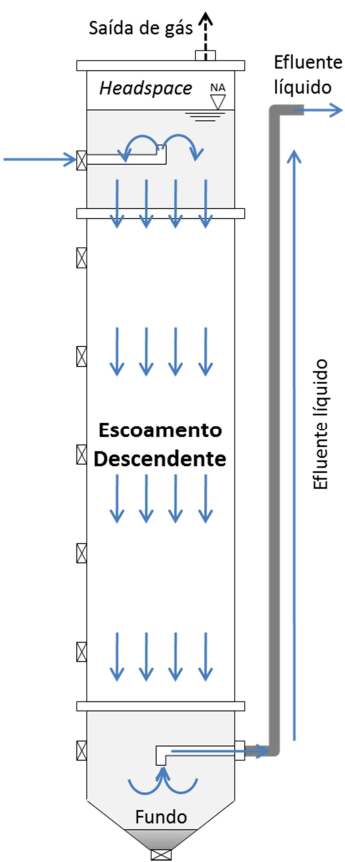

(c)

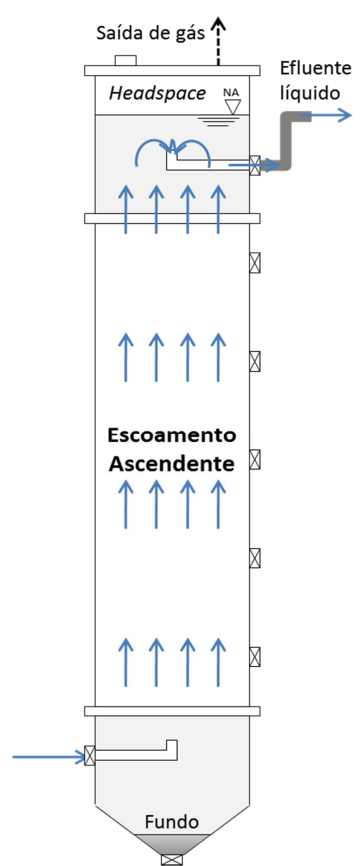

(d)

Figura 7 - Configuração do reator anaeróbio de leito fixo utilizado para produção de hidrogênio (a) com leito ordenado (b) com leito empacotado (c) escoamento descendente (d) escoamento ascendente.

\subsection{Material suporte}

O material suporte para adesão da biomassa foi escolhido em função da estruturação do leito. No caso do leito empacotado optou-se pelo uso de materiais reportados em trabalhos anteriores desenvolvidos no LPB-EESC-USP. Já para o leito ordenado optou-se por materiais de fácil manipulação na hora da montagem da estrutura e com características similares aos usados no leito empacotado.

\subsubsection{Leito empacotado}

Durante a estratégia 1, os materiais usados para adesão da biomassa foram o polietileno de baixa densidade (denominado polietileno ao longo do texto), carvão vegetal (denominado carvão ao longo do testo) e argila expandida (denominada argila ao longo do texto), conforme apresentado na Figura 8a, c e d, respectivamente. Estes materiais foram utilizados anteriormente por Fernandes (2008), porém as partículas de polietileno usadas aqui foram de diâmetro médio menor comparadas com as do trabalho anterior.

A preparação do material consistiu em cortar manualmente o carvão, enquanto que a argila e o polietileno mantiveram o tamanho inicial de fabricação. Os materiais foram submetidos a prévio peneiramento utilizando um Agitador Solotest ${ }^{\circledR}$ (No. 7, serie 0805, 
Referência - 1202230) e peneiras com abertura comercial de $12,7 \mathrm{~mm}, 9,52 \mathrm{~mm}, 7,93 \mathrm{~mm}$, $6,35 \mathrm{~mm}$ e 4,22 mm. Cada um dos materiais foi submetido a agitação constante por 15 minutos. Para empacotar o leito de polietileno foram utilizadas as partículas retidas na peneira de 4,22 mm, resultando em diâmetro médio de 5,3 mm. Para os leitos de carvão e argila, 50\% do leito foi preenchido com partículas de diâmetro de $8,7 \mathrm{~mm}$ e $50 \%$ com 7,1 mm, sendo o diâmetro médio de 7,93 mm.

Durante a estratégia 3, o material usado para adesão da biomassa também foi polietileno (Figura 8b), porém o tamanho médio das partículas foi de 12,70 $\mathrm{mm}$ e coeficiente de uniformidade 1,26 (FERNANDES, 2008; PEIXOTO, 2011).
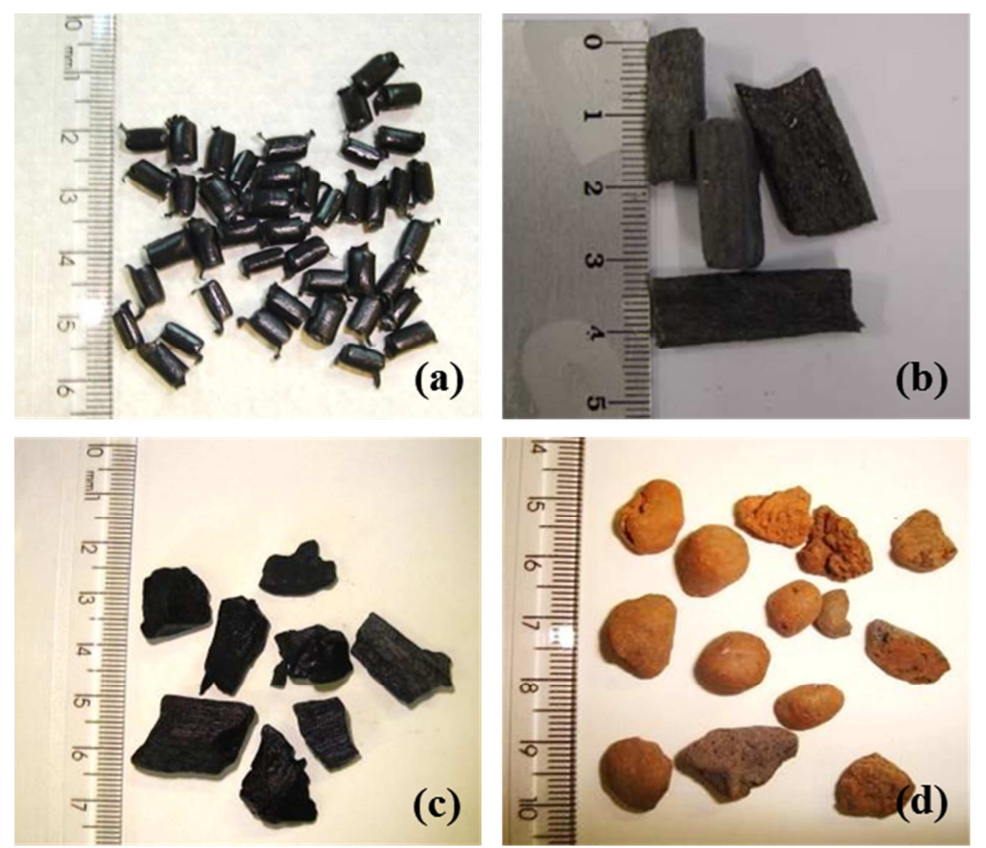

(c)

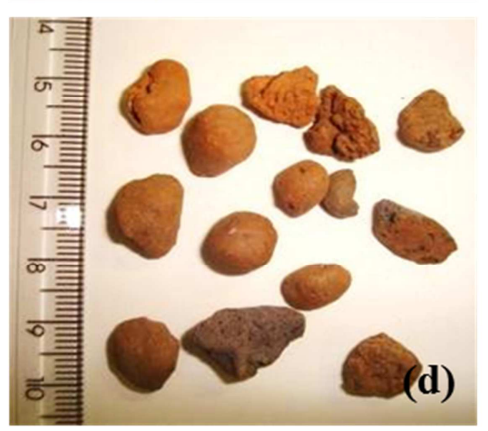

Figura 8 - Materiais suporte para adesão da biomassa (a) e (b) polietileno de baixa densidade (c) carvão vegetal (d) argila expandida

Na Tabela 1 encontra-se a caracterização desses materiais realizada pelo Centro de Caracterização de Materiais (CCDM) da Universidade Federal de São Carlos (UFSCar) e reportado por Fernandes (2008).

Tabela 1 - Características físicas dos materiais usados no leito empacotado (FERNANDES, 2008)

\begin{tabular}{ccc}
\hline Material & $\begin{array}{c}\text { Área superficial específica } \\
\left(\mathbf{m}^{\mathbf{2}} \mathbf{~ g}^{\mathbf{- 1}}\right)\end{array}$ & $\begin{array}{c}\text { Porosidade } \\
(\boldsymbol{\%})\end{array}$ \\
\hline Polietileno de baixa densidade & 7,9401 & Não se aplica \\
Carvão vegetal & 3,5117 & 42,5 \\
Argila expandida & 1,0778 & 53,8 \\
\hline
\end{tabular}




\subsubsection{Leito ordenado}

Para estruturação do leito ordenado se utilizaram pequenos cilindros de polietileno de baixa densidade (polietileno), espuma de poliuretano (espuma) e cerâmica especial à base de sílica aluminosa (cerâmica). Os cilindros de polietileno foram adquiridos da empresa Ambio Engenharia, sediada na cidade de Rio de Janeiro, RJ, a cerâmica do Departamento de Engenharia de Materiais da Universidade Federal de São Carlos, SP (DEMa-UFSCar) e os cilindros de espuma foram confeccionados a partir de espuma de colchão D33. Tal como apresentado na Figura 9, cada cilindro media aproximadamente $25 \mathrm{~mm}$ de comprimento e 20 $\mathrm{mm}$ de diâmetro. A estruturação do leito consistiu em ordenar os cilindros alternadamente por meio de hastes de fixação verticais.
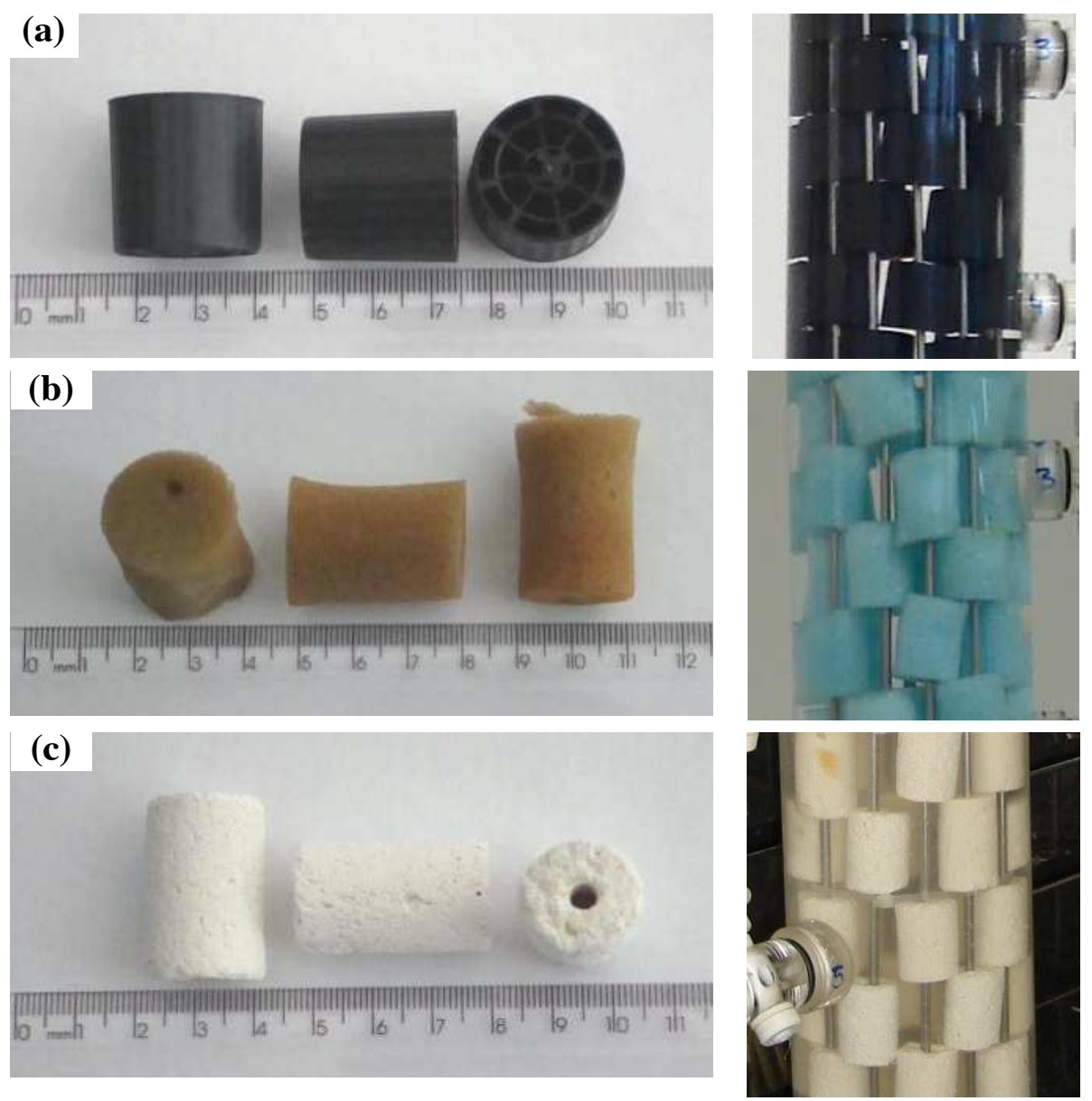

Figura 9 - Materiais suporte para adesão da biomassa (a) polietileno de baixa densidade (b) espuma de poliuretano (c) cerâmica

Na Tabela 2 são apresentadas as características físicas dos materiais determinadas no Instituto de Química de São Carlos (IQSC) usando o Analisador de Sorção de Gás de Alta Velocidade de Quantachrome instruments ${ }^{\circledR}$ - Nova 1000, versão 10.02. e reportadas por Peixoto (2011). A porosidade da espuma foi considerada acima de 95\% (RODRIGUEZ, 2010; 
OLIVEIRA NETTO, 2011) e da cerâmica próxima de 60\%, esta última calculada pelo método de Arquimedes segundo a norma ASTM C373-88 (ASTM INTERNATIONAL, 2006).

Tabela 2 - Características físicas dos materiais usados no leito ordenado (PEIXOTO, 2011)

\begin{tabular}{ccc}
\hline Material & $\begin{array}{c}\text { Área superficial específica } \\
\left(\mathbf{m}^{\mathbf{2}} \mathbf{g}^{\mathbf{- 1}}\right)\end{array}$ & $\begin{array}{c}\text { Densidade } \\
\left(\mathbf{g} \mathbf{~} \mathbf{L L}^{-\mathbf{1}}\right)\end{array}$ \\
\hline Polietileno de baixa densidade & 7,9448 & 0,9600 \\
Espuma de poliuretano & 11,7881 & 0,0350 \\
Cerâmica & 25,5759 & 2,5000 \\
\hline
\end{tabular}

\subsection{Substrato}

Como substrato, foi preparada água residuária sintética a base de sacarose. Durante o desenvolvimento das estratégias 1, 2, 3 e 4, a concentração do substrato foi de $2 \mathrm{~g} \mathrm{DQO} \mathrm{L}^{-1}$, enquanto que na estratégia 5 , a concentração variou de $1 \mathrm{~g} \mathrm{DQO} \mathrm{L}^{-1}$ a $16 \mathrm{~g} \mathrm{DQO} \mathrm{L}^{-1}$. Em todas as condições experimentais, a relação carbono/nitrogênio $(\mathrm{C} / \mathrm{N})$ se manteve em 140 mediante a adição de ureia, conforme Anzola-Rojas (2010). O cálculo desta relação foi baseado na quantidade em massa de carbono e nitrogênio da sacarose $\left(\mathrm{C}_{12} \mathrm{H}_{22} \mathrm{O}_{11}\right)$ e ureia $\left(\mathrm{CH}_{4} \mathrm{~N}_{2} \mathrm{O}\right)$, respectivamente.

A adição de micronutrientes para cada $1 \mathrm{~g} \mathrm{DQO} \mathrm{L}^{-1}$, baseado na sacarose, foi adaptada de Del Nery (1987), conforme apresentado na Tabela 3. O pH do meio sintético afluente se manteve entre 6,0 e 6,5 com a adição de bicarbonato de sódio e ácido clorídrico.

Tabela 3 - Micronutrientes adicionados ao meio sintético por cada 1 g DQO L L $^{-1}$ (DEL NERY, 1987)

\begin{tabular}{ccc}
\hline \multicolumn{1}{c}{ Componente } & & $\begin{array}{c}\text { Concentração } \\
\left(\mathbf{m g ~ \mathbf { L } ^ { - 1 }}\right)\end{array}$ \\
\hline Sulfato de níquel & $\mathrm{NiSO}_{4} \cdot \mathrm{H}_{2} \mathrm{O}$ & 0,25 \\
Sulfato ferroso & $\mathrm{FeSO}_{4} \cdot 7 \mathrm{H}_{2} \mathrm{O}$ & 1,25 \\
Cloreto férrico & $\mathrm{FeCl}_{3} \cdot 6 \mathrm{H}_{2} \mathrm{O}$ & 0,125 \\
Cloreto de cálcio & $\mathrm{CaCl}_{2} \cdot 6 \mathrm{H}_{2} \mathrm{O}$ & 1,03 \\
Cloreto de cobalto & $\mathrm{CoCl}_{2} \cdot 2 \mathrm{H}_{2} \mathrm{O}$ & 0,020 \\
Dióxido de selênio & $\mathrm{SeO}_{2}$ & 0,018 \\
Fosfato de potássio monobásico & $\mathrm{KH}_{2} \mathrm{PO}_{4}$ & 2,68 \\
Fosfato de potássio dibásico & $\mathrm{K}_{2} \mathrm{HPO}_{4}$ & 0,65 \\
Fosfato de sódio dibásico & $\mathrm{NaHPO}_{4} \cdot 2 \mathrm{H}_{2} \mathrm{O}$ & 1,35 \\
\hline
\end{tabular}




\subsection{Inóculo}

O inóculo foi obtido de forma natural segundo procedimento adaptado de Leite et al. (2008). Em um recipiente, com água de abastecimento público preparou-se meio suficiente para 24 horas de alimentação com concentração de substrato de $2 \mathrm{~g}$ DQO L ${ }^{-1}$. O meio foi deixado em repouso por três dias a fim de favorecer a primeira fermentação natural, obtida mediante o contato de microorganismos presentes no próprio substrato e provenientes da água utilizada. Passado esse período, para imobilização da biomassa no material suporte, essa substância fermentada foi recirculada através do reator por uma semana. Desta forma, a adesão da biomassa ocorreu por contato do líquido com o material suporte.

\subsection{Métodos}

\subsubsection{Porosidade do leito}

A medida da porosidade inicial do leito foi realizada conforme a metodologia seguida no LPB-EESC-USP (FERNANDES, 2008; PEIXOTO, 2008; RODRIGUEZ, 2010) antes do início do uso dos reatores, considerando o desenvolvimento do biofilme nulo. No intuito de minimizar os efeitos da porosidade intrínseca dos materiais e de calcular a porosidade efetiva do leito, os diferentes materiais foram imersos em água por 24 horas antes de realizar o ensaio.

Após esse período, os materiais foram dispostos dentro do leito e se adicionou água até cobrir completamente o leito. Posteriormente a água foi drenada. A porosidade foi calculada a partir da razão entre o volume líquido drenado do leito com material suporte e o volume líquido drenado da zona do leito vazio (FERNANDES, 2008; PEIXOTO, 2008; RODRIGUEZ, 2010).

\subsubsection{Ensaio hidrodinâmico no reator com leito empacotado}

Neste tipo de reator um estímulo na forma de pulso foi realizado, utilizando dextrana azul como traçador (LEVENSPIEL, 2000). Este traçador, segundo reportado na literatura, diminui o efeito de difusão nos materiais suporte e na biomassa devido a seu elevado peso molecular (JIMENEZ, NOYOLA, et al., 1988).

A montagem do experimento consistiu em adequar a vazão para um TDH teórico de 2 $\mathrm{h}$ usando água de abastecimento como líquido afluente. Na mangueira do afluente, logo antes 
da válvula de entrada do reator, foi aplicado um pulso pontual de $50 \mathrm{~mL}$ de dextrana azul em concentração de 2,5 $\mathrm{g} \mathrm{L}^{-1}$. Em seguida, a cada três minutos foram coletados, em tubos de ensaio, amostras do efluente líquido $(10 \mathrm{~mL})$ durante o período de duas horas. As concentrações de dextrana azul foram medidas em espectrofotômetro com comprimento de onda de $650 \mathrm{~nm}$.

Posteriormente, a partir da curva- resposta (concentração por tempo) e conforme a metodologia descrita por Levenspiel (2000) se traçou a Curva E (normalizada) e calculou-se o TDH médio conforme a Equação 1 e Equação 2, respectivamente.

$$
\begin{gathered}
E(t)=\frac{C(t)}{\int_{0}^{\infty}(t) \cdot d t} \\
\bar{\theta} h=\frac{\int_{0}^{\infty} t \cdot E(t) \cdot d t}{\int_{0}^{\infty} E(t) \cdot d t}
\end{gathered}
$$

Equação 1

Equação 2

Nas quais, $E$ é a distribuição do $T D H$ e $\bar{\theta} h$ o $T D H$ médio.

A representação do padrão de escoamento se realizou pelo modelo dos reatores de mistura completa em série, com cálculo da variância da curva normalizada, segundo as Equações 3 a 5 .

$$
\begin{gathered}
\sigma^{2}=\int_{0}^{\infty}(t-\bar{\theta} h)^{2} \cdot E(t) \cdot d t \\
\sigma_{\Theta}^{2}=\frac{\sigma^{2}}{\bar{\theta} h^{2}} \\
N=\frac{1}{\sigma_{\Theta}^{2}}
\end{gathered}
$$

Equação 3

Equação 4

Equação 5

Nas quais $\sigma^{2}$ é a variância; $\sigma_{\Theta}^{2}$ é a variância adimensional; e $N$ é o número de reatores de mistura completa em série. 


\subsubsection{Ensaio hidrodinâmico no reator com leito ordenado}

Nos reatores com escoamento descendente, devido ao elevado peso molecular da dextrana não foi possível realizar ensaios hidrodinâmicos de tipo pulso, pois o traçador, pela diferença de densidade, não acompanhava adequadamente o escoamento. $\mathrm{O}$ mesmo comportamento foi observado com o cloreto de sódio como traçador. Portanto, optou-se por realizar os ensaios de forma inversa. Encheram-se os reatores com uma solução de cloreto de sódio de $10 \mathrm{~g} \mathrm{~L}^{-1}$ e em seguida realizou-se um estímulo degrau pontual com água limpa mediante o sistema de alimentação do reator.

A montagem do experimento, conforme Peixoto (2008), consistiu em instalar na saída do efluente um vertedor com uma sonda para detecção de condutividade, acoplada a um

dispositivo coletor de dados CBL $2^{\mathrm{TM}}$ e a uma calculadora Texas TI-89 ${ }^{\circledR}$. Coletaram-se valores durante três vezes o TDH teórico até se estabilizar o valor da condutividade.

Posteriormente, traçou-se a curva-resposta e esta foi normalizada por meio da Equação 1 obtendo como resultado a curva $\mathrm{F}$ (F por tempo).

$$
F=\frac{C}{C_{\max }}
$$

Equação 6

Na qual, $C_{\max }$ é a concentração máxima observada do traçador.

Como neste caso, a resposta foi obtida de forma inversa, o TDH médio é representado pela área da curva F em vez da área sobre a curva como indicado na metodologia de Levenspiel (2000). Portanto, traçou-se a curva $F_{i}$ segundo a Equação 7.

$$
F_{i}=1-F
$$

Equação 7

A curva $F_{i}$ é transformada na curva $\mathrm{E}$ gerando uma resposta idêntica à obtida quando a injeção se dá na forma de pulso segundo a Equação 8.

$$
E=\frac{d F_{i}}{d t}
$$

Desta forma, a partir da Curva E, o TDH médio se calculou por meio da Equação 2 e o modelo de reatores de mistura completa em serie segundo a Equação 3 a Equação 5. 


\subsubsection{Medida de vazão de biogás}

No compartimento de saída de cada reator foi acoplado um medidor de vazão de gás on-line milligasCounter, da Ritter ${ }^{\circledR}$ para quantificar o volume de biogás produzido. Cada procedimento de medição da vazão volumétrica de hidrogênio consistiu em anotar o volume do biogás quantificado pelo medidor durante um tempo definido e multiplicado pela fração molar de $\mathrm{H}_{2}$ (ANZOLA-ROJAS, 2010).

\subsubsection{Composição do biogás}

Durante as estratégias $1,2,3$ e 4, a composição do biogás $\left(\mathrm{H}_{2}, \mathrm{CO}_{2}\right.$ e $\left.\mathrm{CH}_{4}\right)$ se determinou por cromatografia gasosa (Shimadzu GC 2021 ${ }^{\circledR}$ ) segundo a metodologia desenvolvida no LPB-EESC-USP, nas seguintes condições:

Coluna capilar: Carboxen 1010, comprimento de $30 \mathrm{~m}$, diâmetro interno de 0,53 mm e espessura da coluna de $0,30 \mu \mathrm{m}$.

Gás de arraste: Argônio.

Temperatura inicial do injetor: $200^{\circ} \mathrm{C}$.

Temperatura inicial do detector: $230^{\circ} \mathrm{C}$.

Vazão do gás de make up (Ar): $12 \mathrm{~mL} \mathrm{~min}^{-1}$.

Detector: condutividade térmica.

Volume de amostra: $200 \mu \mathrm{L}$.

Usando uma seringa de trava (VICI Precision Sampling), as amostras de biogás foram coletadas diretamente na mangueira de entrada do medidor de vazão de biogás, com a frequência de quatro vezes por semana.

Durante a estratégia 5, a composição do biogás $\left(\mathrm{H}_{2}, \mathrm{CO}_{2}, \mathrm{O}_{2}, \mathrm{~N}_{2}\right.$ e $\left.\mathrm{CH}_{4}\right)$ foi determinada por cromatografia gasosa. Usou-se o cromatógrafo CTC Analytics - modelo HTX Pal ${ }^{\circledR}$ equipado com um sistema de detector por condutividade térmica (TCD) e as medições foram feitas segundo metodologia desenvolvida no VITO. Dependendo do gás, as colunas capilares foram:

Para $\mathrm{CO}_{2}$ : Hayesep Q, 80 - 100; 0,25 m 1/8" SS.

Para $\mathrm{H}_{2} \mathrm{O}$ : Hayesep N, $80-100 ; 1,00$ m 1/8" SS.

Para $\mathrm{O}_{2}$ : Molsieve 5A, $80-100 ; 1,00 \mathrm{~m} \mathrm{1/8”}$ SS

Para $\mathrm{N}_{2}$ : Hayesep Q, 80 - 100; 2,00 m 1/8” SS.

Para $\mathrm{H}_{2}$ : Carbosphere, 80 - 100; 2,00 m 1/8" SS. 
Usando uma seringa para coleta de gás marca Hamilton ${ }^{\circledR}$, as amostras de biogás foram coletadas em um septo instalado logo na mangueira de entrada do medidor de vazão de biogás, quatro vezes por semana.

\subsubsection{Determinação dos produtos solúveis da fermentação}

Durante as estratégias 1, 2, 3 e 4, utilizou-se o cromatógrafo Shimadzu GC2010 ${ }^{\circledR}$ (software GC Solution), para as análises de ácidos (acético, propiônico, isobutírico, butírico, isovalérico, valérico e capróico), acetona e álcoois (metanol, etanol e n-butanol). Empregouse o método de "headspace" estático desenvolvido no LPB-EESC-USP, que utiliza o ácido crotônico como padrão para os ácidos e o isobutanol como padrão para álcoois e acetona, com as seguintes características cromatográficas:

Coluna HP-INNOWAX: comprimento de $30 \mathrm{~m}$, diâmetro interno de 0,25 mm e espessura de filme $25 \mu \mathrm{m}$.

Temperatura do injetor: $250^{\circ} \mathrm{C}$.

Temperatura do detector: $280^{\circ} \mathrm{C}$.

Razão do Split: 1,0 .

Fluxo do gás de arraste $\left(\mathrm{H}_{2}\right): 30 \mathrm{~mL} \mathrm{~min}^{-1}$.

Fluxo do make-up ou gás auxiliar $\left(\mathrm{N}_{2}\right)$ : $30 \mathrm{~mL} \mathrm{~min}^{-1}$.

Fluxo do gás da chama (ar sintético): $300 \mathrm{~mL} \mathrm{~min}^{-1}$.

Volume da amostra injetada: $400 \mu \mathrm{L}$.

Seringa de $2,5 \mathrm{~mL}$.

Temperatura da seringa: $90^{\circ} \mathrm{C}$.

Temperatura de incubação da amostra: $100^{\circ} \mathrm{C}$.

O preparo das amostras foi feito em frascos - padrão de vidro com capacidade de 10 $\mathrm{mL}$, com tampa rosqueável e septo de silicone com $18 \mathrm{~mm}$ de diâmetro. Foram adicionados 1 $\mathrm{g}$ de $\mathrm{NaCl}, 2 \mathrm{~mL}$ de amostra, $70 \mu \mathrm{L}$ de solução de isobutanol, $100 \mu \mathrm{L}$ de solução de ácido crotônico $\left(700 \mathrm{mg} \mathrm{L}^{-1}\right)$ e $200 \mu \mathrm{L}$ de solução de $\mathrm{H}_{2} \mathrm{SO}_{4} 2 \mathrm{~mol} \mathrm{~L}^{-1}$.

Durante a estratégia 5, a determinação dos ácidos voláteis (acético, propiônico, isobutírico, butírico, isovalérico, valérico, isocapróico e capróico) foi realizada usando a técnica de cromatografia gasosa segundo metodologia desenvolvida no VITO. Usou-se um cromatógrafo marca FOCUS GC ${ }^{\circledR}$ equipado com detector por ionização de chama (FID), 
coluna $\mathrm{AT}^{\mathrm{M}}{ }(15 \mathrm{~m} \times 0,53 \mathrm{~mm} \times 12 \mu \mathrm{m})$ e sistema de injeção Combi PAL ${ }^{\circledR}$ com as seguintes características:

Ciclo: GC - Inj

Seringa: $10 \mu \mathrm{L}$

Volume de amostra: $1,0 \mu \mathrm{L}$

Volume de ar: $1,0 \mu \mathrm{L}$

Velocidade do injetor: $100 \mu \mathrm{L} \mathrm{s}^{-1}$

Temperatura do forno: $70^{\circ} \mathrm{C}$ isoterma durante $0,6 \mathrm{~min}$; de $70^{\circ} \mathrm{C}$ a $110^{\circ} \mathrm{C}$ com $40^{\circ} \mathrm{C}$ $\min ^{-1}$; de $110^{\circ} \mathrm{C}$ a $172^{\circ} \mathrm{C}$ a $5^{\circ} \mathrm{C} \min ^{-1}$

Gás de arraste: Hélio

Temperatura do injetor: $250^{\circ} \mathrm{C}$

Modo do injetor: CT Splitless

Fluxo do Split: $16 \mathrm{~mL} \mathrm{~min}^{-1}$

Tempo do Splitless: 0,6 min

Fluxo constante: $3,3 \mathrm{~mL} \mathrm{~min}^{-1}$

Temperatura do detector: $250^{\circ} \mathrm{C}$

Fluxo do ar: $350 \mathrm{~mL} \mathrm{~min}^{-1}$

Fluxo do $\mathrm{H}_{2}: 35 \mathrm{~mL} \mathrm{~min}^{-1}$

Fluxo do make-up ou gás auxiliar: $30 \mathrm{~mL} \min ^{-1}$

A determinação do ácido lático se realizou por cromatografia gasosa segundo metodologia desenvolvida no VITO. Usou-se um cromatógrafo marca TRACE GC ${ }^{\circledR}$ equipado com FID, coluna AT-1 ${ }^{\circledR}(30 \mathrm{~m} \times 0,53 \mathrm{~mm} \times 5 \mu \mathrm{m})$ e sistema de injeção Combi PAL ${ }^{\circledR}$ com as seguintes características:

Ciclo: HS - Inj

Seringa: 2,5 mL HS

Volume de amostra: $750 \mu \mathrm{L}$

Temperatura da incubadora: $60^{\circ} \mathrm{C}$

Tempo da incubadora: $10 \mathrm{~min}$

Velocidade do agitador: 300 rpm

Agitador (on time): $5 \mathrm{~s}$

Agitador (off time): $2 \mathrm{~s}$

Temperatura da seringa: $50^{\circ} \mathrm{C}$

Velocidade de preenchimento: $1 \mathrm{~mL} \mathrm{~s}^{-1}$ 
Temperatura do forno: $30^{\circ} \mathrm{C}$ isoterma

Gás de arraste: Helium

Temperatura do injetor: $145^{\circ} \mathrm{C}$

Modo do injetor: CT Splitless

Fluxo do Split: $20 \mathrm{~mL} \min ^{-1}$

Pressão constante: $30 \mathrm{KPa}$

Temperatura do detector: $155^{\circ} \mathrm{C}$

Fluxo do ar: $350 \mathrm{~mL} \mathrm{\textrm {min } ^ { - 1 }}$

Fluxo do $\mathrm{H}_{2}: 35 \mathrm{~mL} \mathrm{~min}^{-1}$

Fluxo do make-up ou gás auxiliar: $30 \mathrm{~mL} \mathrm{~min}^{-1}$

A determinação dos álcoois (acetona, metanol, etanol, propanol e butanol) foi feita por cromatografia gasosa segundo metodologia desenvolvida no VITO. Usou-se um cromatógrafo marca FOCUS GC ${ }^{\circledR}$ equipado com FID, coluna AT WAX ${ }^{\circledR}(60 \mathrm{~m} \times 0,32 \mathrm{~mm} \times 1,0 \mu \mathrm{m}) \mathrm{e}$ sistema de injeção Combi PAL® com as seguintes características:

Ciclo: HS - Inj

Seringa: 2,5 mL HS

Volume de amostra: $750 \mu \mathrm{L}$

Temperatura da incubadora: $60^{\circ} \mathrm{C}$

Tempo da incubadora: $10 \mathrm{~min}$

Velocidade do agitador: $300 \mathrm{rpm}$

Agitador (on time): $5 \mathrm{~s}$

Agitador (off time): $2 \mathrm{~s}$

Temperatura da seringa: $70^{\circ} \mathrm{C}$

Velocidade de preenchimento: $1 \mathrm{~mL} \mathrm{~s}^{-1}$

Temperatura do forno: $40^{\circ} \mathrm{C}$ a $3^{\circ} \mathrm{C} \mathrm{min}^{-1}$

Gás de arraste: Helium

Temperatura do injetor: $145^{\circ} \mathrm{C}$

Modo do injetor: CT Split

Fluxo do Split: $10 \mathrm{~mL} \mathrm{~min}^{-1}$

Fluxo constante: $1,6 \mathrm{~mL} \mathrm{~min}{ }^{-1}$

Temperatura do detector: $200^{\circ} \mathrm{C}$

Fluxo do ar: $350 \mathrm{~mL} \mathrm{~min}^{-1}$

Fluxo do $\mathrm{H}_{2}: 35 \mathrm{~mL} \mathrm{~min}^{-1}$ 
Fluxo do make-up ou gás auxiliar: $30 \mathrm{~mL} \mathrm{~min}^{-1}$

\subsubsection{Análises e frequência das análises}

$\mathrm{Na}$ Tabela 4 são apresentadas as análises realizadas durante o desenvolvimento experimental, tipo de amostra, método e frequência.

Tabela 4 - Análises realizadas durante o tempo experimental e a frequência

\begin{tabular}{|c|c|c|c|c|}
\hline Parâmetro & Estratégia & Amostra & Método & Frequência \\
\hline Vazão de biogás & $\begin{array}{c}1,2,3,4 \mathrm{e} \\
5\end{array}$ & Biogás & $\begin{array}{l}\text { Volumétrico (Medidor } \\
\text { de vazão) }\end{array}$ & $\begin{array}{l}4 \text { vezes por } \\
\text { semana }\end{array}$ \\
\hline $\begin{array}{l}\text { Composição do } \\
\text { biogás }\end{array}$ & $2,3,4$ & Biogás & $\begin{array}{c}\text { GC }^{*} \\
(\text { LPB-EESC-USP) }\end{array}$ & $\begin{array}{l}2 \text { vezes por } \\
\text { semana }\end{array}$ \\
\hline $\begin{array}{l}\text { Composição do } \\
\text { biogás }\end{array}$ & 5 & Biogás & $\begin{array}{c}\mathrm{GC} \\
(\mathrm{VITO})\end{array}$ & $\begin{array}{l}2 \text { vezes por } \\
\text { semana }\end{array}$ \\
\hline Sacarose & $2,3,4$ e 5 & $\begin{array}{l}\text { Líquido afluente e } \\
\text { efluente }\end{array}$ & $\begin{array}{l}\text { Dubois, Gilles, et al., } \\
\text { (1956) }\end{array}$ & $\begin{array}{l}4 \text { vezes por } \\
\text { semana }\end{array}$ \\
\hline $\mathrm{pH}$ & $2,3,4$ e 5 & $\begin{array}{l}\text { Líquido afluente e } \\
\text { efluente }\end{array}$ & potenciométrico & $\begin{array}{l}4 \text { vezes por } \\
\text { semana }\end{array}$ \\
\hline $\begin{array}{l}\text { Demanda química de } \\
\text { oxigênio (DQO) }\end{array}$ & 2,3 e 4 & Líquido efluente & APHA (2005) & $\begin{array}{l}2 \text { vezes por } \\
\text { semana }\end{array}$ \\
\hline $\begin{array}{l}\text { Demanda química de } \\
\text { oxigênio (DQO) }\end{array}$ & 5 & Líquido efluente & $\begin{array}{c}\text { Kit HACH }{ }^{\circledR} \\
(\text { JIRKA e CARYER, } \\
1975)\end{array}$ & $\begin{array}{l}2 \text { vezes por } \\
\text { semana }\end{array}$ \\
\hline $\begin{array}{l}\text { Ácidos graxos } \\
\text { voláteis (AGV) }\end{array}$ & $2,3,4$ & Líquido efluente & $\begin{array}{c}\text { GC } \\
\text { (LPB-EESC-USP) }\end{array}$ & $\begin{array}{l}2 \text { vezes por } \\
\text { semana }\end{array}$ \\
\hline $\begin{array}{l}\text { Ácidos graxos } \\
\text { voláteis (AGV) }\end{array}$ & 5 & Líquido efluente & $\begin{array}{c}\mathrm{GC} \\
(\mathrm{VITO})\end{array}$ & $\begin{array}{l}2 \text { vezes por } \\
\text { semana }\end{array}$ \\
\hline Ácido lático & 5 & Líquido efluente & $\begin{array}{c}\text { GC } \\
(\mathrm{VITO})\end{array}$ & $\begin{array}{l}2 \text { vezes por } \\
\text { semana }\end{array}$ \\
\hline Álcoois & $2,3,4$ & Líquido efluente & $\begin{array}{c}\text { GC } \\
\text { (LPB-EESC-USP) }\end{array}$ & $\begin{array}{l}2 \text { vezes por } \\
\text { semana }\end{array}$ \\
\hline Álcoois & 5 & Líquido efluente & $\begin{array}{c}\text { GC } \\
(\mathrm{VITO})\end{array}$ & $\begin{array}{l}2 \text { vezes por } \\
\text { semana }\end{array}$ \\
\hline $\begin{array}{l}\text { Sólidos suspensos } \\
\text { voláteis (SSV) }\end{array}$ & $2,3,4$ e 5 & Líquido efluente & APHA (2005) & $\begin{array}{l}2 \text { vezes por } \\
\text { semana }\end{array}$ \\
\hline $\begin{array}{l}\text { Sólidos voláteis totais } \\
\text { (SVT) }\end{array}$ & 2 & $\begin{array}{l}\text { Biomassa do fundo } \\
\text { dos reatores }\end{array}$ & APHA (2005) & $\begin{array}{l}\text { A cada } 20 \\
\text { dias }\end{array}$ \\
\hline $\begin{array}{l}\text { Sólidos voláteis totais } \\
\text { (SVT) }\end{array}$ & $2,3,4$ e 5 & $\begin{array}{l}\text { Biomassa suspensa e } \\
\text { aderida ao leito }\end{array}$ & APHA (2005) & $\begin{array}{l}\text { Final da } \\
\text { operaçãao }\end{array}$ \\
\hline Sólidos totais (ST) & $2,3,4$ e 5 & Material suporte & APHA (2005) & $\begin{array}{l}\text { Final da } \\
\text { operação }\end{array}$ \\
\hline
\end{tabular}




\subsection{Cálculos}

A partir dos resultados das análises descritas anteriormente, utilizou-se o Microsoft Excel $^{\circledR}$ como ferramenta para realizar os cálculos dos valores máximos, médios e desvio padrão do desempenho geral do reator, produção de hidrogênio, COVe e balanço de carbono.

\subsubsection{Desempenho do reator e produção de hidrogênio}

Vazão de líquido no reator $(Q)$ em $\mathrm{L} \mathrm{h}^{-1}$ :

$$
Q=\frac{V_{u}}{T D H}
$$

\section{Equação 9}

Na qual, $V_{u}$ o volume útil do reator em L e TDH o tempo de detenção hidráulica teórico aplicado em $\mathrm{h}$.

Eficiência de conversão de sacarose $\left(E_{s}\right)$ em \%:

$$
E_{S}=\frac{\left(C s_{0}-C s\right)}{C s_{0}} \cdot 100 \%
$$

Na qual, $C s_{0}$ é a concentração de sacarose afluente em $\mathrm{mg} \mathrm{L}^{-1}$ e $C s$ a concentração de sacarose efluente em $\mathrm{mg} \mathrm{L}^{-1}$.

Velocidade de conversão de sacarose $\left(v_{S}\right)$ em $\mathrm{mmol} \mathrm{h}^{-1}$ :

$$
v_{S}=\frac{Q \cdot\left(C s_{0}-C s\right)}{M M_{S}}
$$

Equação 11

Na qual, $M M_{S}$ é a massa molar da sacarose.

Vazão de biogás $\left(Q_{\text {biogás }}\right)$ em $\mathrm{mL} \mathrm{h}^{-1}$ :

$$
Q_{\text {biogás }}=\frac{V_{m} \cdot F_{m}}{t}
$$


Na qual, $V_{m}$ é o volume de gás marcado pelo medidor, $F_{m}$ é o fator de calibração do medidor obtido por calibração com bolhômetro padrão e $t$ é o tempo da medida.

Distribuição percentual de hidrogênio $\left(\%_{\mathrm{H}_{2}}\right)$, dióxido de carbono $\left(\%_{\mathrm{CO}_{2}}\right)$, nitrogênio $\left(\%_{N_{2}}\right)$ e metano $\left(\%_{C_{4}}\right)$ no biogás:

$$
\begin{gathered}
\%_{\mathrm{H}_{2}}=\frac{n_{\mathrm{H}_{2}}}{n} \\
\%_{\mathrm{CO}_{2}}=\frac{n_{\mathrm{CO}_{2}}}{n} \\
\%_{\mathrm{N}_{2}}=\frac{n_{\mathrm{N}_{2}}}{n} \\
\%_{\mathrm{CH}_{4}}=\frac{n_{\mathrm{CH}_{4}}}{n}
\end{gathered}
$$

Equação 15

Equação 16

Na qual, $n_{\mathrm{H}_{2}}, n_{\mathrm{CO}_{2}}, n_{\mathrm{N}_{2}}$ e $n_{\mathrm{CH}_{4}}$ correspondem ao número de mols de cada um dos gases contidos no biogás: hidrogênio, dióxido de carbono, nitrogênio e metano, respectivamente. Esse conteúdo foi medido por cromatografia e calculado pelas curvas de calibração do cromatógrafo. $\mathrm{O}$ valor de $n$ corresponde ao número de mols totais na amostra de gás injetado, calculado usando a equação dos gases ideais (Equação 17).

$$
n=\frac{P \cdot V_{i}}{R \cdot T}
$$

Equação 17

Na qual, $P$ é a pressão de gás em atm, $V_{i}$ o volume de gás injetado em $\mathrm{mL}, R$ a constante universal dos gases ideais e $T$ a temperatura absoluta. Nesse trabalho a pressão foi de $1 \mathrm{~atm}$ e a temperatura de $25^{\circ} \mathrm{C}$ (temperatura absoluta $=298 \mathrm{~K}$ ).

Vazão molar de hidrogênio $\left(v_{H_{2}}\right)$ em $\mathrm{mmol} \mathrm{h}^{-1}$ :

$$
v_{H_{2}}=\frac{Q_{\text {biogás }} \cdot n_{H_{2}}}{V_{i}}
$$


Rendimento de hidrogênio $\left(Y_{\mathrm{H}_{2}}\right)$ em mol H $\operatorname{mol}^{-1}{ }_{\text {sc }}$ :

$$
Y_{H_{2}}=\frac{v_{H_{2}}}{v_{S}}
$$

Produção volumétrica de hidrogênio $(P V H)$ em $\mathrm{L} \mathrm{H}_{2} \mathrm{~L}^{-1} \mathrm{~d}^{-1}$ :

$$
P V H=\frac{Q_{\text {biogás }} \cdot \%_{H_{2}}}{V_{u}} \cdot \frac{24}{1000}
$$

Na qual, $\frac{24}{1000}$ é o fator de conversão de unidades.

\subsubsection{Carga orgânica volumétrica específica (COVe)}

A COVe é definida como a carga orgânica volumétrica aplicada (COV) por uma quantidade de biomassa por tempo ( $\mathrm{g}$ substrato $\mathrm{g}^{-1} \mathrm{SSV} \mathrm{d}^{-1}$ ). Neste trabalho, para o cálculo da COVe em um determinado tempo foi necessário estimar a quantidade de biomassa presente no reator. No intuito de aferir o coeficiente de rendimento celular $\left(Y x_{/ s}\right)$, ao final de cada operação, realizou-se a medida de biomassa total produzida e o total de substrato consumido. Assim, o cálculo do $Y x / s$ se realizou mediante a Equação 21.

$$
Y x / s=\frac{x_{t}}{s_{c}}
$$

\section{Equação 21}

Sendo

$$
x_{t}=x_{a}+x_{s}+x_{e}+x_{d}
$$

Na qual $Y x / s$ é o coeficiente de rendimento celular em g SSV g ${ }^{-1}$ sacarose consumida ( $\left.\mathrm{g} \mathrm{SSV} \mathrm{g}^{-1}{ }_{\mathrm{sc}}\right) ; x_{t}$ é a quantidade de SSV total produzido durante o tempo de operação em $\mathrm{g} ; x_{a}$ é a quantidade de SSV aderidos e intersticiais no material suporte ao final da operação em g; $x_{s}$ é a quantidade de SSV do líquido drenado do reator ao final da operação em g; $x_{e}$ é o total de SSV no efluente líquido durante o período experimental em g; $x_{d}$ é a quantidade de SSV dos descartes realizados do fundo do reator em g e $s_{c}$ é o total de substrato consumido durante o período experimental em $\mathrm{g}$. 
Para o cálculo do $x_{a}$, no final de cada operação após a drenagem, parte do leito foi retirada e lavada com aproximadamente $150 \mathrm{~mL}$ de água destilada. A solução de lavagem foi acondicionada em estufa por $24 \mathrm{~h}$ a $105^{\circ} \mathrm{C}$ e depois em mufla por $0,5 \mathrm{~h}$ a $550{ }^{\circ} \mathrm{C}$ para calcular os SSV. O material suporte foi seco em uma câmara de aquecimento a $55^{\circ} \mathrm{C}$ por $48 \mathrm{~h}$. A razão entre os SSV do líquido da lavagem e o peso do material suporte seco multiplicado pelo peso total do material suporte do leito corresponde ao valor do $x_{a}$.

$x_{e}$ foi determinado por meio da integral da vazão mássica da biomassa de arraste em função do tempo segundo a Equação 23.

$$
x_{e}=\int_{0}^{t} \dot{w}_{x} \cdot d t
$$

$\mathrm{Na}$ qual $\dot{w}_{x}$ é a vazão mássica da biomassa de arraste em $\mathrm{g} \mathrm{SSV} \mathrm{h}^{-1}$, que correspondente à concentração de SSV saindo no efluente líquido pela vazão conforme a Equação 24.

$$
\dot{w}_{x}=S S V_{e} \cdot Q
$$

\section{Equação 24}

Na qual $S S V_{e}$ é a concentração de sólidos suspensos voláteis no efluente em $\mathrm{g} \mathrm{L}^{-1}$ e $Q$ é a vazão do líquido em $\mathrm{L} \mathrm{h}^{-1}$. Do mesmo modo, estimou-se o $s_{c}$ por meio da integral do substrato consumido em função do tempo segundo a Equação 25.

$$
s_{c}=\int_{0}^{t} Q_{s} \cdot d t
$$

Equação 25

Na qual $Q_{S}$ em $\mathrm{g} \mathrm{h}^{-1}$ é a concentração de substrato consumido pela vazão do líquido calculada conforme a Equação 26.

$$
Q_{s}=Q \cdot\left(C s_{0}-C s\right)
$$

\section{Equação 26}

Após o calculo do $Y x / s$, estimou-se a vazão mássica de biomassa produzida $\left(Q_{\dot{w}}\right)$ em g $\mathrm{SSV} \mathrm{h}^{-1}$ por meio da Equação 27. 


$$
Q_{\dot{w}}=Q_{s} \cdot Y_{x / s}
$$

Equação 27

Desta forma, a estimativa da biomassa dentro do reator em um determinado tempo foi dada pela Equação 28 quando não houve descartes de biomassa.

$$
x_{n}=\left[\frac{Q_{\dot{w}} \Delta t}{V_{u}} \cdot\left(\frac{x_{a}+x_{s}}{x_{t}}\right)\right]+x_{n-1}
$$

Equação 28

Na qual $x_{n}$ é a concentração de biomassa em um determinado tempo em g SSV L ${ }^{-1} \mathrm{e}$ $x_{n-1}$ é a concentração de biomassa no tempo menos um. Quando o reator foi operado com descartes de biomassa o $x_{n}$ foi calculado pela Equação 29 .

$$
x_{n}=\left[\frac{Q_{\dot{w}} \Delta t}{V_{u}} \cdot\left(\frac{x_{a}+x_{s}+x_{d}}{x_{t}}\right)\right]+x_{n-1}-\frac{d}{V_{u}}
$$

Na qual, $d$ em g SSV corresponde à quantidade de sólidos suspensos voláteis descartada do fundo do reator. No tempo igual a zero, o $x_{n}$ foi estimado pela Equação 30 .

$$
x_{0}=\frac{C s_{0} \cdot Y x / s}{V_{u}}
$$

Na qual $V_{\text {in }}$ é o volume em L da sustância preparada para iniciar a inoculação natural. Neste trabalho, prepararam-se $45 \mathrm{~L}$ de substrato por cada reator. Assim, a COVe em um determinado tempo em g sacarose $\mathrm{g}^{-1} \mathrm{SSV} \mathrm{d}^{-1}$ se calculou como a carga orgânica volumétrica aplicada (COV) em g sacarose $\mathrm{L}^{-1} \mathrm{~h}^{-1}$ dividido pelo $x_{n}$ segundo Equação 31 .

$$
\text { COVe }=\frac{\operatorname{COV}}{x_{n}} \cdot 24
$$

\section{Equação 31}

\subsubsection{Reações químicas e balanço de carbono}

O balanço de carbono foi realizado com base na DQO afluente e efluente como forma de avaliar se os compostos gerados no reator acidogênico estavam sendo quantificados 
adequadamente e para garantir a consistência dos dados obtidos, conforme Equação 32 e Equação 33:

$$
\begin{array}{cc}
D Q O_{a f}=D Q O_{e f} & \text { Equação 32 } \\
D Q O_{e f}=D Q O_{t(P S F)}+D Q O_{x}+D Q O_{S E}+D Q O_{H_{2}} & \text { Equação 33 }
\end{array}
$$

Na qual $D Q O_{a f}$ corresponde à DQO afluente; $D Q O_{e f}$ à DQO efluente; $D Q O_{t(P S F)}$ à DQO teórica dos produtos solúveis da fermentação calculados conforme a Reação 4 à Reação 12; $D Q O_{x}$ à DQO da biomassa, igual ao substrato consumido pelo $Y_{x / s} ; D Q O_{S E}$ à DQO da sacarose efluente conforme Reação 13 e $D_{Q} O_{H_{2}}$ à DQO envolvida na produção de hidrogênio conforme Reação 14.

Ácido acético

$$
\begin{gathered}
\mathrm{C}_{2} \mathrm{H}_{4} \mathrm{O}_{2}+2 \mathrm{O}_{2} \rightarrow 2 \mathrm{CO}_{2}+2 \mathrm{H}_{2} \mathrm{O} \\
\mathrm{DQO}_{\mathrm{t}}=1,07 \mathrm{~g} \mathrm{O}_{2} \mathrm{~g}^{-1} \text { ácido acético }
\end{gathered}
$$

Reação 4

Ácido butírico

$$
\begin{gathered}
\mathrm{C}_{4} \mathrm{H}_{8} \mathrm{O}_{2}+5 \mathrm{O}_{2} \rightarrow 4 \mathrm{CO}_{2}+4 \mathrm{H}_{2} \mathrm{O} \\
\mathrm{DQO}_{\mathrm{t}}=1,82 \mathrm{~g} \mathrm{O}_{2} \mathrm{~g}^{-1} \text { ácido butírico }
\end{gathered}
$$

Reação 5

Ácido propiônico

$$
\begin{gathered}
\mathrm{C}_{3} \mathrm{H}_{6} \mathrm{O}_{2}+\frac{7}{2} \mathrm{O}_{2} \rightarrow 3 \mathrm{CO}_{2}+3 \mathrm{H}_{2} \mathrm{O} \\
\mathrm{DQO}_{\mathrm{t}}=1,51 \mathrm{~g} \mathrm{O}_{2} \mathrm{~g}^{-1} \text { ácido propiônico }
\end{gathered}
$$

Reação 6

Ácido valérico/isovalérico

$$
\begin{gathered}
\mathrm{C}_{5} \mathrm{H}_{10} \mathrm{O}_{2}+\frac{13}{2} \mathrm{O}_{2} \rightarrow 5 \mathrm{CO}_{2}+5 \mathrm{H}_{2} \mathrm{O} \\
\mathrm{DQO}_{\mathrm{t}}=2,04 \mathrm{~g} \mathrm{O}_{2} \mathrm{~g}^{-1} \text { ácido valérico/isovalérico }
\end{gathered}
$$

Ácido capróico

$$
\begin{gathered}
\mathrm{C}_{6} \mathrm{H}_{12} \mathrm{O}_{2}+8 \mathrm{O}_{2} \rightarrow 6 \mathrm{CO}_{2}+6 \mathrm{H}_{2} \mathrm{O} \\
\mathrm{DQO}_{\mathrm{t}}=2,21 \mathrm{~g} \mathrm{O}_{2} \mathrm{~g}^{-1} \text { ácido capróico }
\end{gathered}
$$


Ácido lático

$$
\begin{gathered}
\mathrm{C}_{3} \mathrm{H}_{6} \mathrm{O}_{3}+3 \mathrm{O}_{2} \rightarrow 3 \mathrm{CO}_{2}+3 \mathrm{H}_{2} \mathrm{O} \\
\mathrm{DQO}_{\mathrm{t}}=1,07 \mathrm{~g} \mathrm{O}_{2} \mathrm{~g}^{-1} \text { ácido lático }
\end{gathered}
$$

Reação 9

Etanol

$$
\begin{gathered}
\mathrm{C}_{6} \mathrm{H}_{2} \mathrm{O}+2 \mathrm{O}_{2} \rightarrow 2 \mathrm{CO}_{2}+3 \mathrm{H}_{2} \mathrm{O} \\
\mathrm{DQO}_{\mathrm{t}}=1,39 \mathrm{~g} \mathrm{O}_{2} \mathrm{~g}^{-1} \text { etanol }
\end{gathered}
$$

Reação 10

Butanol

$$
\begin{gathered}
\mathrm{C}_{4} \mathrm{H}_{10} \mathrm{O}+6 \mathrm{O}_{2} \rightarrow 4 \mathrm{CO}_{2}+5 \mathrm{H}_{2} \mathrm{O} \\
\mathrm{DQO}_{\mathrm{t}}=2,59 \mathrm{~g} \mathrm{O}_{2} \mathrm{~g}^{-1} \text { butanol }
\end{gathered}
$$

Reação 11

Propanol

$$
\begin{aligned}
& \mathrm{C}_{3} \mathrm{H}_{8} \mathrm{O}+\frac{9}{2} \mathrm{O}_{2} \rightarrow 3 \mathrm{CO}_{2}+4 \mathrm{H}_{2} \mathrm{O} \\
& \mathrm{DQO}_{\mathrm{t}}=2,40 \mathrm{~g} \mathrm{O}_{2} \mathrm{~g}^{-1} \text { propanol }
\end{aligned}
$$

Reação 12

Sacarose

$$
\begin{gathered}
\mathrm{C}_{12} \mathrm{H}_{22} \mathrm{O}_{11}+12 \mathrm{O}_{2} \rightarrow 12 \mathrm{CO}_{2}+11 \mathrm{H}_{2} \mathrm{O} \\
\mathrm{DQO}_{\mathrm{t}}=1,12 \mathrm{~g} \mathrm{O}_{2} \mathrm{~g}^{-1} \text { sacarose }
\end{gathered}
$$

Reação 13

Hidrogênio

$$
\begin{gathered}
2 \mathrm{H}_{2}+\mathrm{O}_{2} \rightarrow 2 \mathrm{H}_{2} \mathrm{O} \\
\mathrm{DQO}_{\mathrm{H}_{2}}=8 \mathrm{~g} \mathrm{O}_{2} \mathrm{~g}^{-1} \text { hidrogênio }
\end{gathered}
$$

Reação 14 


\section{RESULTADOS E DISCUSSÃO}

Neste capítulo são apresentados os resultados e discussão referentes às cinco estratégias propostas neste trabalho conforme exposto na Figura 6. No desenvolvimento experimental de cada estratégia, realizou-se o monitoramento dos parâmetros descritos na Tabela 4, visando avaliar principalmente a produção de hidrogénio ao longo do tempo.

\subsection{Estratégia 1 - Reator anaeróbio de leito empacotado e escoamento descendente}

\subsubsection{Produção de hidrogênio}

Os reatores anaeróbios de leito empacotado e escoamento descendente foram operados continuamente por 10 dias com TDH teórico de $2 \mathrm{~h}$ e temperatura controlada de $25^{\circ} \mathrm{C}$. A montagem experimental é apresentada na Figura 10.

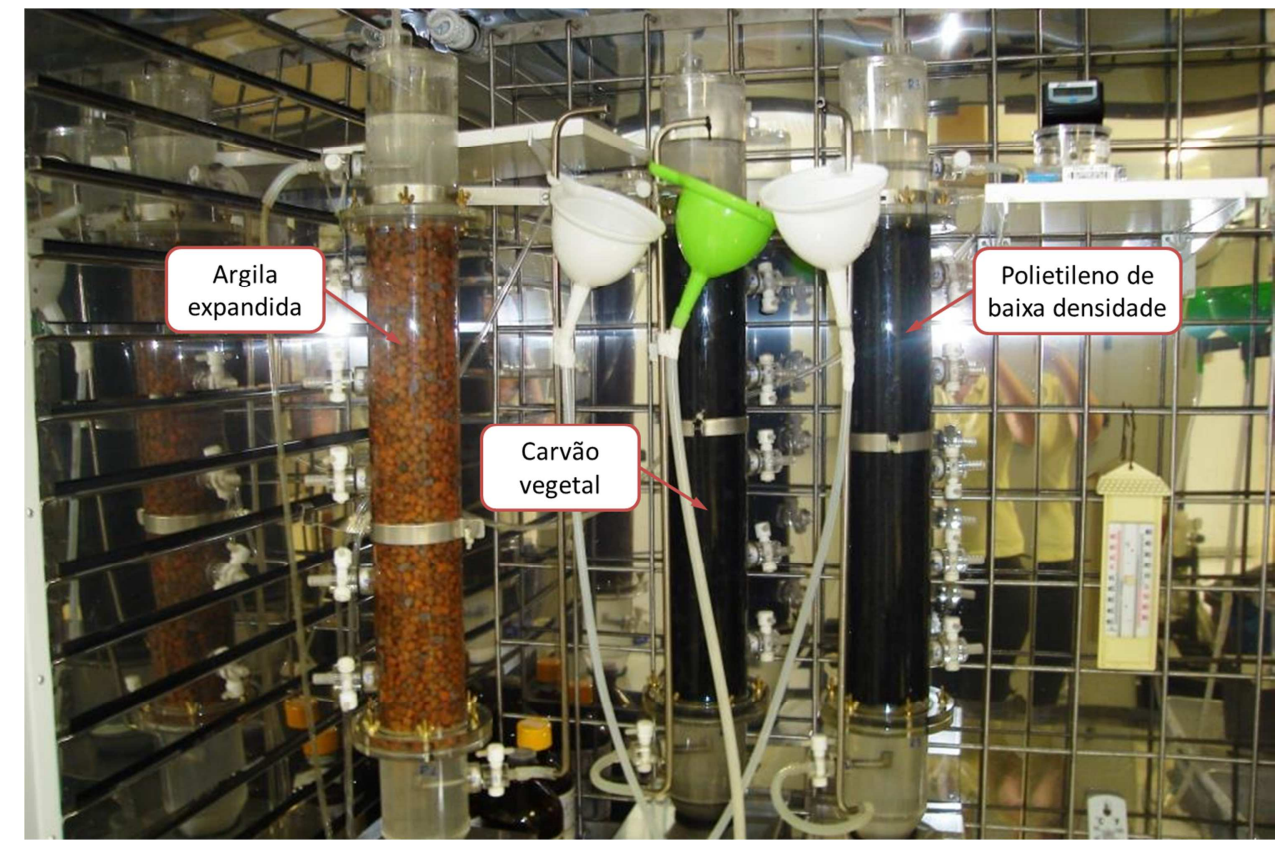

Figura 10 - Montagem experimental dos reatores de leito empacotado

Observou-se produção de biogás nos três reatores. Porém, houve impossibilidade física de quantificação e análise da composição, uma vez que o biogás ficou retido nos espaços intersticiais do leito independentemente do material suporte utilizado. Esse fenômeno foi observado nos três reatores. O biogás foi acumulando até formar uma bolha do tamanho do leito, que causou a diminuição do volume líquido do reator. O problema poderia estar associado à porosidade ou a anomalias no padrão do escoamento dos leitos. 


\subsubsection{Porosidade e ensaios hidrodinâmicos}

Calculou-se a porosidade do leito conforme o método descrito no item 4.5.1. e realizaram-se os ensaios hidrodinâmicos conforme descrito no item 4.5.2. As curvas de concentração em função do tempo são exibidas na Figura 11 e na Tabela 5 os valores encontrados do TDH real e o N.

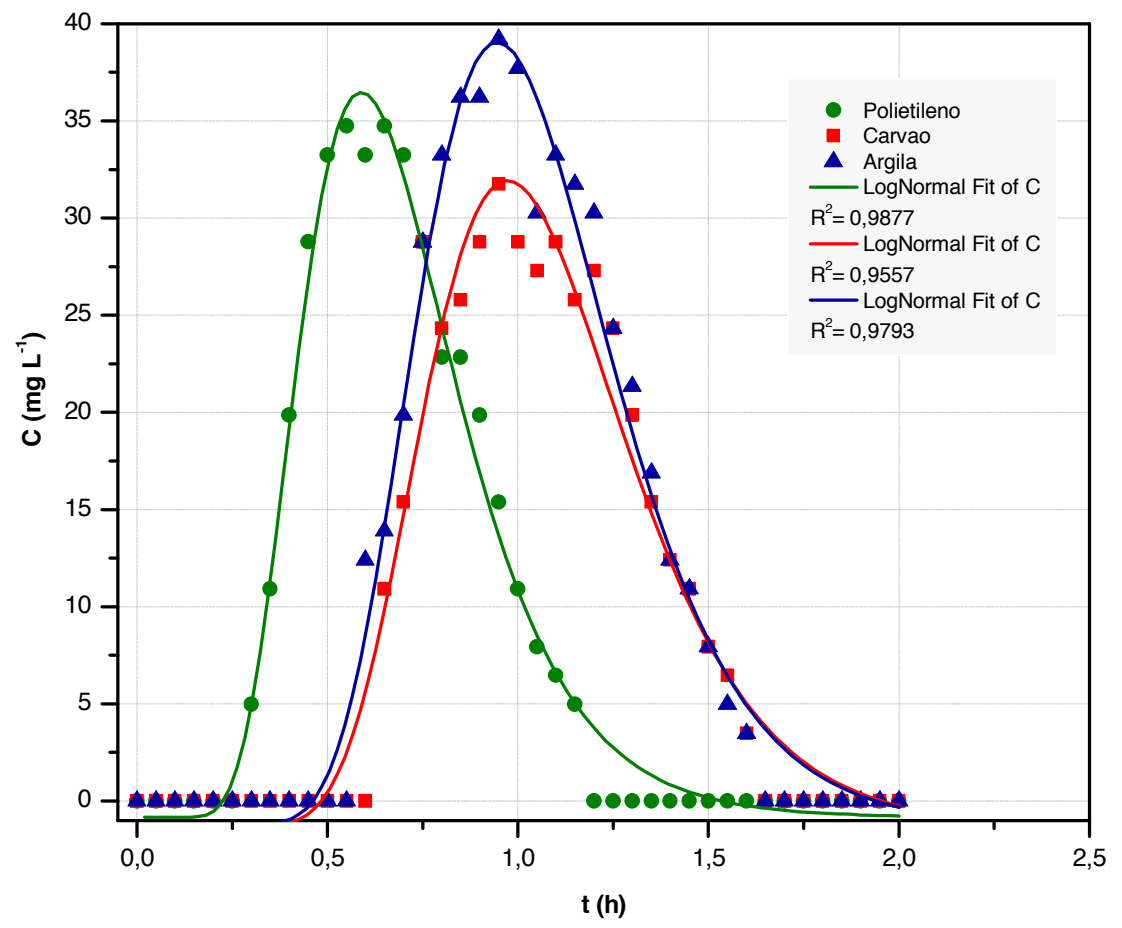

Figura 11- Concentração de dextrana em função do tempo em reatores com leito empacotado livres de biomassa. Leitos: (๑) polietileno de baixa densidade ( $\square$ ) carvão vegetal $(\Delta)$ argila expandia

Tabela 5 - Resultados dos ensaios hidrodinâmicos e porosidade dos leitos empacotados

\begin{tabular}{cccc}
\hline Leito & $\begin{array}{c}\text { Porosidade do leito } \\
(\boldsymbol{\%})\end{array}$ & $\begin{array}{c}\text { TDH real } \\
(\mathbf{h})\end{array}$ & $\begin{array}{c}\mathbf{N} \\
\text { (reatores em serie) }\end{array}$ \\
\hline $\begin{array}{c}\text { Polietileno de baixa } \\
\text { densidade }\end{array}$ & 54 & 0,68 & 16 \\
Carvão vegetal & 48 & 1,09 & 24 \\
Argila expandida & 42 & 1,05 & 21 \\
\hline
\end{tabular}

Ainda que os ensaios hidrodinâmicos demonstrassem que o escoamento se aproximou mais ao ideal pistonado, os baixos valores do TDH real comparado com o TDH teórico indicaram severas anomalias no padrão do escoamento, como zonas mortas ou caminhos preferenciais (LEVENSPIEL, 2000). A baixa porosidade dos leitos poderia ter causado essas anomalias e dificultado a saída do biogás contracorrente do líquido afluente, tornando inviável 
a utilização do reator de leito empacotado e escoamento descendente para produção de hidrogênio.

\subsubsection{Conclusões parciais - Estratégia 1}

Os resultados observados nesta estratégia invalidaram, em parte, a sub-hipótese 1 deste trabalho, referente à inversão do escoamento em reatores de leito fixo empacotado, não tendo sido possível a produção de hidrogênio neste tipo de reator nas condições ensaiadas.

A produção de hidrogênio é inviável em reatores de leito empacotado e escoamento descendente, usando como material suporte polietileno de baixa densidade, carvão vegetal e argila expandida, uma vez que a baixa porosidade dos leitos impede a saída do biogás produzido, impossibilitando a quantificação e análise. 


\subsection{Estratégia 2 - Reator anaeróbio de leito ordenado e escoamento descendente}

\subsubsection{Porosidade e ensaios hidrodinâmicos}

Inicialmente, realizou-se o ensaio de porosidade conforme o item 4.5.1. As porosidades aferidas foram $85 \%$ no leito de polietileno de baixa densidade (polietileno), $70 \%$ no leito de espuma de poliuretano (espuma) e $72 \%$ no leito de cerâmica. Desta forma, comprovou-se que a ordenação do leito aumentou a porosidade em aproximadamente $28 \%$, se comparado com os reatores de leito empacotado.

A seguir, com os reatores livres de biomassa e utilizando cloreto de sódio como traçador foram realizados os ensaios hidrodinâmicos conforme o item 4.5.3. A Figura 12 apresenta as curvas-resposta ao estímulo degrau nos três reatores. Com o auxílio do programa OriginPro $8.0^{\circledR}$, estes dados se normalizaram pelo ajuste sigmoidal de Boltzmann e se traçaram-se as curvas E conforme Figura 13.

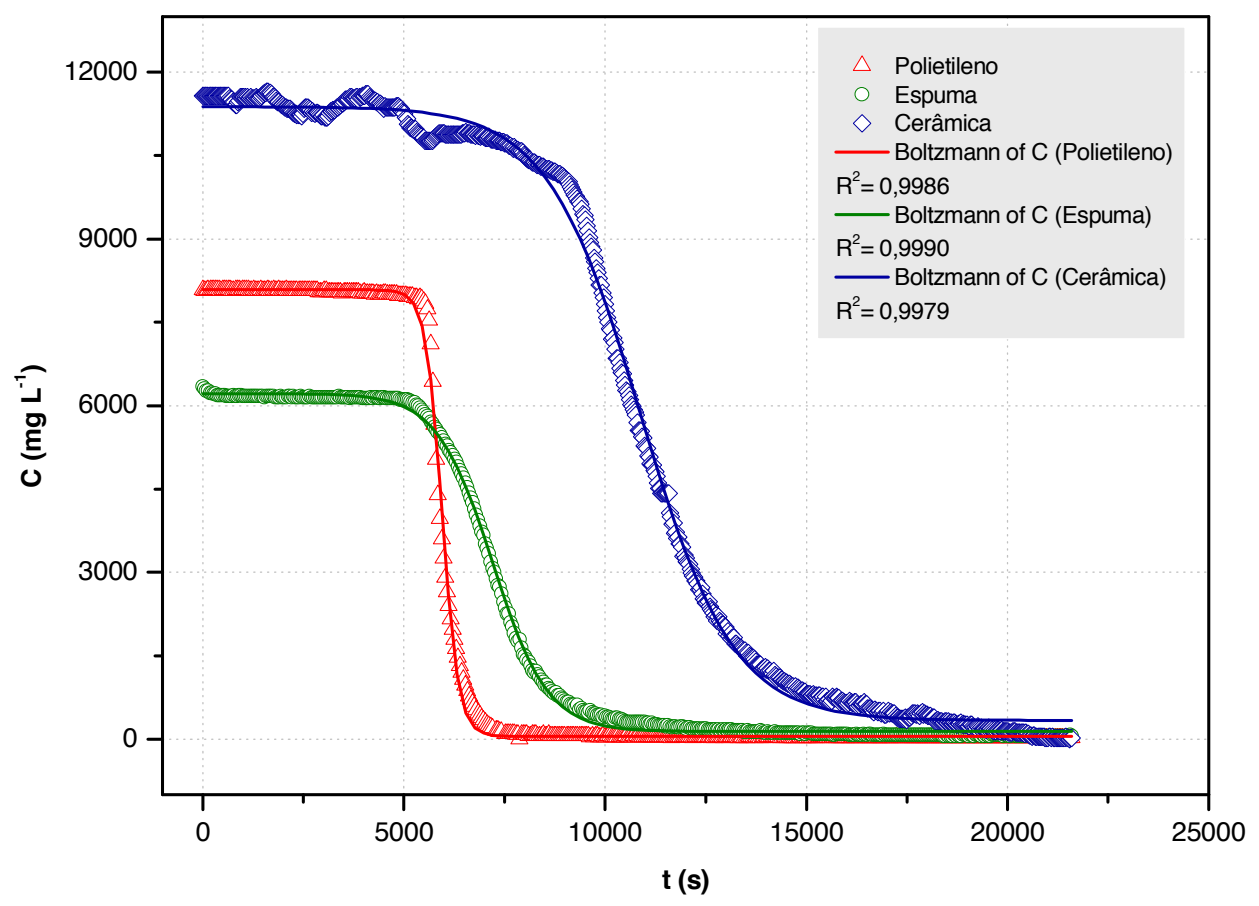

Figura 12 - Resposta ao estímulo degrau em reatores com leito ordenado livres de biomassa. Concentração $(\mathbf{C})$ em relação ao tempo $(t) ;(\triangle)$ Leito de polietileno; $(O)$ Leito de espuma; $(\diamond)$ leito de cerâmica

O TDH médio e o padrão de escoamento foram calculados a partir das curvas $\mathrm{E}$ conforme Tabela 6. Observa-se que só no caso do reator com leito de espuma, o TDH real coincidiu com o TDH teórico. Com leito de polietileno, o TDH real foi menor em relação ao leito de espuma e cerâmica, fato que foi atribuído à porosidade nula deste material e 
provavelmente à presença de caminhos preferenciais. Contrariamente, a porosidade própria da cerâmica poderia ter ocasionado difusão do traçador atrasando a saída do mesmo, o que foi refletido no atraso do TDH real (JIMENEZ, NOYOLA, et al., 1988). O elevado número $\mathrm{N}$ em todos os reatores indicou que o padrão de escoamento se aproximou mais ao pistonado ideal (LEVENSPIEL, 2000).

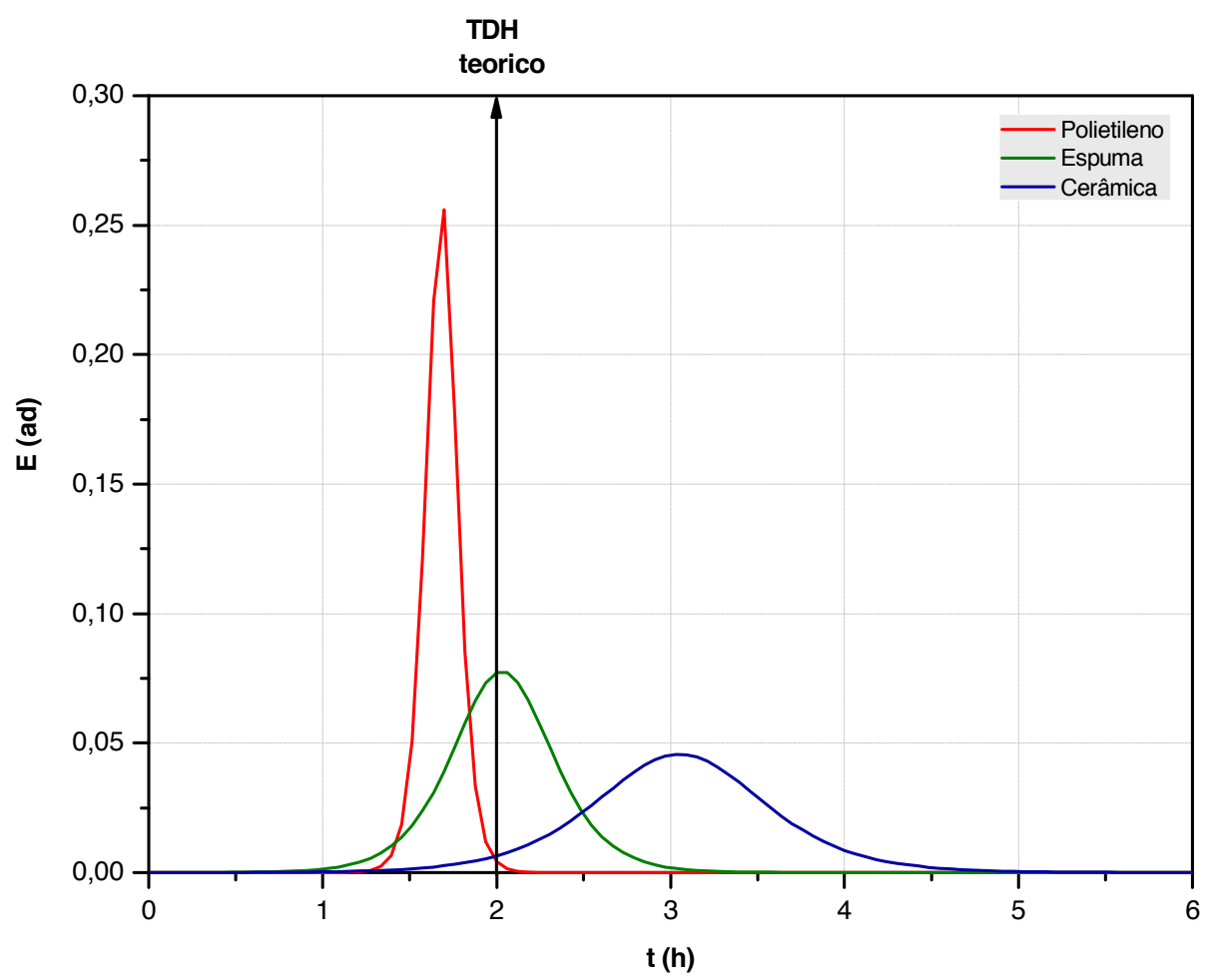

Figura 13 - Curva E em reator anaeróbio de leito ordenado e escoamento descendente livre de biomassa (-) leito de polietileno; (-) leito de espuma; (-) leito de cerâmica.

Tabela 6 - TDH médio e padrão de escoamento em reatores de leito ordenado e escoamento descendente

\begin{tabular}{ccc}
\hline Leito & $\begin{array}{c}\text { TDH real } \\
(\mathbf{h})\end{array}$ & $\begin{array}{c}\text { N } \\
\text { (reatores em serie) }\end{array}$ \\
\hline Polietileno & 1,71 & 503 \\
Espuma & 2,12 & 72 \\
Cerâmica & 3,14 & 59 \\
\hline
\end{tabular}

Dessa forma, se comparados os TDH reais dos reatores de leito ordenado com os reatores de leito empacotado, é possível observar que houve uma notável diminuição das anomalias no padrão de escoamento quando os leitos foram ordenados, principalmente usando polietileno e espuma como material suporte. 


\subsubsection{Desempenho dos reatores operados com e sem descarte de biomassa}

Em ambos os estágios, com e sem descartes de biomassa, a ordenação dos leitos e o escoamento descendente mostraram ser viáveis para a produção de biogás conforme apresentado na Figura 14. No primeiro estágio, os reatores foram operados continuamente durante 120 dias realizando descartes de biomassa a cada 20 dias. No segundo estágio, a operação foi contínua durante 90 dias sem realizar descartes de biomassa.

Com e sem descartes, a produção máxima de biogás ocorreu durante os primeiros 40 dias nos reatores com leito de polietileno e espuma (Figura 14a e Figura 14b, respectivamente). Após esse período, a produção diminuiu até aproximadamente um terço do ponto máximo e se manteve contínua até o final com um desvio padrão próximo de $45 \%$.

Já no reator com leito de cerâmica, a produção máxima ocorreu durante os primeiros 20 dias em ambas as operações. No entanto, após esse período com descartes de biomassa a produção diminuiu quase $65 \%$ do ponto máximo e se manteve até o final da operação com um desvio padrão de 55\%. Neste reator, quando operado sem descartes, a produção de biogás cessou completamente por volta do quinquagésimo dia de operação (Figura 14c).

A partir dessas observações iniciais, o tempo experimental foi dividido em fase transiente e fase de estabilidade. A fase transiente nos reatores com leito de polietileno e espuma corresponde aos primeiros quarenta dias de operação e com leito de cerâmica a os primeiros vinte dias. A fase de estabilidade se iniciou a partir do quadragésimo primeiro dia nos reatores de polietileno e espuma e a partir do vigésimo primeiro dia com leito de cerâmica.

A Tabela 7 apresenta o valor máximo de vazão de biogás e o valor médio durante a fase de estabilidade em ambas as operações, com e sem descartes de biomassa.

Tabela 7 - Vazão máxima e média de biogás em reator anaeróbio de leito ordenado, escoamento descendente, operado com e sem descartes de biomassa

\begin{tabular}{|c|c|c|c|c|}
\hline \multirow[b]{2}{*}{ Leito } & \multicolumn{2}{|c|}{ Com descarte de biomassa } & \multicolumn{2}{|c|}{ Sem descarte de biomassa } \\
\hline & $\begin{array}{c}Q_{\text {biogás }} \text { máximo } \\
\left(\mathrm{mL} \mathrm{h}^{-1}\right)\end{array}$ & $\begin{array}{c}Q_{\text {biogás }} \text { média } \\
\left(\mathrm{mL} \mathrm{h}^{-1}\right)\end{array}$ & $\begin{array}{c}Q_{\text {biogás }} \text { máximo } \\
\left(\mathrm{mL} \mathrm{h}^{-1}\right)\end{array}$ & $\begin{array}{c}Q_{\text {biogás }} \text { média } \\
\left(\mathrm{mL} \mathrm{h}^{-1}\right)\end{array}$ \\
\hline Polietileno & 368 & $134 \pm 56$ & 362 & $115 \pm 42$ \\
\hline Espuma & 402 & $132 \pm 68$ & 272 & $131 \pm 52$ \\
\hline Cerâmica & 259 & $66 \pm 36$ & 179 & $38 \pm 31$ \\
\hline
\end{tabular}


(a)
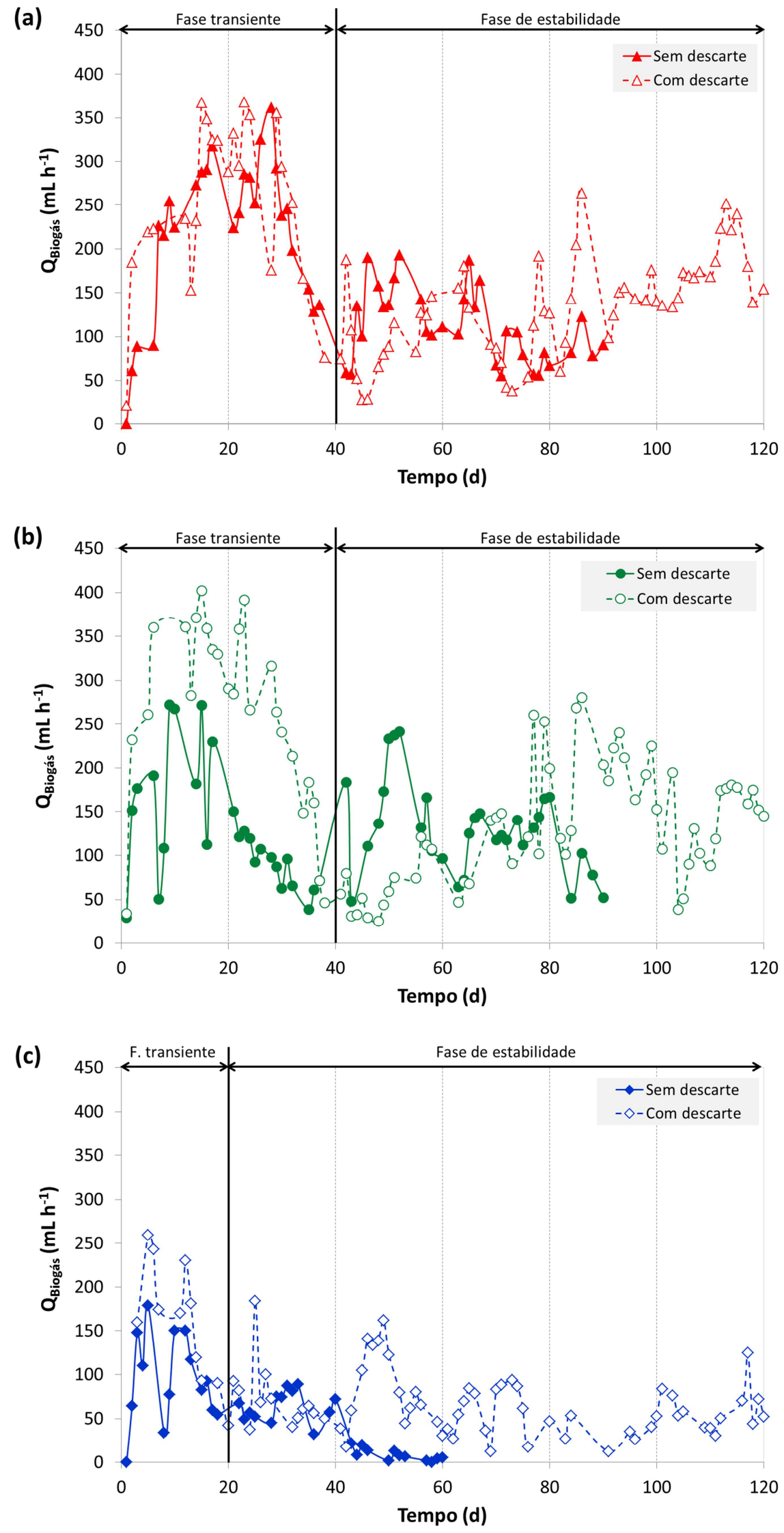

Figura 14 - Produção temporal de biogás em reator anaeróbio de leito ordenado, escoamento descendente operado com e sem descarte de biomassa; (a) polietileno; (b) espuma; (c) cerâmica 
Comparando as duas operações, as produções máximas de biogás foram $48 \%$ e $44 \%$ maiores com os leitos de espuma e cerâmica, respectivamente com a retirada frequente de biomassa. Este aumento não foi observado no reator com leito de polietileno. Durante a fase de estabilidade, sem descartes de biomassa, a produção média de biogás com polietileno diminuiu 14\%, Já no reator com leito de espuma não houve alteração e com cerâmica a produção cessou completamente.

Segundo a Tabela 8, a porcentagem de composição do biogás foi similar para todos os casos com aproximadamente $70 \%$ de hidrogênio e $30 \%$ de dióxido de carbono. Em nenhum caso foi detectada a presença de metano.

Tabela 8 - Porcentagem média da composição do biogás em reator anaeróbio de leito ordenado, escoamento descendente operado com e sem descartes de biomassa

\begin{tabular}{ccc|cc}
\hline \multirow{2}{*}{ Leito } & \multicolumn{2}{c|}{ Com descarte de biomassa } & \multicolumn{2}{c}{ Sem descarte de biomassa } \\
\cline { 2 - 5 } & $\mathbf{H}_{\mathbf{2}}$ & $\mathbf{C O}_{\mathbf{2}}$ & $\mathbf{H}_{\mathbf{2}}$ & $\mathbf{C O}_{\mathbf{2}}$ \\
& $(\boldsymbol{\%})$ & $(\boldsymbol{\%})$ & $(\boldsymbol{\%})$ & $(\boldsymbol{\%})$ \\
\hline Polietileno & $69 \pm 7$ & $31 \pm 7$ & $69 \pm 4$ & $31 \pm 4$ \\
Espuma & $67 \pm 6$ & $33 \pm 6$ & $69 \pm 4$ & $31 \pm 4$ \\
Cerâmica & $70 \pm 5$ & $30 \pm 5$ & $74 \pm 5$ & $26 \pm 5$ \\
\hline
\end{tabular}

Os perfis temporais da eficiência de conversão de sacarose $\left(E_{S}\right)$ são apresentados na Figura 15 e as $E_{s}$ médias durante a fase de estabilidade na Tabela 9. Os reatores com leito de polietileno e espuma tiveram uma $E_{S}$ média similar em ambas as operações, porém sem descartes de biomassa houve um aumento próximo de $8 \%$ nos dois reatores. Com leito de cerâmica este incremento foi de $21 \%$. No entanto, se comparado com os outros leitos, a $E_{s}$ média da cerâmica foi $26 \%$ e $18 \%$ menor com e sem descartes de biomassa, respectivamente.

Tabela 9 - Eficiência média de conversão de sacarose em reator anaeróbio de leito ordenado, escoamento descendente operado com e sem descartes de biomassa

\begin{tabular}{cc|c}
\hline \multirow{2}{*}{ Leito } & Com descarte de biomassa & Sem descarte de biomassa \\
\cline { 2 - 3 } & $\boldsymbol{E}_{\boldsymbol{s}}$ média & $\boldsymbol{E}_{\boldsymbol{s}}$ média \\
$(\boldsymbol{\%})$ & $70 \pm 11$ \\
\hline Polietileno & $64 \pm 11$ & $71 \pm 10$ \\
Espuma & $66 \pm 09$ & $58 \pm 14$ \\
Cerâmica & $48 \pm 11$ & \\
\hline
\end{tabular}



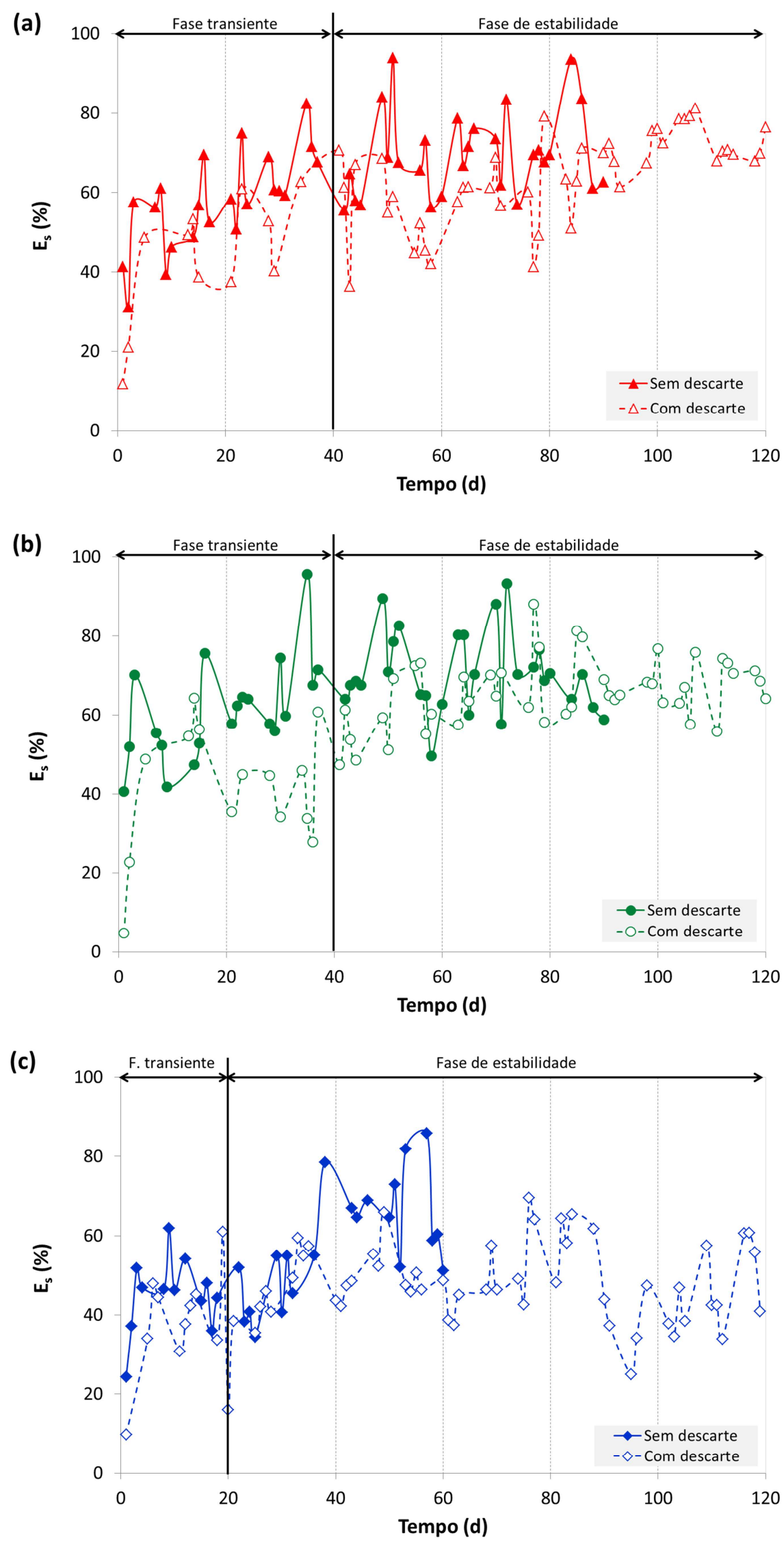

Figura 15 - Eficiência de conversão de sacarose $\left(E_{s}\right)$ em reator anaeróbio de leito ordenado, escoamento descendente operado com e sem descartes de biomassa (a) polietileno (b) espuma (c) cerâmica 
O leito ordenado e o escoamento descendente facilitaram o acúmulo de biomassa na parte inferior dos reatores, conforme pode ser observado na Figura 16. A cada 20 dias foram descartados $200 \mathrm{~mL}$ de líquido do fundo dos reatores com concentração média de SVT de $12 \pm 1 \mathrm{~g} \mathrm{~L}^{-1}$ no reator com leito de polietileno, $11 \pm 7 \mathrm{~g} \mathrm{~L}^{-1}$ com leito de espuma e $13 \pm 3 \mathrm{~g} \mathrm{~L}^{-1}$ com leito de cerâmica.

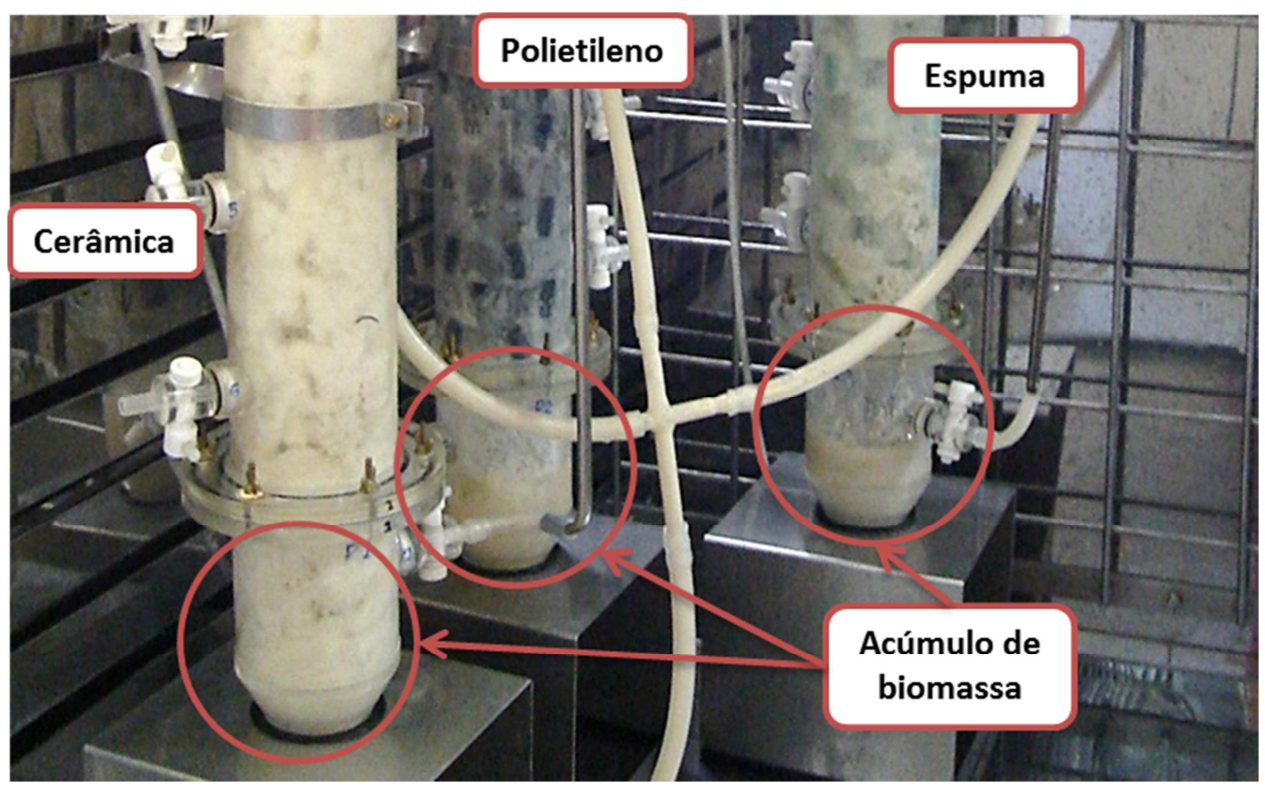

Figura 16 - Acúmulo de biomassa no fundo dos reatores de leito ordenado operado com escoamento descendente

O arraste de biomassa do sistema ocorreu de forma contínua, embora sem nenhuma tendência, como observado na Figura 17. De tal modo, em todos os casos, a média da vazão mássica de SSV no efluente foi calculada tendo em conta todo o período experimental conforme Tabela 10.

Tabela 10 - Vazão mássica média da biomassa de arraste em reator anaeróbio de leito ordenado, escoamento descendente operado com e sem descartes de biomassa

\begin{tabular}{|c|c|c|}
\hline & Com descarte de biomassa & Sem descarte de biomassa \\
\hline Leito & $\begin{array}{c}\dot{w}_{x} \text { média } \\
\left(\mathrm{mg} \mathrm{SSV} \mathrm{h}^{-1}\right)\end{array}$ & $\begin{array}{c}\dot{w}_{x} \text { média } \\
\left(\mathrm{mg} \mathrm{SSV} \mathrm{h}^{-1}\right)\end{array}$ \\
\hline Polietileno & $119 \pm 87$ & $85 \pm 55$ \\
\hline Espuma & $96 \pm 62$ & $119 \pm 93$ \\
\hline Cerâmica & $68 \pm 64$ & $88 \pm 47$ \\
\hline
\end{tabular}



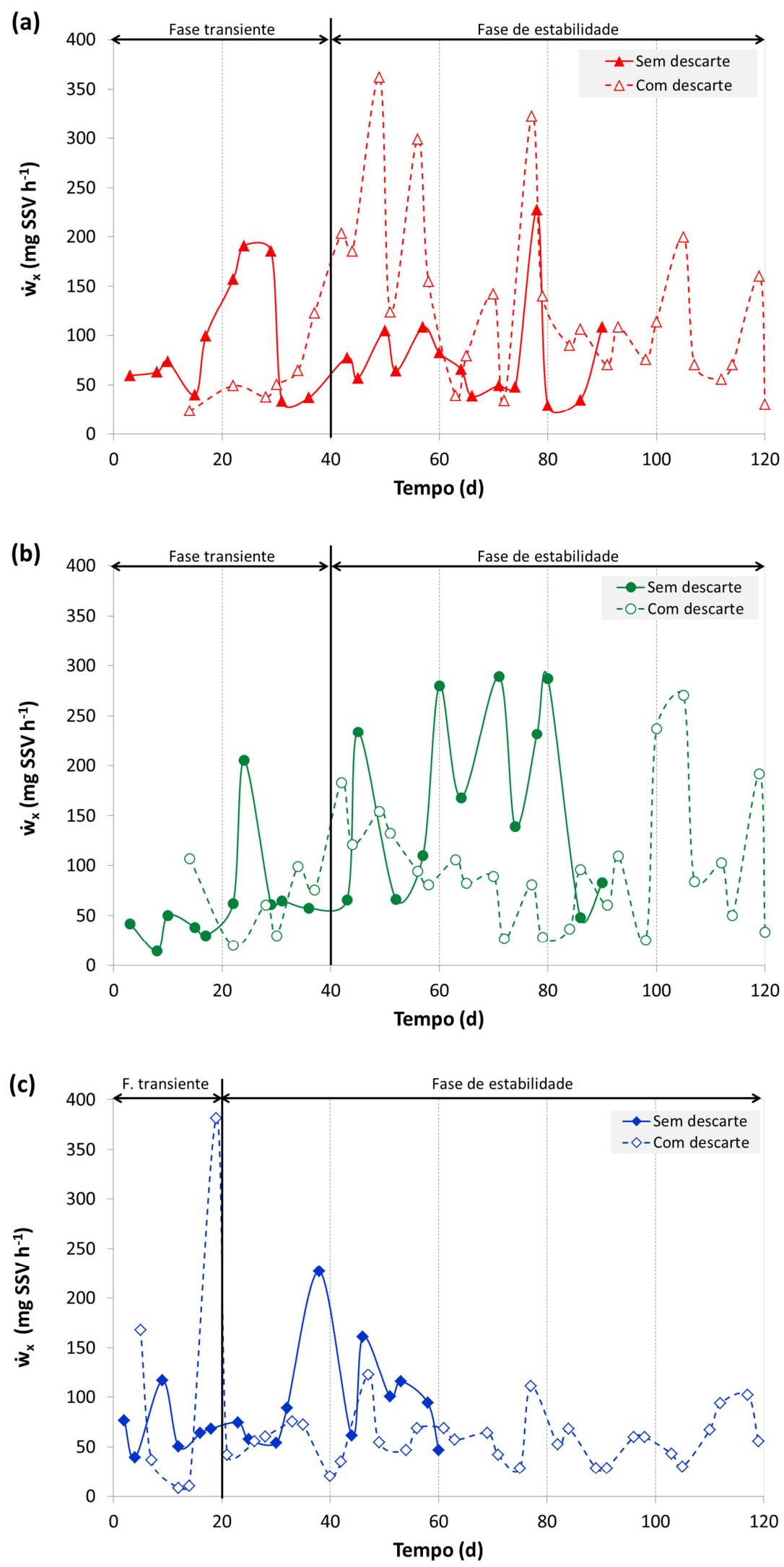

Figura 17 - Vazão mássica da biomassa de arraste $\left(\dot{w}_{x}\right)$ em reator anaeróbio de leito ordenado, escoamento descendente operado com e sem descartes de biomassa (a) polietileno (b) espuma (c) cerâmica 
Outro parâmetro analisado no meio líquido foi a formação de produtos solúveis da fermentação (PSF) conforme Tabela 11. O ácido acético, o ácido butírico e o etanol foram os principais PSF nos três reatores em ambas as operações, com e sem descartes de biomassa. Ocasionalmente, observou-se a produção de traços do ácido propiônico, sendo este relacionado com o consumo de hidrogênio.

Tabela 11 - Produção média dos PSF em reator anaeróbio de leito ordenado, escoamento descendente operado com e sem descartes de biomassa durante a fase de estabilidade

\begin{tabular}{|c|c|c|c|c|}
\hline Leito & $\begin{array}{c}\text { Etanol } \\
\left(\mathrm{mg} \mathrm{DQO} \mathrm{L}^{-1}\right)\end{array}$ & $\begin{array}{c}\begin{array}{c}\text { Ácido } \\
\text { acético }\end{array} \\
\left.(\mathbf{m g ~ D Q O ~ L})^{-1}\right) \\
\end{array}$ & $\begin{array}{c}\text { Ácido } \\
\text { butírico } \\
\left(\mathbf{m g ~ D Q O ~ L ~}{ }^{-1}\right) \\
\end{array}$ & $\begin{array}{l}\text { Ácido propiônico } \\
\left(\mathbf{m g} \mathrm{DQO} \mathrm{L}^{-1}\right)\end{array}$ \\
\hline \multicolumn{5}{|c|}{ Com descartes de biomassa } \\
\hline Polietileno & $439 \pm 150$ & $378 \pm 105$ & $252 \pm 119$ & $6 \pm 10$ \\
\hline Espuma & $427 \pm 248$ & $319 \pm 105$ & $327 \pm 183$ & $13 \pm 20$ \\
\hline Cerâmica & $175 \pm 186$ & $203 \pm 82$ & $151 \pm 86$ & $0 \pm 0$ \\
\hline \multicolumn{5}{|c|}{ Sem descartes de biomassa } \\
\hline Polietileno & $266 \pm 142$ & $321 \pm 87$ & $333 \pm 110$ & $8 \pm 9$ \\
\hline Espuma & $142 \pm 195$ & $429 \pm 134$ & $241 \pm 136$ & $25 \pm 36$ \\
\hline Cerâmica & $90 \pm 83$ & $268 \pm 102$ & $211 \pm 189$ & $9 \pm 24$ \\
\hline
\end{tabular}

O balanço de carbono foi calculado conforme item 4.6.3 e é apresentado na Tabela 12. A diferença entre a DQO afluente e efluente foi atribuída a PSF não detectados pelo método de cromatografia usado nesta estratégia.

Tabela 12 - Balanço de carbono em reator anaeróbio de leito ordenado, escoamento descendente operado com e sem descartes de biomassa

\begin{tabular}{|c|c|c|c|c|c|c|c|}
\hline Leito & $\begin{array}{c}D Q O_{a f} \\
\left(\mathrm{mg} \mathrm{L}^{-1}\right)\end{array}$ & $\begin{array}{c}D Q O_{t(P S F)} \\
\left(\mathrm{mg} \mathrm{L}^{-1}\right)\end{array}$ & $\begin{array}{c}D Q O_{x} \\
\left(\operatorname{mg~L}^{-1}\right)\end{array}$ & $\begin{array}{c}D Q O_{S E} \\
\left(\mathrm{mg} \mathrm{L}^{-1}\right)\end{array}$ & $\begin{array}{l}D Q O_{H_{2}} \\
\left(\mathrm{mg} \mathrm{L}^{-1}\right)\end{array}$ & $\begin{array}{c}D Q O_{e f} \\
\left(\mathrm{mg} \mathrm{L}^{-1}\right)\end{array}$ & $D Q O_{e f} / a f$ \\
\hline \multicolumn{8}{|c|}{ Com descartes } \\
\hline Polietileno & 2.057 & 1.075 & 90 & 730 & 52 & 1.800 & 0,95 \\
\hline Espuma & 2.057 & 1.086 & 86 & 704 & 47 & 1.780 & 0,93 \\
\hline Cerâmica & 2.031 & 529 & 70 & 1044 & 14 & 1.598 & 0,82 \\
\hline \multicolumn{8}{|c|}{ Sem descartes } \\
\hline Polietileno & 1.958 & 928 & 69 & 586 & 35 & 1.528 & 0,83 \\
\hline Espuma & 1.958 & 840 & 82 & 570 & 45 & 1.488 & 0,79 \\
\hline Cerâmica & 1.782 & 578 & 64 & 735 & 11 & 1.359 & 0,78 \\
\hline
\end{tabular}




\subsubsection{Produção de hidrogênio em reatores com leito ordenado}

Para avaliar o desempenho dos reatores na produção de hidrogênio utilizou-se a produção volumétrica de hidrogênio $(P V H)$ representada em litros de hidrogênio por litro de reator por dia $\left(\mathrm{L} \mathrm{H}_{2} \mathrm{~L}^{-1} \mathrm{~d}^{-1}\right)$ e o rendimento de hidrogênio $\left(Y_{\mathrm{H}_{2}}\right)$ em mol de hidrogênio por mol de sacarose convertida ( $\left.\mathrm{mol} \mathrm{H}_{2} \mathrm{~mol}^{-1}{ }_{\mathrm{sc}}\right)$.

A Tabela 13 apresenta os valores máximos de $P V H$ e $Y_{H_{2}}$, sendo estes observados durante a fase transiente do sistema nos três reatores operados com e sem descartes de biomassa. Se comparadas as duas operações, os melhores $P V H$ e $Y_{H_{2}}$ foram obtidos nos três reatores quando operados com descartes de biomassa. Dentre os três leitos, a melhor PVH foi atingida no leito de espuma e os melhores $Y_{H_{2}}$ nos leitos de polietileno e espuma. Entretanto, estes valores foram $29 \%$ e $47 \%$ menores, respectivamente, quando os reatores foram operados sem descartes de biomassa.

Tabela 13 - Valores máximos de produção de hidrogênio em reator anaeróbio de leito ordenado, escoamento descendente operado com e sem descartes de biomassa (fase transiente)

\begin{tabular}{|c|c|c|c|c|}
\hline \multirow[b]{2}{*}{ Leito } & \multicolumn{2}{|c|}{ Com descarte de biomassa } & \multicolumn{2}{|c|}{ Sem descarte de biomassa } \\
\hline & $\begin{array}{c}P V H \\
\left(\mathbf{L} \mathbf{H}_{2} \mathbf{L}^{-1} \mathbf{d}^{-1}\right)\end{array}$ & $\begin{array}{c}Y_{H_{2}} \\
\left(\mathbf{m o l ~ H}_{2} \text { mol }_{s c}^{-1}\right)\end{array}$ & $\begin{array}{c}P V H \\
\left(\mathbf{L} \mathbf{H}_{2} \mathbf{L}^{-1} \mathbf{d}^{-1}\right)\end{array}$ & $\begin{array}{c}Y_{H_{2}} \\
\left(\mathbf{m o l ~ H}_{2} \text { mol }_{\mathrm{sc}}^{-1}\right)\end{array}$ \\
\hline Polietileno & 1,7 & 3,8 & 1,5 & 2,0 \\
\hline Espuma & 2,1 & 3,7 & 1,5 & 2,0 \\
\hline Cerâmica & 1,4 & 2,2 & 1,1 & 0,8 \\
\hline
\end{tabular}

Durante a fase de estabilidade, a produção média de hidrogênio caiu consideravelmente em relação à etapa transiente tal como apresentado na Tabela 14. No entanto, na maioria dos casos com exceção do leito de cerâmica operado sem descartes de biomassa, a produção de hidrogênio foi contínua até o final da operação.

Tabela 14 - Valores médios de produção de hidrogênio em reator anaeróbio de leito ordenado, escoamento descendente operado com e sem descartes de biomassa (fase de estabilidade)

\begin{tabular}{|c|c|c|c|c|}
\hline \multirow[b]{2}{*}{ Leito } & \multicolumn{2}{|c|}{ Com descarte de biomassa } & \multicolumn{2}{|c|}{ Sem descarte de biomassa } \\
\hline & $\begin{array}{c}P V H \\
\left(\mathbf{L} \mathbf{H}_{2} \mathbf{L}^{-1} d^{-1}\right)\end{array}$ & $\begin{array}{c}Y_{H_{2}} \\
\left(\mathrm{~mol} \mathrm{H}_{2} \text { mol }_{s c}^{-1}\right)\end{array}$ & $\begin{array}{c}P V H \\
\left(\mathbf{L} \mathbf{H}_{2} \mathbf{L}^{-1} \mathbf{d}^{-1}\right)\end{array}$ & $\begin{array}{c}Y_{H_{2}} \\
\left(\mathrm{~mol} \mathrm{H}_{2} \mathrm{~mol}_{\mathrm{sc}}{ }^{-1}\right)\end{array}$ \\
\hline Polietileno & $0,6 \pm 0,2$ & $0,6 \pm 0,2$ & $0,5 \pm 0,2$ & $0,4 \pm 0,2$ \\
\hline Espuma & $0,6 \pm 0,3$ & $0,5 \pm 0,2$ & $0,6 \pm 0,3$ & $0,5 \pm 0,2$ \\
\hline Cerâmica & $0,3 \pm 0,2$ & $0,4 \pm 0,3$ & $0,2 \pm 0,2$ & $0,1 \pm 0,2$ \\
\hline
\end{tabular}


Se comparado com os trabalhos anteriores desenvolvidos no LPB-EESC-USP em reatores de leito fixo empacotado e escoamento ascendente (FERNANDES, 2008; ANZOLAROJAS, 2010; GODOI, 2010; LIMA e ZAIAT, 2012; PENTEADO, LAZARO, et al., 2013; CARMINATO, 2013), a ordenação do leito e o escoamento descendente foram favoráveis para a produção contínua e estável de hidrogênio. A primeira característica (ordenação do leito) contribuiu para a diminuição do acúmulo de biomassa no leito e a segunda (escoamento descendente) facilitou a saída natural de biomassa no efluente e também a sedimentação no fundo dos reatores. Essa afirmação pode ser suportada pela estimativa geral de biomassa em ambas as operações com e sem descartes (Tabela 15 e Tabela 16, respectivamente).

Por um lado, o acúmulo de biomassa no leito, representada pela biomassa aderida e intersticial, correspondeu em média a aproximadamente 5\% do total de biomassa produzida. Em leito empacotado com polietileno de baixa densidade e escoamento ascendente, AnzolaRojas et al. (2014) observaram que essa porcentagem foi igual a $20 \%$, ou seja, a ordenação do leito diminuiu o acúmulo de biomassa no leito em aproximadamente $15 \%$.

Por outro lado, a saída natural de biomassa no leito ordenado em todos os casos foi maior que $80 \%$, enquanto no reator de leito fixo chegou até $70 \%$ do total de biomassa produzida (ANZOLA-ROJAS, GONÇALVES , et al., 2014). Adicionalmente, em relação à sedimentação, a biomassa descartada periodicamente pelo fundo dos reatores correspondeu a $46 \%, 40 \%$ e $32 \%$ do total da biomassa dentro do reator no leito de polietileno, espuma e cerâmica, respectivamente.

Tabela 15 - Estimativa de biomassa total gerada e substrato total consumido em reator de leito ordenado, escoamento descendente operado com descartes de biomassa

\begin{tabular}{lrrr}
\hline \multicolumn{1}{c}{ Biomassa/Substrato } & Polietileno & Espuma & Cerâmica \\
\hline Biomassa gerada após 120 dias de operação & & & \\
Dentro do reator $(\mathrm{mg})$ & 32.524 & 33.703 & 48.972 \\
$\quad$ Aderida e intersticial & 8.566 & 9.533 & 6.653 \\
$\quad$ Suspensa & 8.970 & 10.908 & 26.550 \\
$\quad$ Descartada periodicamente $(\mathrm{mg})$ & 14.988 & 13.262 & 15.768 \\
Arrastada naturalmente $(\mathrm{mg})$ & 340.115 & 283.298 & 212.613 \\
\hline Total biomassa gerada $(\mathrm{mg})$ & 372.640 & 316.597 & 261.585 \\
Total sacarose consumida $(\mathrm{mg})$ & 5.615 .419 & 5.132 .970 & 3.958 .149 \\
Coeficiente $Y x /{ }\left(\mathrm{g} \mathrm{SSV}^{-1}{ }_{\text {sc }}\right)$ & 0,066 & 0,062 & 0,066 \\
\hline Biomassa arrastada $(\%)$ & 91 & 90 & 81 \\
Biomassa dentro do reator $(\%)$ & 9 & 10 & 19 \\
\hline
\end{tabular}


Tabela 16 - Estimativa de biomassa total gerada e substrato total consumido em reator de leito ordenado, escoamento descendente operado sem descarte de biomassa

\begin{tabular}{lrrr}
\hline \multicolumn{1}{c}{ Biomassa/Substrato } & Polietileno & Espuma & Cerâmica $^{*}$ \\
\hline Biomassa gerada após 90 dias de operação & & & \\
Dentro do reator $(\mathrm{mg})$ & 42.699 & 15.520 & 23.471 \\
$\quad$ Aderida e intersticial & 8.625 & 9.148 & 13.985 \\
$\quad$ Suspensa & 34.074 & 6.372 & 9.486 \\
Arrastada naturalmente $(\mathrm{mg})$ & 187.463 & 240.342 & 116.372 \\
\hline Total biomassa gerada $(\mathrm{mg})$ & 230.162 & 255.862 & 139.843 \\
Total sacarose consumida $(\mathrm{mg})$ & 4.485 .950 & 4.244 .892 & 2.208 .476 \\
Coeficiente $Y{ } /{ }_{\mathrm{s}}\left(\mathrm{g} \mathrm{SSV} \mathrm{g}{ }^{-1}{ }_{\text {sc }}\right)$ & 0,051 & 0,060 & 0,063 \\
\hline Biomassa arrastada $(\%)$ & 81 & 94 & 83 \\
Biomassa dentro do reator $(\%)$ & 19 & 6 & 17 \\
\hline
\end{tabular}

*Após 60 dias quando a produção de biogás cessou completamente.

5.2.4. Comparação entre as operações em reator anaeróbio de leito ordenado, escoamento descendente, com e sem descartes de biomassa e com diferentes materiais suporte

Em geral, se comparados os três leitos independente da operação observa-se que o polietileno e a espuma tiveram comportamento similar, pois em ambos os reatores foram observados os maiores valores de $\mathrm{PVH}, \mathrm{Y}_{\mathrm{H}_{2}}$ e $E_{S}$ (Tabela 13 e Tabela 9, respectivamente).

A cerâmica indicou ser um material suporte não adequado para produção de hidrogênio, uma vez que apresentou a maior anomalia no padrão de escoamento com atraso de aproximadamente $1 \mathrm{~h}$ no TDH médio. A $E_{s}$ média foi próxima de $50 \%$ com elevado desvio padrão e a produção de biogás foi a mais baixa entre os três reatores, sendo que em uma das operações a produção cessou completamente. No balanço de carbono, apresentado na Tabela 12, também é possível observar que a cerâmica teve a menor porcentagem da DQO envolvida na produção de hidrogênio.

Por outro lado, comparando as duas operações, com e sem descartes de biomassa, nos três reatores foi feito o Teste de Tukey utilizando o programa Microsoft Excel ${ }^{\circledR}$. Este teste permite verificar se existem diferenças entre dois grupos de dados mediante a porcentagem de diferença, sendo estatisticamente diferentes quando essa percentagem é menor que $5 \%(0,05)$. Entre as duas operações e reatores, a $E_{S}, P H V, Y_{H_{2}}$ e produção de ácido propiônico foram comparadas durante a fase de estabilidade. Os resultados do teste são apresentados da Tabela 17 a Tabela 20. 
Tabela 17 - Teste t para duas amostras supondo variâncias desiguais. $E_{s}$ em reator anaeróbio de leito ordenado, escoamento descendente, com e sem descartes de biomassa

\begin{tabular}{lrr|rr|rr}
\hline \multicolumn{1}{c}{ Leito/operação } & $\begin{array}{r}\text { Polietileno } \\
\text { CD }\end{array}$ & $\begin{array}{r}\text { Polietileno } \\
\text { SD }\end{array}$ & Espuma & Espuma & Cerâmica & Cerâmica \\
Média & 64,52 & 69,67 & 66,32 & 70,51 & 48,15 & 58,24 \\
Variância & 123,10 & 115,12 & 65,77 & 103,06 & 96,12 & 206,48 \\
Observações & 46,00 & 28,00 & 45,00 & 28,00 & 53,00 & 21,00 \\
$\begin{array}{l}\text { Diferença hipotética } \\
\text { das médias }\end{array}$ & 0,00 & & 0,00 & & 0,00 & \\
Graus de liberdade & 59,00 & & 48,00 & & 28,00 & \\
Estadístico t & $-1,98$ & & $-1,85$ & & $-2,96$ & \\
P(T<=t) uma calda & 0,03 & & 0,04 & & 0,00 & \\
Valor crítico de t & 1,67 & & 1,68 & & 1,70 & \\
(uma calda) & & & & & & \\
P(T<=t) duas caldas & $\mathbf{0 , 0 5 3}$ & Igual & $\mathbf{0 , 0 7 0}$ & Igual & $\mathbf{0 , 0 0 6}$ & Diferente \\
$\begin{array}{l}\text { Valor crítico de t } \\
\text { (duas caldas) }\end{array}$ & 2,00 & & 2,01 & & 2,05 & \\
\hline
\end{tabular}

"CD: com descarte. ${ }^{* *}$ SD: sem descarte

Tabela 18 - Teste t para duas amostras supondo variâncias desiguais. $P V H$ em reator anaeróbio de leito ordenado, escoamento descendente, com e sem descartes de biomassa

\begin{tabular}{|c|c|c|c|c|c|c|}
\hline Leito/operação & $\begin{array}{c}\text { Polietileno } \\
\text { CD }^{*}\end{array}$ & $\begin{array}{c}\text { Polietileno } \\
\text { SD }^{* *}\end{array}$ & $\begin{array}{l}\text { Espuma } \\
\text { CD }^{*}\end{array}$ & $\begin{array}{c}\text { Espuma } \\
\text { SD }^{* *}\end{array}$ & $\begin{array}{c}\text { Cerâmica } \\
\text { CD* }\end{array}$ & $\begin{array}{c}\text { Cerâmica } \\
\text { SD** }\end{array}$ \\
\hline Média & 0,59 & 0,45 & 0,61 & 0,63 & 0,32 & 0,19 \\
\hline Variância & 0,04 & 0,03 & 0,10 & 0,07 & 0,04 & 0,03 \\
\hline Observações & 43,00 & 28,00 & 46,00 & 26,00 & 44,00 & 20,00 \\
\hline $\begin{array}{l}\text { Diferença hipotética } \\
\text { das médias }\end{array}$ & 0,00 & & 0,00 & & 0,00 & \\
\hline Graus de liberdade & 66,00 & & 60,00 & & 48,00 & \\
\hline Estadístico t & 3,02 & & $-0,32$ & & 2,59 & \\
\hline $\mathrm{P}(\mathrm{T}<=\mathrm{t})$ uma calda & 0,00 & & 0,37 & & 0,01 & \\
\hline $\begin{array}{l}\text { Valor crítico de } t \\
\text { (uma calda) }\end{array}$ & 1,67 & & 1,67 & & 1,68 & \\
\hline$P(T<=t)$ duas caldas & 0,004 & Diferente & $\mathbf{0 , 7 5}$ & Igual & 0,01 & Diferente \\
\hline $\begin{array}{l}\text { Valor crítico de } \mathrm{t} \\
\text { (duas caldas) }\end{array}$ & 2,00 & & 2,00 & & 2,01 & \\
\hline
\end{tabular}

"CD: com descarte. ${ }^{* *}$ SD: sem descarte 
Tabela 19 - Teste t para duas amostras supondo variâncias desiguais. $Y_{H_{2}}$ em reator anaeróbio de leito ordenado escoamento descendente, com e sem descartes de biomassa

\begin{tabular}{|c|c|c|c|c|c|c|}
\hline Leito/operação & $\begin{array}{c}\text { Polietileno } \\
\text { CD }^{*}\end{array}$ & $\begin{array}{c}\text { Polietileno } \\
\text { SD }^{* *}\end{array}$ & $\begin{array}{c}\text { Espuma } \\
\text { CD }^{*}\end{array}$ & $\underset{\text { SD }^{* *}}{\text { Espuma }}$ & $\begin{array}{c}\text { Cerâmica } \\
\text { CD* }\end{array}$ & $\begin{array}{c}\text { Cerâmica } \\
\text { SD** }\end{array}$ \\
\hline Média & 0,59 & 0,42 & 0,53 & 0,55 & 0,42 & 0,26 \\
\hline Variância & 0,06 & 0,02 & 0,06 & 0,05 & 0,07 & 0,05 \\
\hline Observações & 42,00 & 28,00 & 44,00 & 26,00 & 41,00 & 20,00 \\
\hline $\begin{array}{l}\text { Diferença hipotética } \\
\text { das médias }\end{array}$ & 0,00 & & 0,00 & & 0,00 & \\
\hline Graus de liberdade & 68,00 & & 56,00 & & 45,00 & \\
\hline Estadístico t & 3,61 & & $-0,21$ & & 2,43 & \\
\hline $\mathrm{P}(\mathrm{T}<=\mathrm{t})$ uma calda & 0,00 & & 0,42 & & 0,01 & \\
\hline $\begin{array}{l}\text { Valor crítico de } t \\
\text { (uma calda) }\end{array}$ & 1,67 & & 1,67 & & 1,68 & \\
\hline$P(T<=t)$ duas caldas & 0,0006 & Diferente & 0,8316 & Igual & 0,0191 & Diferente \\
\hline $\begin{array}{l}\text { Valor crítico de } \mathrm{t} \\
\text { (duas caldas) }\end{array}$ & 2,00 & & 2,00 & & 2,01 & \\
\hline
\end{tabular}

*CD: com descarte. ${ }^{* *} \mathrm{SD}$ : sem descarte

Tabela 20 - Teste t para duas amostras supondo variâncias desiguais. Produção de ácido propiônico em reator anaeróbio de leito ordenado, escoamento descendente, com e sem descartes de biomassa

\begin{tabular}{|c|c|c|c|c|c|c|}
\hline Leito/operação & $\begin{array}{l}\text { Polietileno } \\
\text { CD }^{*}\end{array}$ & $\begin{array}{l}\text { Polietileno } \\
\text { SD }\end{array}$ & $\underset{\text { CD }^{*}}{\text { Espuma }}$ & $\begin{array}{c}\text { Espuma } \\
\text { SD }^{* *}\end{array}$ & $\begin{array}{c}\text { Cerâmica } \\
\text { CD* }\end{array}$ & $\begin{array}{c}\text { Cerâmica } \\
\text { SD** }\end{array}$ \\
\hline Média & 5,59 & 7,88 & 13,62 & 27,61 & 0,00 & 9,20 \\
\hline Variância & 97,38 & 77,08 & 409,14 & $\begin{array}{r}1327,3 \\
6\end{array}$ & 0,00 & 593,05 \\
\hline Observações & 18,00 & 8,00 & 22,00 & 12,00 & 23,00 & 7,00 \\
\hline $\begin{array}{l}\text { Diferença hipotética } \\
\text { das médias }\end{array}$ & 0,00 & & 0,00 & & 0,00 & \\
\hline Graus de liberdade & 15,00 & & 15,00 & & 6,00 & \\
\hline Estadístico t & $-0,59$ & & $-1,23$ & & $-1,00$ & \\
\hline $\mathrm{P}(\mathrm{T}<=\mathrm{t})$ uma calda & 0,28 & & 0,12 & & 0,18 & \\
\hline $\begin{array}{l}\text { Valor crítico de } t \\
\text { (uma calda) }\end{array}$ & 1,75 & & 1,75 & & 1,94 & \\
\hline$P(T<=t)$ duas caldas & 0,56 & Igual & 0,24 & Diferente & 0,36 & Diferente \\
\hline $\begin{array}{l}\text { Valor crítico de } t \\
\text { (duas caldas) }\end{array}$ & 2,13 & & 2,13 & & 2,45 & \\
\hline
\end{tabular}

${ }^{*} \mathrm{CD}$ : com descarte. ${ }^{* *} \mathrm{SD}$ : sem descarte 
Observou-se que no leito de polietileno, ainda que a $E_{S}$ média tenha sido estatisticamente igual em ambas as operações, sem descartes de biomassa, a $P V H$ média e o $Y_{\mathrm{H}_{2}}$ médio foram $23 \%$ e $29 \%$ menores, respectivamente, enquanto a produção de ácido propiônico não teve alteração. No leito de espuma, a $E_{S}$ média, $P V H$ média e $Y_{H_{2}}$ entre as duas operações foram estatisticamente iguais, no entanto, a produção de ácido propiônico sem descartes de biomassa foi duas vezes o valor atingido com descartes de biomassa. No leito de cerâmica, a $E_{S}$ média sem descartes de biomassa foi $21 \%$ maior, porém a $P V H$ média e o $Y_{H_{2}}$ médio foram $41 \%$ e $38 \%$ menores, respectivamente, enquanto houve aparecimento de ácido propiônico.

Desta forma, as observações nos testes estatísticos permitiram inferir que os descartes de biomassa favoreceram a produção de hidrogênio, provavelmente devido à renovação da população microbiana, uma vez que na ausência dos descartes observou-se formação de PSF não relativos ou adversos para este fim tais como o ácido propiônico. Segundo Dinamarca e Bakke (2009) este comportamento poderia estar relacionado com a idade e envelhecimento do lodo, uma vez que os descartes permitiram a saída de biomassa mais antiga onde provavelmente foram estabelecidos os microorganismos consumidores ou não produtores de hidrogênio.

Assim, poderia se explicar o fato dos picos máximos de $\mathrm{PVH}$ e $Y_{\mathrm{H}_{2}}$ observados no tempo transiente serem coincidentes com o primeiro descarte nos três reatores. Provavelmente, a porcentagem de biomassa retirada no primeiro descarte em comparação com a biomassa acumulada dentro do reator pode ter sido maior que a porcentagem de biomassa retirada durante a fase de estabilidade, sugerindo que descartes maiores ou mais frequentes poderiam melhorar a produção de hidrogênio nesta última fase.

Contudo, apesar das variações entre os leitos e as operações, em todos os sistemas a tendência do desempenho ao longo do tempo foi similar a resultados observados em reatores do mesmo tipo, embora com escoamento ascendente, leito empacotado e alteração de alguns parâmetros, tais como relação C/N (ANZOLA-ROJAS, 2010), material suporte e TDH (FERNANDES, 2008), inóculo e pré-tratamentos (PENTEADO, LAZARO, et al., 2013), grau de mistura (LIMA e ZAIAT, 2012) e variação da concentração de cálcio (CARMINATO, 2013).

Em todos os trabalhos, inclusive neste, a maior vazão de biogás ocorre durante a fase transiente seguido de uma queda contínua, que em muitos casos cessa completamente. No entanto, a composição do biogás manteve a distribuição similar independente do volume 
produzido. Foram observados, principalmente, hidrogênio e dióxido de carbono com percentagens próximas de $60 \%$ e $40 \%$, respectivamente.

A divisão do tempo experimental em fase transiente e de estabilidade foi definida pela eficiência de conversão de sacarose, uma vez que durante a fase transiente este parâmetro aumenta continuamente até alcançar um patamar que no qual passa a ser constante. A fase de estabilização que começa justamente no ponto de início do patamar vai até o final da operação, sendo neste período que geralmente ocorre a diminuição na produção de biogás.

Essa queda contínua tem sido associada a mudanças na estrutura microbiana ocasionada pelo acúmulo de biomassa no reator ao longo do tempo. As mudanças poderiam incluir o desenvolvimento de microorganismos consumidores de hidrogênio ou não produtores, ou a ativação de rotas metabólicas adversas tais como a produção de ácido acético pela homoacetogênese. Estudos recentes também apontaram que estes problemas poderiam surgir pelo aumento da competição pelo substrato, uma vez que a quantidade de substrato alimentado é inalterada causando o decréscimo constante da carga orgânica volumétrica específica (COVe) (ANZOLA-ROJAS, GONÇALVES , et al., 2014; CARMINATO, 2013).

5.2.5. O comportamento da COVe em reator anaeróbio de leito ordenado, escoamento descendente, com e sem descartes de biomassa

Para avaliar o comportamento da COVe ao longo do tempo, inicialmente foi estimado o coeficiente de rendimento celular $(Y x / s)$ conforme o item 4.2. Considerando os seis reatores, $\mathrm{o} Y x / s$ foi em média $0,063 \mathrm{~g} \mathrm{SSV} \mathrm{g}^{-1}{ }_{\text {sc }}$ (Tabela 15 e Tabela 16). Este valor foi próximo do observado por Kim, Han e Shin (2006) de $\approx 0,09 \mathrm{~g} \mathrm{SSV} \mathrm{g}^{-1} \mathrm{SC}$ em reator CSTR operado a $35^{\circ} \mathrm{C}$ e utilizando sacarose como substrato e ao crescimento descrito por Drake, Göbner e Daniel (2008) ao observar que 6\% do carbono afluente foi utilizado para síntese de biomassa por bactérias acetogênicas.

A Figura 18 apresenta a COVe em cada reator e operação. Observa-se que a queda deste parâmetro ocorreu de forma potencial não mostrando um tempo de estabilização, sendo que todas as curvas se ajustaram a uma função do tipo Harris $\left(y=\left(a+b x^{c}\right)^{-1}\right)$ com ajuda do OriginPro $8.0^{\circledR}$ com coeficiente de determinação $\left(\mathrm{R}^{2}\right)$ acima de 0,95 na operação com descartes de biomassa e de 0,99 na operação sem descartes de biomassa. Vale ressaltar que este ajuste representou a tendência matemática do parâmetro não tendo sentido físico.

Dado que os valores máximos de produção de hidrogênio foram observados no período relativo à fase transiente, a Tabela 21 mostra a faixa da COVe e o valor médio para 
este mesmo período. Observa-se que em todos os reatores a COVe foi similar com uma média

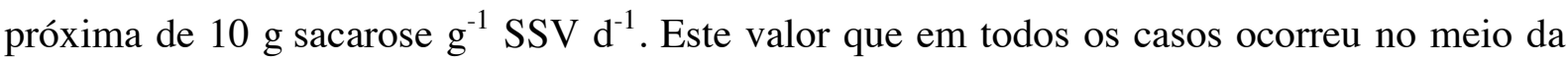
fase transiente coincidiu com os picos máximos de produção de hidrogênio.

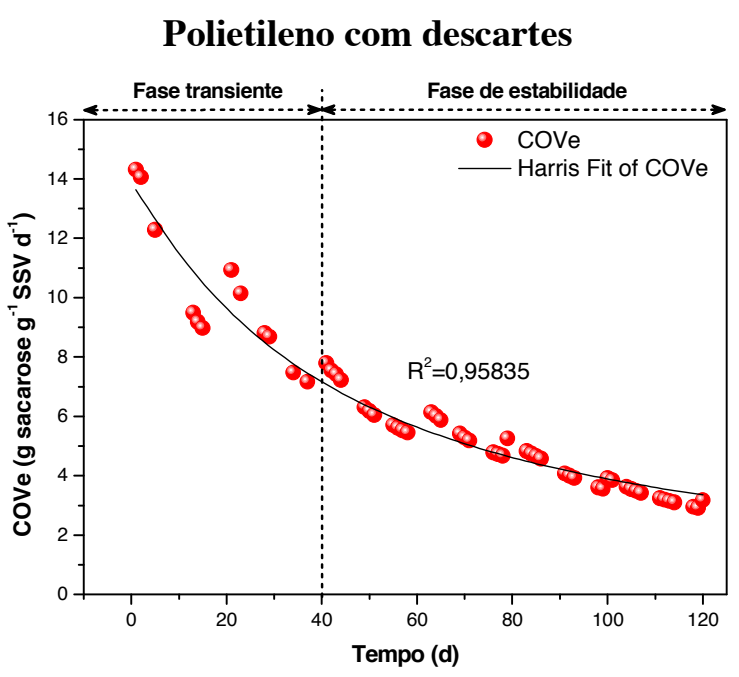

Espuma com descartes

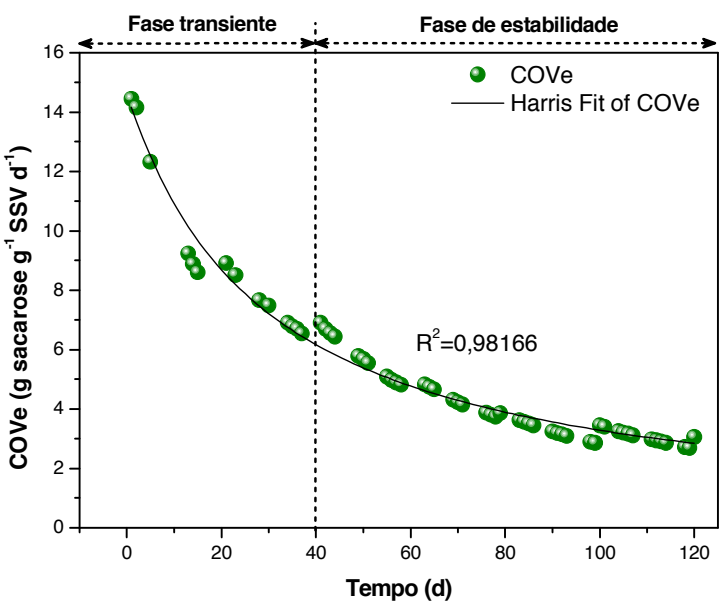

Cerâmica com descartes

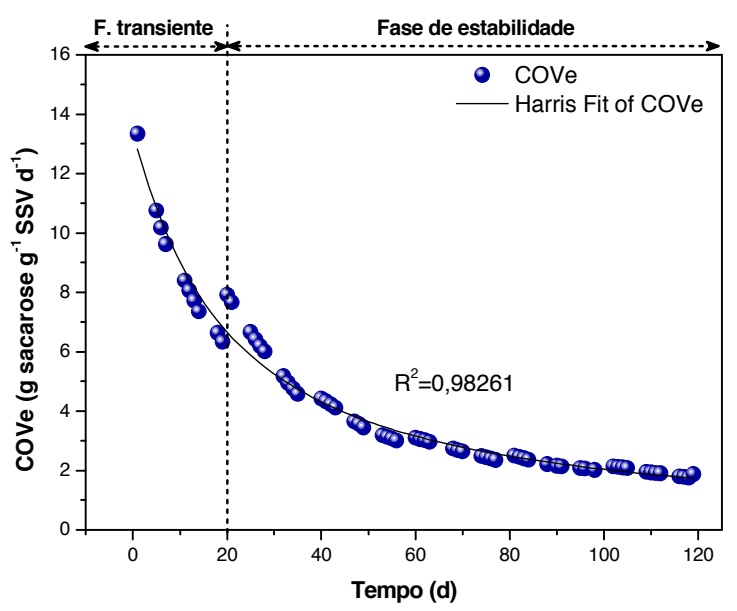

Polietileno sem descartes

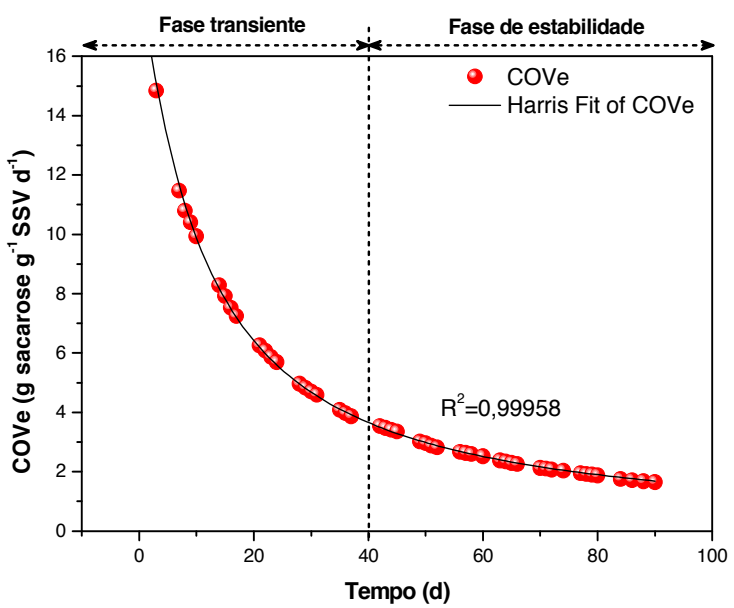

Espuma sem descartes

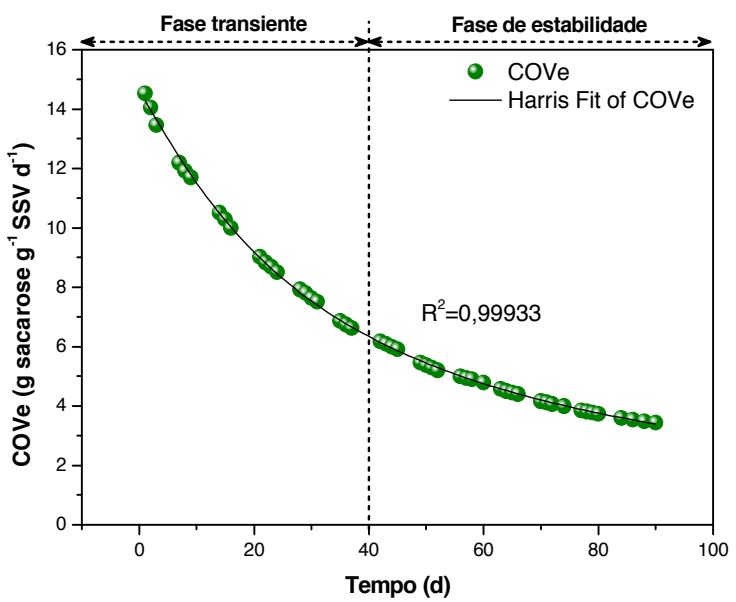

Espuma sem descartes

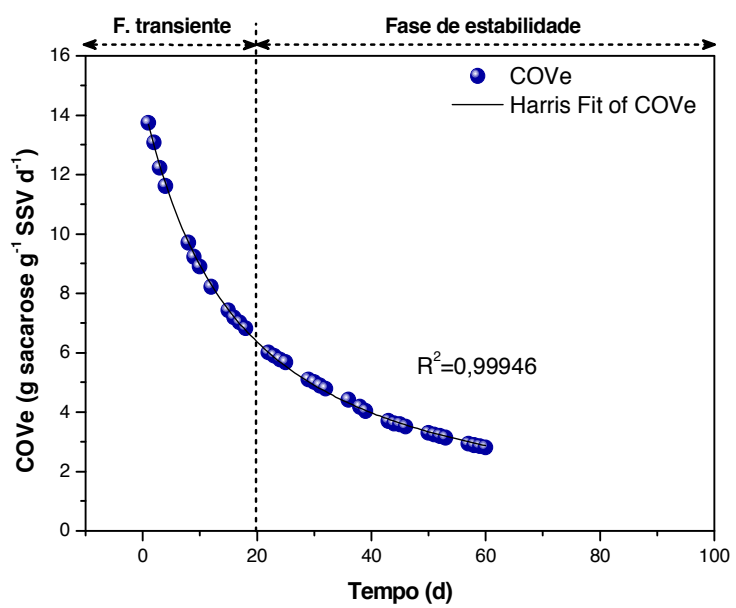

Figura 18 - COVe ao longo do tempo em reator de leito ordenado, escoamento descendente operado com e sem descartes de biomassa 
Tabela 21 - Faixa da COVe e COVe média na fase transiente em reator anaeróbio de leito ordenado, escoamento descendente operado com e sem descartes de biomassa

\begin{tabular}{|c|c|c|c|c|}
\hline \multirow[b]{2}{*}{ Leito } & \multicolumn{2}{|c|}{ Com descarte de biomassa } & \multicolumn{2}{|c|}{ Sem descarte de biomassa } \\
\hline & $\begin{array}{l}\text { COVe Faixa } \\
\left({\text { g sacarose } \text { g }^{-1}}^{\text {SSV d }} \text { d }^{-1}\right.\end{array}$ & $\begin{array}{l}\text { COVe Média } \\
{\text { (g sacarose } \text { g }^{-1}}_{\left.\text {SSV d }^{-1}\right)}\end{array}$ & $\begin{array}{c}\text { COVe Faixa } \\
\left({\text { g sacarose } \text { g }^{-1}}^{\text {SSV d }}{ }^{-1}\right)\end{array}$ & $\begin{array}{c}\text { COVe Média } \\
\text { (g sacarose } \text { g }^{-1} \\
\left.\text { SSV d }{ }^{-1}\right)\end{array}$ \\
\hline Polietileno & $13,6-7,2$ & $10,4 \pm 4,6$ & $17,4-3,7$ & $10,5 \pm 9,7$ \\
\hline Espuma & $14,2-6,2$ & $10,2 \pm 5,7$ & $14,3-6,3$ & $10,3 \pm 5,6$ \\
\hline Cerâmica & $12,8-6,7$ & $9,7 \pm 4,4$ & $13,7-6,4$ & $10,0 \pm 5,2$ \\
\hline
\end{tabular}

Da mesma forma, a faixa da COVe e a média durante a fase de estabilidade é apresentada na Tabela 22. É possível notar que, durante este período a COVe média na

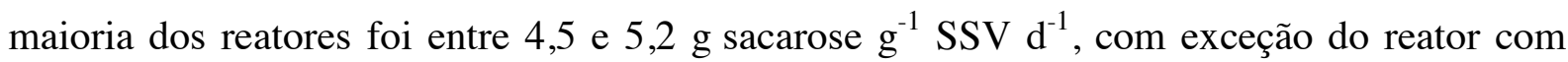
leito de polietileno operado sem descartes de biomassa. Esta faixa que indica uma queda

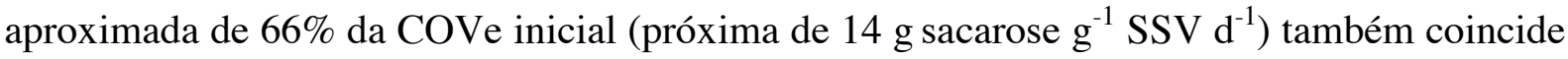
com a diminuição na produção de hidrogênio. No caso do reator com leito de polietileno, durante este período a porcentagem da queda da COVe foi próxima de $81 \%$.

Tabela 22 - Faixa da COVe e COVe média na fase de estabilidade em reator anaeróbio de leito ordenado, escoamento descendente operado com e sem descartes de biomassa

\begin{tabular}{|c|c|c|c|c|}
\hline \multirow[b]{2}{*}{ Leito } & \multicolumn{2}{|c|}{ Com descarte de biomassa } & \multicolumn{2}{|c|}{ Sem descarte de biomassa } \\
\hline & $\begin{array}{l}\text { COVe Faixa } \\
\left(\text { g sacarose }^{-1}\right. \\
\text { SSV d } \\
\text {-1) }\end{array}$ & 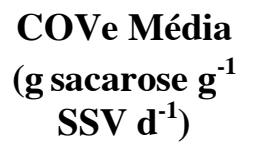 & $\begin{array}{l}\text { COVe Faixa } \\
\left({\text { g sacarose } \text { g }^{-1}}^{\text {SSV d }} \text { d }^{-1}\right)\end{array}$ & $\begin{array}{l}\text { COVe Média } \\
\left.{\text { (g sacarose } \mathbf{g}^{-1}}_{\text {SSV d }}{ }^{-1}\right)\end{array}$ \\
\hline Polietileno & $7,1-3,4$ & $5,2 \pm 2,6$ & $3,6-1,7$ & $2,6 \pm 1,3$ \\
\hline Espuma & $6,1-2,8$ & $4,5 \pm 2,3$ & $6,2-3,4$ & $4,8 \pm 2,0$ \\
\hline Cerâmica & $6,5-1,7$ & $4,8 \pm 2,4$ & $6,2-2,9$ & $4,5 \pm 2,3$ \\
\hline
\end{tabular}

Em um trabalho anterior, Anzola-Rojas et al. (2014) sugeriram que um sistema em que o valor da COVe é próximo de $6 \mathrm{~g}$ sacarose $\mathrm{g}^{-1} \mathrm{SSV} \mathrm{d}^{-1}$ poderia manter a produção de hidrogênio contínua em um reator de leito fixo e escoamento ascendente. Similarmente, Hafez et al. (2010) indicaram uma faixa adequada entre 4,4 e 6,4 $\mathrm{g} \mathrm{DQO} \mathrm{g}^{-1} \mathrm{SSV} \mathrm{d}^{-1}$ em reatores de mistura completa. Nesta estratégia, durante a fase de estabilidade, em quatro das seis operações, a ordenação do leito e o escoamento descendente permitiram manter a COVe perto do valor sugerido e foi observada continuidade na $\mathrm{PVH}$ e no $Y_{\mathrm{H}_{2}}$ ainda que com elevado desvio padrão.

Observaram-se dois casos pontuais com comportamento diferente. No reator com leito de cerâmica operado sem descartes de biomassa, a produção de hidrogênio cessou por volta 


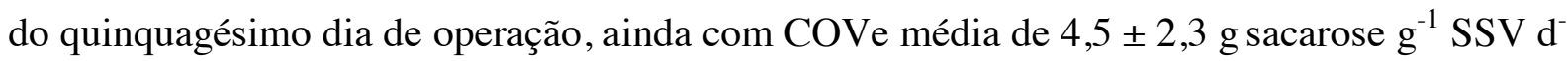

${ }^{1}$. Contrariamente, no reator com leito de polietileno operado sem descartes de biomassa a produção de hidrogênio foi contínua durante a fase de estabilidade, embora o valor médio da

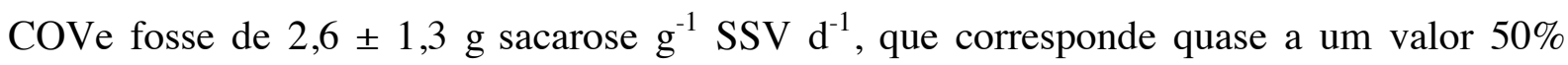
menor em comparação com os outros reatores deste trabalho.

Ambos os casos poderiam ser um indicio de marcantes variações na estrutura microbiana devido à forma de retenção da biomassa dentro do reator, ou seja, à distribuição porcentual entre a biomassa aderida e intersticial e a biomassa suspensa. No caso do leito de cerâmica operado sem descartes, $60 \%$ da biomassa retida no reator esteve aderida ao leito facilitando o seu envelhecimento, enquanto que com descartes a percentagem de adesão foi de 14\%. O envelhecimento poderia ser associado a bactérias consumidoras de hidrogênio, pois se comparadas as duas operações, observa-se que com uma maior adesão de biomassa houve produção de ácido propiônico, enquanto que com descartes de biomassa a geração deste ácido foi nula e a produção de hidrogênio contínua.

Ao contrário, no reator com leito de polietileno operado sem descartes, $80 \%$ da biomassa retida esteve suspensa, o que sugere a facilidade de renovação da biomassa. Esta renovação poderia ser associada a bactérias produtoras de PFS favoráveis para a produção de hidrogênio como o ácido butírico, pois se comparadas as duas operações, observa-se que com descartes, a diminuição da geração deste ácido (24\% menor) foi concomitante com a diminuição da somatória da percentagem de biomassa em suspensão mais os descartes (6\% menor).

Desta forma, vale ressaltar que, ainda que o valor da COVe tenha influência sobre a produção de hidrogênio e o desempenho dos reatores em sistemas de culturas mistas, o valor adequado deste parâmetro pode depender da distribuição da estrutura microbiana. Isso ficou mais evidente nestes últimos dois casos, pois os reatores foram mais afetados pela forma de acumulação de biomassa que pela própria diminuição da COVe.

5.2.6. Homoacetogênese e hidrogênio não liberado em reator anaeróbio de leito ordenado, escoamento descendente, com e sem descartes de biomassa

Segundo a estequiometria da reação, a geração do ácido acético e do butírico poderia ser indicador de elevados rendimentos de hidrogênio, uma vez que o valor teórico do rendimento de hidrogênio a partir de sacarose formando só ácido acético é de $8 \mathrm{~mol} \mathrm{H}_{2} \mathrm{~mol}^{-1}$ sacarose e formando só ácido butírico é de $4 \mathrm{~mol} \mathrm{H}_{2} \mathrm{~mol}^{-1}$ sacarose (MAINTINGUER, 
FERNANDES, et al., 2008). No entanto, o ácido acético pode ser produzido pela rota de produção de hidrogênio conforme Reação 15 , pela via homoacetogênica conforme Reação 16 ou por ambas.

$$
\begin{gathered}
\mathrm{C}_{12} \mathrm{H}_{22} \mathrm{O}_{11}+5 \mathrm{H}_{2} \mathrm{O} \rightarrow 4 \mathrm{CH}_{3} \mathrm{COOH}+4 \mathrm{CO}_{2}+8 \mathrm{H}_{2} \\
4 \mathrm{H}_{2}+2 \mathrm{CO}_{2} \rightarrow \mathrm{CH}_{3} \mathrm{COOH}+2 \mathrm{H}_{2} \mathrm{O}
\end{gathered}
$$

Reação 15

Reação 16

Sendo assim, a vazão molar do ácido acético pode ser calculada pela Equação 34 .

$$
[\mathrm{HAc}]=[\mathrm{HAc}]_{\mathrm{H}_{2}}+[\mathrm{HAc}]_{\mathrm{Hc}}
$$

\section{Equação 34}

$\mathrm{Na}$ qual [HAc] corresponde à vazão molar de ácido acético total em $\mathrm{mmol} \mathrm{h}^{-1}$; $[\mathrm{HAc}]_{\mathrm{H}_{2}}$ à vazão molar de ácido acético liberando hidrogênio em mmol h${ }^{-1} \mathrm{e}[\mathrm{HAc}]_{\mathrm{Hc}}$ à vazão molar de ácido acético via homoacetogênese $\mathrm{em} \mathrm{mmol} \mathrm{h}^{-1}$.

Desta forma, a vazão molar de hidrogênio $\left[\mathrm{H}_{2}\right]$ pode ser determinada pela Equação 35 (LUO, KARAKASHEV, et al., 2011).

$$
\left[\mathrm{H}_{2}\right]=4[\mathrm{HAc}]_{\mathrm{H}_{2}}+4[\mathrm{HBu}]-[\mathrm{HPr}]-4[\mathrm{HAc}]_{\mathrm{Hc}}
$$

Equação 35

Na qual, $[\mathrm{HBu}]$ à vazão molar de ácido butírico em $\mathrm{mmol} \mathrm{h}^{-1} \mathrm{e}[\mathrm{HPr}]$ à vazão molar de ácido propiônico em $\mathrm{mmol} \mathrm{h}^{-1}$.

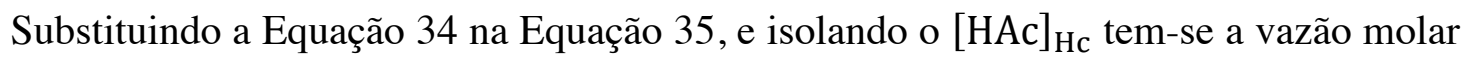
de ácido acético formado via homoacetogênese como apresentado na Equação 36.

$$
[\mathrm{HAc}]_{\mathrm{Hc}}=\frac{4[\mathrm{HAc}]_{\mathrm{H}_{2}}+4[\mathrm{HBu}]-[\mathrm{HPr}]-\left[\mathrm{H}_{2}\right]}{8}
$$

\section{Equação 36}

Dessa forma, com os valores médios experimentais dos PSF e do hidrogênio calculouse a percentagem de ácido acético produzido via homoacetogênese nos três reatores, em ambas as operações durante todo o período experimental (Tabela 23). Observou-se que para todos os casos essa porcentagem foi próxima de $60 \%$ desde o inicio da operação, sugerindo que o método de inoculação e modo de operação do reator (estruturação do leito e escoamento descendente) não foram adequados para inibir as bactérias homoacetogênicas. 
Adicionalmente, o acúmulo de biomassa poderia não estar relacionado com este tipo de bactérias e sim com outros microorganismos consumidores ou não produtores de hidrogênio, pois, enquanto a COVe diminuiu ao longo do tempo, a percentagem de homoacetogênese pareceu inalterada.

Tabela 23 - Percentagem de ácido acético gerado via homoacetogênese em reator anaeróbio de leito ordenado, escoamento descendente operado com e sem descartes de biomassa

\begin{tabular}{ccc}
\hline \multirow{2}{*}{ Leito } & Com descartes de biomassa & Sem descartes de biomassa \\
\cline { 2 - 3 } & {$[\mathbf{H A c}]_{\mathbf{H c}}$} & {$[\mathbf{H A c}]_{\mathrm{Hc}}$} \\
$(\boldsymbol{\%})$ & $65 \pm 15$ \\
\hline Polietileno & $58 \pm 9$ & $61 \pm 11$ \\
Espuma & $63 \pm 10$ & $61 \pm 9$ \\
Cerâmica & $63 \pm 12$ & \\
\hline
\end{tabular}

Descontada a percentagem de ácido acético gerado pela homoacetogênese, o hidrogênio teórico a partir dos PSF foi calculado pela Equação 35. A porcentagem de hidrogênio liberado em relação ao teórico durante a fase de estabilidade em ambas as operações é apresentado na Tabela 24.

Tabela 24 - Porcentagem da vazão molar de hidrogênio $\left(v_{H_{2}}\right)$ liberada em relação à teórica durante a fase de estabilidade em reator anaeróbio de leito ordenado, escoamento descendente operado com e sem descartes de biomassa

\begin{tabular}{|c|c|c|c|c|c|c|}
\hline \multirow{3}{*}{ Leito } & \multicolumn{3}{|c|}{ Com descarte de biomassa } & \multicolumn{3}{|c|}{ Sem descarte de biomassa } \\
\hline & \multirow{2}{*}{$\begin{array}{c}v_{\mathrm{H}_{2}} \text { teórica } \\
\left(\mathrm{mmol} \mathrm{h}^{-1}\right) \\
\end{array}$} & \multicolumn{2}{|c|}{$v_{H_{2}}$ liberada } & \multirow{2}{*}{$\begin{array}{c}v_{H_{2}} \text { teórica } \\
\left(\mathrm{mmol} \mathrm{h}^{-1}\right) \\
\end{array}$} & \multicolumn{2}{|c|}{$v_{H_{2}}$ liberada } \\
\hline & & $\left(\mathrm{mmol} \mathrm{h}^{-1}\right)$ & $\%$ & & $\left(\mathrm{mmol} \mathrm{h}^{-1}\right)$ & $\%$ \\
\hline Polietileno & $28,8 \pm 7,0$ & $3,8 \pm 1,3$ & 14 & $26,7 \pm 6,0$ & $2,4 \pm 1,2$ & 10 \\
\hline Espuma & $25,7 \pm 5,5$ & $3,5 \pm 1,4$ & 15 & $29,1 \pm 8,1$ & $3,4 \pm 1,7$ & 12 \\
\hline Cerâmica & $13,7 \pm 4,6$ & $1,4 \pm 0,9$ & 10 & $18,3 \pm 3,3$ & $1,1 \pm 1,1$ & 6 \\
\hline
\end{tabular}

Observa-se que a porção de hidrogênio liberado não supera $15 \%$ do hidrogênio teórico em nenhum dos casos. Uma parte do hidrogênio inicialmente produzido pode ter sido utilizada para síntese celular, enquanto outra pode ter ficado presa no meio líquido. No entanto, não é possível definir quais as percentagens em cada caso. Para Pauss et al. (1990) as perdas de hidrogênio dissolvido no efluente líquido chegaram a $62 \%$ em um reator de manta de lodo e filtro operado com escoamento ascendente. Os autores observaram que em uma ampla faixa de condições de mistura e de carga orgânica aplicada, o hidrogênio foi entre 35 e 71 vezes mais concentrado do que o valor de equilíbrio esperado. 
Em sistemas anaeróbios onde espécies gasosas são formadas na fase líquida e tendem a escapar para a fase gasosa, as limitações de transferência implicam concentrações de gás dissolvido maiores que os valores correspondentes ao equilíbrio. Tais superconcentrações podem ser adversas para o sistema biológico, gerando efeitos termodinâmicos negativos (PAUSS, ANDRE, et al., 1990). Para Zhang et al. (2012) a supersaturação de hidrogênio no meio líquido é inevitável em um sistema fermentativo de cultura mista e ocorre justamente porque a velocidade de produção de hidrogênio é maior que a velocidade de transferência de massa líquido-gás.

Em reatores com retenção física de biomassa, como os utilizados nesta estratégia, o decréscimo na eficiência de transferência de massa depois de um tempo de operação tem sido associado à aglomeração de biomassa e à falta de mistura eficiente. Não havendo força de cisalhamento suficiente para ajudar a separar o biogás aderido às partículas do lodo, as bolhas fazem com que as partículas flutuem e cubram a superfície no topo do reator, resultando em um processo fermentativo ineficiente e instável e mesmo na desativação do reator (REN, TANG, et al., 2010).

Evidências fotográficas apresentadas na Figura 19 podem ser um indício do comportamento descrito por Ren et al. (2010) nesta estratégia.
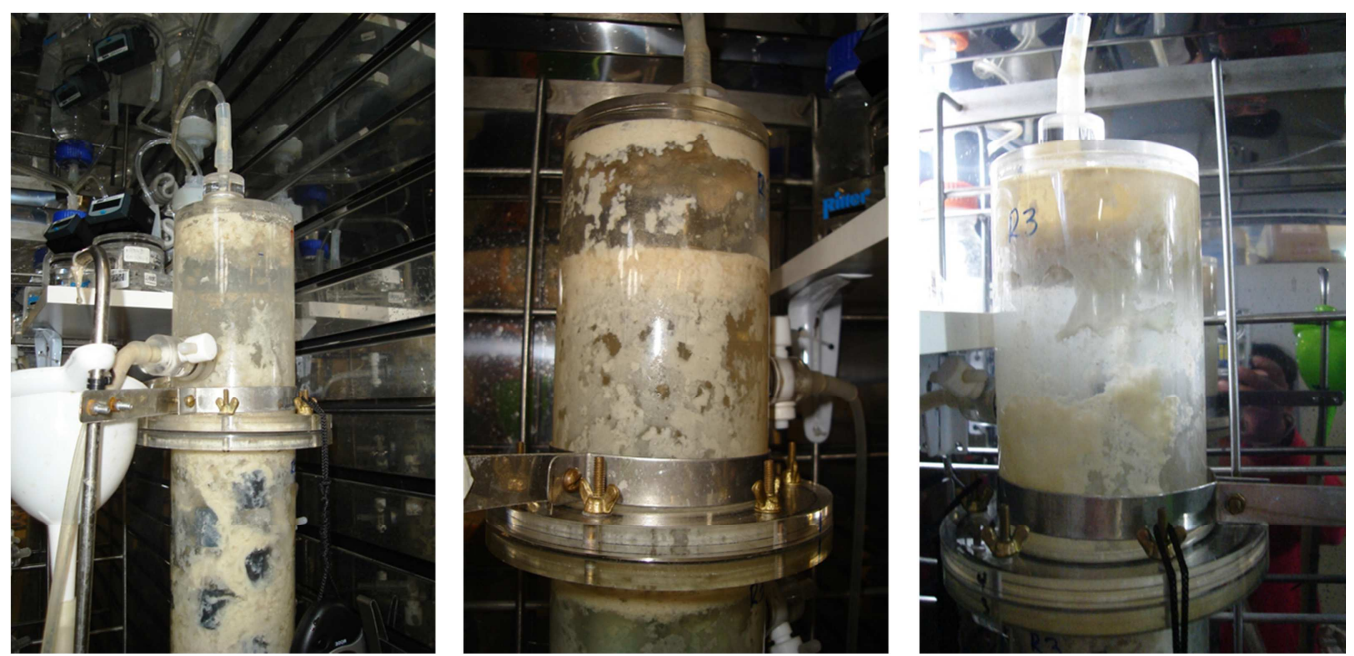

Figura 19 - Evidências fotográficas de biomassa flutuando no topo do reator anaeróbio de leito ordenado e escoamento descendente, operado com TDH de 2 h e concentração de substrato de 2 g DQO $\mathrm{L}^{-1}$.

Sendo assim, as perdas de hidrogênio aqui observadas podem ter sido causadas pelas limitações de transferência de massa que levaram à supersaturação de hidrogênio no meio líquido. Adicionalmente, esse hidrogênio dissolvido junto com o dióxido de carbono podem 
ter promovido a homoacetogênese ou outras reações metabólicas secundárias não favoráveis para o sistema (ZHANG, ZHANG, et al., 2012; KRAEMER e BAGLEY, 2008).

\subsubsection{Conclusões parciais - Estratégia 2}

Os resultados da estratégia 2 permitiram observar que manter a COVe em uma faixa adequada pode levar à produção de hidrogênio de forma contínua, validando, em parte, a subhipótese 2, com relação à operação do reator de leito ordenado e escoamento descendente com ou sem descarte programado de biomassa.

A ordenação do leito permitiu resolver os problemas físicos observados no leito empacotado utilizado na estratégia 1, uma vez que houve aumento na porosidade do leito de aproximadamente $28 \%$, diminuindo as anomalias no padrão de escoamento, pois os TDH reais do leito ordenado com leito de polietileno e espuma (1,71 e 2,12 h, respectivamente) foram mais próximos do TDH teórico $(2 \mathrm{~h})$. Com isso, a recuperação do biogás foi viável no reator anaeróbio com leito ordenado e escoamento descendente. A vazão máxima de biogás foi de 368,402 e $250 \mathrm{~mL} \mathrm{~h}^{-1}$ com leitos de polietileno, espuma e cerâmica, respectivamente.

Comparado com o leito empacotado com escoamento ascendente utilizado por Anzola-Rojas et al. (2014), a ordenação do leito diminuiu o acúmulo de biomassa em aproximadamente $15 \%$ e o escoamento descendente aumentou a saída natural de biomassa em aproximadamente $10 \%$ e permitiu que $5 \%$ do total de biomassa fosse sedimentada para posteriores descartes. Estas características permitiram manter o valor da carga orgânica

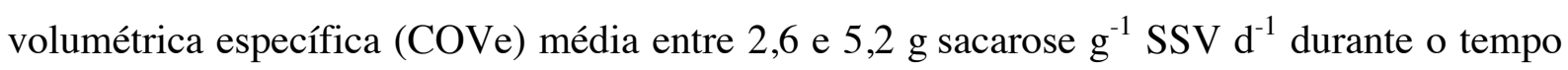
de estabilidade, observando continuidade na produção de hidrogênio até o final da operação com $P V H$ média de $0,6 \mathrm{~L} \mathrm{H}_{2} \mathrm{~L}^{-1} \mathrm{~d}^{-1}$ e $Y_{\mathrm{H}_{2}}$ médio de $0,5 \mathrm{~mol} \mathrm{H}_{2} \mathrm{~mol}_{\mathrm{sc}}{ }^{-1}$ nos reatores com leito de polietileno e espuma.

Dentre os três materiais usados para a adesão da biomassa (polietileno, espuma e cerâmica), a cerâmica se mostrou como não adequado para a produção de hidrogênio em reator anaeróbio de leito ordenado e escoamento descendente, uma vez que apresentou a menor eficiência de conversão de sacarose $(48 \%), P V H$ média $\left(0,2 \mathrm{~L} \mathrm{H}_{2} \mathrm{~L}^{-1} \mathrm{~d}^{-1}\right)$ e $Y_{\mathrm{H}_{2}}$ médio $\left(0,1 \mathrm{~mol} \mathrm{H}_{2} \mathrm{~mol}_{\mathrm{sc}}{ }^{-1}\right)$. Adicionalmente, a produção de biogás cessou completamente quando este reator foi operado sem descartes de biomassa.

Os descartes de biomassa sedimentada foram favoráveis para a produção de hidrogênio em reator anaeróbio de leito ordenado e escoamento descendente, uma vez que tais 
descartes poderiam ter sido em sua maioria microorganismos consumidores ou não produtores de hidrogênio.

Manter um valor adequado da COVe constante em um reator anaeróbio de leito ordenado e escoamento descendente pode ser a chave para manter a continuidade na produção de hidrogênio. No entanto, em culturas mistas, como no caso desta estratégia, o valor sugere uma dependência da distribuição da biomassa dentro do reator.

A principal perda de hidrogênio no reator anaeróbio de leito ordenado e escoamento descendente ocorre no efluente líquido, uma vez que provavelmente devido à baixa velocidade de transferência de massa líquido-gás houve supersaturação de hidrogênio dissolvido. Adicionalmente, esse fenômeno que ocorreu desde o começo da operação contínua pode ter propiciado o consumo de hidrogênio e dióxido de carbono pela homoacetogênese. 


\subsection{Estratégia 3 - Reator anaeróbio com leito empacotado operado com escoamento ascendente e descartes frequentes de biomassa.}

Os resultados da estratégia 2 permitiram observar que a manutenção da COVe em uma faixa adequada, por meio da ordenação do leito, o escoamento descendente e os descartes de biomassa, pode levar a produção de hidrogênio de forma contínua ao longo do tempo. A comparação entre ambas as operações, com e sem descarte de biomassa, indicou que aumentar o volume ou a frequência dos descartes durante a fase de estabilidade poderia melhorar essa produção devido à renovação de biomassa favorável para tal fim dentro do reator. Por outro lado, reatores de leito empacotado e escoamento ascendente têm mostrado melhor eficiência de conversão de sacarose (FERNANDES, 2008; ANZOLA-ROJAS, 2010), o que também poderia terminar no aumento da produção de hidrogênio.

Deste modo, essas observações sugeriram que a operação de um reator de leito empacotado com controle da COVe por meio de descartes de biomassa, porém com escoamento ascendente, uma vez que os resultados da estratégia 1 indicaram inviabilidade do escoamento descendente neste tipo de leito, poderia melhorar o desempenho geral do reator de leito fixo e consequentemente garantir uma produção contínua e estável de hidrogênio.

Assim, durante 103 dias, operou-se continuamente um reator anaeróbio de leito empacotado, usando polietileno de baixa densidade como material suporte, escoamento ascendente e descartes frequentes de biomassa. O TDH aplicado foi de $2 \mathrm{~h}$ e a temperatura se manteve controlada em $25^{\circ} \mathrm{C}$. Os descartes de biomassa foram programados tentando manter a COVe próxima de $6 \mathrm{~g}$ sacarose $\mathrm{g}^{-1} \mathrm{SSV} \mathrm{d}^{-1}$, sendo esse valor o sugerido por Anzola-Rojas et al. (2014) para manter contínua a produção de hidrogênio neste tipo de reator.

\subsubsection{Descartes de biomassa}

Para programar os descartes de biomassa foram consideradas a eficiência de conversão de sacarose $\left(E_{S}\right)$ constante de $80 \%$ e a porcentagem de biomassa saindo no efluente de $70 \%$ conforme resultados observados por Anzola-Rojas et al. (2014). O coeficiente de rendimento celular $\left(Y x_{/ s}\right)$ foi considerado $0,06 \mathrm{~g} \mathrm{SSV} \mathrm{g}^{-1}{ }_{\text {sc }}$ conforme observado na estratégia 2, sendo este valor mais próximo ao descrito na literatura (KIM, HAN e SHIN, 2006; DRAKE, GÖBNER e DANIEL, 2008).

No décimo dia de operação contínua, coletaram-se $200 \mathrm{~mL}$ do fundo do reator a fim de conhecer a concentração de sólidos suspensos voláteis (SSV) acumulados e desta forma, 
estimar o próximo descarte buscando manter a COVe constante conforme apresentado na Figura 20.

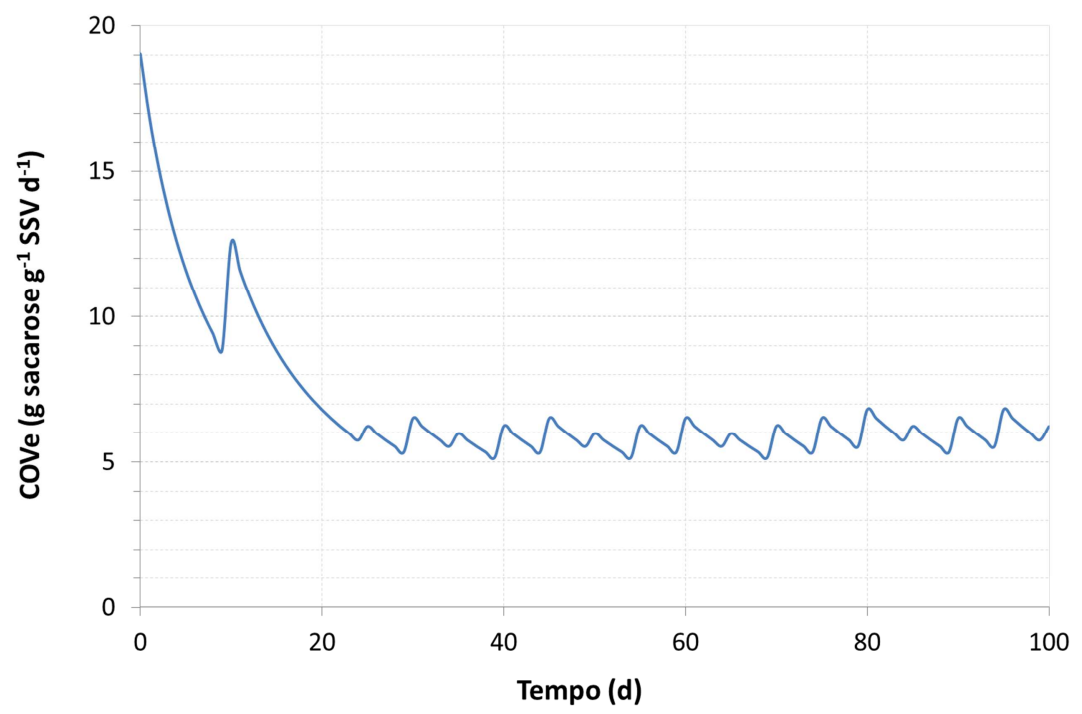

Figura 20 - Carga orgânica volumétrica específica (COVe) estimada a partir da concentração de sólidos suspensos voláteis (SSV) do primeiro descarte de biomassa em reator anaeróbio de leito empacotado e escoamento ascendente

No entanto, o acúmulo de sólidos no fundo do reator foi variável e com tendência a diminuir, uma vez que a biomassa ficou retida no leito tal como mostrado na Figura 21. Esse comportamento levou a que o volume dos descartes fosse cada vez maior tentando-se retirar biomassa do próprio leito.

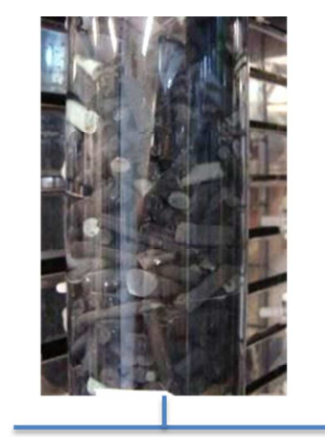

DIA 0

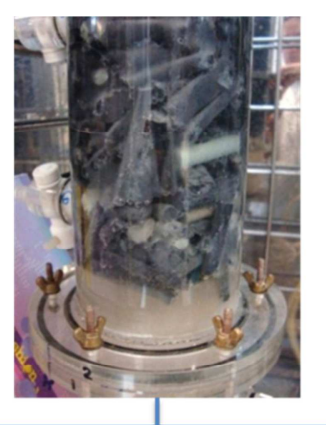

DIA 10

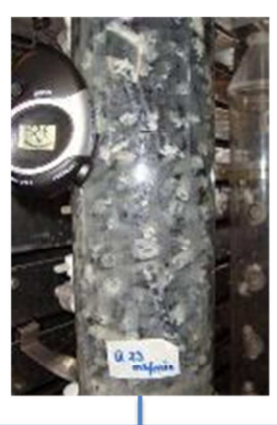

DIA 30

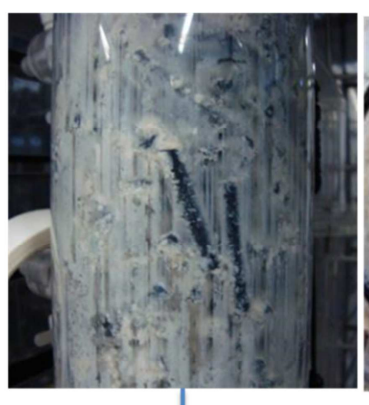

DIA 100

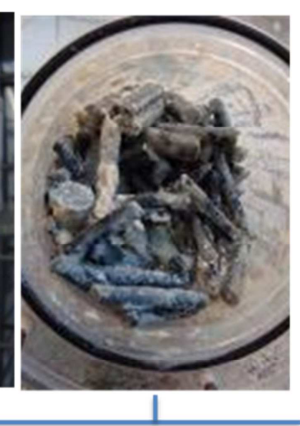

Desmonte

Figura 21 - Crescimento e retenção de biomassa no leito empacotado ao longo do tempo

Assim, por volta do sexagésimo dia os descartes foram de aproximadamente $2 \mathrm{~L}$ com concentração de SSV próxima de $2 \mathrm{~g} \mathrm{~L}^{-1}$ conforme mostrado na Figura 22. Vale ressaltar, que devido à impossibilidade de filtragem das amostras causada pela elevada concentração de biomassa, a concentração de SSV foi estimada como a concentração dos sólidos voláteis totais (SVT). 


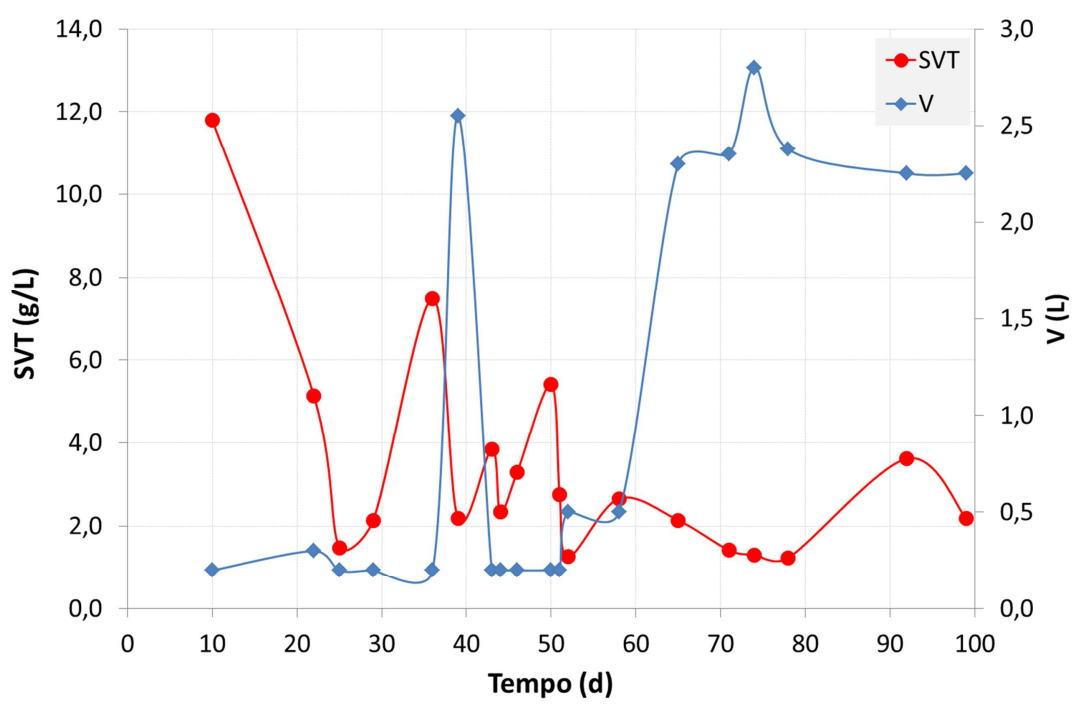

Figura 22 - Descartes frequentes de biomassa em reator anaeróbio de leito empacotado. Concentração de sólidos voláteis totais (SVT) e volume total descartado (V).

A COVe ao longo do tempo foi calculada conforme a metodologia descrita no item 4.6. Inicialmente, a estimativa de biomassa total produzida e a sacarose total consumida foi feita após 103 dias de operação contínua conforme Tabela 25.

Tabela 25 - Estimativa da biomassa total gerada e substrato total consumido em reator anaeróbio de leito empacotado e escoamento ascendente

\begin{tabular}{|c|c|c|}
\hline Biomassa/Substrato & $\begin{array}{c}\text { Nesta estratégia* } \\
\text { (com descartes de } \\
\text { biomassa) }\end{array}$ & $\begin{array}{l}\text { Anzola-Rojas et al. (2014) } \\
\text { (sem descartes de biomassa) }\end{array}$ \\
\hline Dentro do reator (mg) & 67.417 & 19.293 \\
\hline Aderida e intersticial & 15.504 & 12.941 \\
\hline Suspensa & 5.760 & 6.352 \\
\hline Descartada periodicamente (mg) & 46.152 & 0 \\
\hline Arrastada naturalmente (mg) & 149.612 & 44.297 \\
\hline Total biomassa gerada (mg) & 217.029 & 63.590 \\
\hline Total sacarose consumida (mg) & 5.000 .691 & 2.294 .417 \\
\hline Coeficiente $Y x_{/ s}\left(\mathrm{~g} \mathrm{SSV} \mathrm{g}^{-1}{ }_{\mathrm{sc}}\right)$ & 0,043 & 0,028 \\
\hline Biomassa arrastada (\%) & $69 \%$ & $70 \%$ \\
\hline Biomassa dentro do reator $(\%)$ & $31 \%$ & $30 \%$ \\
\hline
\end{tabular}

Se comparado com os valores inicialmente considerados para estimar a COVe, na Tabela 25 é possível notar que a porcentagem de biomassa arrastada foi coincidente, enquanto o $Y x / s$ foi $20 \%$ menor. Desta forma, a COVe real ao longo do tempo foi calculada e 
comparada com a COVe estimada e a COVe observada por Anzola-Rojas et al. (2014) na Figura 23.

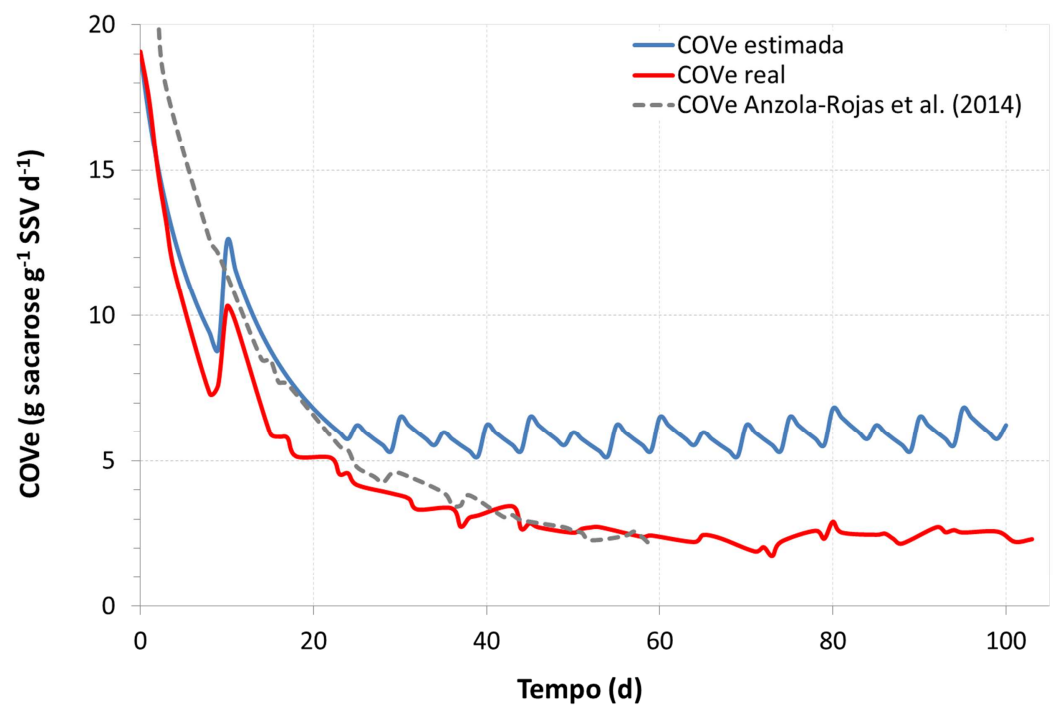

Figura 23 - Comparativo da COVe real e estimada em reator anaeróbio de leito empacotado, escoamento ascendente com descartes de biomassa e COVe observada por Anzola-Rojas et al. (2014) em reator anaeróbio de leito empacotado, escoamento ascendente sem descartes de biomassa

É possível notar que, apesar de serem insuficientes para alcançar o valor planejado de $6 \mathrm{~g}$ sacarose $\mathrm{g}^{-1} \mathrm{SSV} \mathrm{d}^{-1}$, nesta estratégia os descartes de biomassa permitiram manter a COVe

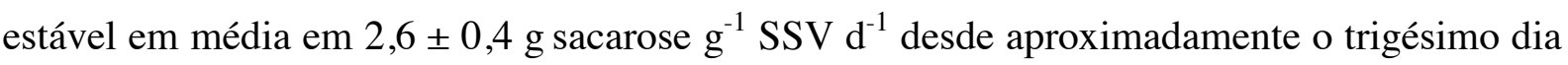
de operação.

5.3.2. Desempenho de reator anaeróbio de leito empacotado, escoamento ascendente e descartes frequentes de biomassa

Os perfis temporais do desempenho geral do reator anaeróbio de leito empacotado, escoamento ascendente e descartes frequentes de biomassa ( $P V H$, o $Y_{H_{2}}$ e $\left.E_{S}\right)$ junto com o perfil da COVe são apresentados na Figura 24. No intuito de ter um padrão de comparação com os trabalhos desenvolvidos anteriormente no LPB-EESC-USP, na mesma figura também são mostrados os resultados descritos por Anzola-Rojas et al. (2014) em um reator anaeróbio de leito fixo, escoamento ascendente sem descartes de biomassa e relação $\mathrm{C} / \mathrm{N}$ de 140 . Similarmente aos trabalhos de Anzola-Rojas (2010), Godoi (2010), Lima e Zaiat (2012), Penteado et al. (2013) e Carminato (2013), o tempo experimental foi dividido em fase transiente e fase de estabilidade, definidas pela conversão da sacarose. Nesta estratégia, observou-se que a fase de estabilidade começou por volta do trigésimo dia de operação. 

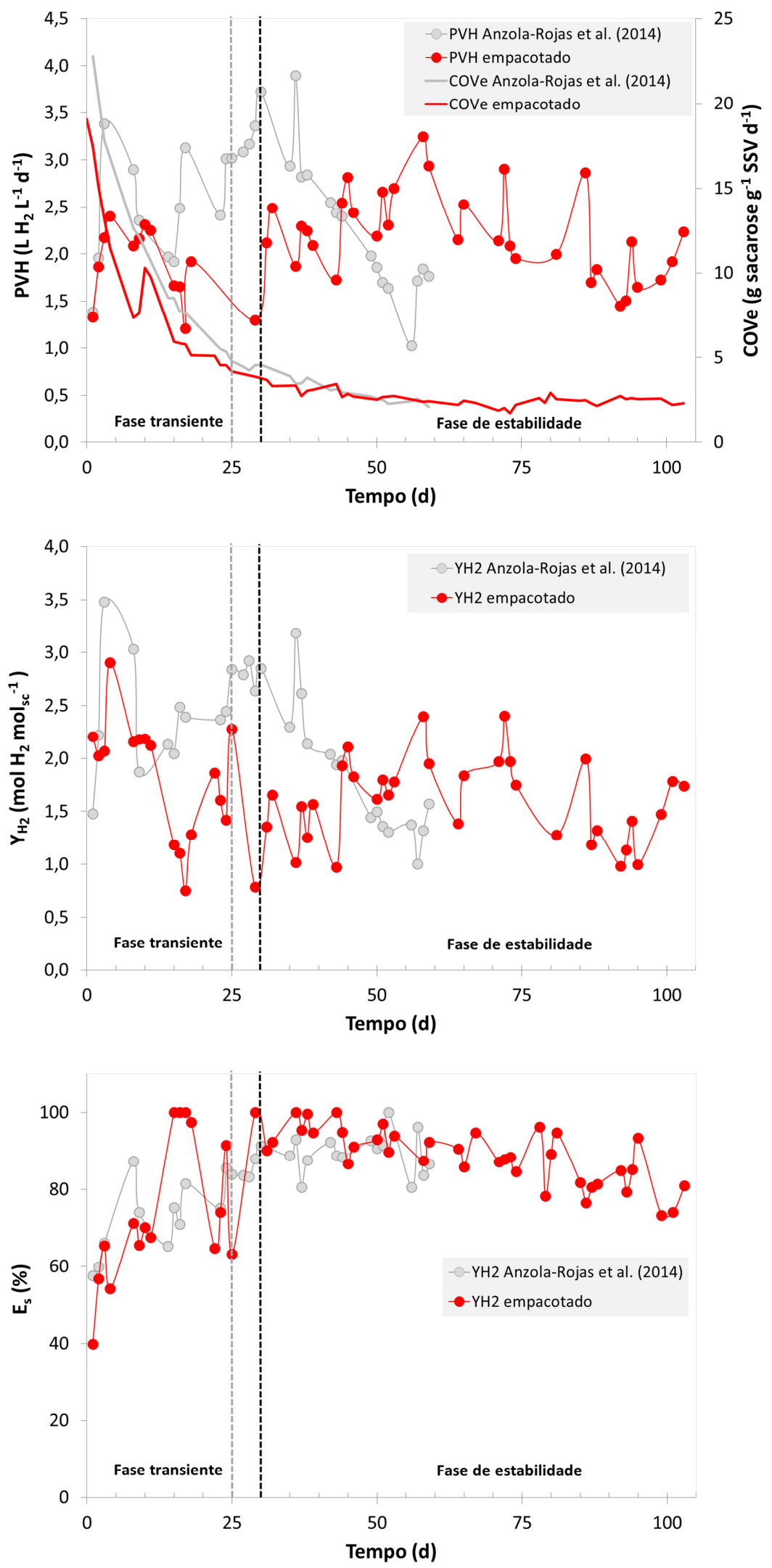

Figura 24 - Desempenho de reator anaeróbio de leito empacotado, escoamento ascendente e descartes periódicos de biomassa (-). Desempenho de reator anaeróbio de leito empacotado, escoamento ascendente sem descartes periódicos de biomassa (- $\bullet$ ) (Anzola-Rojas et al, 2014). Produção volumétrica de hidrogênio ( $P H V$ ); rendimento de hidrogênio $\left(Y_{H_{2}}\right)$; eficiência de conversão de sacarose $\left(E_{s}\right)$. 
Diferente desses trabalhos, durante a fase de estabilidade a produção de hidrogênio foi contínua até o final da operação com $P V H$ média de 2,2 $\pm 0,2 \mathrm{~L} \mathrm{H}_{2} \mathrm{~L}^{-1} \mathrm{~d}^{-1}$ e $Y_{H_{2}}$ médio de 1,6 $\pm 0,4 \mathrm{~mol} \mathrm{H}_{2} \mathrm{~mol}^{-1}$ sc. Adicionalmente, a $P V H$ e o $Y_{H_{2}}$ foram $11 \%$ e $9 \%$ mais estáveis, respectivamente, se comparado com os desvios padrão observados por Anzola-Rojas et al. (2014) no mesmo período conforme apresentado na Tabela 26. Os descartes de biomassa

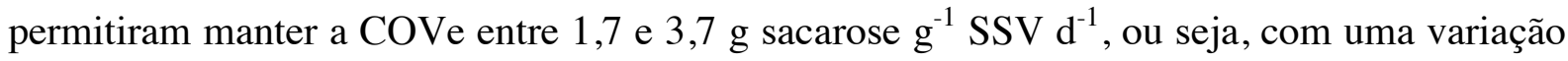
de $16 \%$ durante aproximadamente 70 dias que durou a fase de estabilidade.

Tabela 26 - Desempenho de reator anaeróbio de leito empacotado e escoamento ascendente durante a fase de estabilidade

\begin{tabular}{|c|c|c|c|}
\hline \multicolumn{2}{|c|}{ Parâmetro operacional/reator } & $\begin{array}{c}\text { Nesta estratégia } \\
\text { (com descartes de } \\
\text { biomassa) }\end{array}$ & $\begin{array}{l}\text { Anzola-Rojas et al. (2014) } \\
\text { (sem descartes de biomassa) }\end{array}$ \\
\hline \multirow{4}{*}{$\begin{array}{c}P V H \\
\left(\mathrm{~L} \mathrm{H}_{2} \mathrm{~L}^{-1} \mathrm{~d}^{-1}\right)\end{array}$} & Mínimo & 1,3 & 1,0 \\
\hline & Máximo & 3,2 & 3,9 \\
\hline & Média & $2,2 \pm 0,2$ & $2,5 \pm 0,8$ \\
\hline & $\begin{array}{c}\text { Desvio padrão } \\
(\%)\end{array}$ & 20 & 31 \\
\hline \multirow{4}{*}{$\begin{array}{c}Y_{\mathrm{H}_{2}} \\
\left(\mathrm{~mol} \mathrm{H}_{2} \mathrm{~mol}^{-1}{ }_{\mathrm{sc}}\right)\end{array}$} & Mínimo & 0,8 & 1,0 \\
\hline & Máximo & 2,4 & 3,2 \\
\hline & Média & $1,6 \pm 0,4$ & $2,1 \pm 0,7$ \\
\hline & $\begin{array}{c}\text { Desvio padrão } \\
(\%)\end{array}$ & 24 & 33 \\
\hline \multirow{4}{*}{$\begin{array}{l}E_{S} \\
(\%)\end{array}$} & Mínimo & 72 & 81 \\
\hline & Máximo & 100 & 100 \\
\hline & Média & $89 \pm 7$ & $89 \pm 5$ \\
\hline & $\begin{array}{c}\text { Desvio padrão } \\
(\%)\end{array}$ & 8 & 6 \\
\hline \multirow{4}{*}{$\begin{array}{c}\text { COVe } \\
\text { (g sacarose } \mathrm{g}^{-1} \mathrm{SSV} \\
\left.\mathrm{d}^{-1}\right)\end{array}$} & Mínimo & 1,7 & 2,1 \\
\hline & Máximo & 3,7 & 4,8 \\
\hline & Média & $2,6 \pm 0,4$ & $3,3 \pm 0,9$ \\
\hline & $\begin{array}{c}\text { Desvio padrão } \\
(\%)\end{array}$ & 16 & 27 \\
\hline
\end{tabular}

Por outro lado, se comparada a produção média de hidrogênio desta estratégia com a estratégia 2, durante a fase de estabilidade nos reatores com leito de polietileno e espuma, observa-se um aumento de quase 4 vezes na $P V H$ médio $\left(\approx 0,6 \mathrm{~L} \mathrm{H}_{2} \mathrm{~L}^{-1} \mathrm{~d}^{-1}\right)$ e quase 3 vezes no $Y_{H_{2}}$ médio $\left(\approx 0,5 \mathrm{~mol} \mathrm{H}_{2} \mathrm{~mol}^{-1}{ }_{\text {sc }}\right.$ ), ainda com a COVe próxima da observada no reator de

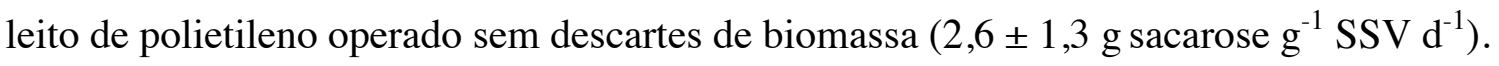


A manutenção da COVe em um valor estável durante a fase de estabilidade, embora menor que o sugerido por Anzola-Rojas et al. (2014) $\left(\approx 6 \mathrm{~g}\right.$ sacarose $\left.\mathrm{g}^{-1} \mathrm{SSV} \mathrm{d}^{-1}\right)$, favoreceram a continuidade na produção de hidrogênio sem alterar a eficiência de conversão de sacarose. Entretanto, observou-se variação da estrutura microbiana segundo a formação e distribuição dos produtos solúveis da fermentação (PSF).

A concentração média dos PSF no meio líquido encontra-se na Tabela 27 e o balanço da DQO na Tabela 28. Similar às observações de Anzola-Rojas et al. (2014), os principais PSF foram o ácido acético, o ácido butírico e o etanol. A produção de ácido propiônico não superou os $60 \mathrm{mg} \mathrm{L}^{-1}$, sendo este valor equivalente a $3 \%$ da DQO afluente.

Tabela 27 - Concentração média dos produtos solúveis da fermentação em reator anaeróbio de leito empacotado e escoamento ascendente durante a fase de estabilidade

\begin{tabular}{ccc}
\hline Leito & $\begin{array}{c}\text { Nesta estratégia } \\
\text { (com descartes de biomassa) } \\
\left(\mathbf{m g ~ D Q O ~ L}^{\mathbf{1}}\right)\end{array}$ & $\begin{array}{c}\text { Anzola-Rojas et al. (2014) } \\
(\text { sem descartes de biomassa) } \\
\left(\mathbf{m g ~ D Q O ~ L}^{\mathbf{- 1}}\right)\end{array}$ \\
\hline Ácido acético & $455 \pm 106$ & $435 \pm 55$ \\
Ácido butírico & $212 \pm 39$ & $338 \pm 124$ \\
Ácido propiônico & $61 \pm 20$ & $64 \pm 19$ \\
Etanol & $344 \pm 101$ & $712 \pm 56$ \\
\hline
\end{tabular}

Tabela 28 - Balanço da DQO em reator anaeróbio de leito empacotado e escoamento ascendente durante a fase de estabilidade

\begin{tabular}{|c|c|c|c|c|c|c|c|}
\hline Leito & $\begin{array}{c}D Q O_{a f} \\
\left(\mathrm{mg} \mathrm{L}^{-1}\right)\end{array}$ & $\begin{array}{c}D Q O_{t(P S F)} \\
\left(\mathrm{mg} \mathrm{L}^{-1}\right)\end{array}$ & $\begin{array}{c}D Q O_{x} \\
\left(\mathbf{m g ~ L}^{-1}\right)\end{array}$ & $\begin{array}{c}D Q O_{S E} \\
\left(\mathrm{mg} \mathrm{L}^{-1}\right)\end{array}$ & $\begin{array}{l}D^{D Q O_{H_{2}}} \\
\left(\mathrm{mg} \mathrm{L}^{-1}\right)\end{array}$ & $\begin{array}{c}D Q O_{e f} \\
\left(\mathrm{mg} \mathrm{L}^{-1}\right)\end{array}$ & $D Q O_{e f} / a f$ \\
\hline $\begin{array}{c}\text { Nesta } \\
\text { estratégia }\end{array}$ & 1.887 & 1.084 & 71 & 234 & 56 & 1.330 & 0,77 \\
\hline $\begin{array}{l}\text { Anzola } \\
\text { Rojas et al. } \\
(2014)\end{array}$ & 1.835 & 1.549 & 46 & 182 & 70 & 1.847 & 1,01 \\
\hline
\end{tabular}

Nesta estratégia, a concentração de etanol foi aproximadamente 52\% menor comparado com o observado por Anzola-Rojas et al. (2014), enquanto a diferença entre a DQO afluente e efluente aumentou 23\%. Essa diferença, como na estratégia 2, pode ser atribuída a produtos não detectados pelo método cromatográfico usado.

Provavelmente, os descartes de biomassa promoveram a utilização da sacarose para formação de outros PSF como o ácido lático. Na glicólise, o ácido lático emerge diretamente do piruvato, enquanto o etanol emerge do Acetil-CoA, ou seja, de um passo adicional no processo. Contudo, a geração de um ou ambos, etanol e/ou ácido lático, é indesejável no 
processo fermentativo quando o objetivo é a produção de hidrogênio, uma vez que não estão relacionados com este fim (NTAIKOU, ANTONOPOULOU e LYBERATOS, 2010).

5.3.3. Homoacetogênese e hidrogênio não liberado em reator anaeróbio de leito empacotado operado com escoamento ascendente e descartes de biomassa

Conforme Tabela 29, a atividade homoacetogênica não mostrou alteração com os descartes de biomassa, pois a porcentagem de ácido acético gerado por esta rota foi similar ao observado por Anzola-Rojas et al. (2014). Se comparada essa atividade com a dos reatores de leito ordenado de polietileno e espuma da estratégia 2 , observa-se em média uma atividade $21 \%$ e $26 \%$ menor.

Tabela 29 - Ácido acético gerado via homoacetogênese em reator anaeróbio de leito empacotado e escoamento ascendente durante a fase de estabilidade

\begin{tabular}{ccc}
\hline Parâmetro & $\begin{array}{c}\text { Nesta estratégia } \\
\text { (com descartes de biomassa) }\end{array}$ & $\begin{array}{c}\text { Anzola-Rojas et al. (2014) } \\
\text { (sem descartes de biomassa) }\end{array}$ \\
\hline$[\mathrm{HAc}]_{\mathrm{Hc}}(\%)$ & $46 \pm 4$ & $48 \pm 8$ \\
\hline
\end{tabular}

Por outro lado, se comparados os reatores com leito de polietileno na Tabela 30, observa-se que a vazão molar de hidrogênio teórica foi similar em todos os casos independente da estruturação do leito, direção do escoamento, descartes de biomassa e COVe. Porém, nos reatores de leito empacotado e escoamento ascendente, a porcentagem de vazão liberada foi $22 \%$ maior com descartes de biomassa e $30 \%$ maior sem descartes de biomassa.

Tabela 30 - Percentagem da vazão molar de hidrogênio $\left(v_{H_{2}}\right)$ liberada em relação à teórica em reator anaeróbio de leito fixo, usando polietileno como material suporte

\begin{tabular}{|c|c|c|c|c|c|c|}
\hline \multirow[b]{2}{*}{ Trabalho } & \multirow{2}{*}{$\begin{array}{l}\text { Descartes } \\
\text { de } \\
\text { biomassa }\end{array}$} & \multirow{2}{*}{$\begin{array}{c}\text { Leito e } \\
\text { direção do } \\
\text { escoamento }\end{array}$} & \multirow{2}{*}{$\begin{array}{l}\text { COVe média } \\
\left({\text { g sacarose } \mathrm{g}^{-}}^{1} \mathrm{SSV} \mathrm{d}^{-1}\right)\end{array}$} & \multirow{2}{*}{$\begin{array}{l}v_{H_{2}} \text { teórica } \\
\left(\mathrm{mmol} \mathrm{h}^{-1}\right)\end{array}$} & \multicolumn{2}{|c|}{$v_{H_{2}}$ liberada } \\
\hline & & & & & $\left(\mathrm{mmol} \mathrm{h}^{-1}\right)$ & $\%$ \\
\hline $\begin{array}{c}\text { Nesta } \\
\text { estratégia }\end{array}$ & $\begin{array}{c}\text { Com } \\
\text { descartes }\end{array}$ & $\begin{array}{l}\text { Empacotado } \\
\text { Ascendente }\end{array}$ & $2,6 \pm 0,4$ & $27,5 \pm 4,9$ & $9,6 \pm 9,6$ & 36 \\
\hline $\begin{array}{c}\text { Estratégia } \\
2\end{array}$ & $\begin{array}{c}\text { Com } \\
\text { descartes }\end{array}$ & $\begin{array}{c}\text { Ordenado } \\
\text { Descendente }\end{array}$ & $5,2 \pm 2,6$ & $28,8 \pm 7,0$ & $3,8 \pm 1,3$ & 14 \\
\hline $\begin{array}{c}\text { Estratégia } \\
2\end{array}$ & $\begin{array}{c}\text { Sem } \\
\text { descartes }\end{array}$ & $\begin{array}{c}\text { Ordenado } \\
\text { Descendente }\end{array}$ & $2,6 \pm 1,3$ & $26,7 \pm 6,0$ & $2,4 \pm 1,2$ & 10 \\
\hline $\begin{array}{l}\text { Anzola- } \\
\text { Rojas et al. } \\
(2014)\end{array}$ & $\begin{array}{c}\text { Sem } \\
\text { descartes }\end{array}$ & $\begin{array}{l}\text { Empacotado } \\
\text { Ascendente }\end{array}$ & $3,3 \pm 0,9$ & $26,8 \pm 3,2$ & $10,7 \pm 3,4$ & 40 \\
\hline
\end{tabular}


Sendo assim, as anteriores observações permitem inferir que o leito empacotado e o escoamento ascendente provavelmente melhoraram a velocidade de transferência de massa líquido-gás, favorecendo a liberação de hidrogênio e ao mesmo tempo diminuindo a atividade homoacetogênica provocada pelo hidrogênio dissolvido.

Por outro lado, o fato de atingir o mesmo valor de vazão teórica de hidrogênio sob diferentes valores da COVe reforça a suposição da dependência deste parâmetro com a distribuição percentual de biomassa dentro do reator. Tanto no reator de leito ordenado de polietileno operado com escoamento descendente e sem descartes de biomassa, como no reator de leito empacotado operado com escoamento ascendente e com descartes de biomassa, a distribuição percentual de biomassa $(\approx 20 \%$ aderida e $\approx 80 \%$ suspensa) junto com a COVe média e a vazão média teórica de hidrogênio foram similares $\left(\approx 2,6 \mathrm{~g}\right.$ sacarose $\mathrm{g}^{-1} \mathrm{SSV} \mathrm{d}^{-1} \mathrm{e} \approx$ $27 \mathrm{mmol} \mathrm{h}^{-1}$, respectivamente).

Já no resto dos reatores (i.e., de leito ordenado de polietileno e leito ordenado de espuma operados com descartes de biomassa e de leito ordenado de espuma operado sem descartes de biomassa) onde a distribuição percentual de biomassa foi de quase $50 \%$ aderida e $50 \%$ suspensa, a COVe média foi próxima de $5 \mathrm{~g}$ sacarose $\mathrm{g}^{-1} \mathrm{SSV} \mathrm{d}^{-1}$ para atingir a mesma vazão teórica de hidrogênio $\left(\approx 27 \mathrm{mmol} \mathrm{h}^{-1}\right)$.

\subsubsection{Conclusões parciais - Estratégia 3}

Os resultados nessa etapa validam, em parte, a sub-hipótese 1, com respeito ao controle da COVe por meio da operação de leito empacotado e escoamento ascendente com descartes periódicos de biomassa.

Os descartes frequentes de biomassa em reator com leito empacotado e escoamento ascendente, usando polietileno de baixa densidade como material suporte permitiram manter a COVe estável em 2,6 $\pm 0,4 \mathrm{~g}$ sacarose $\mathrm{g}^{-1} \mathrm{SSV} \mathrm{d}^{-1}$, favorecendo a continuidade e estabilidade na produção de hidrogênio com $P H V$ média de 2,2 $\pm 0,2 \mathrm{~L} \mathrm{H}_{2} \mathrm{~L}^{-1} \mathrm{~d}^{-1}$ e $Y_{H_{2}}$ médio de $1,6 \pm 0,4$ mol H $\mathrm{mol}^{-1}{ }_{\mathrm{sc}}$, sem alterar a eficiência média de conversão de sacarose próxima de $89 \%$.

Comparado com o leito ordenado e o escoamento descendente, o leito empacotado junto com o escoamento ascendente favoreceram a velocidade de transferência de massa líquido-gás, aumentando a liberação de hidrogênio em aproximadamente $25 \%$ e diminuindo a atividade homoacetogênica em $15 \%$. No entanto, a supersaturação de hidrogênio dissolvido continua sendo motivo de perdas no reator de leito fixo. 
A similitude da vazão teórica de hidrogênio baseada na geração dos produtos solúveis da fermentação (PSF) sob diferente valor da COVe reforça a suposição de que este parâmetro depende da distribuição percentual da biomassa dentro do reator. 


\subsection{Estratégia 4 - Reator anaeróbio com leito ordenado operado com escoamento ascendente e descartes frequentes de biomassa}

Os resultados observados na estratégia 3 foram bem sucedidos, uma vez que os descartes de biomassa permitiram manter a COVe em um valor constante, favorecendo a liberação contínua de hidrogênio sem alterar a estabilidade do meio líquido. No entanto, esses descartes não foram suficientes para manter a COVe no valor ótimo sugerido por Anzola-

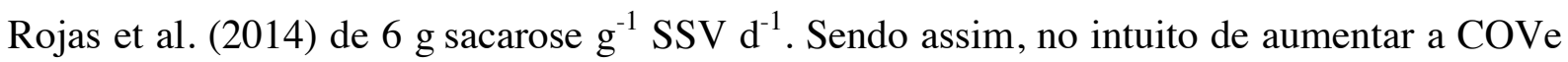
em um reator anaeróbio de leito fixo e escoamento ascendente, optou-se pela ordenação do leito, pois os resultados da estratégia 2 confirmaram que esta permite a diminuição do acúmulo de biomassa. Sendo assim, neste reator se realizaram descartes de biomassa similares aos efetuados na estratégia 3 .

\subsubsection{Descartes de biomassa}

Para programar os descartes de biomassa neste caso, considerou-se a eficiência de conversão de sacarose $\left(E_{S}\right)$ constante de $70 \%$, o coeficiente de rendimento celular $\left(Y x_{/ s}\right)$ de $0,06 \mathrm{~g} \mathrm{SSV} \mathrm{g}_{\text {sc }}^{-1}$ e a porcentagem de biomassa saindo no efluente de $86 \%$ conforme observado na estratégia 2 , no reator de leito ordenado de polietileno operado sem descartes de biomassa. Um primeiro descarte de $200 \mathrm{~mL}$ foi realizado no vigésimo sexto dia de operação quando a estimativa da COVe teórica foi de $5 \mathrm{~g}$ sacarose $\mathrm{g}^{-1} \mathrm{SSV} \mathrm{d}^{-1}$. A partir da concentração de SSV deste descarte os demais foram programados segundo a Figura 25.

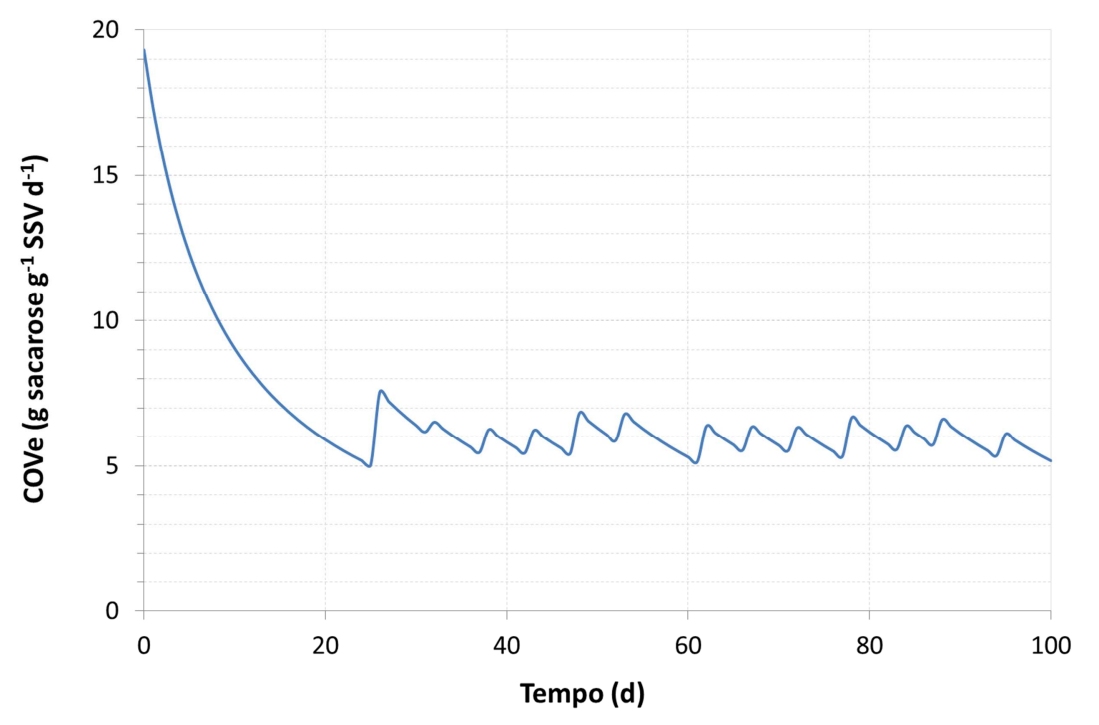

Figura 25 - Carga orgânica volumétrica específica (COVe) estimada a partir da concentração de sólidos suspensos voláteis (SSV) do primeiro descarte de biomassa em reator anaeróbio de leito ordenado e escoamento ascendente 
Realizado o segundo descarte, observou-se um comportamento similar à estratégia 3, pois houve uma marcada diminuição do acúmulo de sólidos no fundo do reator, que foi associada com a ascensão do escoamento. Desta forma, o volume e a frequência dos descartes foram alterados conforme Figura 26.

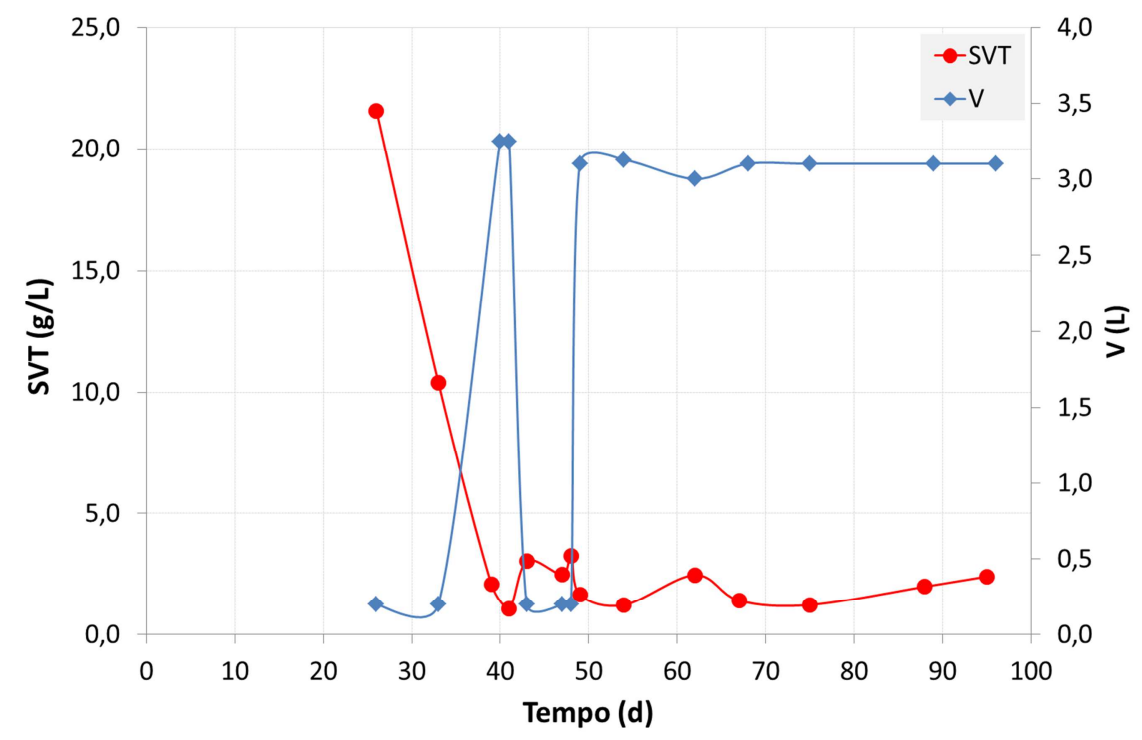

Figura 26 - Descartes frequentes de biomassa em reator anaeróbio de leito ordenado. Concentração de sólidos voláteis totais (SVT) e volume total descartado (V).

$\mathrm{O}$ reator operou continuamente por 100 dias, com TDH de $2 \mathrm{~h}$ e temperatura controlada de $25^{\circ} \mathrm{C}$. Logo após este período, realizou-se a estimativa de biomassa total gerada e a sacarose total consumida conforme Tabela 31.

Tabela 31 - Estimativa de biomassa total gerada e substrato total consumido em reator anaeróbio de leito ordenado, escoamento ascendente e descartes de biomassa

\begin{tabular}{lc}
\hline \multicolumn{1}{c}{ Biomassa/Substrato } & Quantidade \\
\hline Dentro do reator $(\mathrm{mg})$ & 74.042 \\
Aderida e intersticial & 10.207 \\
Suspensa & 7.502 \\
Descartada periodicamente $(\mathrm{mg})$ & 56.334 \\
Arrastada naturalmente $(\mathrm{mg})$ & 192.282 \\
\hline Total biomassa gerada $(\mathrm{mg})$ & 266.324 \\
Total sacarose consumida $(\mathrm{mg})$ & 4.505 .748 \\
Coeficiente $Y{ } / \mathrm{s}\left(\mathrm{g} \mathrm{SSV} \mathrm{g}^{-1}{ }_{\mathrm{sc}}\right)$ & 0,059 \\
\hline Biomassa arrastada $(\%)$ & $72 \%$ \\
Biomassa dentro do reator $(\%)$ & $28 \%$ \\
\hline
\end{tabular}


Observa-se que o fator $Y x / s$ foi próximo de $0,06 \mathrm{~g} \mathrm{SSV} \mathrm{g}^{-1}{ }_{\mathrm{sc}}$, coincidente com o valor considerado inicialmente, enquanto a porcentagem de biomassa saindo do reator foi $14 \%$ menor. Entretanto, os descartes frequentes foram $8 \%$ maiores em relação à biomassa dentro do reator, comparado com a estratégia 3 (Tabela 25). Desta forma, a COVe real ao longo do tempo foi calculada conforme apresentado na Figura 27 e comparada com a COVe estimada e a COVe real da estratégia 3 .

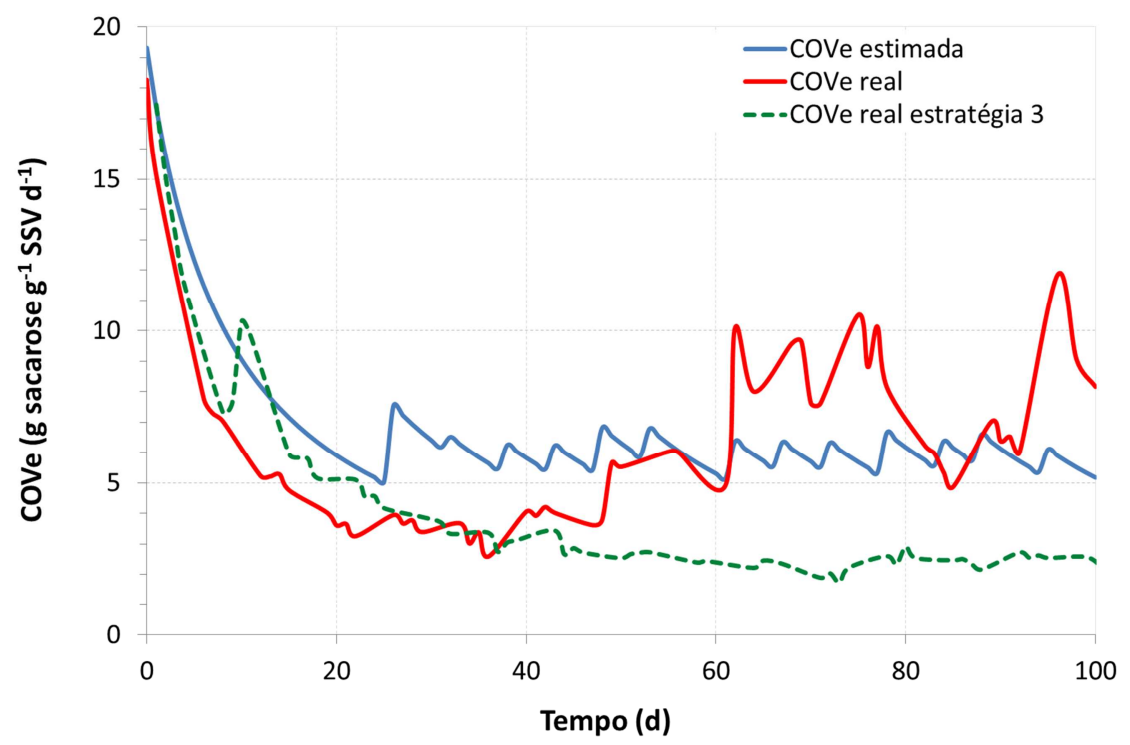

Figura 27 - Comparativo da COVe estimada com a COVe real em reator anaeróbio de leito ordenado, escoamento ascendente e descartes de biomassa e COVe real em reator anaeróbio de leito empacotado, escoamento ascendente e descartes de biomassa observada na estratégia 3

Nesta ocasião, após o dia 40 de operação os descartes foram excessivos, levando a

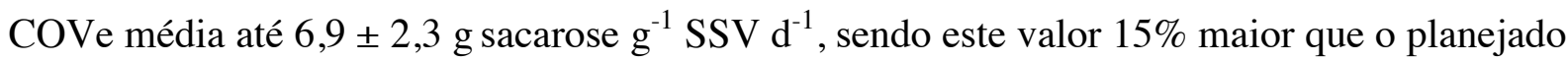
e com desvio padrão igual a $33 \%$.

5.4.2. Desempenho em reator de leito ordenado, escoamento ascendente e descartes frequentes de biomassa

Na Figura 28 são apresentados os perfis temporais da $P V H$, o $Y_{H_{2}}$ e a $E_{S}$ junto com a COVe no reator anaeróbio de leito ordenado com descartes programados de biomassa. A produção máxima de hidrogênio ocorreu durante a fase transiente. No entanto, neste caso observou-se um pico máximo, contínuo e estável durante dez dias consecutivos com $P V H$ média de 3,13 $\pm 0,07 \mathrm{~L} \mathrm{H}_{2} \mathrm{~L}^{-1} \mathrm{~d}^{-1}$, ou seja, com desvio padrão igual a $2 \%$. 

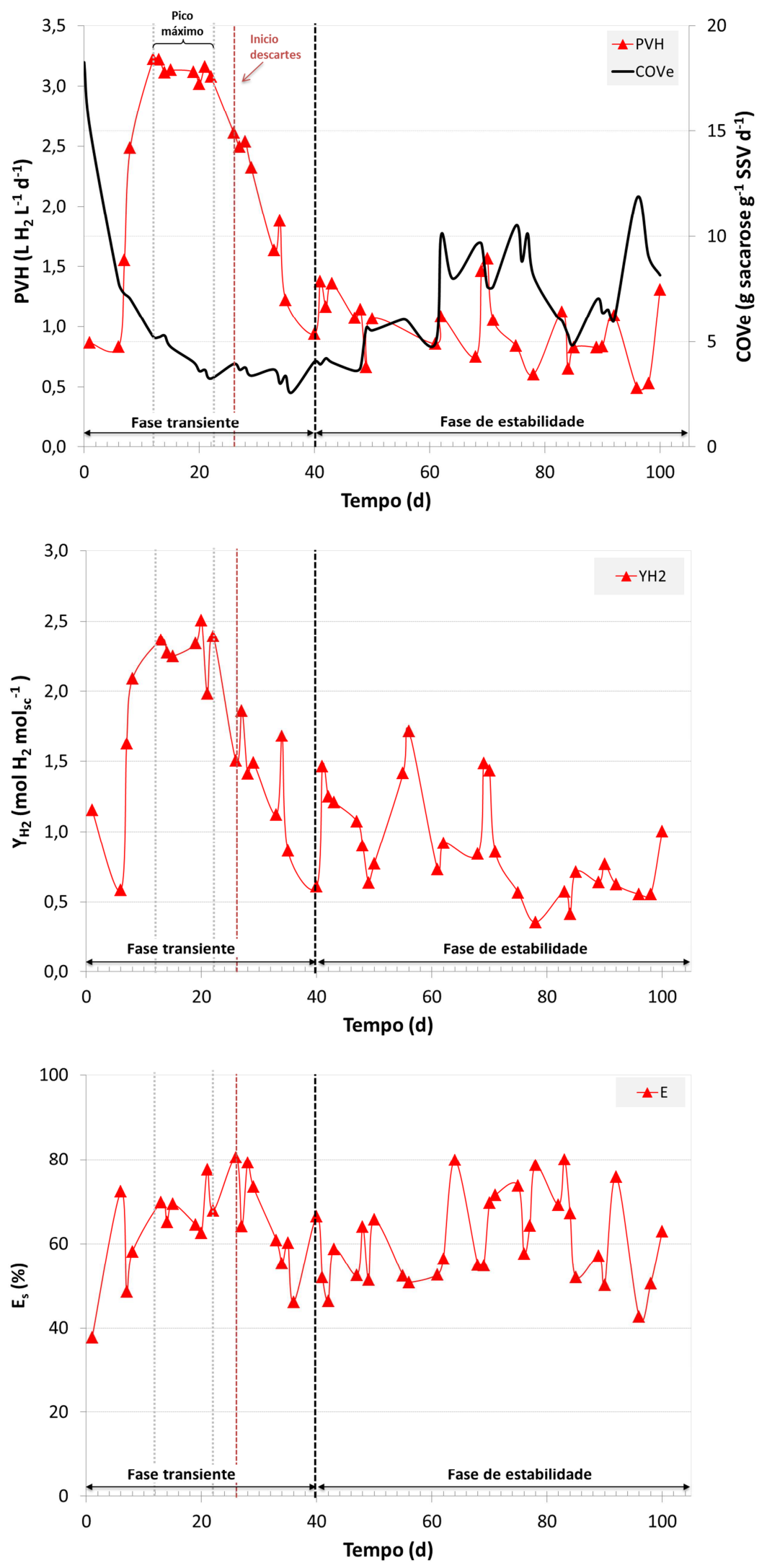

Figura 28 - Desempenho de reator anaeróbio de leito ordenado, escoamento ascendente e descartes periódicos de biomassa $(\star)$. Produção volumétrica de hidrogênio $(P H V)$; rendimento de hidrogênio $\left(Y_{H_{2}}\right)$; eficiência de conversão de sacarose $\left(E_{s}\right)$. 
A continuidade e estabilidade nesse valor de $P V H$, não observada antes em reatores similares (FERNANDES, 2008; ANZOLA-ROJAS, 2010; GODOI, 2010; LIMA e ZAIAT, 2012; PENTEADO, LAZARO, et al., 2013; CARMINATO, 2013) e inclusive em nenhum

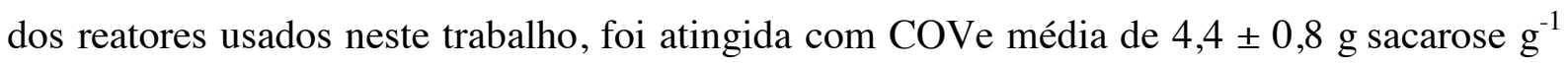
$\mathrm{SSV} \mathrm{d}{ }^{-1}$, isto é, um incremento de $69 \%$ neste parâmetro comparado com a estratégia 3.

Durante o mesmo período, o $Y_{\mathrm{H}_{2}}$ médio atingiu 2,3 $0,2 \mathrm{~mol} \mathrm{H}_{2} \mathrm{~mol}^{-1}$ sc e a $E_{S}$ foi de 68 $\pm 5 \%$, ambos com desvio padrão equivalente a $7 \%$ conforme Tabela 32 . Se comparados estes valores com a estratégia 3 durante a fase de estabilidade (Tabela 26), a $\mathrm{PVH}$ e o $\mathrm{Y}_{\mathrm{H}_{2}}$ foram $42 \%$ e $44 \%$ maiores e $13 \%$ e $9 \%$ mais estáveis, respectivamente.

Tabela 32 - Desempenho de reator anaeróbio de leito ordenado, escoamento ascendente e descartes de biomassa

\begin{tabular}{|c|c|c|c|}
\hline \multicolumn{2}{|c|}{ Parâmetro operacional/reator } & \multirow{2}{*}{$\frac{\text { Pico máximo }}{3,02}$} & \multirow{2}{*}{$\frac{\text { Fase de estabilidade }^{* * *}}{0,5}$} \\
\hline \multirow{4}{*}{$\begin{array}{c}P V H \\
\left(\mathrm{~L} \mathrm{H}_{2} \mathrm{~L}^{-1} \mathrm{~d}^{-1}\right)\end{array}$} & Mínimo & & \\
\hline & Máximo & 3,22 & 1,6 \\
\hline & Média & $3,13 \pm 0,07$ & $1,0 \pm 0,3$ \\
\hline & $\begin{array}{c}\text { Desvio padrão } \\
(\%)\end{array}$ & 2 & 30 \\
\hline \multirow{4}{*}{$\begin{array}{c}Y_{H_{2}} \\
\left(\mathrm{~mol} \mathrm{H}_{2} \mathrm{~mol}^{-1}{ }_{\text {sc }}\right)\end{array}$} & Mínimo & 1,98 & 0,4 \\
\hline & Máximo & 2,51 & 1,7 \\
\hline & Média & $2,30 \pm 0,16$ & $0,9 \pm 0,4$ \\
\hline & $\begin{array}{c}\text { Desvio padrão } \\
(\%)\end{array}$ & 7 & 41 \\
\hline \multirow{4}{*}{$\begin{array}{c}E_{S} \\
(\%)\end{array}$} & Mínimo & 62 & 43 \\
\hline & Máximo & 77 & 80 \\
\hline & Média & $68 \pm 5$ & $61 \pm 10$ \\
\hline & $\begin{array}{c}\text { Desvio padrão } \\
(\%)\end{array}$ & 7 & 17 \\
\hline \multirow{4}{*}{$\begin{array}{c}\text { COVe } \\
\text { (g sacarose } \mathrm{g}^{-1} \mathrm{SSV} \\
\left.\mathrm{d}^{-1}\right)\end{array}$} & Mínimo & 3,3 & 3,6 \\
\hline & Máximo & 5,3 & 11,8 \\
\hline & Média & $4,4 \pm 0,8$ & $6,9 \pm 2,3$ \\
\hline & $\begin{array}{c}\text { Desvio padrão } \\
(\%)\end{array}$ & 19 & 33 \\
\hline
\end{tabular}

*Entre os dias 12 e 22 de operação. ${ }^{* *}$ A partir do quadragésimo dia de operação.

Apesar disso, imediatamente após o pico máximo, observa-se um forte declínio no desempenho geral do reator até aproximadamente o quadragésimo dia de operação, quando se observou uma possível fase de estabilidade do sistema. O critério de estabilidade baseou-se em um desvio padrão menor que $25 \%$ em pelo menos um dos três parâmetros, $\mathrm{PVH}, \mathrm{Y}_{\mathrm{H}_{2}}$ ou 
$E_{s}$. Neste caso, somente a $E_{s}$ se mostrou estável com desvio padrão igual a $17 \%$ segundo a Tabela 32.

O início dessa queda no desempenho foi coincidente com o início dos descartes de biomassa no vigésimo sexto dia de operação, ainda com COVe estável em 3,4 \pm 0,4 g sacarose $\mathrm{g}^{-1} \mathrm{SSV} \mathrm{d}{ }^{-1}$ entre o dia 26 e 40 de operação. Este comportamento leva a supor que os descartes de biomassa realizados durante este período foram excessivos, causando a desestabilização da comunidade microbiana. A partir do quadragésimo primeiro dia de operação, o sistema tendeu a se estabilizar de novo com uma $E_{S}$ média de $61 \pm 10 \%$, embora com COVe média acima do valor esperado.

A concentração média dos PSF no meio líquido é apresentada na Tabela 33 e o balanço da DQO na Tabela 34. No pico máximo se observou principalmente produção de ácido butírico, enquanto que durante a fase de estabilidade predominaram o ácido acético e o etanol. Adicionalmente, no balanço da DQO se observa que entre o pico máximo e a fase de estabilidade houve diminuição de 3 vezes a DQO envolvida na produção de hidrogênio, coincidente com o aumento de quase 3 vezes na concentração do ácido propiônico.

Tabela 33 - Concentração média dos produtos solúveis da fermentação em reator anaeróbio de leito ordenado, escoamento ascendente e descartes de biomassa

\begin{tabular}{ccc}
\hline PSF & $\begin{array}{c}\text { Pico máximo* }^{*} \\
\left(\text { mg DQO L }^{-1}\right)\end{array}$ & $\begin{array}{c}\text { Fase de estabilidade }^{* * *} \\
\left(\mathbf{m g ~ D Q O ~ ~ ^ { - 1 }}\right)\end{array}$ \\
\hline Ácido acético & $214 \pm 36$ & $289 \pm 103$ \\
Ácido butírico & $293 \pm 43$ & $166 \pm 40$ \\
Ácido propiônico & $18 \pm 4$ & $50 \pm 25$ \\
Etanol & $256 \pm 74$ & $364 \pm 159$ \\
\hline
\end{tabular}

Tabela 34 - Balanço da DQO em reator anaeróbio de leito ordenado, escoamento ascendente e descartes de biomassa

\begin{tabular}{|c|c|c|c|c|c|c|c|}
\hline Leito & $\begin{array}{c}D Q O_{a f} \\
\left(\mathrm{mg} \mathrm{L}^{-1}\right)\end{array}$ & $\begin{array}{c}D Q O_{t(P S F)} \\
\left(\mathrm{mg} \mathrm{L}^{-1}\right)\end{array}$ & $\begin{array}{c}D Q O_{x} \\
\left(\mathrm{mg} \mathrm{L}^{-1}\right)\end{array}$ & $\begin{array}{c}D Q O_{S E} \\
\left(\mathrm{mg} \mathrm{L}^{-1}\right)\end{array}$ & $\begin{array}{l}D O_{H_{2}} \\
\left(\mathrm{mg} \mathrm{L}^{-1}\right)\end{array}$ & $\begin{array}{c}D Q O_{e f} \\
\left(\mathrm{mg} \mathrm{L}^{-1}\right)\end{array}$ & $D Q O_{e f} / a f$ \\
\hline Pico máximo* & 1.829 & 781 & 73 & 585 & 60 & 1.413 & 0,82 \\
\hline $\begin{array}{c}\text { Fase de } \\
\text { estabilidade }\end{array}$ & 1.829 & 868 & 68 & 690 & 20 & 1.524 & 0,90 \\
\hline
\end{tabular}

"Entre os dias 12 e 22 de operação. ${ }^{* *}$ A partir do quadragésimo dia de operação.

Apesar da diminuição na concentração dos PSF, comparado com a estratégia 3 e com o trabalho de Anzola-Rojas et al. (2104), a percentagem da atividade homoacetogênica não foi alterada com a ordenação do leito (Tabela 35), sendo este valor próximo de $50 \%$ em todos os 
casos. Sendo assim, a homoacetogênese pode estar mais relacionada com o efeito de transferência de massa que com a COVe como sugerido na estratégia 3.

Tabela 35 - Ácido acético gerado via homoacetogênese e percentagem da vazão molar de hidrogênio liberado em reator anaeróbio de leito ordenado, escoamento ascendente e descartes de biomassa

\begin{tabular}{ccc}
\hline Parâmetro & Pico máximo $^{*}$ & Fase de estabilidade $^{* *}$ \\
\hline$[\mathrm{HAc}]_{\mathrm{Hc}}(\%)$ & $49 \pm 4$ & $54 \pm 4$ \\
\hline$v_{\mathrm{H}_{2}}$ teórica $\left(\mathrm{mmol} \mathrm{h}^{-1}\right)$ & $25,2 \pm 2,4$ & $22,7 \pm 5,4$ \\
$v_{\mathrm{H}_{2}}$ liberada $\left(\mathrm{mmol} \mathrm{h}^{-1}\right)$ & $13,5 \pm 0,4$ & $4,5 \pm 1,3$ \\
$v_{\mathrm{H}_{2}}$ liberada $(\%)$ & 54 & 21 \\
\hline "Entre os dias 12 e 22 de operação. ${ }^{* *}$ A partir do quadragésimo dia de operação.
\end{tabular}

Por outro lado, na Tabela 35 também é possível observar que a percentagem de hidrogênio liberado durante o pico máximo foi aproximadamente 2,5 vezes maior que a observada durante a fase de estabilidade. Este aumento foi coincidente com uma produção de ácido butírico aproximadamente 2 vezes maior durante o mesmo período (Tabela 33), indicando que esta rota metabólica é a mais favorável para a produção de hidrogênio neste tipo de sistema.

\subsubsection{Conclusões parciais - Estratégia 4}

Os resultados observados nessa estratégia de operação validam, em parte, a subhipótese 1, com relação ao controle da COVe mediante descartes programados de biomassa em reator de escoamento ascendente e, em parte, a sub-hipótese 2, em relação à diminuição do acúmulo intersticial de biomassa por meio da ordenação do leito.

A ordenação do leito no reator anaeróbio com escoamento ascendente permitiu no período de pico um aumento da COVe média de $69 \%$ comparado com a estratégia 3 . A COVe média atingiu 4,4 $\pm 0,8 \mathrm{~g}_{\text {sacarose }} \mathrm{g}^{-1} \mathrm{SSV} \mathrm{d} \mathrm{d}^{-1}$, levando a $P V H$ média a $3,13 \pm 0,07 \mathrm{~L} \mathrm{H}_{2} \mathrm{~L}^{-1} \mathrm{~d}^{-}$

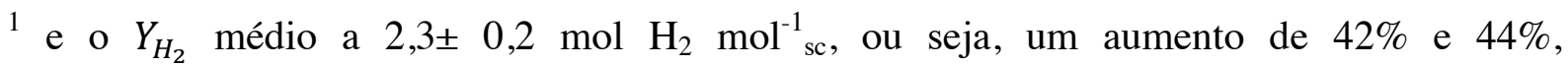
respectivamente. No entanto, os descartes de biomassa realizados após este período de continuidade e estabilidade foram excessivos, causando instabilidade no sistema. 


\subsection{Estratégia 5: Variação da carga orgânica volumétrica (COV) em reator anaeróbio de leito ordenado e escoamento descendente.}

Nesta estratégia, o objetivo principal foi evitar a diminuição da COVe mediante a variação da COV. Para isto, operou-se um reator anaeróbio com leito ordenado de polietileno, escoamento descendente e sem descartes de biomassa durante 185 dias. O tempo experimental se dividiu em 6 fases operacionais consecutivas de aproximadamente 30 dias cada uma, sem reinoculação do sistema.

Cada fase consistiu em operar o reator sob uma COV diferente. Durante as duas primeiras fases o TDH aplicado foi de $2 \mathrm{~h}$ e concentração de substrato de 1 e $2 \mathrm{~g}$ DQO L ${ }^{-1}$, perfazendo uma COV de 12 e $24 \mathrm{~g}$ DQO L ${ }^{-1} \mathrm{~d}^{-1}$, respectivamente. Logo após, durante as fases seguintes o TDH aplicado foi de $4 \mathrm{~h}$ e concentrações de substrato de 2, 4, 8 e 16 g DQO L ${ }^{-1}$, perfazendo uma COV de 12, 24, 48 e $96 \mathrm{~g}^{\mathrm{DQO}} \mathrm{L}^{-1} \mathrm{~d}^{-1}$, respectivamente.

5.5.1. Desempenho geral de reator anaeróbio de leito ordenado, escoamento descendente e variação da COV

Os perfis temporais da $E_{S}, Q_{\text {biogás }}$ e composição do biogás são exibidos na Figura 29 e na Tabela 36 são apresentados os valores médios por fase de cada um dos parâmetros.

Tabela 36 - Desempenho médio de reator anaeróbio de leito ordenado e escoamento descendente com variação da $\mathrm{COV}$

\begin{tabular}{|c|c|c|c|c|c|c|}
\hline Fase & $\begin{array}{c}C O V \\
\left(\mathrm{~g} \mathrm{DQO} \mathrm{L}^{-1} \mathrm{~d}^{-1}\right)\end{array}$ & $\begin{array}{l}E_{s} \\
(\%)\end{array}$ & $\begin{array}{c}Q_{b i o g a ́ s} \\
\left(\mathbf{m L ~ h}^{-1}\right)\end{array}$ & $\begin{array}{c}\mathrm{H}_{2} \\
(\%)\end{array}$ & $\begin{array}{l}\mathrm{CO}_{2} \\
(\%)\end{array}$ & $\begin{array}{c}\text { pH } \\
\text { efluente }\end{array}$ \\
\hline 1 & 12 & $62 \pm 10$ & $31 \pm 51$ & $45 \pm 16$ & $22 \pm 5$ & $5,1 \pm 0,6$ \\
\hline 2 & 24 & $49 \pm 5$ & $136 \pm 55$ & $51 \pm 4$ & $35 \pm 4$ & $4,6 \pm 0,1$ \\
\hline 3 & 12 & $74 \pm 7$ & $5 \pm 11$ & $48 \pm 7$ & $35 \pm 7$ & $4,4 \pm 0,1$ \\
\hline 4 & 24 & $83 \pm 14$ & $768 \pm 167$ & $44 \pm 1$ & $56 \pm 2$ & $4,3 \pm 0,1$ \\
\hline 5 & 48 & $83 \pm 9$ & $1743 \pm 339$ & $40 \pm 1$ & $59 \pm 3$ & $4,0 \pm 0,1$ \\
\hline 6 & 96 & $71 \pm 11$ & $3472 \pm 570$ & $37 \pm 1$ & $60 \pm 1$ & $4,2 \pm 0,2$ \\
\hline
\end{tabular}

Durante as fases 1 e 2, a vazão de biogás aumentou de 31 a $136 \mathrm{~mL} \mathrm{~h}^{-1}$ quando a carga orgânica passou de 12 para $24 \mathrm{~g}$ DQO L $\mathrm{L}^{-1} \mathrm{~d}^{-1}$ com TDH de $2 \mathrm{~h}$. O biogás foi composto por hidrogênio, dióxido de carbono e nitrogênio. Metano não foi detectado. 

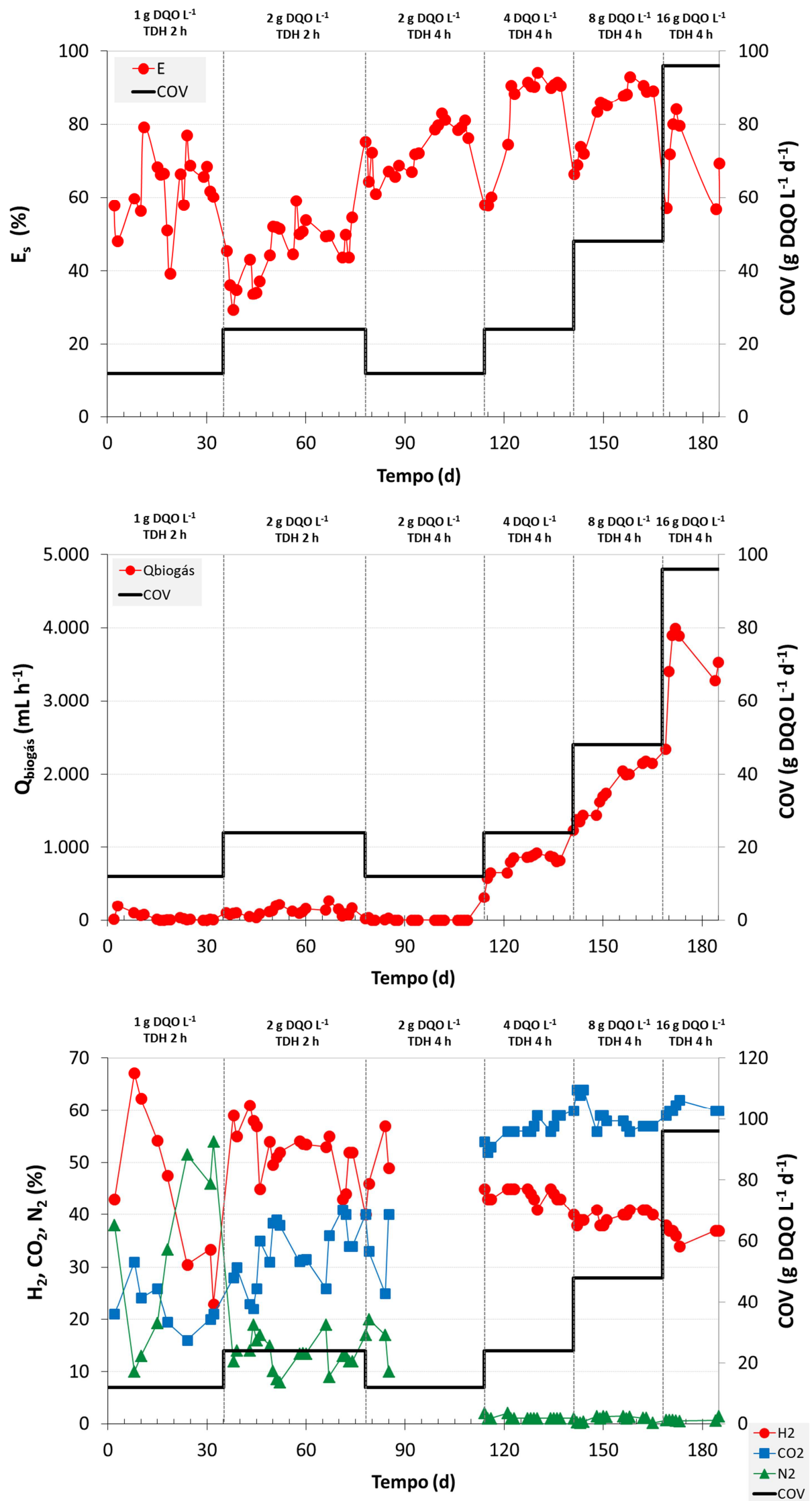

Figura 29 - Perfil temporal da eficiência média de conversão de sacarose $\left(E_{s}\right)$ vazão ( $\left.Q_{\text {biogás }}\right)$ e composição de biogás em reator anaeróbio de leito ordenado, escoamento descendente e variação da COV 
Durante a fase 1, a diminuição da vazão de biogás alterou a sua composição, sendo observado um aumento constante na porcentagem de nitrogênio devido à uma maior diluição, gerada pelo ar contaminante na amostragem. Na fase 2, a vazão de biogás e a composição foram constantes, no entanto o aumento da COV afetou negativamente a $E_{S}$ com uma diminuição de $21 \%$.

Na fase 3, o aumento do TDH para $4 \mathrm{~h}$ com consequente diminuição da COV para 12 g DQO L $\mathrm{L}^{-1} \mathrm{~d}^{-1}$ aumentou $25 \%$ a $E_{S}$ média, porém durante os primeiros 10 dias da mudança, observaram-se pequenas oscilações de biogás de menos de $50 \mathrm{~mL} \mathrm{~h}^{-1}$ seguidas de uma produção completamente nula. Nas fases 4 e 5, com o aumento da concentração do substrato até uma COV de 24 e $48 \mathrm{~g}$ DQO L ${ }^{-1} \mathrm{~d}^{-1}$, respectivamente, a vazão de biogás atingiu um pouco mais de $1,7 \mathrm{~L} \mathrm{~h}^{-1}$ e a $E_{S}$ média aumentou $9 \%$.

Finalmente, na fase 6, o aumento da COV até $96 \mathrm{~g}$ DQO $\mathrm{L}^{-1} \mathrm{~d}^{-1}$ levou a vazão média de biogás próxima de $3,5 \mathrm{~L} \mathrm{~h}^{-1}$, porém a $E_{S}$ média teve uma queda de $14 \%$. O biogás foi composto principalmente por dióxido de carbono e hidrogênio e a porcentagem de nitrogênio caiu para aproximadamente $1 \%$ entre as fases 4 e 6 .

Os PSF se dividiram em principais e secundários dependendo da concentração, assim o valor médio de cada um, em cada fase é apresentado na Tabela 37 e na Tabela 38, respectivamente. Durante as fases 1, 2 e 3 os principais produtos foram o ácido acético, o ácido butírico e o etanol. Já durantes as fases 4, 5 e 6, com o aumento da concentração do substrato de 4 para $16 \mathrm{~g}$ DQO L ${ }^{-1}$ observaram-se principalmente a produção de ácido acético, ácido lático e etanol.

Tabela 37 - Produção média dos PSF principais em reator anaeróbio de leito ordenado, escoamento descendente e variação da COV

\begin{tabular}{|c|c|c|c|c|}
\hline Fase & $\begin{array}{l}\text { Ácido acético } \\
\left.(\mathbf{m g ~ D Q O ~ L})^{-1}\right)\end{array}$ & $\begin{array}{c}\text { Ácido Butírico } \\
\left(\mathbf{m g} D Q O \mathbf{L}^{-1}\right)\end{array}$ & $\begin{array}{c}\text { Ácido Lático } \\
\left.(\mathbf{m g ~ D Q O ~ L})^{-1}\right)\end{array}$ & $\begin{array}{c}\text { Etanol } \\
\left(\mathrm{mg} \mathrm{DQOL}^{-1}\right)\end{array}$ \\
\hline 1 & $110 \pm 30$ & $157 \pm 45$ & $24 \pm 7$ & $144 \pm 54$ \\
\hline 2 & $153 \pm 34$ & $204 \pm 29$ & $31 \pm 5$ & $259 \pm 43$ \\
\hline 3 & $296 \pm 40$ & $285 \pm 46$ & $45 \pm 15$ & $370 \pm 116$ \\
\hline 4 & $688 \pm 162$ & $353 \pm 47$ & $280 \pm 93$ & $1.304 \pm 321$ \\
\hline 5 & $1.140 \pm 130$ & $239 \pm 58$ & $805 \pm 110$ & $3.250 \pm 460$ \\
\hline 6 & $1.929 \pm 438$ & $400 \pm 240$ & $1.038 \pm 605$ & $5.474 \pm 1.368$ \\
\hline
\end{tabular}

Nos produtos secundários, a principal mudança ocorreu durante as fases 4, 5 e 6 com o aparecimento do butanol e propanol, enquanto a produção de ácido isobutírico diminuiu. $\mathrm{O}$ ácido propiônico não apresentou variação entre as fases, indicando que sua produção não 
esteve relacionada com a mudança do TDH ou com a concentração inicial de substrato. Por outro lado, os traços do ácido valérico e isovalérico foram observados somente quando a COV foi de $12 \mathrm{~g} \mathrm{DQO} \mathrm{L}^{-1} \mathrm{~d}^{-1}$ e finalmente a maior concentração de ácido capróico foi observada na

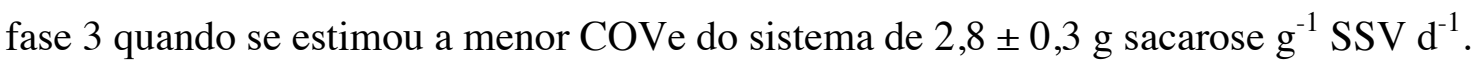

Tabela 38 - Produção média dos PSF secundários em reator anaeróbio de leito ordenado, escoamento descendente e variação da COV

\begin{tabular}{|c|c|c|c|c|c|c|c|}
\hline Fase & $\begin{array}{c}\text { Bu-OH }^{1} \\
\left(\mathrm{mg} \mathrm{DQO}^{-1}\right) \\
\left.\mathbf{L}^{-1}\right)\end{array}$ & $\begin{array}{c}\text { Pro-OH } \\
\left(\mathrm{mg} \mathrm{DQO}^{2}\right. \\
\left.\mathrm{L}^{-1}\right)\end{array}$ & $\begin{array}{c}\text { H-Pr } \\
\left(\mathrm{mg} \mathrm{DQO}^{3}\right. \\
\left.\mathbf{L}^{-1}\right)\end{array}$ & $\begin{array}{c}\text { H-Isobu } \\
\left(\mathrm{mg} \mathrm{DQO}^{4}\right. \\
\left.\mathrm{L}^{-1}\right)\end{array}$ & $\begin{array}{c}\text { H-Isova } \\
\left(\mathrm{mg} \mathrm{DQO}^{5}\right. \\
\left.\mathrm{L}^{-1}\right)\end{array}$ & $\begin{array}{c}\mathrm{H}-\mathrm{Va}^{6} \\
(\mathrm{mg} \mathrm{DQO} \\
\left.\mathrm{L}^{-1}\right)\end{array}$ & $\begin{array}{c}\mathrm{H}-\mathrm{Ca}^{7} \\
(\mathrm{mg} \mathrm{DQO} \\
\left.\mathbf{L}^{-1}\right)\end{array}$ \\
\hline 1 & $0 \pm 0$ & $0 \pm 0$ & $9 \pm 3$ & $23 \pm 15$ & $1 \pm 1$ & $2 \pm 2$ & $41 \pm 14$ \\
\hline 2 & $0 \pm 0$ & $0 \pm 0$ & $20 \pm 5$ & $45 \pm 16$ & $0 \pm 0$ & $0 \pm 0$ & $53 \pm 11$ \\
\hline 3 & $0 \pm 0$ & $0 \pm 0$ & $34 \pm 7$ & $93 \pm 15$ & $0 \pm 0$ & $3 \pm 3$ & $160 \pm 35$ \\
\hline 4 & $8 \pm 6$ & $3 \pm 5$ & $37 \pm 9$ & $29 \pm 47$ & $0 \pm 0$ & $0 \pm 0$ & $110 \pm 35$ \\
\hline 5 & $6 \pm 2$ & $11 \pm 2$ & $46 \pm 21$ & $2 \pm 4$ & $0 \pm 0$ & $0 \pm 0$ & $52 \pm 37$ \\
\hline 6 & $4 \pm 6$ & $12 \pm 2$ & $41 \pm 41$ & $5 \pm 7$ & $0 \pm 1$ & $0 \pm 0$ & $33 \pm 43$ \\
\hline
\end{tabular}
Ácido isovalérico. ${ }^{6} \mathrm{H}-\mathrm{Va}$ : Ácido valérico. ${ }^{7} \mathrm{H}-\mathrm{Ca}$ : Capróico.

No balanço de carbono apresentado na Tabela 39, observou-se uma diferença entre a DQO efluente e afluente de menos de $10 \%$ em todas as fases. Excetuando a fase 2, em todas os casos pelo menos $50 \%$ da DQO afluente foi convertida em PSF. Por outro lado, a percentagem da DQO envolvida na produção de hidrogênio nas fases com COV igual ou maior que $24 \mathrm{~g}$ DQO L $\mathrm{L}^{-1} \mathrm{~d}^{-1}(2,4,5$ e 6$)$ correspondeu a $2 \%$, enquanto que nas fases 1 e 3 quando a COV foi de $12 \mathrm{~g}$ DQO $\mathrm{L}^{-1} \mathrm{~d}^{-1}$ essa percentagem foi de $0,9 \%$ e $0,03 \%$, respectivamente.

Tabela 39 - Balanço de carbono em reator anaeróbio de leito ordenado, escoamento descendente e variação da $\mathrm{COV}$

\begin{tabular}{|c|c|c|c|c|c|c|c|}
\hline Fase & $\begin{array}{c}D Q O_{a f} \\
\left(\mathrm{mg} \mathrm{L}^{-1}\right)\end{array}$ & $\begin{array}{c}D Q O_{t(P S F)} \\
\left(\mathrm{mg} \mathrm{L}^{-1}\right)\end{array}$ & $\begin{array}{c}D Q O_{x} \\
\left(\mathrm{mg} \mathrm{L}^{-1}\right)\end{array}$ & $\begin{array}{c}D Q O_{S E} \\
\left(\mathrm{mg} \mathrm{L}^{-1}\right)\end{array}$ & $\begin{array}{c}D Q O_{H_{2}} \\
\left(\mathrm{mg} \mathrm{L}^{-1}\right)\end{array}$ & $\begin{array}{c}D Q O_{e f} \\
\left(\mathrm{mg} \mathrm{L}^{-1}\right)\end{array}$ & $D Q O_{e f} / a f$ \\
\hline 1 & 896 & 510 & 38 & 331 & 7,9 & 818 & 0,99 \\
\hline 2 & 2.098 & 765 & 71 & 1.042 & 41,3 & 1.805 & 0,91 \\
\hline 3 & 1.889 & 1.286 & 94 & 487 & 0,6 & 1.664 & 0,99 \\
\hline 4 & 4.139 & 2.812 & 226 & 759 & 89,8 & 3.396 & 0,94 \\
\hline 5 & 8.282 & 5.551 & 464 & 1.364 & 194,7 & 6.461 & 0,91 \\
\hline 6 & 15.223 & 8.864 & 718 & 5.019 & 332,8 & 13.209 & 0,98 \\
\hline
\end{tabular}


5.5.2. O comportamento da COVe mediante variação da COV em reator anaeróbio de leito ordenado e escoamento descendente

Como nas estratégias anteriores, a COVe em cada fase foi estimada conforme a metodologia descrita no item 4.6. Após o período experimental, a estimativa de biomassa total gerada e substrato total consumido foi feita conforme apresentado na Tabela 40. Desta forma, o comportamento temporal da COVe em relação à variação da COV é apresentado na Figura 30 e os valores médios por fase na Tabela 41.

Tabela 40 - Estimativa de biomassa total gerada e substrato total consumido em reator anaeróbio de leito ordenado, escoamento descendente e variação da COV

\begin{tabular}{lc}
\hline \multicolumn{1}{c}{ Biomassa/Substrato } & Quantidade \\
\hline Dentro do reator $(\mathrm{mg})$ & 52.102 \\
Aderida e intersticial & 7.994 \\
Suspensa & 26.399 \\
Acumulada no fundo do reator & 17.709 \\
Arrastada naturalmente $(\mathrm{mg})$ & 711.354 \\
\hline Total biomassa gerada $(\mathrm{mg})$ & 763.456 \\
Total sacarose consumida $(\mathrm{mg})$ & 11.471 .571 \\
Coeficiente $Y{ } / \mathrm{s}\left(\mathrm{g} \mathrm{SSV} \mathrm{g}^{-1}\right.$ sc & 0,067 \\
\hline Biomassa arrastada $(\%)$ & $93 \%$ \\
Biomassa dentro do reator $(\%)$ & $7 \%$ \\
\hline
\end{tabular}

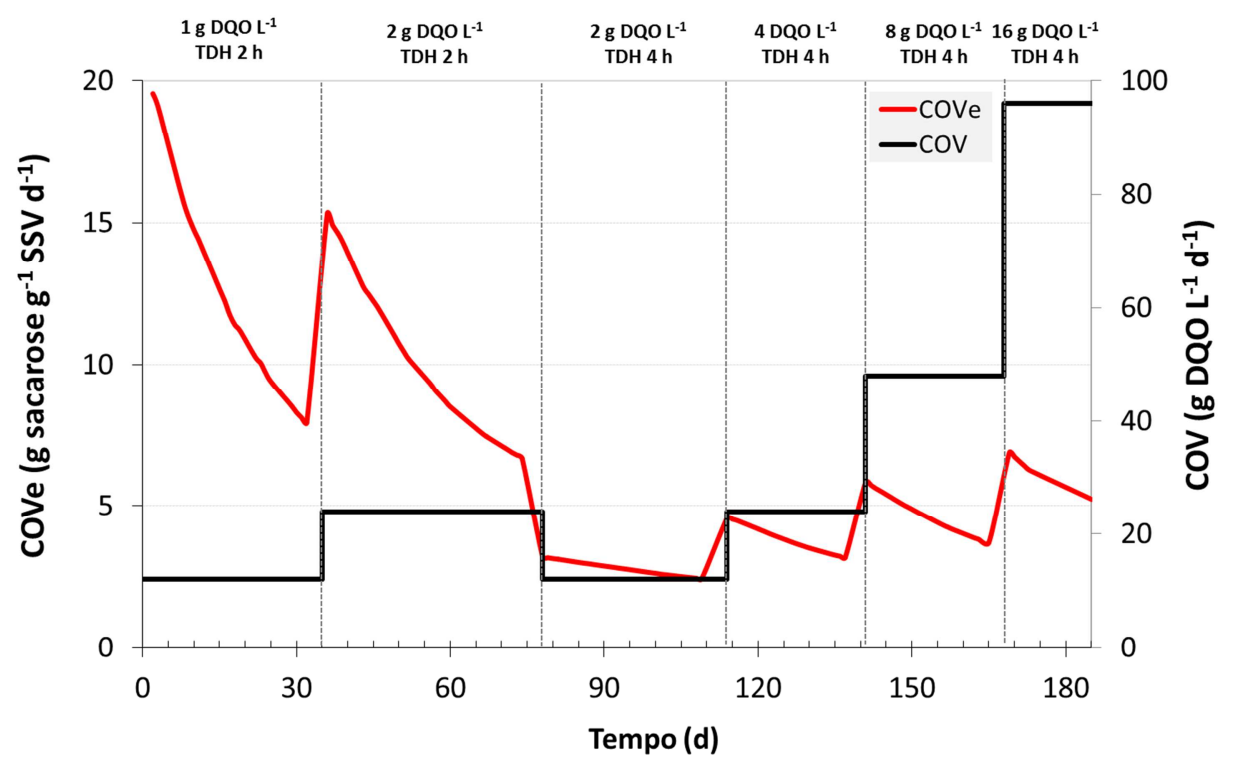

Figura 30 - Comportamento temporal da COVe (-) em relação à variação da COV (-) em reator anaeróbio, leito ordenado e escoamento descendente 
Tabela 41 - COVe média estimada em cada fase operacional em reator anaeróbio de leito ordenado, escoamento descende e variação da $\mathrm{COV}$

\begin{tabular}{|c|c|c|c|}
\hline Fase & $\begin{array}{c}\text { COV } \\
\left(\text { g DQO L }^{-1} d^{-1}\right)\end{array}$ & $\begin{array}{c}\text { COVe média } \\
\left(\text { g sacarose } \mathrm{g}^{-1} \mathrm{SSV} \mathrm{d}^{-1}\right)\end{array}$ & $\begin{array}{c}\text { Desvio padrão } \\
(\%)\end{array}$ \\
\hline 1 & 12 & $12,0 \pm 3,5$ & 30 \\
\hline 2 & 24 & $8,8 \pm 1,7$ & 19 \\
\hline 3 & 12 & $2,8 \pm 0,3$ & 10 \\
\hline 4 & 24 & $3,8 \pm 0,4$ & 11 \\
\hline 5 & 48 & $4,8 \pm 0,7$ & 16 \\
\hline 6 & 96 & $6,2 \pm 0,7$ & 11 \\
\hline
\end{tabular}

Os maiores desvios padrão se observaram durante a fase 1 e 2 quando a COV foi de 12 e $24 \mathrm{~g} \mathrm{DQO} \mathrm{L} \mathrm{L}^{-1} \mathrm{~d}^{-1}$ e o TDH aplicado foi de $2 \mathrm{~h}$. A COV aplicada levou a COVe média ao dobro do valor sugerido por Anzola-Rojas et al. (2014) $\left(\approx 6 \mathrm{~g}\right.$ sacarose $\left.\mathrm{g}^{-1} \mathrm{SSV} \mathrm{d}^{-1}\right)$ durante a fase 1 e a um valor $46 \%$ maior durante a fase 2 . Já durante as fases seguintes, o incremento do TDH de 4 h favoreceu a estabilidade deste parâmetro com desvios padrão de menos de $16 \%$. Adicionalmente, o aumento da concentração de substrato de 4 para $16 \mathrm{~g}$ DQO L ${ }^{-1}$ (COV de 24 para $96 \mathrm{~g}^{\mathrm{DQO}} \mathrm{L}^{-1} \mathrm{~d}^{-1}$ ) manteve a COVe entre 3,8 e 6,2 $\mathrm{g}$ sacarose $\mathrm{g}^{-1} \mathrm{SSV} \mathrm{d}^{-1}$, sendo estes valores mais próximos aos indicados na literatura (ANZOLA-ROJAS, GONÇALVES , et al., 2014; HAFEZ, NAKHLA, et al., 2010; PAN, ZHANG, et al., 2008).

5.5.3. Influência da COVe sobre a produção de hidrogênio em reator anaeróbio de leito ordenado, escoamento descendente e variação da COV

O perfil temporal de produção de hidrogênio ( $P V H$ e $Y_{H_{2}}$ ) junto com a COVe é apresentado na Figura 31 e os valores médios por fase na Tabela 42.

Tabela 42 - Produção de hidrogênio em reator anaeróbio de leito ordenado e escoamento descendente com variação da $\mathrm{COV}$

\begin{tabular}{|c|c|c|c|}
\hline Fase & $\begin{array}{c}\text { COVe média } \\
\left(\text { g sacarose } \mathrm{g}^{-1} \mathrm{SSV} \mathrm{d}^{-1}\right)\end{array}$ & $\begin{array}{c}P V H \\
\left(\mathbf{L ~} \mathbf{H}_{2} \mathbf{L}^{-1} \mathbf{d}^{-1}\right)\end{array}$ & $\begin{array}{c}Y_{H_{2}} \\
\left(\mathbf{m o l ~ H}_{2} \mathbf{m o l}^{-1}{ }_{\text {sc }}\right)\end{array}$ \\
\hline 1 & $12,0 \pm 3,5$ & $0,1 \pm 0,1$ & $0,2 \pm 0,4$ \\
\hline 2 & $8,8 \pm 1,7$ & $0,5 \pm 0,2$ & $0,6 \pm 0,3$ \\
\hline 3 & $2,8 \pm 0,3$ & $0,0 \pm 0,0$ & $0,0 \pm 0,1$ \\
\hline 4 & $3,8 \pm 0,4$ & $2,4 \pm 0,5$ & $1,9 \pm 0,3$ \\
\hline 5 & $4,8 \pm 0,7$ & $4,9 \pm 1,0$ & $1,9 \pm 0,2$ \\
\hline 6 & $6,2 \pm 0,7$ & $8,9 \pm 1,3$ & $2,2 \pm 0,2$ \\
\hline
\end{tabular}



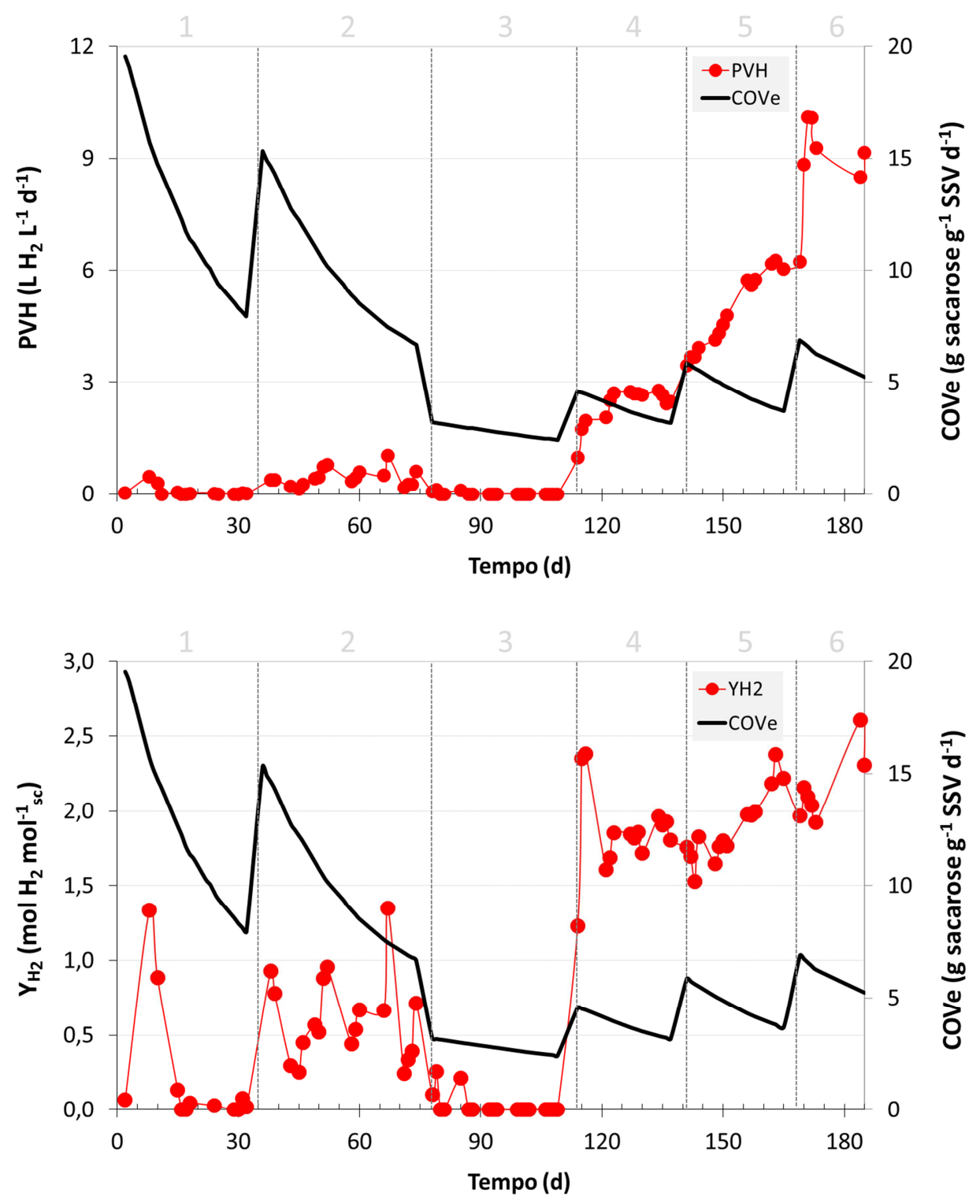

Figura 31 - Perfil temporal da produção de hidrogênio e COVe em reator anaeróbio de leito ordenado e escoamento descendente. Produção volumétrica de hidrogênio $(P V H)$; rendimento de hidrogênio $\left(Y_{H_{2}}\right)$

Observa-se que entre a fase 1 e 2 quando a COVe média diminuiu de 12,0 para 8,8 g sacarose $\mathrm{g}^{-1} \mathrm{SSV} \mathrm{d}^{-1}$ houve um aumento da $P V H$ e do $Y_{H_{2}}$ médio de 5 e 3 vezes, respectivamente. No entanto, no passo para a fase 3 com queda excessiva da COVe média

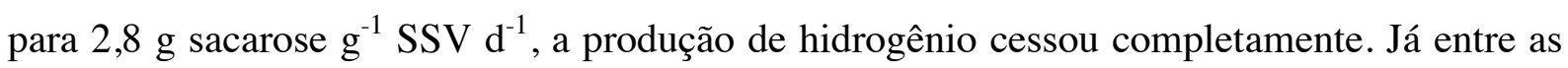
fases 4 e 6, a manutenção da COVe média entre 3,8 e 6,2 $\mathrm{g}$ sacarose $\mathrm{g}^{-1} \mathrm{SSV} \mathrm{d}^{-1}$ foi coincidente com o aumento constante da PVH (de 2,4 a 8,9 $\mathrm{L} \mathrm{H}_{2} \mathrm{~L}^{-1} \mathrm{~d}^{-1}$ ) e a estabilidade do $Y_{\mathrm{H}_{2}}$ ao redor de $2 \mathrm{~mol} \mathrm{H}_{2} \mathrm{~mol}^{-1}{ }_{\text {sc }}$ em aproximadamente 90 dias. Vale ressaltar que este $Y_{\mathrm{H}_{2}}$ foi aproximadamente 4 vezes maior se comparado com os resultados da estratégia 2 em faixas similares de COVe (Tabela 14 e Tabela 22). 
A tendência da produção média de hidrogênio por fase em relação à COVe média é exibida na Figura 32. Os pontos se ajustaram a uma função do tipo GaussAmp $\left(y=y_{0}+\right.$ $A e^{\wedge}\left(-\left(x-x_{c}\right)^{2} / 2 w^{2}\right)$ com ajuda do OriginPro $8.0^{\circledR}$ com coeficiente de determinação $\left(\mathrm{R}^{2}\right)$ de 0,9734 para a $P V H$ média e 0,6030 para o $Y_{H_{2}}$ médio. Vale ressaltar que essa função representou a tendência matemática e foi usada somente para calcular os pontos máximos não tendo sentido físico. Por meio da derivação da função de ajuste, chegou-se a um ponto de COVe de 6,0 g sacarose $\mathrm{g}^{-1} \mathrm{SSV} \mathrm{d} \mathrm{d}^{-1}$ para alcançar uma $P V H$ máxima de $8,8 \mathrm{~L} \mathrm{H}_{2} \mathrm{~L}^{-1} \mathrm{~d}^{-1}$ e COVe de 5,7 g sacarose $\mathrm{g}^{-1} \mathrm{SSV} \mathrm{d}^{-1}$ para atingir um $Y_{\mathrm{H}_{2}}$ máximo de 2,3 $\mathrm{mol} \mathrm{H}_{2} \mathrm{~mol}^{-1}$ sc, sendo estes valores de COVe próximos aos sugeridos na literatura (ANZOLA-ROJAS, GONÇALVES , et al., 2014; HAFEZ, NAKHLA, et al., 2010; PAN, ZHANG, et al., 2008).

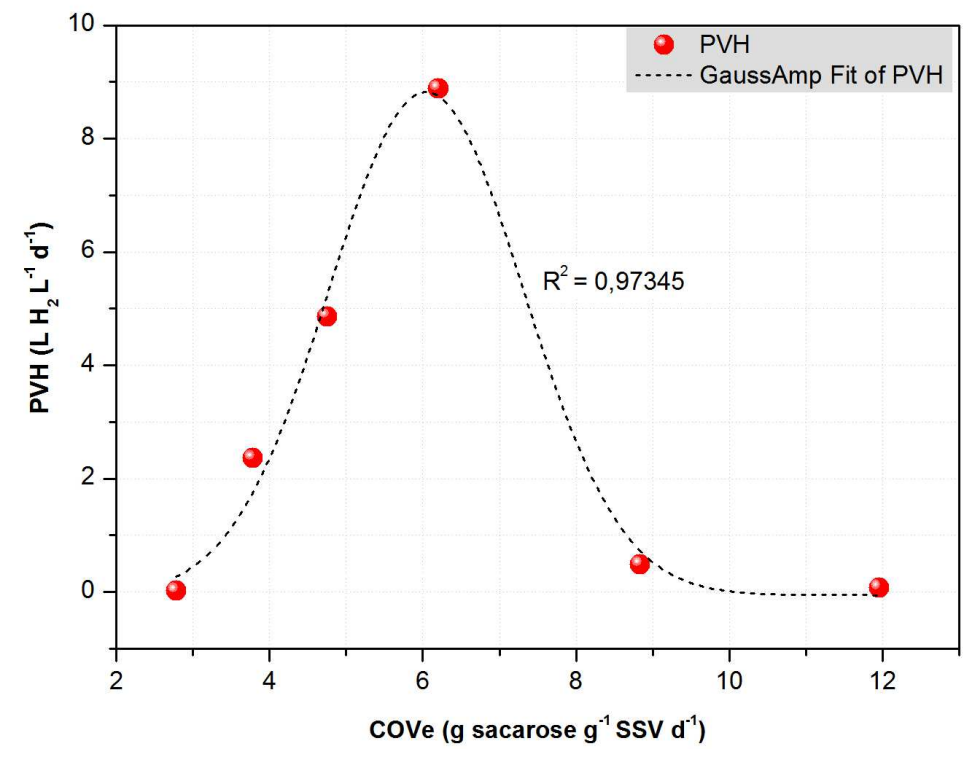

(a)

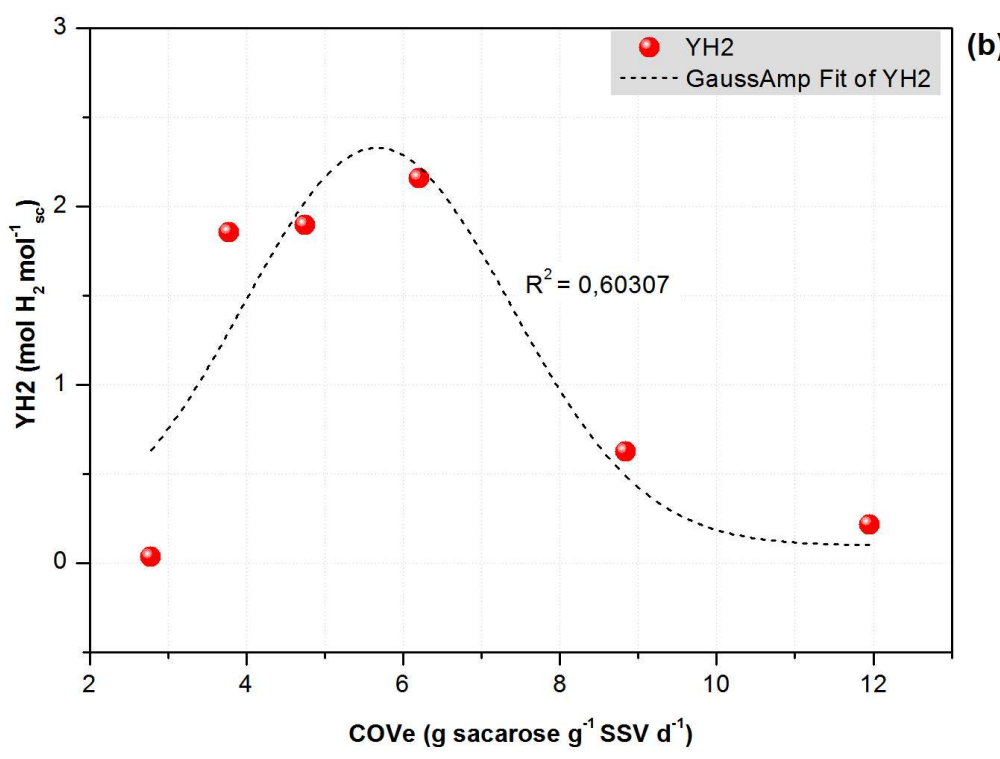

Figura 32 - Tendência da produção de hidrogênio em relação à COVe em reator anaeróbio de leito ordenado e escoamento descendente e variação da COV (a) PVH (b) $\boldsymbol{Y}_{\mathrm{H}_{2}}$ 
Elevadas concentrações da COVe, no caso maior que $6 \mathrm{~g}$ sacarose $\mathrm{g}^{-1} \mathrm{SSV} \mathrm{d}^{-1}$, poderiam ter causado alguma inibição por sobrecarga de substrato como aconteceu nas fases 1 e 2 quando se observaram as menores eficiências de conversão de sacarose (Tabela 36).

Por outro lado, a variação da COVe pela alteração da COV coincide com algumas mudanças na estrutura microbiana ou nas rotas metabólicas. Para observar isto, na Figura 33 se apresenta a distribuição percentual dos PSF em relação à COVe.
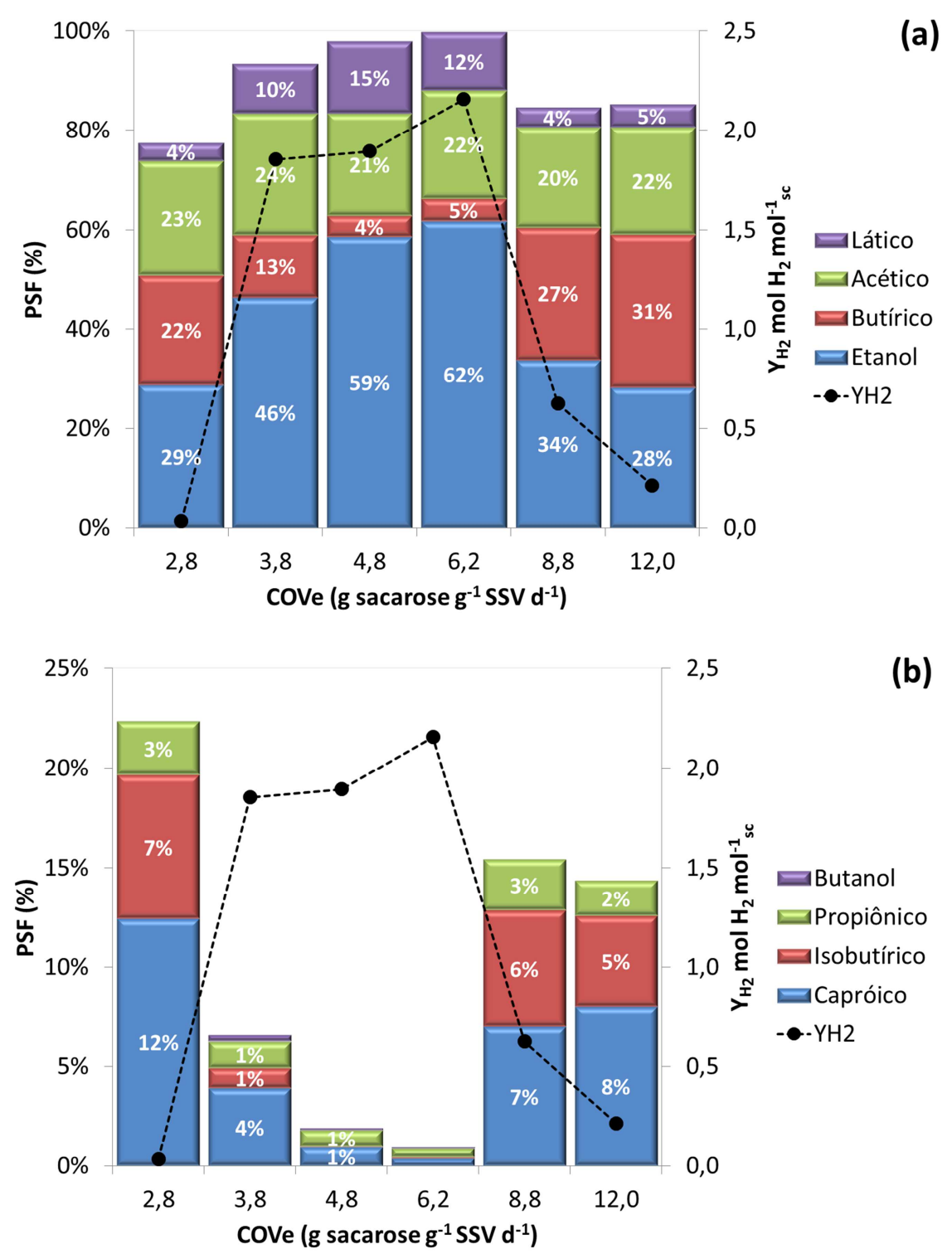

Figura 33 - Distribuição percentual dos PSF em relação à COVe em reator anaeróbio de leito ordenado, escoamento descendente e variação da COV (a) PSF principais; (b) PSF secundários

É possível notar que a tendência da produção de hidrogênio foi similar à produção de

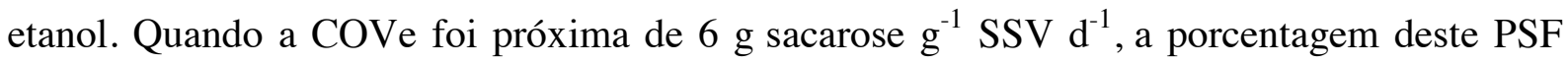


chegou a $62 \%$, enquanto que para COVe de 2,8 e 12,0 g sacarose $\mathrm{g}^{-1} \mathrm{SSV} \mathrm{d}^{-1}$ a percentagem foi próxima de $28 \%$ (Figura 33a). Na literatura a produção de etanol tem sido associada com a preferência dos microorganismos produtores de hidrogênio para produzir solventes a baixos valores de pH. Segundo Ren et al. (2007) a faixa adequada para a fermentação do tipo etanol está entre 4,0 e 5.,0, sendo esta faixa observada durante todo o período experimental (Tabela 36). De forma similar pode ter acontecido com a formação do butanol, observado em percentagens abaixo de $0,3 \%$ na mesma faixa de COVe.

Algumas espécies de Clostridium geralmente produzem etanol após a produção de hidrogênio. No entanto, tem sido reportado que este PSF pode ser gerado concomitantemente com hidrogênio em sistemas contínuos (KIM, HAN e SHIN, 2006; ZHU, PARKER, et al., 2009; REN, XING, et al., 2007). Similarmente, C. acetobutylicum, microorganismo produtor de hidrogênio pode produzir butanol sob certas quantidades de ácido butírico e pH abaixo de 5 (MINTON e CLARKE, 1989).

As maiores percentagens de produção de ácido lático também foram observadas com COVe entre 3,8 e 6,2 $\mathrm{g}$ sacarose $\mathrm{g}^{-1} \mathrm{SSV} \mathrm{d}^{-1}$. Porém, este produto não relacionado com a produção ou consumo de hidrogênio pode ter sido favorecido pelo incremento da pressão parcial de hidrogênio quando a produção de biogás aumentou (LEVIN, PITT e LOVE, 2004) ou como reportado por Minton e Clarke (1989) foi beneficiado pelo aumento da concentração do substrato afluente.

Contrariamente, nas COVe com menor produção de hidrogênio, observou-se aumento percentual de ácido propiônico, ácido capróico e oscilações de ácido valérico (Figura 33b), sendo estes produtos associados com o consumo de hidrogênio ou não relacionados à produção deste gás.

Ainda que a percentagem total da formação de ácido acético não parecesse ter sido afetada com a variação da COVe, a porção deste ácido formado pela via homoacetogênica

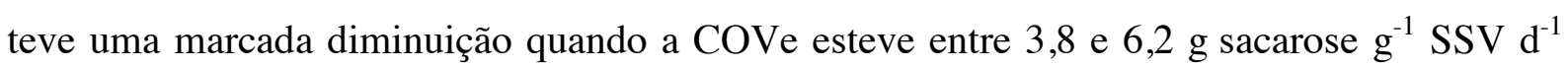
(Figura 34). Diferentemente das estratégias 2, 3 e 4 onde a homoacetogênese parece não ter sido afetada pela variação da COVe mediante o controle da biomassa, neste caso o controle da COVe pela mudança da COV pode ter inibido de certa forma essa atividade, favorecendo a liberação de hidrogênio.

Esta inferência pode ser suportada pela quantidade de hidrogênio liberado em relação ao teórico, uma vez que na Figura 35 se observou um comportamento inverso com o da homoacetogênese, a maior percentagem de hidrogênio liberado foi atingida com COVe entre 3,8 e 6,2 ${\mathrm{g} \text { sacarose } \mathrm{g}^{-1} \mathrm{SSV} \mathrm{d}}^{-1}$. Os valores médios por fase são apresentados na Tabela 43. 


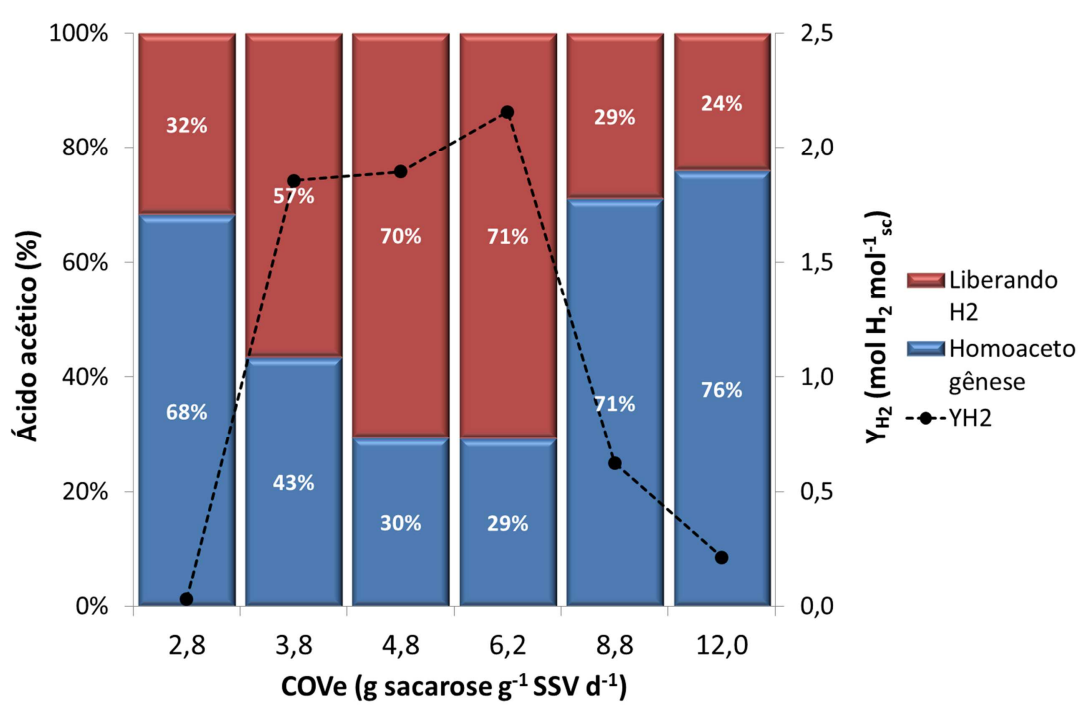

Figura 34 - Porcentagem de ácido acético formado pela via homoacetogênica em relação à COVe em reator anaeróbio de leito ordenado, escoamento descendente e variação da COV

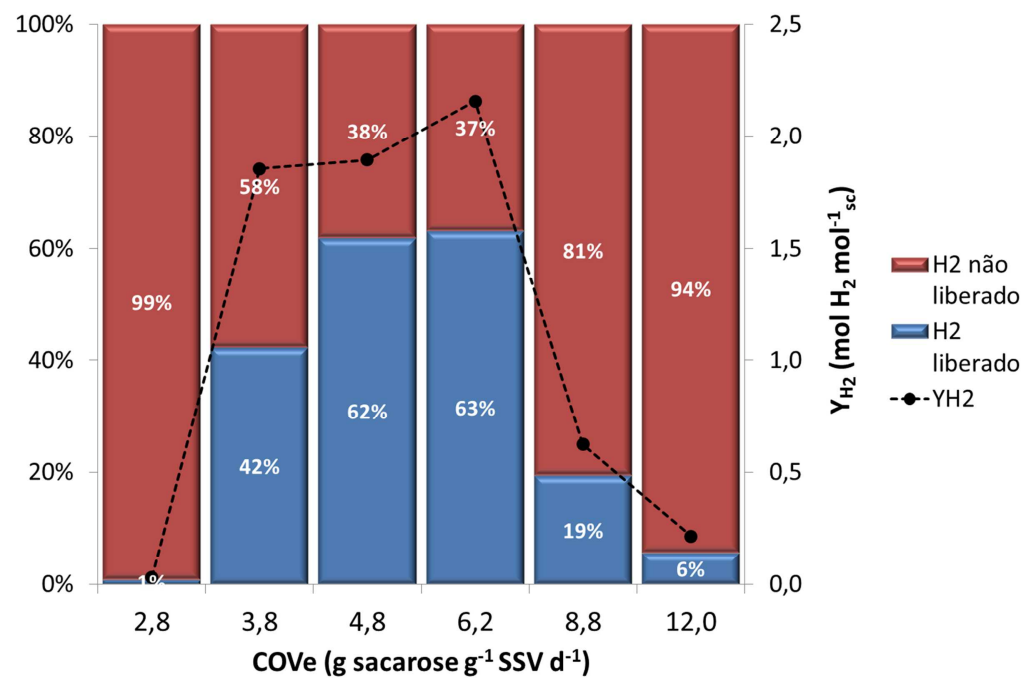

Figura 35 - Distribuição percentual do hidrogênio teórico em relação à COVe em reator anaeróbio de leito ordenado, escoamento descendente e variação da COV

Tabela 43 - Percentagem vazão molar de hidrogênio $\left(v_{H_{2}}\right)$ liberada em relação ao teórico em reator anaeróbio de leito ordenado, escoamento descendente e com variação da COV

\begin{tabular}{|c|c|c|c|c|}
\hline \multirow{2}{*}{ Fase } & \multirow{2}{*}{ 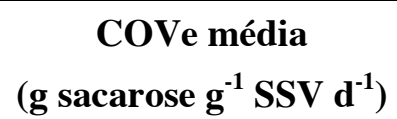 } & \multirow{2}{*}{$\begin{array}{l}v_{H_{2}} \text { teórica } \\
\left(\mathbf{m m o l ~ h}^{-1}\right)\end{array}$} & \multicolumn{2}{|c|}{$v_{\mathrm{H}_{2}}$ liberada } \\
\hline & & & $\left(\mathrm{mmol} \mathrm{h}^{-1}\right)$ & $\%$ \\
\hline 1 & $12,0 \pm 3,5$ & 9,6 & 0,6 & 6 \\
\hline 2 & $8,8 \pm 1,7$ & 12,1 & 2,4 & 19 \\
\hline 3 & $2,8 \pm 0,3$ & 10,7 & 0,1 & 1 \\
\hline 4 & $3,8 \pm 0,4$ & 33,1 & 13,4 & 42 \\
\hline 5 & $4,8 \pm 0,7$ & 46,8 & 29,2 & 62 \\
\hline 6 & $6,2 \pm 0,7$ & 79,9 & 50,4 & 63 \\
\hline
\end{tabular}


5.5.4. $\mathrm{O}$ TDH e a concentração do substrato em reator anaeróbio de leito ordenado e escoamento descendente

Como observado anteriormente, na Figura 31, a manutenção da COVe quase constante mediante a variação da COV foi favorável para a produção de hidrogênio, uma vez que durante as fases 4,5 e 6 , quando a COVe média foi de $4,7 \pm 1,1 \mathrm{~g}$ sacarose $\mathrm{g}^{-1} \mathrm{SSV} \mathrm{d}^{-1}$ observou-se estabilidade no $Y_{\mathrm{H}_{2}}$ médio com 1,9 $\pm 0,3 \mathrm{~mol} \mathrm{H}_{2} \mathrm{~mol}^{-1}{ }_{\mathrm{sc}}$ e incremento contínuo na $P V H$. No entanto, alguns dos resultados sugerem que o TDH e a concentração do substrato também poderiam ter influenciado separadamente o sistema.

Por um lado, incrementar a concentração do substrato parece ter sido favorável para velocidade de produção de hidrogênio e para sua transferência do meio líquido para o gasoso. Na Figura 36 é possível observar que o aumento da concentração ocorreu de forma linear com o aumento da vazão molar de hidrogênio teórico, melhorando a liberação do gás e inversamente diminuindo a percentagem da atividade homoacetogênica (Figura 37). Segundo Ren et al. (2010) aumentar a concentração do substrato no meio líquido pode melhorar o efeito de transferência de massa em sistemas com biomassa aderida, o que pode ter sucedido neste reator.

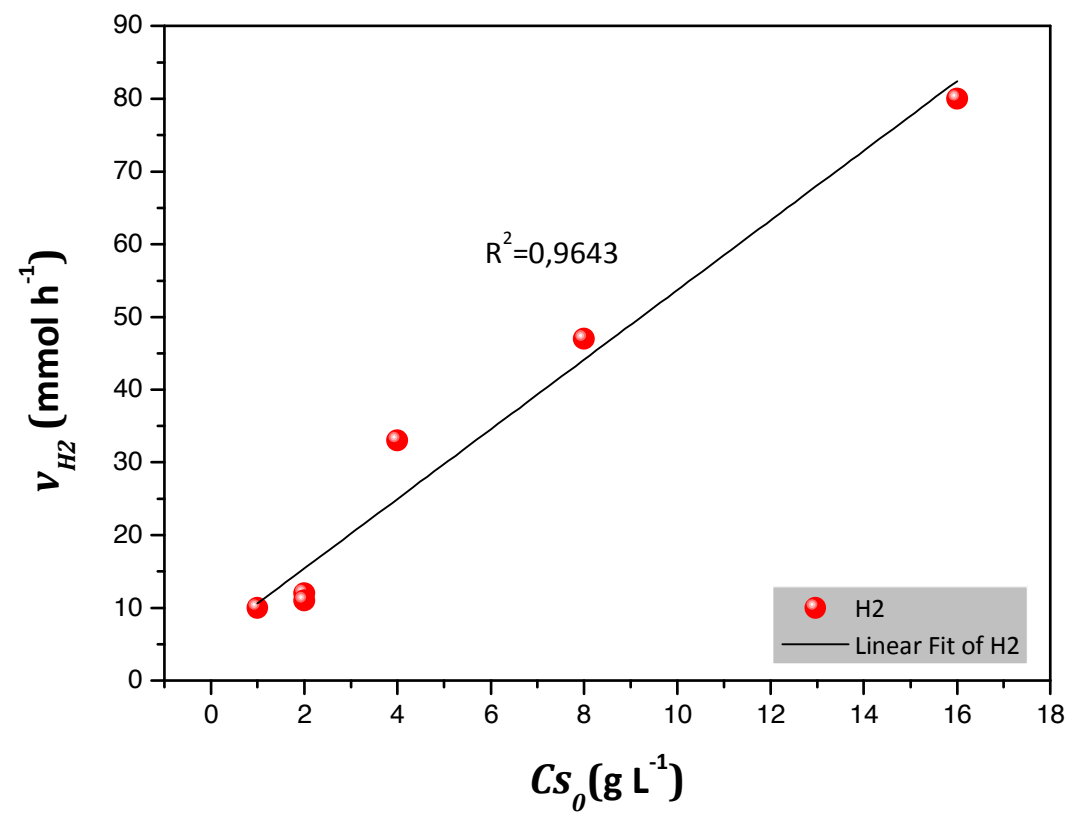

Figura 36 - Vazão molar de hidrogênio teórico $\left(v_{H_{2}}\right)$ em relação à concentração de substrato afluente $\left(C s_{0}\right)$ em reator anaeróbio de leito ordenado e escoamento descendente 


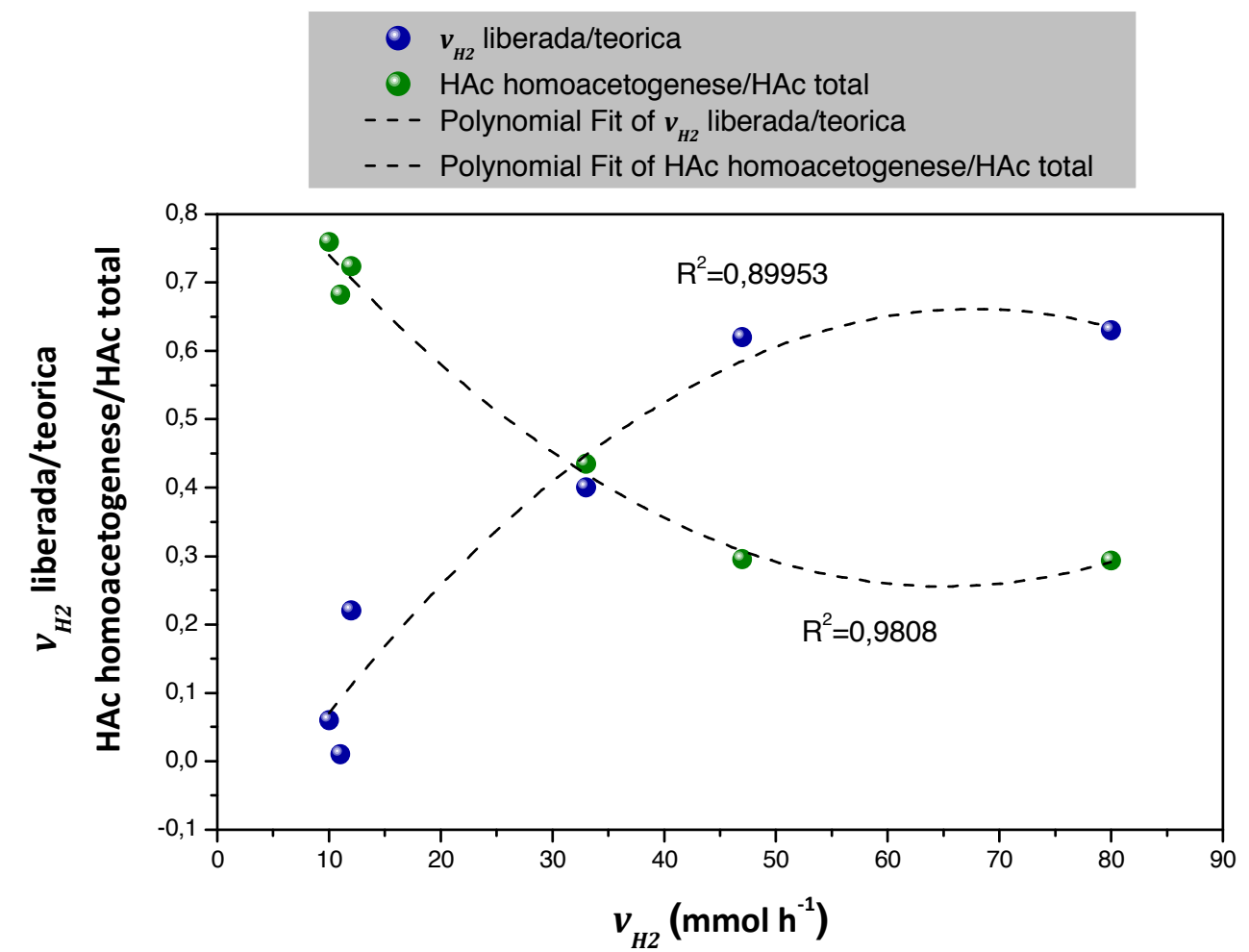

Figura 37 - Percentagem de vazão molar de hidrogênio liberado e homoacetogênese em relação à vazão molar de hidrogênio teórica

Uma evidência fotográfica também poderia contribuir com essa inferência. Na Figura 38 observa-se o registro do reator com 35 dias de operação, quando a concentração de substrato foi de $2 \mathrm{~g}$ DQO L ${ }^{-1}$, e com 121 dias, quando a concentração foi de $4 \mathrm{~g}$ DQO L $\mathrm{L}^{-1}$. Notou-se no primeiro caso uma grande capa de biomassa flutuando no topo do reator, enquanto que no segundo é possível enxergar a superfície líquida quase livre de biomassa.
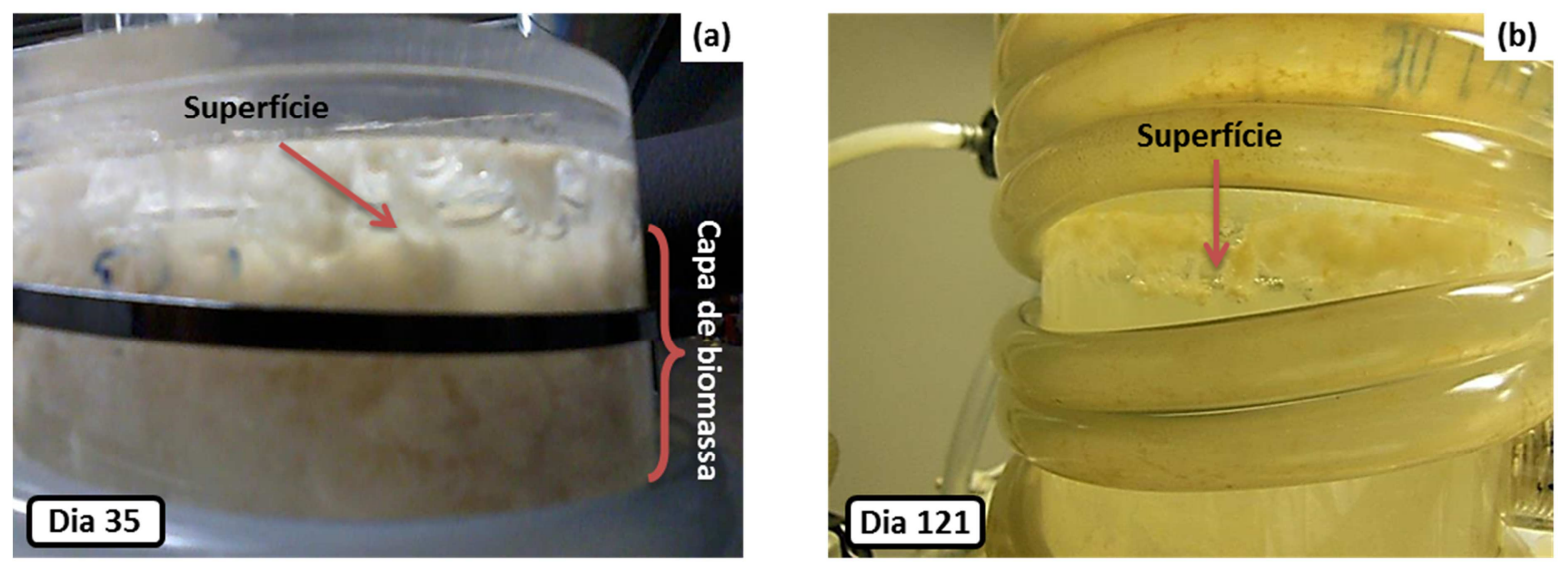

Figura 38 - Fotografia da superfície líquida do reator anaeróbio de leito ordenado, escoamento descendente e variação da $\mathrm{COV}$ (a) reator com 35 dias de operação, TDH de $2 \mathrm{~h}$, concentração de substrato de $2 \mathrm{~g} \mathrm{DQO} \mathrm{L}^{-1}$ perfazendo uma COV de $24 \mathrm{~g}^{\mathrm{DQO}} \mathrm{L}^{-1} \mathrm{~d}^{-}$ ${ }^{1}$ e COVe de 15 g sacarose $\mathrm{g}^{-1} \mathrm{SSV} \mathrm{d}^{-1}$ (b) reator com 121 dias de operação, TDH de $4 \mathrm{~h}$, concentração de substrato de $4 \mathrm{~g}$ DQO $\mathrm{L}^{-1}$ perfazendo uma COV de $24 \mathrm{~g}$ DQO L $\mathrm{L}^{-1} \mathrm{~d}^{-1}$ COVe de 4,1 g sacarose $\mathrm{g}^{-1} \mathrm{SSV} \mathrm{d}^{-1}$ 
Como na estratégia 2, quando a concentração foi de $2 \mathrm{~g}$ DQO $\mathrm{L}^{-1}$, o fato da biomassa flutuar foi associado à baixa eficiência de transferência que impediu que as bolhas de gás se desprendessem das partículas de biomassa, levando-as ao topo do reator. Já com o aumento da concentração nesta estratégia esse fenômeno não foi observado.

Por outro lado, as baixas eficiências de conversão de sacarose $\left(E_{s}\right)$ durante as fases $1 \mathrm{e}$ 2, que inicialmente foram associadas a uma sobrecarga de substrato devido às elevadas COVe (12,0 e 8,8 $\mathrm{g}$ sacarose $\mathrm{g}^{-1} \mathrm{SSV}^{-1}$, respectivamente), podem ter sido causadas pelo baixo tempo de reação quando o TDH aplicado foi $2 \mathrm{~h}$. Estes resultados que também foram observados durante as estratégias 2 e 4 , com $E_{S}$ máxima de $70 \%$ em reatores de leito ordenado indiferente da direção do escoamento, foram superados com o aumento do TDH para $4 \mathrm{~h}$ nesta estratégia.

O incremento do TDH parece ter favorecido as velocidades de reação, levando a $E_{S}$ média até $83 \%$ e adicionalmente diminuindo a instabilidade da COVe, medida pelo desvio padrão em até $20 \%$, sendo esta última uma característica necessária para a continuidade da produção de hidrogênio. Essa inferência sobre as velocidades de reação poderia ser suportada pela modelagem matemática realizada a partir dos dados experimentais do perfil espacial do reator obtidos no final de cada fase operacional, como a seguir.

\subsubsection{Modelagem matemática do desempenho espacial do reator anaeróbio de leito ordenado, escoamento descendente e variação da COV}

No intuito de comparar o desempenho do reator anaeróbio de leito ordenado, escoamento descendente e variação da $\mathrm{COV}$ ao longo do cumprimento em cada fase experimental, adaptou-se o modelo matemático sugerido por Tavares (2008). A diferença do modelo reportado pelo autor anterior, e que neste trabalho considerou a sacarose como substrato em vez de glicose.

Para tanto, realizou-se um perfil espacial no final de cada fase experimental, sendo as concentrações do substrato e dos PSF apresentadas da Tabela 44 a 48. 
Tabela 44 - Concentração de sacarose ao longo do reator anaeróbio de leito ordenado, escoamento descendente e variação da $\mathrm{COV}$ em cada fase operacional

\begin{tabular}{|c|c|c|c|c|c|c|}
\hline$L / D$ & $\begin{array}{c}\text { Fase } 1 \\
\left(\mathrm{mg} \mathrm{L}^{-1}\right)\end{array}$ & $\begin{array}{c}\text { Fase } 2 \\
\left(\mathrm{mg} \mathrm{L}^{-1}\right)\end{array}$ & $\begin{array}{c}\text { Fase } 3 \\
\left(m g L^{-1}\right)\end{array}$ & $\begin{array}{c}\text { Fase } 4 \\
\left(\mathrm{mg} \mathrm{L}^{-1}\right)\end{array}$ & $\begin{array}{c}\text { Fase } 5 \\
\left(\mathrm{mg} \mathrm{L}^{-1}\right)\end{array}$ & $\begin{array}{c}\text { Fase } 6 \\
\left(m g L^{-1}\right)\end{array}$ \\
\hline 0,00 & 899,5 & 1833,3 & 1936,0 & 3875,9 & 7186,6 & 13970,4 \\
\hline 1,25 & 767,8 & 1354,4 & 1008,3 & 2435,1 & 3682,0 & 13389,9 \\
\hline 2,50 & 667,3 & 1161,2 & 388,4 & 562,2 & 985,4 & 4713,3 \\
\hline 3,75 & 608,8 & 1157,2 & 401,9 & 513,9 & 577,6 & 4695,1 \\
\hline 5,00 & 480,4 & 1019,0 & 393,4 & 441,1 & 836,5 & 4483,2 \\
\hline 6,25 & 492,7 & 843,2 & 382,0 & 443,8 & 941,2 & 4626,4 \\
\hline 7,50 & 367,9 & 860,0 & 376,7 & 382,7 & 804,3 & 4333,0 \\
\hline 8,75 & 305,1 & 876,8 & 442,4 & 413,6 & 612,5 & 4412,7 \\
\hline
\end{tabular}

Tabela 45 - Concentração de etanol ao longo do reator anaeróbio de leito ordenado, escoamento descendente e variação da COV em cada fase operacional

\begin{tabular}{ccccccc}
\hline L/D & $\begin{array}{c}\text { Fase 1 } \\
\left(\mathbf{m g ~ L}^{-\mathbf{1}}\right)\end{array}$ & $\begin{array}{c}\text { Fase 2 } \\
\left(\mathbf{m g ~ L}^{-\mathbf{1}}\right)\end{array}$ & $\begin{array}{c}\text { Fase 3 } \\
\left(\mathbf{m g ~ L}^{-\mathbf{1}}\right)\end{array}$ & $\begin{array}{c}\text { Fase 4 } \\
\left(\mathbf{m g ~ L}^{-\mathbf{1}}\right)\end{array}$ & $\begin{array}{c}\text { Fase 5 } \\
\left(\mathbf{m g ~ L}^{\mathbf{- 1}}\right)\end{array}$ & $\begin{array}{c}\text { Fase 6 } \\
\left(\mathbf{m g ~ L}^{-\mathbf{1}}\right)\end{array}$ \\
\hline 0,00 & 5,08 & 28,00 & 30,54 & 72,46 & 0,00 & 0,00 \\
1,25 & 23,37 & 85,90 & 182,64 & 332,84 & 794,43 & 68,78 \\
2,50 & 25,66 & 120,44 & 270,52 & 765,89 & 1572,88 & 2323,21 \\
3,75 & 41,60 & 122,35 & 263,67 & 771,51 & 1585,90 & 2106,72 \\
5,00 & 39,01 & 126,19 & 261,61 & 777,70 & 1609,19 & 2331,17 \\
6,25 & 60,07 & 157,05 & 253,71 & 789,54 & 1614,68 & 2405,51 \\
7,50 & 67,35 & 156,62 & 262,57 & 800,62 & 1621,49 & 2421,36 \\
8,75 & 70,15 & 156,20 & 257,06 & 804,79 & 1617,55 & 2483,29 \\
\hline
\end{tabular}

Tabela 46 - Concentração de ácido butírico ao longo do reator anaeróbio de leito ordenado, escoamento descendente e variação da COV em cada fase operacional

\begin{tabular}{ccccccc}
\hline L/D & $\begin{array}{c}\text { Fase 1 } \\
\left(\mathbf{m g ~ L}^{-\mathbf{1}}\right)\end{array}$ & $\begin{array}{c}\text { Fase 2 } \\
\left(\mathbf{m g ~ L}^{-\mathbf{1}}\right)\end{array}$ & $\begin{array}{c}\text { Fase 3 } \\
\left(\mathbf{m g ~ L}^{-\mathbf{1}}\right)\end{array}$ & $\begin{array}{c}\text { Fase 4 } \\
\left(\mathbf{m g ~ L}^{-\mathbf{1}}\right)\end{array}$ & $\begin{array}{c}\text { Fase 5 } \\
\left(\mathbf{m g ~ L}^{-\mathbf{1}}\right)\end{array}$ & $\begin{array}{c}\text { Fase 6 } \\
\left(\mathbf{m g ~ L}^{-\mathbf{1}}\right)\end{array}$ \\
\hline 0,00 & 2,9 & 0,00 & 0,00 & 0,00 & 0,00 & 0,00 \\
1,25 & 14,6 & 38,98 & 107,87 & 77,46 & 125,64 & 3,807 \\
2,50 & 26,1 & 65,93 & 152,06 & 133,02 & 117,8 & 337,88 \\
3,75 & 34,4 & 71,97 & 144,05 & 138,7 & 122,8 & 327,96 \\
5,00 & 31,0 & 74,35 & 137,81 & 143,74 & 131,88 & 322,64 \\
6,25 & 41,7 & 88,66 & 139,28 & 150,22 & 118,32 & 323,76 \\
7,50 & 71,3 & 93,31 & 137,34 & 150,02 & 127,68 & 324,64 \\
8,75 & 64,5 & 97,96 & 137,12 & 144,64 & 113,76 & 328,04 \\
\hline
\end{tabular}


Tabela 47 - Concentração de ácido lático ao longo do reator anaeróbio de leito ordenado, escoamento descendente e variação da COV em cada fase operacional

\begin{tabular}{|c|c|c|c|c|c|c|}
\hline L/D & $\begin{array}{c}\text { Fase } 1 \\
\left(\mathrm{mg} \mathrm{L}^{-1}\right)\end{array}$ & $\begin{array}{c}\text { Fase } 2 \\
\left(\mathrm{mg} \mathrm{L}^{-1}\right)\end{array}$ & $\begin{array}{c}\text { Fase } 3 \\
\left(\mathrm{mg} \mathrm{L}^{-1}\right)\end{array}$ & $\begin{array}{c}\text { Fase } 4 \\
\left(\mathrm{mg} \mathrm{L}^{-1}\right)\end{array}$ & $\begin{array}{c}\text { Fase } 5 \\
\left(\mathrm{mg} \mathrm{L}^{-1}\right)\end{array}$ & $\begin{array}{c}\text { Fase } 6 \\
\left(\mathrm{mg} \mathrm{L}^{-1}\right)\end{array}$ \\
\hline 0,00 & 0,94 & 0,00 & 19,35 & 20,03 & 0,42 & 2,98 \\
\hline 1,25 & 20,14 & 29,70 & 84,51 & 159,19 & 418,46 & 236,62 \\
\hline 2,50 & 18,05 & 28,04 & 77,53 & 322,90 & 789,12 & 1396,68 \\
\hline 3,75 & 21,51 & 28,84 & 77,60 & 319,25 & 792,74 & 1443,40 \\
\hline 5,00 & 21,05 & 28,83 & 77,73 & 386,45 & 797,29 & 1392,57 \\
\hline 6,25 & 22,99 & 25,91 & 81,40 & 399,26 & 780,97 & 1366,85 \\
\hline 7,50 & 23,59 & 25,99 & 78,95 & 412,07 & 800,65 & 1537,27 \\
\hline 8,75 & 24,00 & 26,06 & 79,62 & 412,33 & 788,31 & 1517,63 \\
\hline
\end{tabular}

Tabela 48 - Concentração de ácido propiônico ao longo do reator anaeróbio de leito ordenado, escoamento descendente e variação da COV em cada fase operacional

\begin{tabular}{ccccccc}
\hline L/D & $\begin{array}{c}\text { Fase 1 } \\
\left(\mathbf{m g ~ L}^{-\mathbf{1}}\right)\end{array}$ & $\begin{array}{c}\text { Fase 2 } \\
\left(\mathbf{m g ~ L}^{-\mathbf{1}}\right)\end{array}$ & $\begin{array}{c}\text { Fase 3 } \\
\left(\mathbf{m g ~ L ~}^{-\mathbf{1}}\right)\end{array}$ & $\begin{array}{c}\text { Fase 4 } \\
\left(\mathbf{m g ~ L}^{-\mathbf{1}}\right)\end{array}$ & $\begin{array}{c}\text { Fase 5 } \\
\left(\mathbf{m g ~ L}^{-\mathbf{1}}\right)\end{array}$ & $\begin{array}{c}\text { Fase 6 } \\
\left(\mathbf{m g ~ L ~}^{\mathbf{- 1}}\right)\end{array}$ \\
\hline 0,00 & 0,00 & 0,00 & 0,00 & 0,00 & 0,00 & 0,00 \\
1,25 & 0,00 & 0,00 & 14,28 & 12,76 & 0,00 & 0,00 \\
2,50 & 0,00 & 15,54 & 17,62 & 20,60 & 0,00 & 0,00 \\
3,75 & 0,00 & 13,68 & 15,71 & 14,42 & 0,00 & 0,00 \\
5,00 & 5,18 & 15,29 & 15,00 & 15,30 & 43,44 & 0,00 \\
6,25 & 5,33 & 16,35 & 15,53 & 15,54 & 32,36 & 0,00 \\
7,50 & 6,66 & 16,84 & 16,19 & 16,26 & 0,00 & 0,00 \\
8,75 & 6,71 & 17,32 & 15,19 & 13,96 & 31,68 & 0,00 \\
\hline
\end{tabular}

Tabela 49 - Concentração de ácido acético ao longo do reator anaeróbio de leito ordenado, escoamento descendente e variação da COV em cada fase operacional

\begin{tabular}{ccccccc}
\hline L/D & $\begin{array}{c}\text { Fase 1 } \\
\left(\mathbf{m g ~ L}^{-\mathbf{1}}\right)\end{array}$ & $\begin{array}{c}\text { Fase 2 } \\
\left(\mathbf{m g ~ L}^{-\mathbf{1}}\right)\end{array}$ & $\begin{array}{c}\text { Fase 3 } \\
\left(\mathbf{m g ~ L}^{-\mathbf{1}}\right)\end{array}$ & $\begin{array}{c}\text { Fase 4 } \\
\left(\mathbf{m g ~ L}^{-\mathbf{1}}\right)\end{array}$ & $\begin{array}{c}\text { Fase 5 } \\
\left(\mathbf{m g ~ L}^{-\mathbf{1}}\right)\end{array}$ & $\begin{array}{c}\text { Fase 6 } \\
\left(\mathbf{m g ~ L ~}^{-\mathbf{1}}\right)\end{array}$ \\
\hline 0,00 & 17,60 & 24,94 & 25,63 & 17,56 & 0,00 & 0,00 \\
1,25 & 43,63 & 131,76 & 206,58 & 363,50 & 486,08 & 0,00 \\
2,50 & 49,27 & 148,04 & 319,21 & 678,56 & 1131,52 & 1520,44 \\
3,75 & 60,02 & 164,60 & 304,29 & 709,62 & 1033,48 & 1614,36 \\
5,00 & 59,77 & 169,75 & 294,02 & 724,80 & 987,88 & 1585,52 \\
6,25 & 84,19 & 181,95 & 304,84 & 791,84 & 1068,48 & 1755,80 \\
7,50 & 107,37 & 193,78 & 310,34 & 756,46 & 1121,44 & 1891,68 \\
8,75 & 96,65 & 205,61 & 295,21 & 777,78 & 1098,24 & 1775,84 \\
\hline
\end{tabular}


Neste modelo, considerou-se:

- Todas as reações elementares.

- O volume útil do reator de 3,35 L.

- A solubilidade do gás de 7.36E-4 mol H $\mathrm{L}^{-1}$

- As concentrações de biomassa nas fases 1, 2, 3, 4, 5 e 6, de 1353,9 mg SV; 3219,1 mg SV; 4436,8 mg SV; 6779,5 mg SV; 11638,4 mg SV e 16411,2 mg $\mathrm{SV}$, respectivamente.

\subsubsection{Reações bioquímicas}

As reações bioquímicas envolvidas no processo fermentativo para produção de hidrogênio a partir de sacarose são descritas da Reação 17 a Reação 25 como a seguir:

Sacarose a ácido butírico

$$
\mathrm{C}_{12} \mathrm{H}_{22} \mathrm{O}_{11}+\mathrm{H}_{2} \mathrm{O} \stackrel{\mathrm{k}_{1}}{\rightarrow} 2 \mathrm{C}_{4} \mathrm{H}_{8} \mathrm{O}_{2}+4 \mathrm{CO}_{2}+4 \mathrm{H}_{2}
$$

Reação 17

Sacarose a ácido acético

$$
\mathrm{C}_{12} \mathrm{H}_{22} \mathrm{O}_{11}+5 \mathrm{H}_{2} \mathrm{O} \stackrel{\mathrm{k}_{2}}{\rightarrow} 4 \mathrm{C}_{2} \mathrm{H}_{4} \mathrm{O}_{2}+4 \mathrm{CO}_{2}+8 \mathrm{H}_{2}
$$

Reação 18

Sacarose a ácido propiônico

$$
\mathrm{C}_{12} \mathrm{H}_{22} \mathrm{O}_{11}+4 \mathrm{H}_{2} \stackrel{\mathrm{k}_{3}}{\rightarrow} 4 \mathrm{C}_{3} \mathrm{H}_{6} \mathrm{O}_{2}+3 \mathrm{H}_{2} \mathrm{O}
$$

Reação 19

Sacarose a ácido lático

$$
\mathrm{C}_{12} \mathrm{H}_{22} \mathrm{O}_{11}+\mathrm{H}_{2} \mathrm{O} \stackrel{\mathrm{k}_{4}}{\rightarrow} 4 \mathrm{C}_{3} \mathrm{H}_{6} \mathrm{O}_{3}
$$

Reação 20

Ácido lático a ácido propiônico

$$
\mathrm{C}_{3} \mathrm{H}_{6} \mathrm{O}_{3}+\mathrm{H}_{2} \stackrel{\mathrm{k}_{5}}{\rightarrow} \mathrm{C}_{3} \mathrm{H}_{6} \mathrm{O}_{2}+\mathrm{H}_{2} \mathrm{O}
$$

Reação 21

Ácido butírico a ácido acético

$$
\mathrm{C}_{4} \mathrm{H}_{8} \mathrm{O}_{2}+2 \mathrm{H}_{2} \mathrm{O} \stackrel{\mathrm{k}_{6}}{\rightarrow} 2 \mathrm{C}_{2} \mathrm{H}_{4} \mathrm{O}_{2}+2 \mathrm{H}_{2}
$$


Ácido propiônico a ácido acético

$$
\mathrm{C}_{3} \mathrm{H}_{6} \mathrm{O}_{2}+2 \mathrm{H}_{2} \mathrm{O} \stackrel{\mathrm{k}_{7}}{\rightarrow} \mathrm{C}_{2} \mathrm{H}_{4} \mathrm{O}_{2}+\mathrm{CO}_{2}+3 \mathrm{H}_{2}
$$

Reação 23

Ácido lático a ácido acético

$$
\mathrm{C}_{3} \mathrm{H}_{6} \mathrm{O}_{3}+\mathrm{H}_{2} \mathrm{O} \stackrel{\mathrm{k}_{8}}{\rightarrow} \mathrm{C}_{2} \mathrm{H}_{4} \mathrm{O}_{2}+\mathrm{CO}_{2}+2 \mathrm{H}_{2}
$$

Sacarose a etanol

$$
\mathrm{C}_{12} \mathrm{H}_{22} \mathrm{O}_{11}+\mathrm{H}_{2} \mathrm{O} \stackrel{\mathrm{k}_{9}}{\rightarrow} 4 \mathrm{C}_{2} \mathrm{H}_{6} \mathrm{O}+4 \mathrm{CO}_{2}
$$

\section{Reação 25}

Na qual os índices “ $k$ ” são velocidades constantes.

\subsubsection{Velocidades de reação}

A velocidade de uma reação homogênea $(r)$ pode ser definida como a variação do número de mols ou massa de um reagente ou produto por unidade de tempo e por unidade de volume da mistura da reação. Nas reações consideradas, a velocidade de formação ou consumo de cada composto foi calculada em função da concentração e seus coeficientes estequiométricos e da constante de velocidade (TAVARES, 2008). As equações do consumo e formação dos produtos neste trabalho são exibidas da Equação 37 à Equação 43:

Sacarose

$$
\left(\mathrm{r}_{\mathrm{s}}\right)=-\left(\mathrm{k}_{1}+\mathrm{k}_{2}+\mathrm{k}_{4}+\mathrm{k}_{9}\right) \mathrm{C}_{\mathrm{x}} \mathrm{C}_{\mathrm{s}}-\mathrm{k}_{3} \mathrm{C}_{\mathrm{x}} \mathrm{C}_{\mathrm{s}} \mathrm{C}_{\mathrm{H}_{2}}^{4}
$$

Equação 37

Ácido butírico

$$
\left(\mathrm{r}_{\mathrm{b}}\right)=\mathrm{C}_{\mathrm{x}}\left(\mathrm{k}_{1} \mathrm{C}_{\mathrm{s}}-\mathrm{k}_{6} \mathrm{C}_{\mathrm{b}}\right)
$$

Equação 38

Ácido acético

$$
\left(\mathrm{r}_{\mathrm{a}}\right)=\mathrm{C}_{\mathrm{x}}\left(\mathrm{k}_{2} \mathrm{C}_{\mathrm{s}}+\mathrm{k}_{6} \mathrm{C}_{\mathrm{b}}+\mathrm{k}_{7} \mathrm{C}_{\mathrm{p}}+\mathrm{k}_{8} \mathrm{C}_{\mathrm{l}}\right)
$$

Equação 39

Ácido propiônico

$$
\left(\mathrm{r}_{\mathrm{p}}\right)=\mathrm{C}_{\mathrm{x}}\left(\mathrm{k}_{3} \mathrm{C}_{\mathrm{s}} \mathrm{C}_{\mathrm{H}_{2}}^{4}+\mathrm{k}_{5} \mathrm{C}_{\mathrm{l}} \mathrm{C}_{\mathrm{H}_{2}}-\mathrm{k}_{7} \mathrm{C}_{\mathrm{p}}\right)
$$


Ácido lático

$$
\left(\mathrm{r}_{\mathrm{l}}\right)=\mathrm{C}_{\mathrm{x}}\left(\mathrm{k}_{4} \mathrm{C}_{\mathrm{s}}-\mathrm{C}_{\mathrm{l}}\left(\mathrm{k}_{5} \mathrm{C}_{\mathrm{H}_{2}}+\mathrm{k}_{8}\right)\right)
$$

Equação 41

Etanol

$$
\left(\mathrm{r}_{\mathrm{e}}\right)=\mathrm{k}_{9} \mathrm{C}_{\mathrm{x}} \mathrm{C}_{\mathrm{s}}
$$

Equação 42

Hidrogênio

$$
\mathrm{r}_{\mathrm{H}_{2}}=\mathrm{C}_{\mathrm{x}}\left[\mathrm{C}_{\mathrm{s}}\left(\mathrm{k}_{1}+\mathrm{k}_{2}\right)-\mathrm{C}_{\mathrm{H}_{2}}\left(\mathrm{k}_{3} \mathrm{C}_{\mathrm{s}} \mathrm{C}_{\mathrm{H}_{2}}^{3}+\mathrm{k}_{5} \mathrm{C}_{\mathrm{l}}\right)+\mathrm{k}_{6} \mathrm{C}_{\mathrm{b}}+\mathrm{k}_{7} \mathrm{C}_{\mathrm{p}}+\mathrm{k}_{8} \mathrm{C}_{\mathrm{l}}\right] \quad \text { Equação } 43
$$

A concentração de $\mathrm{H}_{2} \mathrm{O}$ foi desconsiderada, uma vez que é muito mais elevada que qualquer outro produto e ainda depois do consumo de todas as moléculas do reagente, a concentração no final será muito próxima da concentração inicial (TAVARES, 2008). Os

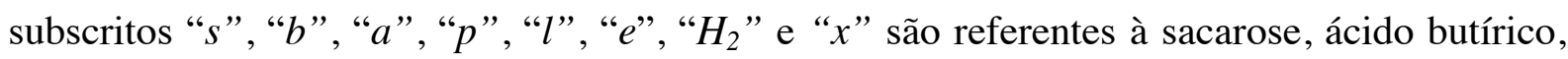
ácido acético, ácido propiônico, ácido lático, etanol, hidrogênio e biomassa, respectivamente.

\subsubsection{Balanço de massa}

O desenvolvimento do modelo partiu do balanço de massa, considerando o reator análogo a um reator ideal pistonado como um elemento de volume $(\partial V)$. A expressão do balanço de massa foi desenvolvida sobre um volume de controle fechado e possui termos de entrada, saída, geração ou consumo e acumulação de materiais dentro do volume em que as reações se processam como a seguir (TAVARES, 2008):

$$
Q C_{i_{0}}-\left(Q C_{i_{0}}+Q C_{i}\right) \pm\left(r_{i}\right) \partial V=V \frac{\partial C_{i}}{\partial t}
$$

Equação 44

Assumindo que $\frac{\partial c_{i}}{\partial t}=0$, tem-se:

$$
\pm\left(r_{i}\right)=Q \frac{\partial C_{i}}{\partial V}
$$

\section{Equação 45}

Pela substituição da Equação 37 a Equação 42 na Equação 45 e solucionando a equação resultante, calculou-se uma expressão para a $i$-ésima concentração: 


$$
\begin{array}{cr}
C_{S}=C_{S_{0}} e^{\left(-C_{x} \theta h\left(k_{3} C_{H_{2}}^{4}+k_{1}+k_{2}+k_{4}+k_{9}\right)\right)} & \text { Equação 46 } \\
C_{b}=\frac{C_{s} k_{1}-e^{\left(-C_{x} \theta h k_{6}\right)}\left(C_{s} k_{1}-C_{b_{0}} k_{6}\right)}{k_{6}} & \text { Equação 47 } \\
C_{p}=\frac{C_{a_{0}}+\theta h\left(C_{s} C_{x} k_{2}+C_{b} C_{x} k_{6}+C_{p} C_{x} k_{7}+C_{l} C_{x} k_{8}\right)}{C_{H_{2}} C_{l} k_{5}-e^{\left(-C_{x} \theta h k_{7}\right)}\left(C_{s} k_{3} C_{H_{2}}^{4}+C_{l} k_{5} C_{H_{2}}-C_{p_{0}} k_{7}\right)+C_{H_{2}}^{4} C_{s} k_{3}} & \text { Equação 48 } \\
k_{7} & \text { Equação 49 } \\
C_{l}=\frac{C_{s} k_{4}+e^{\left(-C_{x} \theta h\left(k_{8}+C_{H_{2}} k_{5}\right)\right)}\left(C_{l_{0}} k_{8}-C_{s} k_{4}+C_{H_{2}} C_{l_{0}} k_{5}\right)}{k_{8}+C_{H_{2}} k_{5}} & \text { Equação 50 } \\
C_{e}=C_{e_{0}}+C_{s} C_{x} \theta h k_{9} & \text { Equação 51 }
\end{array}
$$

Por conveniência, para a quantificação do hidrogênio no elemento de volume, a vazão molar foi calculada pelo balanço de massa na Equação 52 (TAVARES, 2008):

$$
F_{0\left(H_{2}\right)}=F_{\left(H_{2}\right)}+\left(r_{H_{2}}\right)_{N} V-Q s=\frac{\partial N_{H_{2}}}{\partial t}
$$

Equação 52

Considerando o sistema em fase de estabilidade, tem-se:

$$
F_{\left(H_{2}\right)}=F_{0\left(H_{2}\right)}+\left(r_{H_{2}}\right)_{N} V-Q_{s}
$$

\section{Equação 53}

Nas quais $F_{0\left(H_{2}\right)}$ e $F_{\left(H_{2}\right)}$ são a vazão molar de hidrogênio da entrada e na saída, respectivamente, $Q$ é a vazão, e a solubilidade na agua $\left(7.36 \times 10^{-4} \mathrm{~mol} \mathrm{H}_{2} \mathrm{~L}^{-1}\right)$ e $\left(r_{H_{2}}\right)_{N}$ é a velocidade de formação de hidrogênio. A $\left(r_{H_{2}}\right)_{N}$ é igual à relação entre $\left(r_{H_{2}}\right)$ e a massa molar do hidrogênio $\left(\mathrm{MMH}_{2}\right)$.

A vazão molar de hidrogênio é representada pelo produto entre a vazão do biogás e a concentração. Por tanto $\left(r_{H_{2}}\right)$ e $\left(r_{H_{2}}\right)_{N}$ não foram dependentes da concentração de hidrogênio. Pela substituição do $\left(r_{\mathrm{H}_{2}}\right)_{N}$ para $\frac{\left(r_{\mathrm{H}_{2}}\right)}{M M H_{2}}$, tem-se: 


$$
\begin{gathered}
F_{H}=F_{H_{0}}-Q_{s}+V \frac{C_{x}}{M M H_{2}}(\Delta) \\
\Delta=C_{b} k_{6}+C_{l} k_{8}+C_{p} k_{7}-C_{s} k_{3} C_{H_{2}}^{4}+C_{l} k_{5} C_{H_{2}}+C_{S}\left(k_{1}+k_{2}\right)
\end{gathered}
$$

\section{Equação 54}

Uma vez que $C_{H_{2}}$ não é conhecido, uma relação estequiométrica entre a sacarose e o hidrogênio foi estabelecida, como sendo $C_{H_{2}}=\frac{C_{S}}{42.75}$. Aliás, uma relação estequiométrica adicional entre o ácido lático e o hidrogênio foi estabelecida, como sendo $C_{H_{2}}=\frac{C_{l}}{45}$ (TAVARES, 2008). Assim, essas relações foram empregadas nas Equações 34, 37, 38 e 42.

\subsubsection{Constantes cinéticas}

Após a substituição anterior, obteve-se um novo conjunto de equações. Usou-se o algoritmo "trust- region-reflective" no MatLab® (função lsqnonlin) para ajuste não linear de curvas e obteve-se um conjunto de constantes cinéticas, o qual é apresentado na Tabela 50.

\section{Tabela 50 - Constantes cinéticas}

\begin{tabular}{cccccccccc}
\hline Fase & $\boldsymbol{k}_{\boldsymbol{l}}$ & $\boldsymbol{k}_{\mathbf{2}}$ & $\boldsymbol{k}_{\mathbf{3}}$ & $\boldsymbol{k}_{\boldsymbol{4}}$ & $\boldsymbol{k}_{\mathbf{5}}$ & $\boldsymbol{k}_{\boldsymbol{6}}$ & $\boldsymbol{k}_{\boldsymbol{7}}$ & $\boldsymbol{k}_{\boldsymbol{8}}$ & $\boldsymbol{k}_{\boldsymbol{9}}$ \\
\hline 1 & $1,1 \mathrm{E}-04$ & $1,4 \mathrm{E}-04$ & $3,5 \mathrm{E}-14$ & $1,0 \mathrm{E}-04$ & $4,4 \mathrm{E}-03$ & $3,3 \mathrm{E}-05$ & $4,6 \mathrm{E}-13$ & $2,3 \mathrm{E}-05$ & $9,7 \mathrm{E}-05$ \\
2 & $2,1 \mathrm{E}-05$ & $5,0 \mathrm{E}-05$ & $6,0 \mathrm{E}-12$ & $1,9 \mathrm{E}-05$ & $1,1 \mathrm{E}-06$ & $9,6 \mathrm{E}-06$ & $9,5 \mathrm{E}-05$ & $5,6 \mathrm{E}-06$ & $3,6 \mathrm{E}-05$ \\
3 & $3,0 \mathrm{E}-05$ & $3,3 \mathrm{E}-05$ & $2,6 \mathrm{E}-14$ & $2,4 \mathrm{E}-05$ & $1,7 \mathrm{E}-04$ & $8,4 \mathrm{E}-05$ & $1,0 \mathrm{E}-03$ & $7,8 \mathrm{E}-07$ & $5,6 \mathrm{E}-05$ \\
4 & $1,7 \mathrm{E}-05$ & $1,9 \mathrm{E}-05$ & $2,4 \mathrm{E}-14$ & $1,4 \mathrm{E}-05$ & $2,2 \mathrm{E}-05$ & $6,7 \mathrm{E}-05$ & $1,0 \mathrm{E}-03$ & $4,2 \mathrm{E}-08$ & $3,5 \mathrm{E}-05$ \\
5 & $5,1 \mathrm{E}-06$ & $5,5 \mathrm{E}-06$ & $4,5 \mathrm{E}-14$ & $6,7 \mathrm{E}-06$ & $3,1 \mathrm{E}-06$ & $7,9 \mathrm{E}-05$ & $3,0 \mathrm{E}-03$ & $4,4 \mathrm{E}-06$ & $1,9 \mathrm{E}-05$ \\
6 & $2,5 \mathrm{E}-06$ & $2,8 \mathrm{E}-06$ & $2,5 \mathrm{E}-14$ & $3,4 \mathrm{E}-06$ & $9,8 \mathrm{E}-07$ & $4,6 \mathrm{E}-05$ & $3,8 \mathrm{E}-03$ & $2,4 \mathrm{E}-07$ & $9,5 \mathrm{E}-06$ \\
\hline
\end{tabular}

\subsubsection{Concentrações}

Usando o conjunto das constantes cinéticas, o modelo teórico das concentrações foi ajustado aos valores experimentais da Figura 39 a Figura 44. Observa-se que a tendência da vazão molar de hidrogênio foi igual em todas as fases experimentais, sendo a maior produção da cabeça do reator independente do TDH aplicado. 

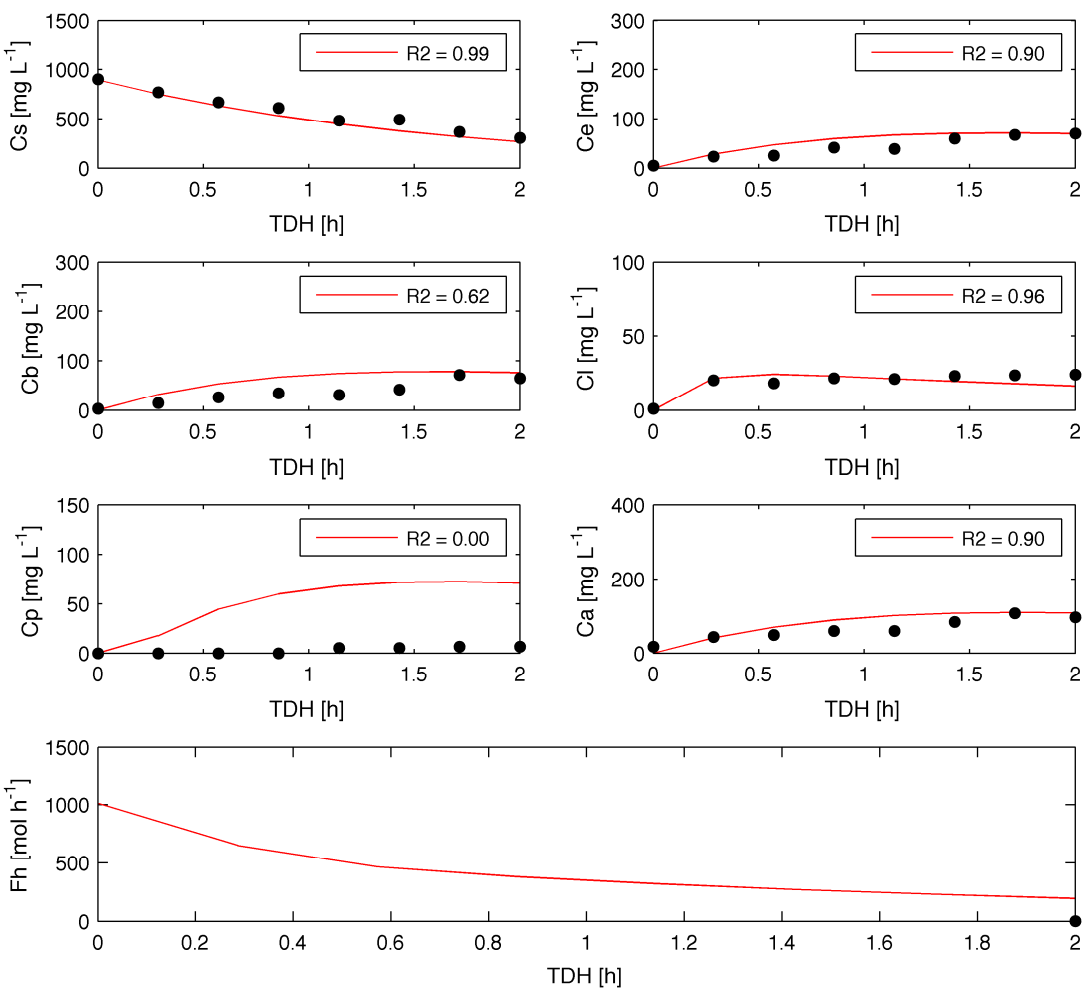

Figura 39 - Ajuste do modelo teórico das concentrações aos dados experimentais da Fase 1
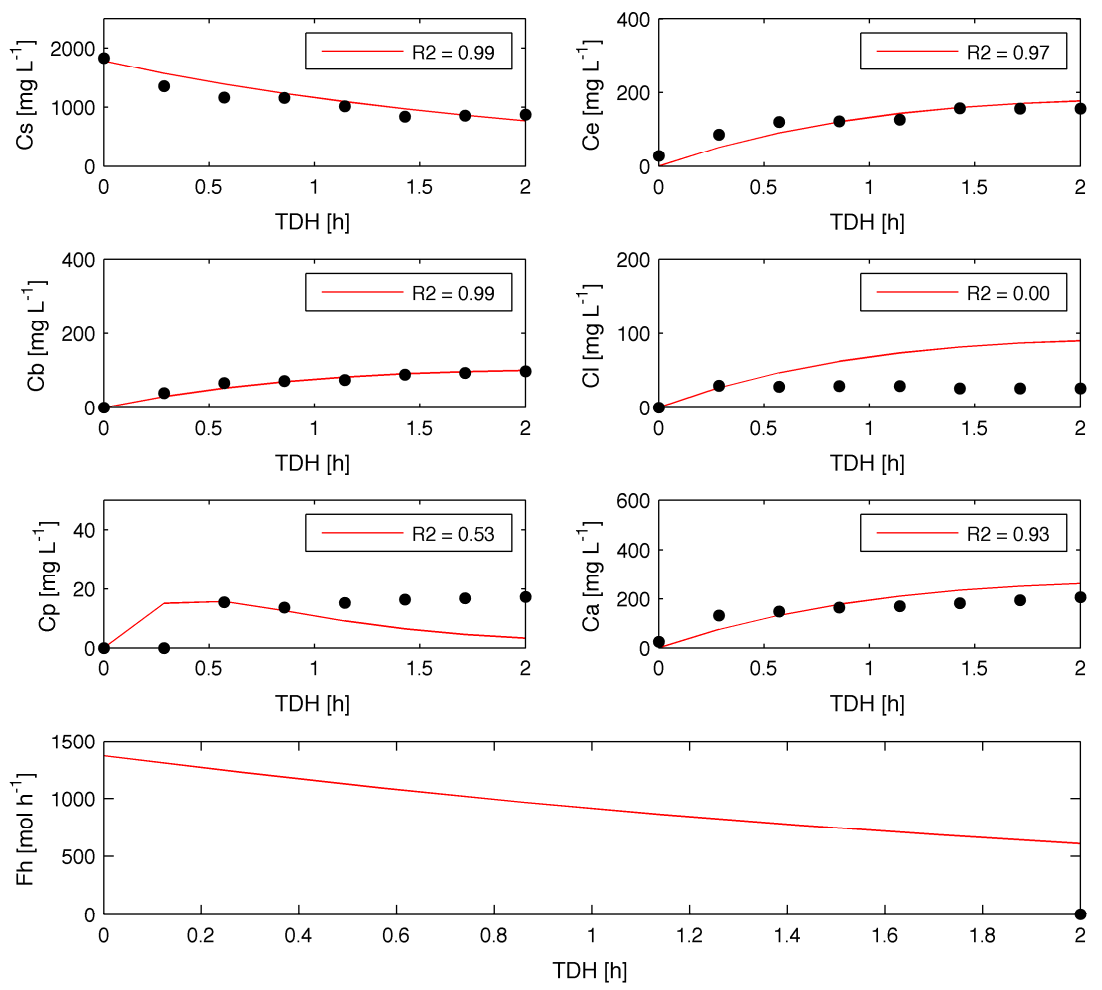

Figura 40 - Ajuste do modelo teórico das concentrações aos dados experimentais da Fase 2 

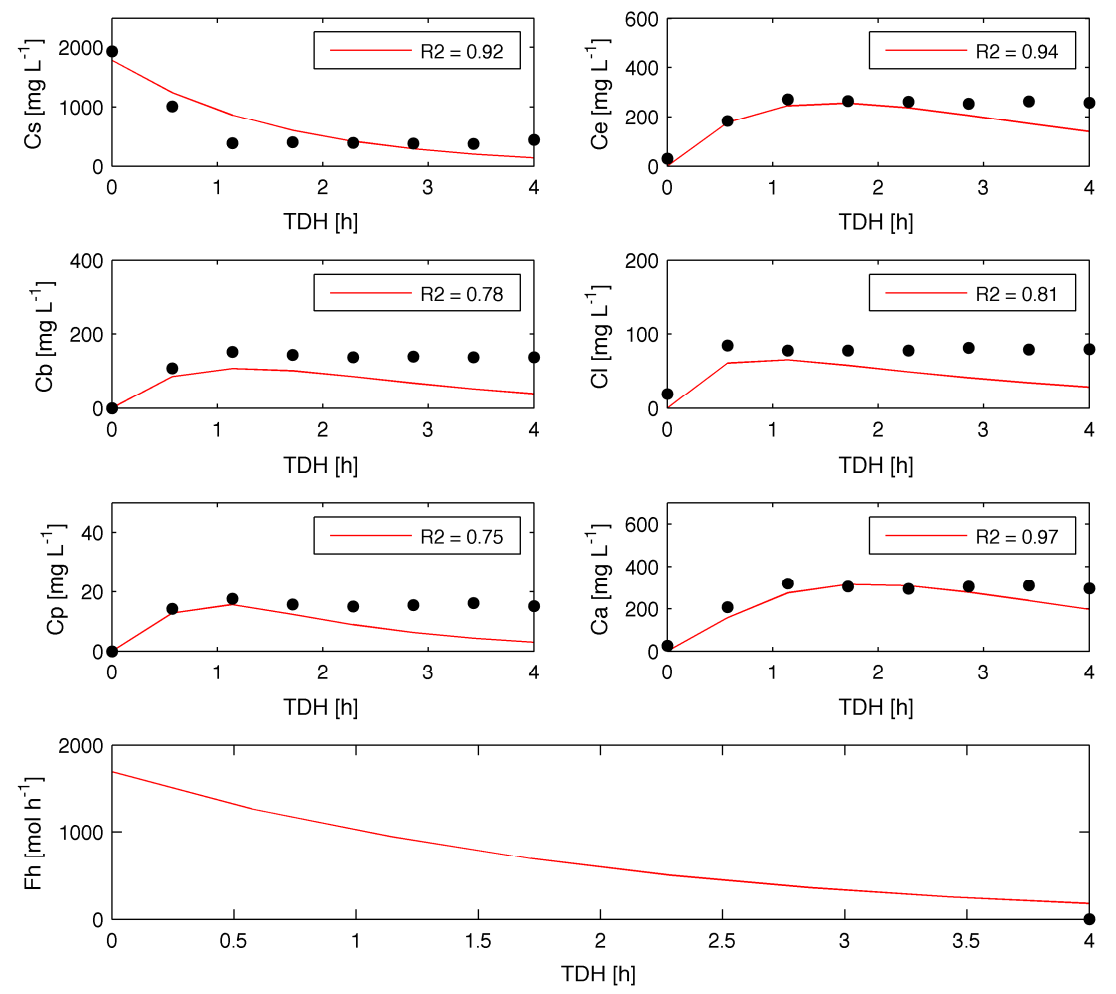

Figura 41 - Ajuste do modelo teórico das concentrações aos dados experimentais da Fase 3
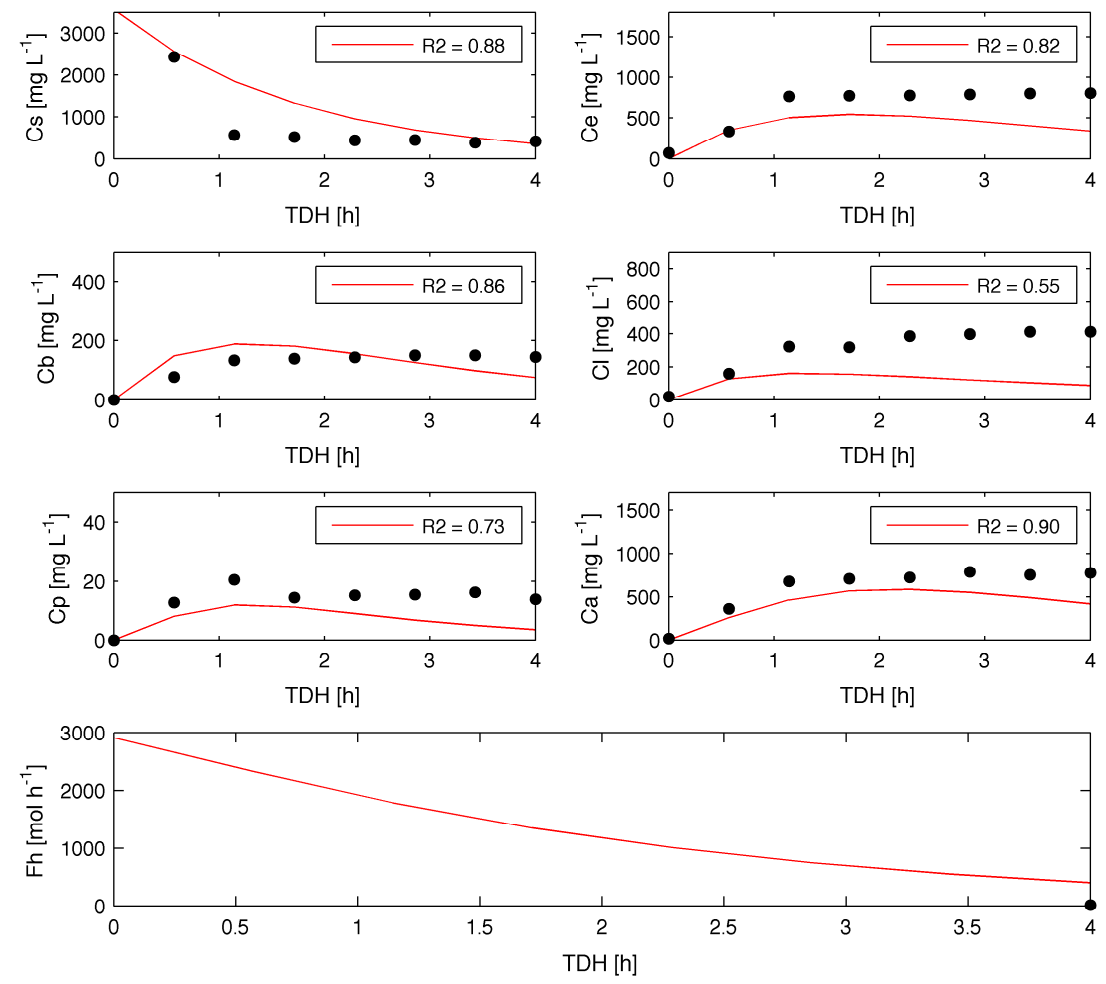

Figura 42 - Ajuste do modelo teórico das concentrações aos dados experimentais da Fase 4 

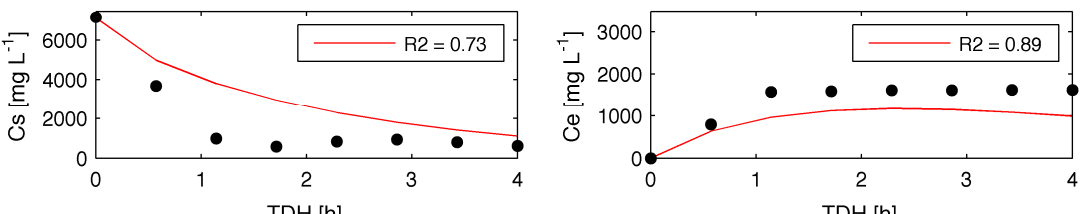

$\mathrm{TDH}[\mathrm{h}]$
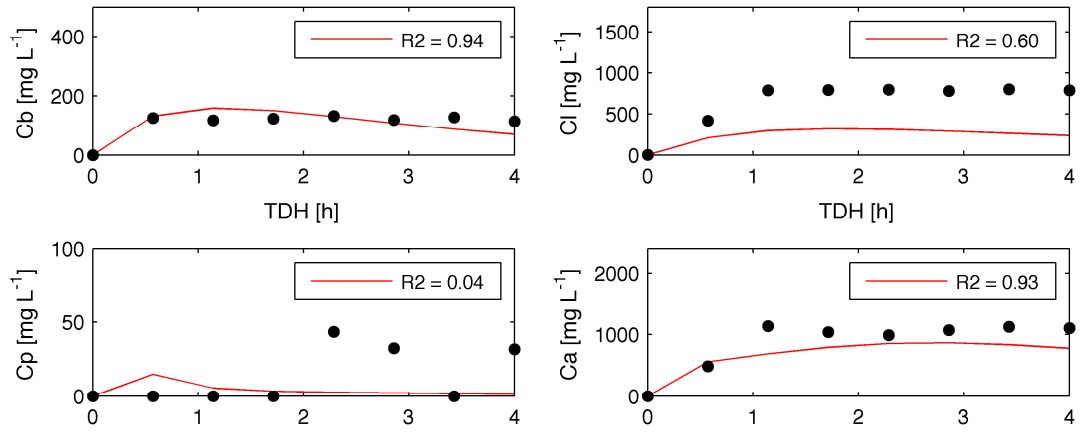

$\mathrm{TDH}[\mathrm{h}]$

TDH [h]

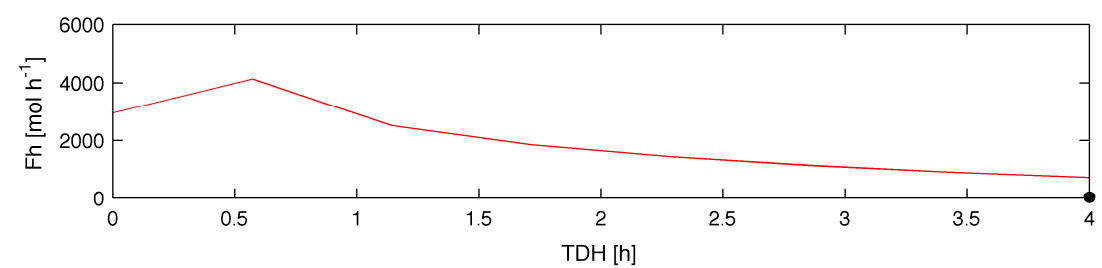

Figura 43 - Ajuste do modelo teórico das concentrações aos dados experimentais da Fase 5
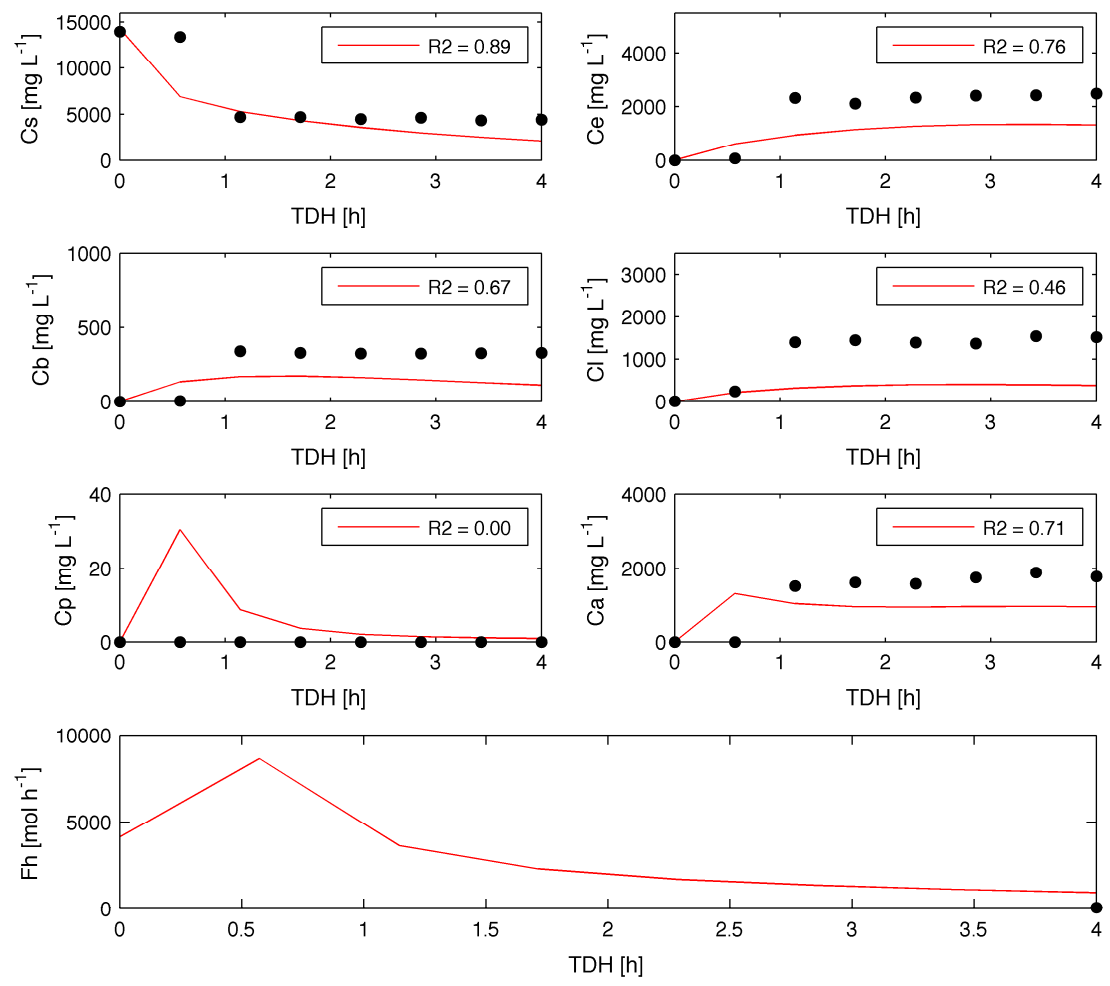

Figura 44 - Ajuste do modelo teórico das concentrações aos dados experimentais da Fase 6 
5.5.5.6. Velocidades de reação ao longo do reator anaeróbio de leito ordenado

Finalmente as velocidades de reação do reator anaeróbio de leito ordenado e escoamento descendente com TDH aplicado de 2 e 4 h são apresentadas da Figura 45 à 53.

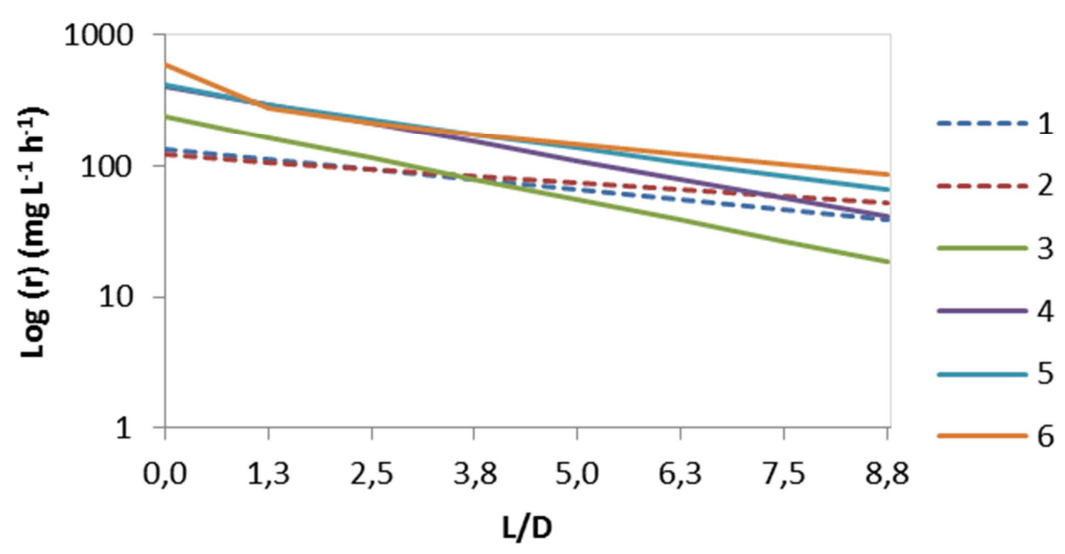

Figura 45 - Velocidade da Reação 17 (Sacarose a ácido butírico) em reator anaeróbio de leito ordenado e escoamento descendente com variação da $\mathrm{COV}$

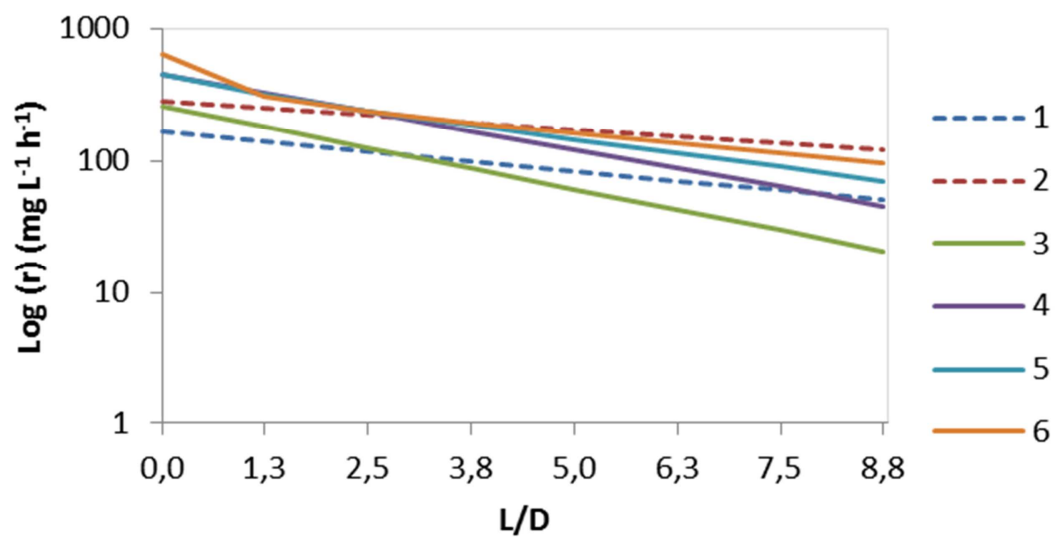

Figura 46 - Velocidade da Reação 18 (Sacarose a ácido acético) em reator anaeróbio de leito ordenado e escoamento descendente com variação da $\mathrm{COV}$

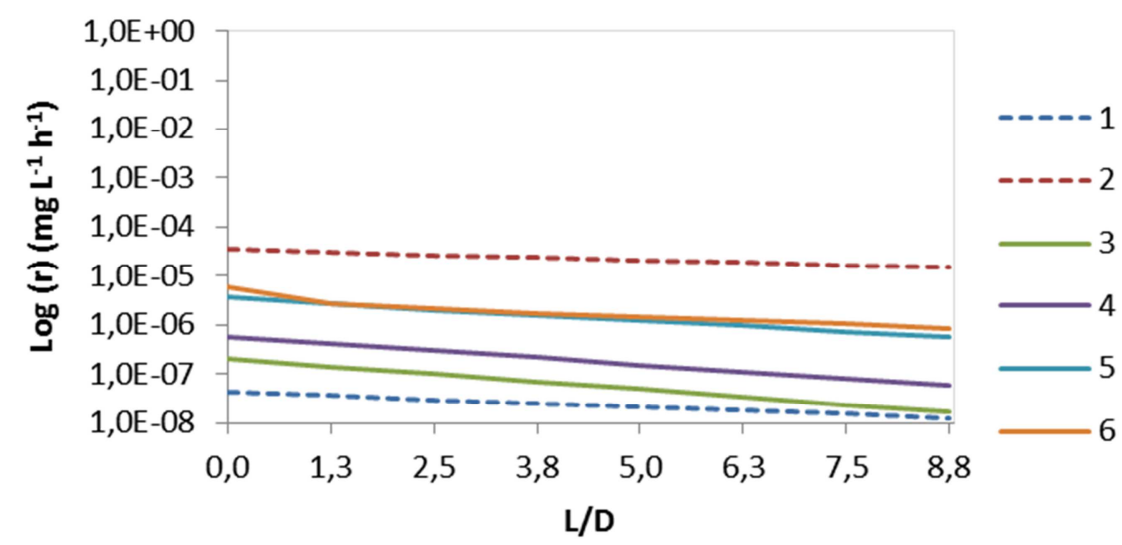

Figura 47 - Velocidade da Reação 19 (Sacarose a ácido propiônico) em reator anaeróbio de leito ordenado e escoamento descendente com variação da $\mathrm{COV}$ 


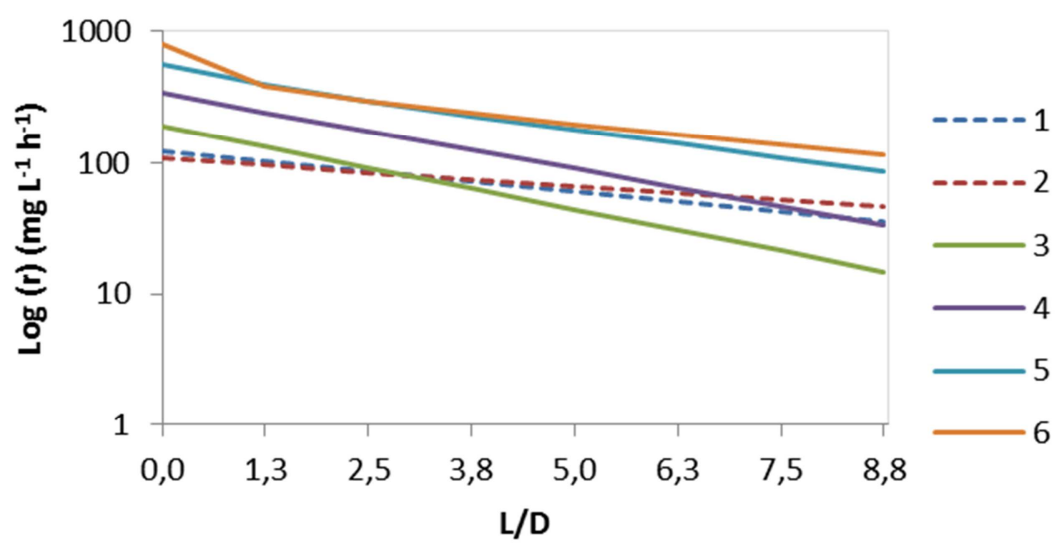

Figura 48 - Velocidade da Reação 20 (Sacarose a ácido lático) em reator anaeróbio de leito ordenado e escoamento descendente com variação da $\mathrm{COV}$

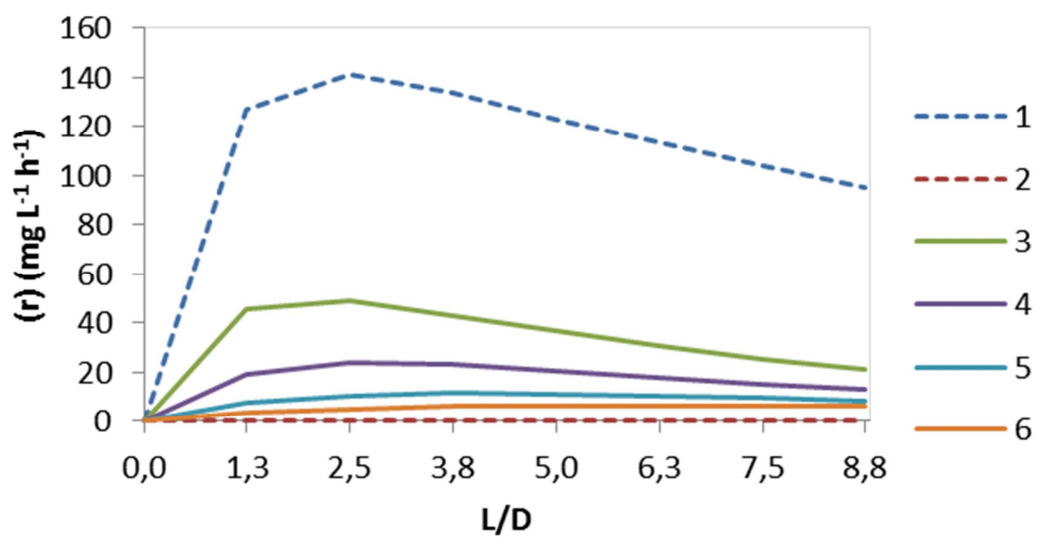

Figura 49 - Velocidade da Reação 21 (Ácido lático a ácido propiônico) em reator anaeróbio de leito ordenado e escoamento descendente com variação da COV

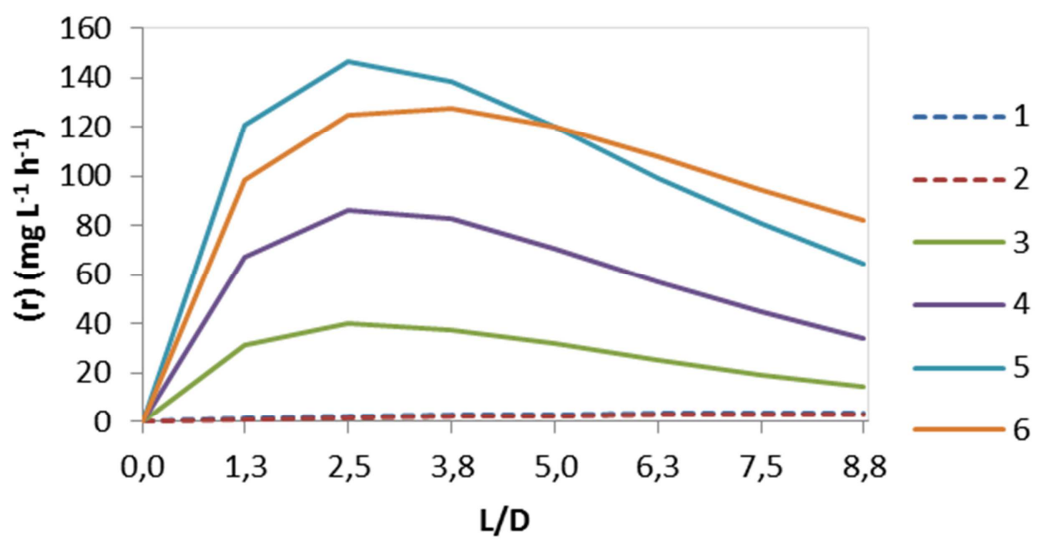

Figura 50 - Velocidade da Reação 22 (Ácido butírico a ácido acético) em reator anaeróbio de leito ordenado e escoamento descendente com variação da $\mathrm{COV}$ 


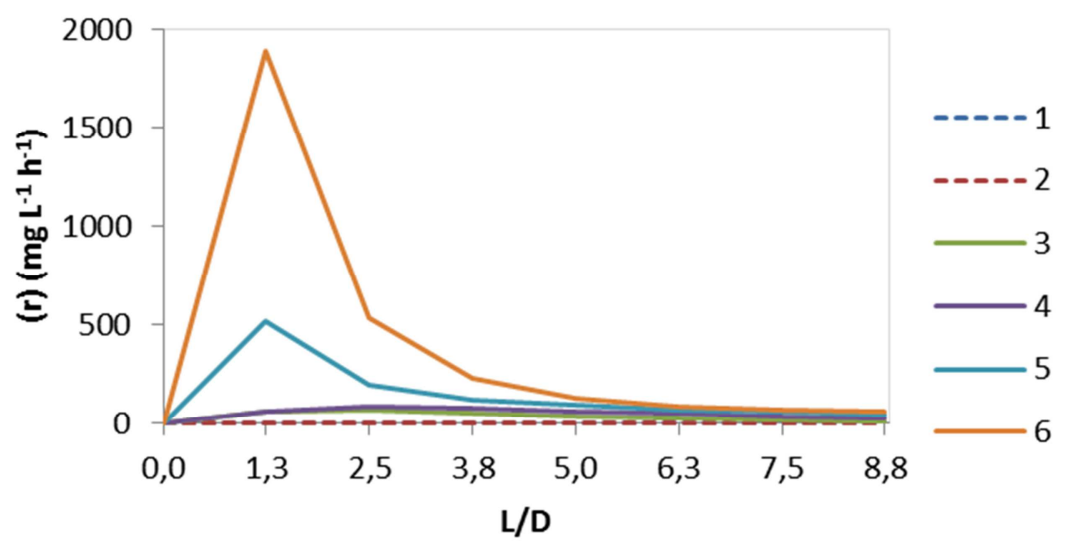

Figura 51 - Velocidade da Reação 23 (Ácido propiônico a ácido acético) em reator anaeróbio de leito ordenado e escoamento descendente com variação da $\mathrm{COV}$

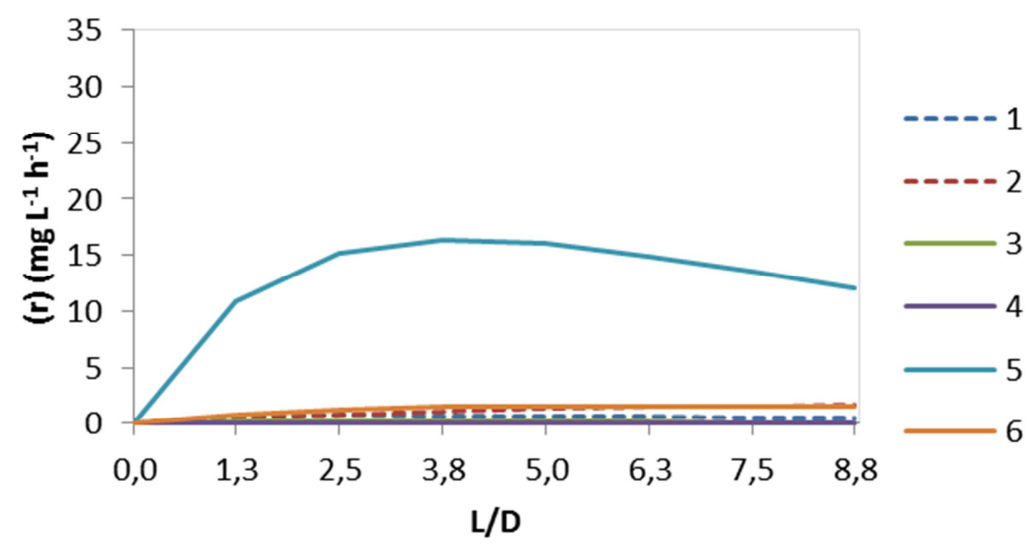

Figura 52 - Velocidade da Reação 24 (Ácido lático a ácido acético) em reator anaeróbio de leito ordenado e escoamento descendente com variação da COV

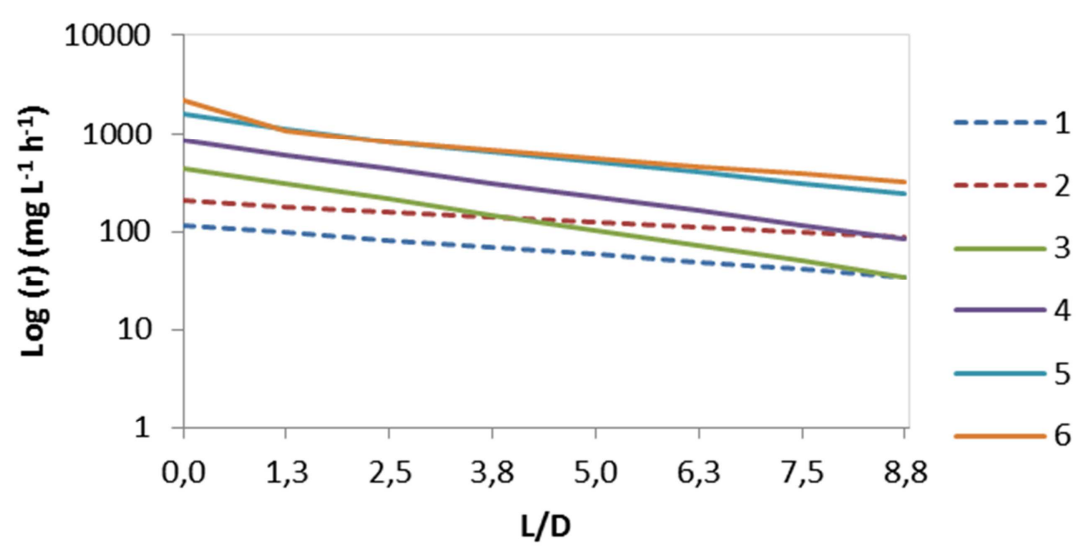

Figura 53 - Velocidade da Reação 25 (Sacarose a etanol) em reator anaeróbio de leito ordenado e escoamento descendente com variação da $\mathrm{COV}$

Observou-se que as velocidades das reações a partir de sacarose formando ácido butírico (Figura 45), ácido acético (Figura 46), ácido lático (Figura 48) e etanol (Figura 53), 
foram todas quase constantes ao longo do reator durante as fases 1 e 2 quando o TDH aplicado foi de $2 \mathrm{~h}$, enquanto nas fases 3 a 6 quando o TDH aplicado foi de $4 \mathrm{~h}$, as velocidades foram diminuindo conforme o escoamento foi descendo, ou seja, essas velocidades de reação foram maiores na cabeça do reator (L/D de 1,3) e adicionalmente acima das observadas com TDH de $2 \mathrm{~h}$ na maioria dos casos. Essa diferença não foi observada na formação do ácido propiônico a partir de sacarose (Figura 47), pois, independente do TDH aplicado, as velocidades foram quase constantes ao longo do comprimento do reator e não foi possível determinar um aumento da velocidade relacionado ao aumento do TDH.

Por outro lado, sendo a formação de ácido butírico, ácido acético e ácido propiônico os principais PSF envolvidos na produção e consumo de hidrogênio, com TDH de $2 \mathrm{~h}$ as velocidades de reação que foram quase constantes ao longo do reator, poderiam ter feito com que o caminho percorrido pelo hidrogênio em direção ao headspace fosse mais longo, facilitando o seu consumo. Já com TDH de 4 h como as velocidades foram maiores na cabeça do reator, esse percurso foi menor favorecendo ainda mais a liberação do gás.

\subsubsection{Conclusões parciais - Estratégia 5}

As mudanças da COV permitiram o controle da COVe em reator anaeróbio de leito ordenado, com polietileno de baixa densidade como material suporte para adesão da biomassa, escoamento descendente e sem descartes de biomassa, levando esse parâmetro a

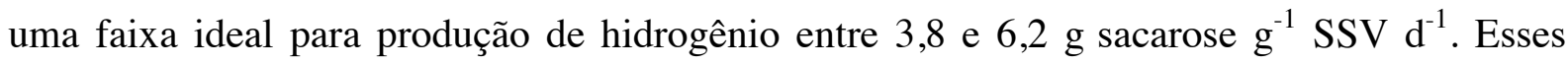
resultados validam a sub-hipótese 3 .

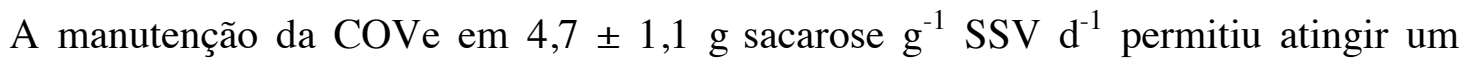
rendimento contínuo e estável de hidrogênio de $1,9 \pm 0,3 \mathrm{~mol} \mathrm{H}_{2} \mathrm{~mol}^{-1}$ sc durante um período de 60 dias e um aumento da $P V H$ de 2,4 a $8,9 \mathrm{~L} \mathrm{H}_{2} \mathrm{~L}^{-1} \mathrm{~d}^{-1}$.

Por meio dos ajustes matemáticos, chegou-se a uma COVe ótima de 6,0 g sacarose $\mathrm{g}^{-1}$ $\mathrm{SSV} \mathrm{d}^{-1}$ para alcançar um $P V H$ máxima de $8,8 \mathrm{~L} \mathrm{H}_{2} \mathrm{~L}^{-1} \mathrm{~d}^{-1}$ e COVe de $5,7 \mathrm{~g}_{\text {sacarose }} \mathrm{g}^{-1} \mathrm{SSV}$ $\mathrm{d}^{-1}$ para atingir um $Y_{\mathrm{H}_{2}}$ máximo de $2,3 \mathrm{~mol} \mathrm{H}_{2} \mathrm{~mol}^{-1}{ }_{\mathrm{sc}}$.

Outros fatores como o TDH e a concentração do substrato também podem afetar o desempenho do reator anaeróbio de leito ordenado e escoamento descendente. Por um lado, o TDH de $2 \mathrm{~h}$ mostrou ser adverso para o sistema fermentativo devido a que o tempo de reação é insuficiente para o metabolismo celular. Por outro, o incremento da concentração do substrato sugere melhorias na eficiência de transferência de massa, favorável para a liberação de hidrogênio e diminuição da atividade homoacetogênica. 
Com a modelagem foi possível corroborar que o escoamento descendente facilitou a liberação do biogás produzido, principalmente no primeiro segmento do leito, uma vez que o biogás contracorrente minimizou o contato do hidrogênio com os possíveis microorganismos consumidores. Este comportamento foi observado marcadamente quando o reator foi operado com TDH de $4 \mathrm{~h}$ ao notar que as velocidades de reação de formação de hidrogênio ocorreram de forma mais rápida na cabeça do reator, enquanto as velocidades de consumo foram mantidas quase constantes ao longo do comprimento.

Desta forma, os resultados observados nessa estratégia validam a sub-hipótese 3, referente ao controle da COVe por meio da variação da COV. Por outro lado, a modelagem matemática realizada a partir dos perfis espaciais em cada fase experimental validam em parte, a sub-hipotese 2, referente à saída do gás em contracorrente com a fase líquida com escoamento descendente em reatores de leito ordenado. 


\section{CONCLUSÕES}

A aplicação das diferentes estratégias operacionais em reator anaeróbio de leito fixo utilizadas neste trabalho, tais como o controle da COVe e das características hidrodinâmicas, mediante a manipulação de variáveis como a direção do escoamento, a variação da COV e a disposição adequada dos materiais suporte para adesão da biomassa levaram à produção de hidrogênio de forma contínua e estável.

A operação de três diferentes reatores anaeróbios de leito empacotado com escoamento descendente permitiu comprovar que o uso deste tipo de escoamento requer a ordenação do leito, uma vez que a baixa porosidade do leito empacotado gerou anomalias no padrão de escoamento que interferiram na saída do biogás contracorrente, impossibilitando a coleta do mesmo.

Em contraposição ao leito empacotado, a ordenação do leito junto com o escoamento descendente permitiram a produção contínua de hidrogênio por meio do controle da COVe. Por um lado, o leito ordenado com maior porosidade diminuiu os interstícios e as anomalias no padrão do escoamento, evitando assim o acúmulo de biomassa, enquanto que o escoamento descendente ajudou com a sedimentação e o arraste natural da biomassa. Adicionalmente, a biomassa sedimentada que foi periodicamente descartada sugeriu ter estimulado a renovação da população microbiana favorável para a produção de hidrogênio. Assim, reatores anaeróbios de leito ordenado e escoamento descendente operados com TDH de $2 \mathrm{~h}$, concentração do substrato de $2 \mathrm{~g}$ DQO L ${ }^{-1}$ perfazendo uma COV de $24 \mathrm{~g}$ DQO L $\mathrm{d}^{-1}$ podem produzir hidrogênio de forma contínua com $P V H$ média de $0,6 \mathrm{~L} \mathrm{H}_{2} \mathrm{~L}^{-1} \mathrm{~d}^{-1}$ e $Y_{\mathrm{H}_{2}}$

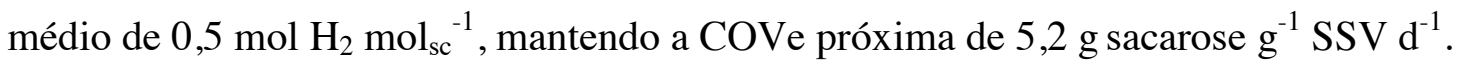

Por outro lado, os descartes de biomassa programados em reatores de leito empacotado e escoamento ascendente também permitiram o controle da COVe, pois embora a biomassa não fosse sedimentada, o esvaziamento do reator de tempos em tempos sugeriu de igual forma estimular a renovação da população microbiana favorável para a produção de hidrogênio. Dessa forma, operar um reator de leito empacotado, fluxo ascendente, TDH de 2 $\mathrm{h}$, concentração do substrato de $2 \mathrm{~g} \mathrm{DQO} \mathrm{L}^{-1}$ perfazendo uma COV de $24 \mathrm{~g} \mathrm{DQO} \mathrm{L}^{-1} \mathrm{~d}^{-1}$ e

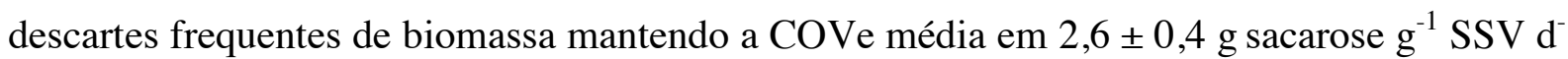
${ }^{1}$, permite produzir hidrogênio continuamente com $P V H$ média de $2,2 \pm 0,2 \mathrm{~L} \mathrm{H}_{2} \mathrm{~L}^{-1} \mathrm{~d}^{-1}$ e $Y_{H_{2}}$ médio de $1,6 \pm 0,4 \mathrm{~mol} \mathrm{H}_{2} \mathrm{~mol}^{-1}{ }_{\mathrm{sc}}$. 
No entanto, esse método de controle da COVe em reatores de leito ordenado e escoamento ascendente mediante descartes de biomassa deve ser realizado mais cuidadosamente, uma vez que a retirada excessiva de lodo pode causar uma desestabilização geral do sistema. Apesar disso, operar um reator de leito ordenado e fluxo ascendente, TDH de $2 \mathrm{~h}$, concentração do substrato de $2 \mathrm{~g}$ DQO L ${ }^{-1}$ perfazendo uma COV de $24 \mathrm{~g} \mathrm{DQO} \mathrm{L}^{-1} \mathrm{~d}^{-1} \mathrm{e}$ mantendo a COVe média em 4,4 $\pm 0,8 \mathrm{~g}$ sacarose $\mathrm{g}^{-1} \mathrm{SSV} \mathrm{d}^{-1}$, pode produzir hidrogênio

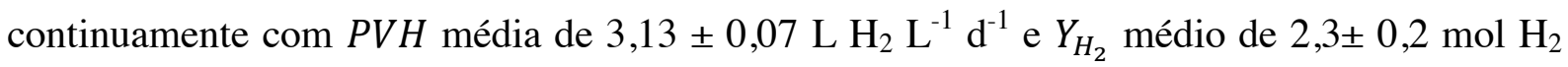
$\mathrm{mol}^{-1}$ sc.

A variação da COV em um reator de leito ordenado e escoamento descendente também indicou ser um método efetivo para o controle da COVe, produzindo hidrogênio continuamente com $Y_{H_{2}}$ médio de $1,9 \pm 0,3 \mathrm{~mol} \mathrm{H}_{2} \mathrm{~mol}^{-1}$ sc quando esse parâmetro foi mantido em 4,7 $\pm 1,1 \mathrm{~g}$ sacarose $\mathrm{g}^{-1} \mathrm{SSV} \mathrm{d}^{-1}$.Adicionalmente, por um lado, com a mudança da COV pelo incremento do TDH, as velocidades de reação favoráveis para a produção de hidrogênio melhoraram no topo do reator, diminuindo o percurso do biogás produzido no meio líquido em direção à fase gasosa. Por outro, o incremento da concentração do substrato parece ter melhorado a eficiência de transferência de massa líquido-gás, aumentando a liberação do hidrogênio produzido e diminuindo a atividade homoacetogênica.

A modelagem matemática dos perfis espaciais do reator anaeróbio de leito empacotado e escoamento descendente permitiu observar que, a saída do gás contracorrente da fase líquida facilitou a liberação do biogás, uma vez que o biogás foi produzido principalmente no primeiro segmento do leito, o que minimizou o contato do hidrogênio com os possíveis microorganismos consumidores.

\subsection{Trabalhos futuros}

- Operação de reatores anaeróbios de leito fixo de forma sequencial, tendo como ponto final de operação o início da diminuição da produção de biogás, isto é, mantendo os reatores em fase transiente.

- Estudo do fenômeno de transferência de massa líquido-gás que abranja a influência da concentração do substrato, a quantidade de biogás produzido e o tamanho das bolhas de gás.

- Monitoramento da supersaturação de biogás no meio líquido em reator anaeróbio de leito fixo sob diferentes condições operacionais. 
- Modelagem matemática e validação do comportamento espacial e temporal do reator anaeróbio de leito fixo, produtor de hidrogênio incluindo a variação de parâmetros como TDH, concentração do substrato, grau de mistura, relação $\mathrm{C} / \mathrm{N}$, concentração de cálcio, origem do inoculo, entre outros. 


\section{REFERÊNCIAS BIBLIOGRÁFICAS}

ALZATE-GAVIRIA, L. M. et al. Comparison of two anaerobic systems for hydrogen production from the organic fraction of municipal solid waste and synthetic wastewater. International Journal of Hydrogen Energy, 32, 2007. 3141-3146.

AMORIM, E. L. C. D. et al. Anaerobic fluidized bed reactor with expanded clay as support for hydrogen production through dark fermentation of glucose. International Journal of Hydrogen Energy, 34, 2009. 783-790.

ANTONOPOULOU, G. et al. Effect of substrate concentration on fermentative hydrogen production from sweet sorghum extract. International Journal of Hydrogen Energy, $36,2011.4843-4851$.

ANZOLA-ROJAS, M. D. P. Influência da relação $C / N$ na produção de hidrogênio em reator anaeróbio de leito fixo. Escola de Engenharia de São Carlos, Universidade de São Paulo. São Carlos, Brasil, p. 89. 2010. Dissertação (Mestrado).

ANZOLA-ROJAS, M. D. P. et al. The use of the carbon/nitrogen ratio and specific organic loading rate as tools for improving biohydrogen production in fixed-bed re. [S.1.]. 2014. Manuscrito em processo de submissão.

APHA. Standard Methods for the Examination of Water and Wastewater. 21. ed. Washington, DC, USA: American Water Works Association / Water Environment Federation, 2005.

AROOJ, M. F. et al. Effect of HRT on ASBR converting starch into biological hydrogen. International Journal of Hydrogen Energy, 33, 2008. 6509-6514.

ASTM INTERNATIONAL. Standard test method for water absorption, bulk density, apparent posority and apparent specific gravity of fired whiteware products. [S.1.]. 2006. (DOI: 10.1520/C0373-88R06).

BABU, V. L.; MOHAN, S. V.; SARMA, P. N. Influence of reactor configuration on fermentative hydrogen production during wastewater treatment. International Journal of Hydrogen Energy, 34, 2009. 3305-3312.

BICAKOVA, O.; STRAKA, P. Production of hydrogen from renewable resources and its effectiveness. International Journal of Hydrogen Energy, 37, 2012. 11563 - 11578.

CALLI, B. et al. Dark fermentative H2 production from xylose and lactose-Effects of online $\mathrm{pH}$ control. International Journal of Hydrogen Energy, 33, 2008. 522-530.

CARMINATO, V. M. Influência do cálcio na produção biológica de hidrogênio a partir de águas residuárias em biorreatores anaeróbios. Escola de Engenharia de São Carlos, Universidade de São Paulo. São Carlos, SP. 2013. Dissertação (Mestrado).

CHENG, C. C.; LIN, C. Y.; CHANG, J. S. Kinetic of hydrogen production with continuous anaerobic cultures utilizing sucrose as the limiting substrate. Applied Microbiology and Biotechnology, 57, n. 1 - 2, 2001. 56 - 64.

CHEONG, D. Y.; HANSEN, C. L. Feasibility of hydrogen production in thermophilic mixed fermentation by natural anaerobes. Bioresource Technology, 98, 2007. 2229-2239.

CHERNICHARO, C. L. Reatores anaeróbios. Princípios do tratamento biológico de águas residuárias. Belo Horizonte: DESA/UFMG, v. 5, 1997. 
DAS, D. Advances in biohydrogen production processes: An approach towards commercialization. International Journal of Hydrogen Energy, 34, 2009. 73497357.

DAS, D.; VEZIROGLU, T. N. Hydrogen production by biological processes: a survey of literature. International Journal of Hydrogen Energy, 26, 2001. 13-28.

DEL NERY, V. Utilização de lodo anaeróbio imobilizado em gel no estudo de partida de reatores de fluxo ascendente com manta de lodo. Escola de Engenharia de São Carlos, Universidade de São Paulo. São Carlos, Brasil. 1987. Dissetação (Mestrado).

DINAMARCA, C.; BAKKE, R. Apparent hydrogen consumption in acid reactors: observations and implications. Water Science \& Technology-WST, 59, n. 7, 2009. 1441-1447.

DRAKE, H. L.; GÖBNER, A. S.; DANIEL, S. L. Old Acetogens, New Light. New York Academy of Sciences, 1125, 2008. 100-128. doi: 10.1196/annals.1419.016.

DRAKE, H. L.; KÜSEL, K.; MATTHIES, C. Ecological consequences of the phylogenetic and physiological diversities of acetogens. Antonie van Leeuwenhoek, 81, 2002. 203-213.

DUBOIS, S. M. et al. Colorimetric Methods for determination of sugar and related substance. Analytical Chemistry, 228, 1956. $13-21$.

FERNANDES, B. S. Produção de hidrogênio em reator anaeróbio de leito fixo. Escola de Engenharia de São Carlos, Universidade de São Paulo. São Carlos, Brasil, p. 100. 2008. Tese (Doutorado).

GALÈS, G. et al. Molecular hydrogen from water radiolysis as an energy source for bacterial growth in a basin containing irradiating waste. FEMS Microbiology Letters, 240, 2004. 155-162.

GODOI, L. A. G. D. Produção de hidrogênio em reator anaeróbio de leito fixo ordenado a partir de sacarose tendo espuma de poliuretano como material suporte. Escola de Engenharia de São Carlos - Univesidade de São Paulo. São Carlos, Brasil, p. 62. 2010. Monografia (Graduação em Engenharia Ambiental).

HAFEZ, H. et al. Effect of organic loading on a novel hydrogen bioreactor. Int. J. Hydrogen Energy, 35, 2010. 81-92.

HALLENBECK, P. C.; ABO-HASHESH, M.; GHOSH, D. Strategies for improving biological hydrogen production. Bioresource Technology, 110, 2012. 1-9.

HALLENBECK, P. C.; GHOSH, D. Advances in fermentative biohydrogen production: the way forward? Trends in Biotechnology, 27, n. 5, 2009. 287-297.

HALLENBECK, P. C.; GHOSH, D. Improvements in fermentative biological hydrogen production through metabolic engineering. Journal of Environmental Management, 95, 2012. S360-S364.

HILIGSMANN, S. et al. Comparative study of biological hydrogen production by pure strains and consortia of facultative and strict anaerobic bacteria. Bioresource Technology, 102, 2011.3810-3818.

HUSSY, I. et al. Continuous Fermentative Hydrogen Production from a Wheat Starch CoProduct by Mixed Microflora. Biotechnology and Bioengineering, 84, n. 6, 2003. 619-626. 
JIMENEZ, B. et al. Dextran blue colorant as a reliable tracer in submerged filters. Water Resources, 22, n. 10, 1988. 1253-1257.

JIRKA, A. M.; CARYER, M. J. Micro Semi-Automated Analysis of Surface and Watewaters for Chemical Oxygen Demand. Analytical Chemistry, 47, n. 8, 1975. 1397 - 1402.

KAHYAOğLU, M.; ŞAHIN, Ö.; SAKA, \&. C. Biohydrogen Production from Waste Substrates as a Clean Energy. Energy Sources, Part A: Recovery, Utilization, and Environmental Effects, 34, 2012. 1084-1103. DOI: 10.1080/15567031003753546.

KIM, D.-H. et al. Effect of gas sparging on continuous fermentative hydrogen production. International Journal of Hydrogen Energy, 31, 2006. 2158 - 2169.

KIM, S.-H.; HAN, S.-K.; SHIN, H.-S. Effect of substrate concentration on hydrogen production and 16S rDNA-based analysis of the microbial community in a continuous fermenter. Process Biochemistry, 41, 2006. 199-207.

KÖPKE, M. et al. Clostridium ljungdahlii represents a microbial production platform based on syngas. PNAS, 107, n. 29, 2010. 13087 - 13092.

KOSKINEN, E. P.; KAKSONEN, A. H.; PUHAKKA, J. A. The Relationship Between Instability of $\mathrm{H} 2$ Production and Compositions of Bacterial Communities Within a Dark Fermentation Fluidized-Bed Bioreactor. Biotechnology and Bioengineering, 97, 2007. 742-758.

KRAEMER, J. T.; BAGLEY, D. Optimisation and design of nitrogen-sparged fermentative hydrogen production bioreactors. International Journal of Hydrogen Energy, 33, 2008. $6558-6565$.

KRAEMER, J. T.; BAGLEY, D. M. Measurement of $\mathrm{H} 2$ consumption and its role in continuous fermentative hydrogen production. Water Science \& Technology, 57, n. $5,2008.681-685$.

LEITE, J. A. et al. Application of an anaerobic packed-bed bioreactor for the production of hydrogen and organic acids. International Journal of Hydrogen Energy, 33, 2008. 579-586.

LEVENSPIEL, O. Engenharia das reações químicas. São Paulo: Edgard Blucher, 2000.

LEVIN, D. B.; PITT, L.; LOVE, M. Biohydrogen production: prospect and limitation to practical application. International Journal of Hydrogen Energy, 29, 2004. 173175.

LIMA, D. M. F.; ZAIAT, M. The influence of the degree of back-mixing on hydrogen production in an anaerobic fixed-bed reactor. International Journal of Hydrogen Energy , 37, n. 12, 2012.9630-5.

LUO, G. et al. Long-term effect of inoculum pretreatment on fermentative hydrogen production by repeated batch cultivations: Homoacetogenesis and methanogenesis as competitors to hydrogen production, 108, n. 8, 2011. 1816-1827.

MAINTINGUER, S. I. et al. Fermentative hydrogen production by microbial consortium. International Journal of Hydrogen Energy, 33, 2008. 4309-4317.

MINTON, P.; CLARKE, D. Clostridia. New York: Plenum Press, v. 3, 1989. Serie: Biotechnology handbooks.

MOCKAITIS, G. Remoção de 'CD POT.2+' e 'CU POT.2+' de águas residuárias utilizando biorreator anaeróbio contínuo de leito fixo ordenado. Escola de 
Engenharia de São Carlos, Universidade de São Paulo. São Carlos - Brasil, p. 327. 2011. Tese (Doutorado).

NTAIKOU, I.; ANTONOPOULOU , G.; LYBERATOS, G. Biohydrogen Production from Biomass and Wastes via Dark Fermentation: A Review. Waste Biomass Valor, 1, $2010.21-39$.

OH, S.-E.; VAN GINKEL , S.; LOGAN, B. E. The Relative Effectiveness of pH Control and Heat Treatment for Enhancing Biohydrogen Gas Production. Environ. Sci. Technol., 37, 2003. 5186-5190.

OLIVEIRA NETTO, A. P. Reator anaeróbio-aeróbio de leito fixo em escala piloto, com recirculação da fase líquida, aplicado ao tratamento de esgoto sanitário. Escola de Engenharia de São Carlos, Universidade de São Paulo. São Carlos - Brasil, p. 195. 2011. Tese (Doutorado).

PAN, J. et al. Effect of food to microorganism ratio on biohydrogen production from food waste via anaerobic fermentation. International Journal of Hydrogen Energy, 33, $2008.6968-6975$.

PAUSS, A. et al. Liquid-to-Gas Mass Transfer in Anaerobic Processes: Inevitable Transfer Limitations of Methane and Hydrogen in the Biomethanation Process. Applied and Environmental Microbiology, 56, n. 6, 1990. 1636 - 1644.

PEIXOTO, G. Produção de hidrogênio em reator anaeróbio de leito fixo e fluxoascendente a partir de água residuária de indústria de refrigerantes. Escola de Engenharia de São Carlos, Universidade de São Paulo. São Carlos, Brasil. 2008. Dissertação (Mestrado).

PEIXOTO, G. Sistema fermentativo de duas fases para a produção de hidrogênio e metano a partir de esgoto sanitário combinado com águas residuárias industriais. Escola de Engenharia de São Carlos, Universidade de São Paulo. São Carlos, SP. 2011. Tese (Doutorado).

PENTEADO, E. D. et al. Influence of seed sludge and pretreatment method on hydrogen production in packed-bed anaerobic reactors, 38, n. 14, 2013. 6137-6145.

REN, N. et al. Biological hydrogen production by dark fermentation: challenges and prospects towards scaled-up production. Current Opinion in Biotechnology, 22, 2011. 365370 .

REN, N. Q. et al. Microbial community structure of ethanol type fermentation in biohydrogen production. Environmental Microbiology, 9, 2007. 1112-1125.

REN, N.-Q. et al. Effects of different pretreatment methods on fermentation types and dominant bacteria for hydrogen production. International Journal of Hydrogen Energy, 33, 2008. 4318 - 4324.

REN, N.-Q. et al. Biological hydrogen production in continuous stirred tank reactor systems with suspended and attached microbial growth. International Journal of Hydrogen Energy, 35, 2010. 2807 - 2813.

RODRIGUEZ, R. P. Aplicação de reatores anaeróbios para remoção de sulfato de águas de drenagem ácida de minas. Escola de Engenharia de São Carlos, Universidade de São Paulo. São Carlos - Brasil, p. 195. 2010. Tese (Doutorado). 
RYAN, P.; FORBES, C.; COLLERAN, E. Investigation of the diversity of homoacetogenic bacteria in mesophilic and thermophilic anaerobic sludge using the formyltetrahydrofolate synthetase gene. Water Sci. Technol., 57, n. 5. 675-680.

SHEN, L.; BAGLEY, D. M.; LISS, S. N. Effect of organic loading rate on fermentative hydrogen production from continuous stirred tank and membrane bioreactors. International Journal of Hydrogen Energy, 34, 2009. 3689 - 3696.

SIRIWONGRUNGSON, V.; ZENG, R. J.; ANGELIDAKI, I. Homoacetogenesis as the alternative pathway for $\mathrm{H} 2$ sink during thermophilic anaerobic degradation of butyrate under suppressed methanogenesis. Water Research, 41, 2007. 4204-4210.

SPEECE, R. E. Anaerobic biotechnology for industrial wastewaters. Nashville, Tenn.: Archae Press., 1996.

SUZUKI, Y. On hydrogen as fuel gas. International Journal of Hydrogen Energy, 7, 1982. 227-230.

TAVARES, A. Modelagem matemática da degradação da glicose, com produção de hidrogênio, em um reator de leito fixo. Escola de Enegenharia de São Carlos, Univesidade de São Paulo. São Carlos, Brasil. 2008. Dissertação (Mestrado).

VAN GINKEL, S.; SUNG, S. W.; LAY, J. J. Biohydrogen production as a function of $\mathrm{pH}$ and substrate concentration. Environmental Science \& Technology, 35, 2001. 47264730 .

WANG, J. L.; WAN, W. Factors influencing fermentative hydrogen production: A review. International Journal of Hydrogen Energy, 34, 2009. 799-811.

ZHANG, F. et al. Hydrogen supersaturation in thermophilic mixed culture. International Journal of Hydrogen Energy, 37, 2012. 17809 - 17816.

ZHU, H. et al. Buffer requirements for enhanced hydrogen production in acidogenic digestion of food wastes. Bioresource Technology, 100, 2009. 5097-5102. 